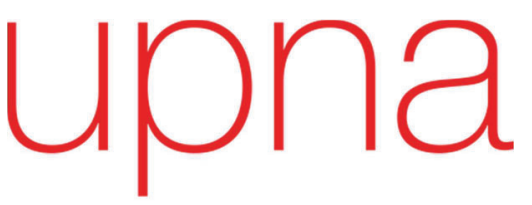

Universidad Pública de Navarra Nafarroako Unibertsitate Publikoa

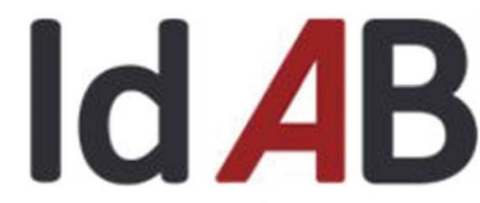

Instituto de Agrobiotecnología Agrobioteknologiako Institutua

\title{
An integrative, multidisciplinary approach to the study of the impact of climate change on legume agro-physiology and metabolism
}

Ph. D. Dissertation submitted by

\section{David Soba Hidalgo}

in fulfilment of the requirements for the degree of

International Doctorate

Supervisors:

Dr. Iker Aranjuelo Michelena

Prof. Sergi Munné-Bosch

Tutor:

Prof. César Arrese-Igor Sánchez

Pamplona, June 2021 
upna

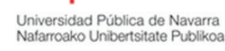


Dr. IKER ARANJUELO MICHELENA, Investigador Principal del Departamento de Agricultura Sostenible y Cambio Climático del Instituto de Agrobiotecnología (IdABCSIC),

Prof. SERGI MUNNÉ-BOSCH, Catedrático del Departamento de Biología Evolutiva, Ecología y Ciencias Ambientales. Universidad de Barcelona,

y Prof. CÉSAR ARRESE-IGOR SÁNCHEZ, Catedrático del Instituto de Investigación Multidisciplinar en Biología Aplicada (IMAB). Universidad Pública de Navarra.

HACEN CONSTAR:

Que la presente Tesis Doctoral, "An integrative, multidisciplinary approach to the study of the impact of climate change on legume agro-physiology and metabolism", elaborada por D. DAVID SOBA HIDALGO, ha sido realizada bajo su dirección, en la modalidad de Compendio de publicaciones, y que cumple las condiciones exigidas por la legislación vigente para optar al grado de Doctor Internacional.

Y para que así conste, firma la presente en Pamplona, a 28 de Junio de 2021.

Fdo. Iker Aranjuelo Michelena Fdo. Sergi Munné-Bosch $\quad$ Fdo. César Arrese-Igor Sánchez 
upna 


\section{Declaration}

The present doctoral thesis, entitled "An integrative, multidisciplinary approach to the study of the impact of climate change on legume agro-physiology and metabolism" has been carried out by D. David Soba Hidalgo. This thesis, in agreement with the "acuerdo A3/2015 del Comité de Dirección de la Escuela de Doctorado de Navarra" is based on a compendium of three articles published in international peerreviewed scientific journals, in co-authorship with the thesis supervisors and other members of the research group and collaborators from other groups.

The references of the papers are presented below:

Soba, D., Shu, T., Runion, G.B., Prior, S.A., Fritschi, F., Aranjuelo, I., Sanz-Saez, A., 2020. Effects of elevated $\left[\mathrm{CO}_{2}\right]$ on photosynthesis and seed yield parameters in two soybean genotypes with contrasting water use efficiency. Environ. Exp. Bot. 178, 104154 https://doi.org/10.1016/j.envexpbot.2020.104154

Soba, D., Müller, M., Aranjuelo, I., Munné-Bosch, S., 2020. Vitamin E in legume nodules: Occurrence and antioxidant function. Phytochemistry. 172, 112261. https://doi.org/10.1016/j.phytochem.2020.112261

Soba, D., Zhou, B., Arrese-Igor, C., Munné-Bosch, S., Aranjuelo, I., 2019. Physiological, hormonal and metabolic responses of two alfalfa cultivars with contrasting responses to drought. Int. J. Mol. Sci. 20, 5099. https://doi.org/10.3390/ijms20205099

Soba, D., Arrese-Igor, C., Aranjuelo, I., 2021. Additive effect of heatwave and water stresses on soybean seed yield is caused by impaired carbon assimilation at pod formation but not at flowering. (Under preparation). 
upna 


\section{Financial Support}

During the doctoral programme, David Soba Hidalgo has been holder of a $\mathrm{PhD}$ fellowship from the Public University of Navarra ("Ayuda predoctoral dentro de la convocatoria de ayudas de nueva solicitud para la Formación de Personal Investigador de la Universidad Pública de Navarra para el año 2017, convocada por Resolución $n^{o}$ 976/2016, de 28 de junio, del Rector y concedida por Resolución n 654/2017, de 29 de marzo, del Rector de la Universidad Pública de Navarra”).

The Ph. D. candidate enjoyed two research stays:

I. Two months stay at the School of Agriculture, Policy and Development, University of Reading, UK (funded by EIT Food KIC) (Sept. - Oct. 2018).

II. Three months stay in the Department of Crop, Soil \& Environmental Sciences, Auburn University, in Auburn, Alabama, United States (mobility grant from Public University of Navarra: "Programa de ayudas a la movilidad de doctorandos”) (Jun. - Sep. 2019). 
upna 
A mis padres, por apoyarme siempre.

A Maider, por estar siempre ahí. 
upna 


\section{Agradecimientos}

Luz (fuego), aire, agua y tierra. Empédocles pensaba que todo en la naturaleza estaba formado por estos cuatro elementos. Hoy sabemos que no es verdad, pero sentó las bases de la química. Pero sí que son cuatro elementos necesarios para el crecimiento de las plantas y, como para ellas, también para esta tesis que pretende estudiarlas. Hay días, capítulos, etapas que un elemento predomina sobre otro, pero es la mezcla de los cuatro la que ha conseguido llevar a buen puerto este barco.

LUZ que ilumina, acompaña y muestra el camino. Gracias Iker por guiarme con tu luz por cuatro años de camino que con esta memoria acaban. Gracias por tu dedicación, paciencia y comprensión. Dentro y fuera del laboratorio.

AIRE que me ha permitido respirar fuera de Pamplona. Gracias Sergi. Por llamarme y ponerme en contacto con Iker, por aceptar ser codirector y por aceptarme luego en tu laboratorio. Gracias César, por ser el nexo de unión entre el laboratorio y la universidad, por tus consejos y correcciones. Gracias Álvaro, por acogerme en tu laboratorio y, a más de $7.000 \mathrm{~km}$, hacerme sentir como en casa.

AGUA que alimenta los buenos ratos y lubrica los malos. Gracias a mis compañeras de laboratorio (Angie, Amaia, Maria, Sinda, Dorra, Garazi...). A mis compañeras en Barcelona (Alba, Paula, Erola, Vero, Marina, Andrea, Celia...). A los que por un tiempo visitasteis nuestro laboratorio (Ana María, Miguel, Carlos, Yosr...). A los que por un tiempo visité yo (Mary, Shu...). A Luisa, por los ratos compartiendo esa "mobile home".

TIERRA que me sustenta, nutre y a la que siempre puedo agarrarme. Mi tierra han sido mis padres que, aun no sabiendo del todo bien que hacia ("es que como esta en inglés"), siempre me han apoyado y animado a seguir. A Maider, el terrón que me sostiene, apoya y acompaña. ¡Gracias a los tres por estar siempre ahí!

Gracias a los que con vuestros conocimientos y ayuda habéis fertilizado esta tesis. En Pamplona, Edurne, Marijose, Fermín. En Barcelona, Marta, Maren. In Auburn, thanks to all the people from the USDA (Steve, Robert, Brett...).

\section{MUCHAS GRACIAS A TODOS!!!}

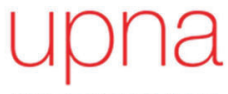


upna 


\section{Summary}

The Leguminosae are second to cereal crops in agricultural importance based on area and total production, covering $14 \%$ of the cultivated land. Within the current and near future context, legume production is threatened by various abiotic stresses associated with climate change, which are expected to increase in number and severity during the following decades. Due to the important challenge to food security, it is important to understand how future legume crops can be bred to withstand adverse environmental conditions. The overall aim of this thesis is to gain further insights on the mechanisms involved in legume response to environmental conditions $\left(\left[\mathrm{CO}_{2}\right]\right.$, drought and temperature) through the integrated investigation of biomass, physiological and biochemical processes and the levels of metabolites and other compounds of the plants.

In chapter 1 , the effect of $\mathrm{e}\left[\mathrm{CO}_{2}\right]$ was studied in two soybean genotypes (Glycine max) selected by their contrasting water use efficiency (WUE). We observed that the genotype selected for their Low_WUE, enhanced leaf daily photosynthetic C gain, mainly due to greater $g_{s}$ but also to biochemical (higher $V_{c \max }$ and $J_{\max }$ ) related limitations under e $\left[\mathrm{CO}_{2}\right]$. However, the genotype selected for High_WUE, compensated their lack of $\left[\mathrm{CO}_{2}\right]$ response at leaf level with a greater leaf area, equating photosynthesis at canopy level under $\mathrm{e}\left[\mathrm{CO}_{2}\right]$. Under these conditions, changes in seed mineral composition were related with dilution effect, since seed yield increases under $\mathrm{e}\left[\mathrm{CO}_{2}\right]$ were bigger that mineral root uptake. Different cultivar distribution has been also shown to induce crop variability in response to environmental stresses, making possible the selection of appropriate traits suitable for future climate conditions. Within this contest, in chapter 2, two alfalfa cultivars (Medicago sativa) from China and Spain were selected between eight cultivars. The study of the drought response at physiological, hormonal and metabolic level revealed contrasting response. While one were found to have a water-saver strategy by closing stomata and fixing less carbon by photosynthesis, the other promoted root growth to enhance water uptake, allowing a greater transpiratory rate to fix more $\mathrm{C}$ and maintaining biomass under drought.

In photosynthetic organs, tocochromanols have been widely reported to have an antioxidant function against lipid peroxidation; however, in underground tissues, their presence and function is unclear. In chapter 3, we reported the presence of tocochromanols, mainly in the $\alpha$-tocopherol form, in nodules of contrasting legume 
genera. Additionally, we described their role against nodule lipid peroxidation and, eventually, improving nodule performance.

Finally, in chapter 4, water stress and heatwave effect on soybean was analyzsed during reproductive stages in isolation and combined, since the combination of these two stresses is common in field crops. Water stress was found to have greater effect on soybean physiological and biochemical parameters when compared to heatwave and, when combined, effects were more similar to those of water stress than those of heatwave, in special when applied at flowering. In nodules, water stress and combined stresses negatively affected nodule functioning, mainly due to poor sugar supply to the bacteroid and N-compounds accumulation; however, heatwave alone were not able to disrupt nodule performance.

To sum up, work presented here provides new insights into the understanding of legume responses to environmental stress conditions and contributes towards elucidating physiological and metabolic traits controlling the response of legume to these conditions. 


\section{Resumen}

Las leguminosas son la segunda familia, tras los cereales, en importancia agrícola, cubriendo el $14 \%$ de la superficie cultivada. En el contexto actual y en un futuro cercano, la producción de leguminosas se ve amenazada por diversos estreses abióticos asociados con el cambio climático. Estos se espera que aumenten en número y severidad durante las próximas décadas. Debido al importante desafío para la seguridad alimentaria, es clave comprender cómo se pueden mejorar los futuros cultivos de leguminosas para resistir condiciones ambientales adversas. El objetivo general de esta tesis es obtener más conocimientos sobre los mecanismos implicados en la respuesta de las leguminosas a las condiciones ambientales $\left(\left[\mathrm{CO}_{2}\right]\right.$, sequía y temperatura) mediante la integración de medidas de biomasa, procesos fisiológicos y bioquímicos y niveles de metabolitos y otros compuestos.

En el capítulo 1, se estudió el efecto del elevado $\mathrm{CO}_{2}$ atmosférico $\left(\mathrm{e}\left[\mathrm{CO}_{2}\right]\right)$ en dos genotipos de soja (Glycine max) seleccionados por su diferente eficiencia en el uso del agua (WUE). Se observó que el genotipo seleccionado por su baja WUE, aumentó la ganancia diaria de $\mathrm{C}$ fotosintético de la hoja, principalmente debido a una mayor $g_{s}$, pero también a las limitaciones bioquímicas ( $V_{c \max }$ y $J_{\max }$ más altas) relacionadas con e $\left[\mathrm{CO}_{2}\right]$. Sin embargo, el genotipo seleccionado por su alta WUE, compensó su falta de respuesta al e[ $\left[\mathrm{CO}_{2}\right]$ a nivel de hoja con una mayor área foliar. En estas condiciones, los cambios en la composición mineral de la semilla se relacionaron con el efecto dilución, ya que los incrementos en el rendimiento de la semilla en e $\left[\mathrm{CO}_{2}\right]$ fueron mayores que la absorción mineral por la raíz. En el capítulo 2, se seleccionaron dos cultivares de alfalfa (Medicago sativa) de China y España entre ocho cultivares distintos. El estudio de la respuesta a la sequía a nivel fisiológico, hormonal y metabólico reveló una respuesta diferenciada. Si bien se encontró que una variedad adoptaba una estrategia de ahorro de agua al cerrar los estomas y fijar menos carbono mediante la fotosíntesis, la otra, por el contrario, promovía el crecimiento de las raíces para mejorar la absorción de agua, lo que permite una mayor tasa de transpiración para fijar más $\mathrm{C}$ y mantener la biomasa en condiciones de sequía.

En los órganos fotosintéticos, se ha descrito ampliamente la función antioxidante que los tococromanoles tienen contra la peroxidación lipídica; sin embargo, en los tejidos subterráneos, su presencia y función no está clara. En el capítulo 3, describimos 
la presencia de tococromanoles, principalmente en la forma $\alpha$-tocoferol, en nódulos de distintos géneros de leguminosas. Además, describimos su papel contra la peroxidación lipídica de los nódulos y, eventualmente, mejorando el rendimiento de los nódulos.

Finalmente, en el capítulo 4, se analizó, de forma aislada y combinada, el estrés hídrico y el efecto de la ola de calor en soja durante la fase reproductiva. Se encontró que el estrés hídrico tiene un mayor efecto sobre la fisiología y los parámetros bioquímicos de la soja en comparación con la ola de calor y, cuando se combinan, los efectos fueron más similares a los del estrés hídrico que a los de la ola de calor, en especial cuando se aplica en la floración. En los nódulos, el estrés hídrico y la interacción de estreses afectaron negativamente al funcionamiento de los nódulos, principalmente debido al escaso suministro de carbono al bacteroide y la acumulación de compuestos nitrogenados; sin embargo, la ola de calor por sí sola no alteró el rendimiento del nódulo.

En resumen, el trabajo presentado aquí proporciona nuevos conocimientos en la respuesta de las leguminosas a las condiciones de estrés ambiental asociadas al cambio climático y contribuye a dilucidar los rasgos fisiológicos y metabólicos que controlan la respuesta de las leguminosas a estas condiciones. 
upna 


\section{Table of contents}

1. GENERAL INTRODUCTION 11

1.1 Climate change: Causes, consequences and predictions. 13

$\begin{array}{ll}1.2 \text { Climate change and agriculture } & 19\end{array}$

1.3 Legumes, a model to study climate change in crops 26

1.4 Effects of climate change on Legumes 31

2. OBJECTIVES 37

3. CHAPTER 1. Effects of elevated $\left[\mathrm{CO}_{2}\right]$ on photosynthesis and seed yield parameters in two soybean genotypes with contrasting $\begin{array}{ll}\text { water use efficiency. } & 42\end{array}$

4. CHAPTER 2. Physiological, hormonal and metabolic responses of two alfalfa cultivars with contrasting responses to drought.

5. CHAPTER 3. Vitamin E in legume nodules: Occurrence and antioxidant function.

6. CHAPTER 4. Additive effect of heatwaves and water stress on soybean seed yield is caused by impaired carbon assimilation at pod formation but not at flowering.

7. GENERAL DISCUSSION 134

8. GENERAL CONCLUSIONS 155

BIBLIOGRAPHY 160

$\begin{array}{ll}\text { ANNEX } & 179\end{array}$ 
"I. GENERAL INTRODUCTION 



\section{GENERAL INTRODUCTION}

\subsection{Climate change: causes, consequences and predictions.}

\section{What is climate change?}

In opposition to weather, which is the state of meteorological variables at a particular place and time, climate refers to weather averaged over three decades or more and generally refers to a wide geographical boundary such as city, region, country, or continent. Then, whereas changes in weather are common from morning to evening or from day to day; changes in climate are very slowly and the changes take place on 100, 1000 , or even 10,000 years' time scale. Therefore, climate change could be defined as consistent changes in the mean of the weather variables over a considerable period of time. In other words, climate change refers to the long-term change in global or regional climate patterns (Bhattacharyya et al., 2020).

\section{What causes climate change?}

Earth's climate is mainly determined by the energy from the sun and for the chemical composition of the atmosphere (IPCC, 2014). There are three basic factors involved in climate change: i) variations in the sun's energy received by the earth; ii) fluctuations of reflectivity of land surface and earth atmosphere and iii) changes in the chemical composition of the atmosphere (IPCC, 2014). Before the industrial revolution $(\sim 1750)$, climatic changes were mainly due to natural causes. These natural causes include earth tilt, ocean current, continental drift, aerosol injections into the atmosphere resulting from volcanic eruptions... Within this context, any disturbance capable of causing changes in the system's energy fluxes and balances will contribute to modify the climate. Although, earth climate is changing since the inception of our planet, since industrial revolution and, in specially, during the last decades, the velocity of these changes is getting faster (Rosenzweig et al., 2008). The emission of greenhouse gases (GHG's) to the atmosphere due to human activities is now the main perturbation of energy into the Earth climate system (IPCC, 2014). This human alteration of the earth's energy balance is known as anthropogenic climate change. Anthropogenic climate change is now beyond dispute, having strong scientific evidence that human activity is responsible for much of the current climate change; according to the $5^{\text {th }}$ 
Intergovernmental Panel on Climate Change (IPCC, 2014) report, it is more than likely $(>90 \%)$ that most of the climatic changes are attributed to increasing human GHG's emissions. Historical emissions have driven atmospheric concentrations of the main three GHG's, carbon dioxide $\left(\mathrm{CO}_{2}\right)$, methane $\left(\mathrm{CH}_{4}\right)$ and nitrous oxide $\left(\mathrm{N}_{2} \mathrm{O}\right)$, to levels that are unprecedented in at least the last 800,000 years, leading to an uptake of energy by the Earth climate system (IPCC, 2014). Since 1750, the concentrations of these three gases $\left(\mathrm{CO}_{2}, \mathrm{CH}_{4}\right.$ and $\left.\mathrm{N}_{2} \mathrm{O}\right)$ have shown increases of $40 \%, 150 \%$ and $20 \%$, respectively (Fig 1). This accumulation of GHG's in the atmosphere traps the infra-red radiation emitted from the Earth surface following absorption of sunlight and heats our planet. This global warming in turn drives to drastic changes in climate, that is accompanied by an increase in in the frequency and intensity of drought and heatwaves (Zandalinas et al., 2021).

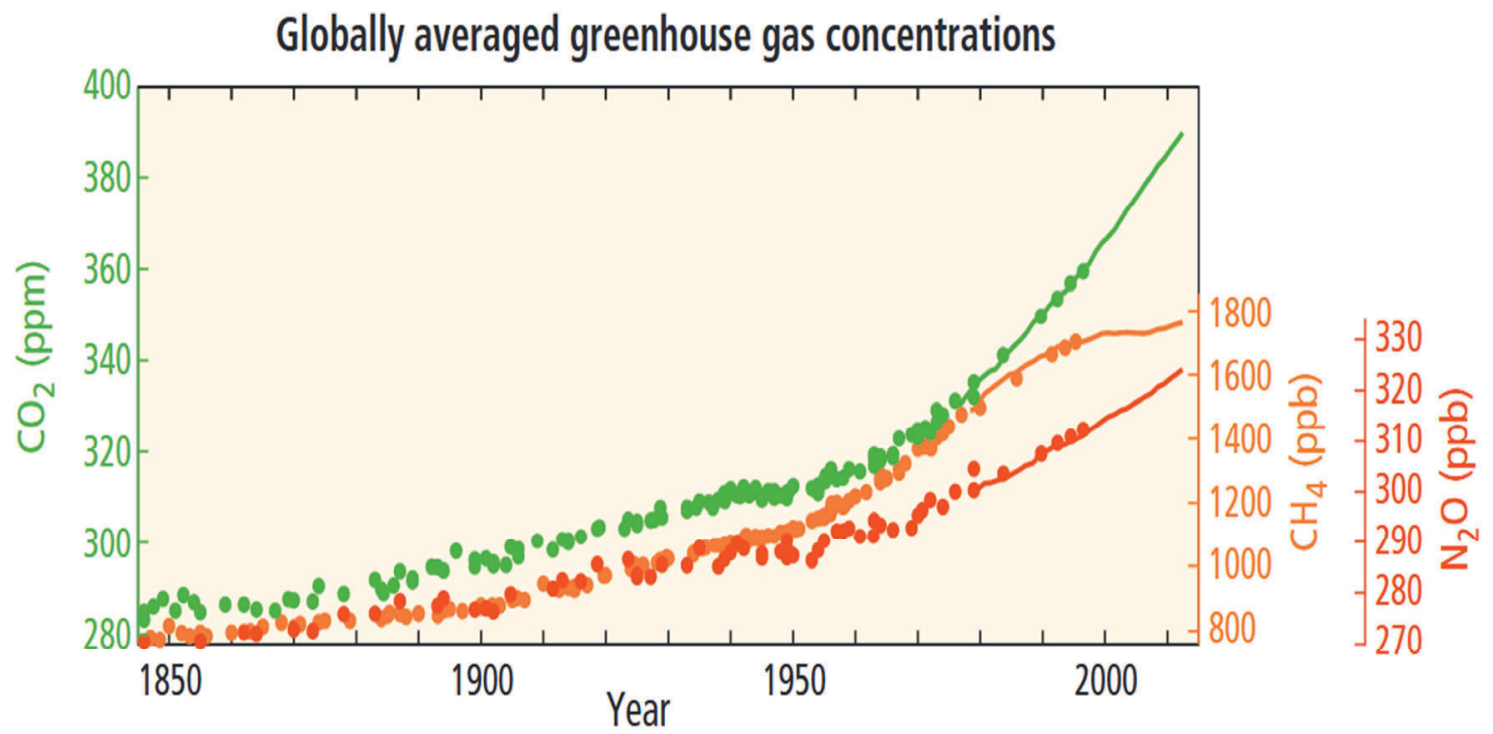

Figure 1. Atmospheric concentrations of the greenhouse gases carbon dioxide $\left(\mathrm{CO}_{2}\right.$, green), methane $\left(\mathrm{CH}_{4}\right.$, orange $)$ and nitrous oxide $\left(\mathrm{N}_{2} \mathrm{O}\right.$, red $)$ determined from ice core data (dots) and from direct atmospheric measurements (lines) (Source: IPCC, 2014).

Total emission level of the main greenhouse gas $\left(\mathrm{CO}_{2}\right)$ can be expressed, according to 'Kaya identity' as the product of four factors: human population, income per capita, energy intensity (energy consumed per \$), and carbon intensity (emissions per unit of energy consumed) (Yamaji et al., 1993). From sources, the overall picture of anthropogenic GHG's emissions is that almost three-quarters of emissions come from 
energy use; almost one-fifth from agriculture and land use; and the remaining $8 \%$ from industry and waste (Fig. 2).

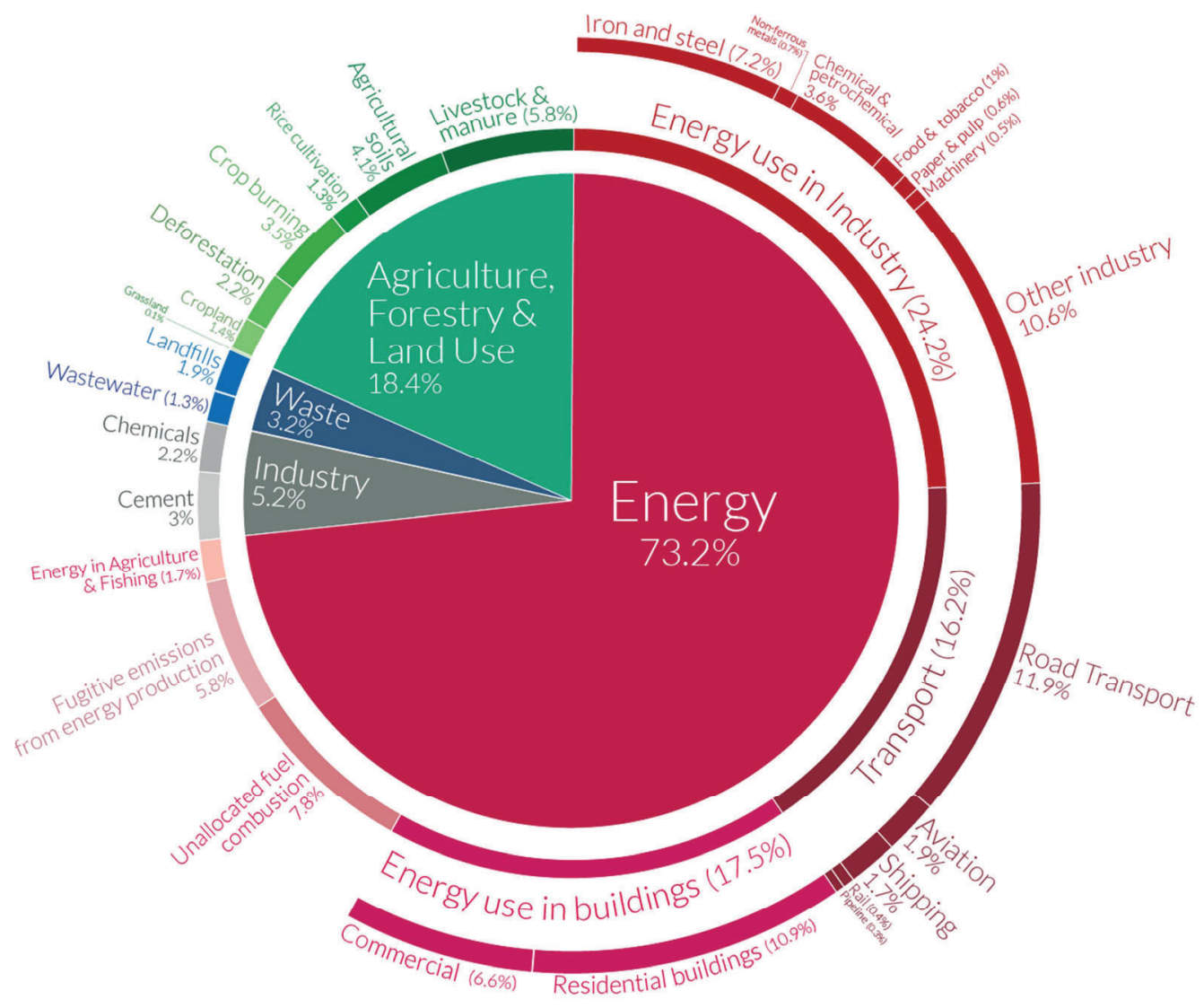

Figure 2. Global greenhouse gas emissions by sector in 2016 (OurWorldinData.org;

Climate Watch, the World Resources Institute (2020)).

\section{What are the consequences of climate change?}

Warming of the climate system is unequivocal, and since the 1950s, many of the observed changes are unprecedented over decades to millennia. For example, each of the last three decades has been successively warmer at the Earth's surface than any preceding decade since 1850 and, over the period 1880 to 2012, the globally averaged combined land and ocean surface temperature show a warming of $0.85^{\circ} \mathrm{C}$ [0.65 to 1.06 ] (IPCC, 2014). This "global warming" in turn drives to drastic changes in climate, that is accompanied by an increase in in the frequency and intensity of drought and heatwaves (Mazdiyasni and AghaKouchak, 2015). Among others, a warming climate will increase evaporation, leading to greater precipitation intensity because of the increased amount of water vapor in the atmosphere leading to an increase in the risk of extreme precipitations and flooding (Wasko and Sharma,2017; Li et al., 
2019). In addition, precipitation patterns have changed in recent decades in many regions around the world and these changes will likely continue in the future (IPCC, 2014).
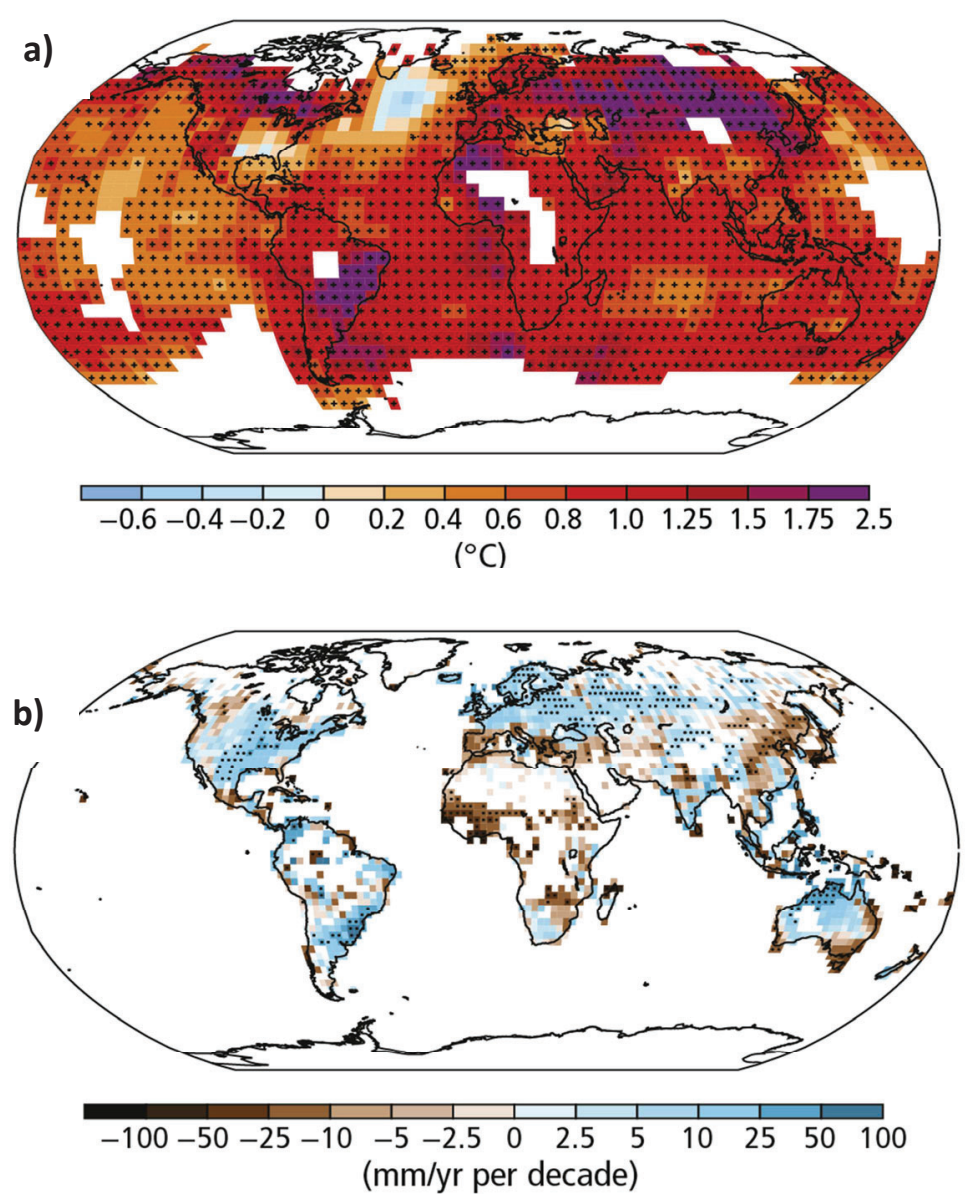

Figure 3. Observed changes in a) surface temperature between 1901 and 2012 and

b) annual precipitation over land between 1951 and 2010 (IPCC, 2014).

Climate change causes a variety of impacts on the earth's system around the world, from polar region to equatorial areas. However, the intensity of these effects is not uniform, differing between regions (Fig. 3). In Europe for example, whereas Mediterranean areas is becoming drier (making it even more vulnerable to drought and wildfires), Northern Europe is getting significantly wetter, and winter floods could become common (European Commission, 2020). Additionally, sea ice declining and melting of glacier is underway; causing sea levels to increase. Increasing atmospheric $\mathrm{CO}_{2}$ concentration $\left(\left[\mathrm{CO}_{2}\right]\right)$ is causing ocean acidification. As a consequence of these physical impacts, wildlife is affected by climate change, so that changes are happening 
so rapidly that many plants and animal species cannot adapt accordingly. Many terrestrial and aquatic species have shifted their geographic ranges, seasonal activities, migration patterns, abundances and species interactions in response to ongoing climate change (IPCC, 2014). As it is described in more detail below, alone or in combination, different environmental factors are likely to affect plants and crops growing in different parts of the planet (Zandalinas et al., 2021). Overall, all those changes are also bringing some additional and target risks for human health such as an increase in the number of heat-related deaths in some regions and the distribution of some water-borne illnesses and disease vectors.

\section{What are the climate predictions for the next decades?}

As it has been previously described, the primary driver of anthropogenic climate change is GHG's emission. Consequently, future climate will depend on committed warming caused by past and future anthropogenic emissions as multiple evidences indicate a strong and consistent relationship between cumulative GHG's emission and projected global temperature changes. Limiting the impact of climate change would require sustained and substantial reduction in GHG's emission to the atmosphere. Anthropogenic GHG's emissions are mainly driven by: human population size, income per capita (determining lifestyle), technology (energy use) and climate policy. Taking into account these drivers, the IPCC makes predictions of GHG's concentration trajectories using the climate models Representative Concentration Pathways (RCPs). During the development of the IPCC 5th Assessment Report (IPCC, 2014), four pathways were used for climate modeling, including a stringent mitigation scenario (RCP2.6), two intermediate scenarios (RCP4.5 and RCP6.0) and one scenario with very high GHG emissions (RCP8.5). Under all four assessed emission scenarios the surface temperature is projected to rise along the $21^{\text {st }}$ century and changes in precipitation patterns will not be uniform (Fig. 4). Average global surface temperature for the end of $21^{\text {st }}$ century (2081-2100) is likely projected to be 0.3 to $1.7{ }^{\circ} \mathrm{C}$ higher relative to 1850 1900, under RCP2.6 and 2.6 to $4.8^{\circ} \mathrm{C}$ under RCP8.5 with intermediate increases under RCP4.5, RCP6.0 scenarios. Additionally, these model systems project a global rise in sea level and increases in ocean acidification and ocean warming as well as reductions in glacier volume. 
Although climate change is a global threat, its direction and severity is not spread equally across continents and regions. In Europe, greatest warming is expected during winter in eastern Europe, while in western and southern Europe considerable warming is projected during summer months by the end of the century (2071-2100). In some parts of France and the Iberian Peninsula it should exceed $6^{\circ} \mathrm{C}$ the worst scenario (Giorgi et al., 2004). On the other hand, the mean annual precipitation generally increases in northern Europe and decreases in the South, in special during summer months, for all emission scenarios and climate models but with substantial changes from season to season and across regions. The mediterranean basin is the zone were the greatest warming and precipitation reduction is projected, especialy in summer, which is the critical time for some important crops of the region (Giorgi et al., 2004).

a)

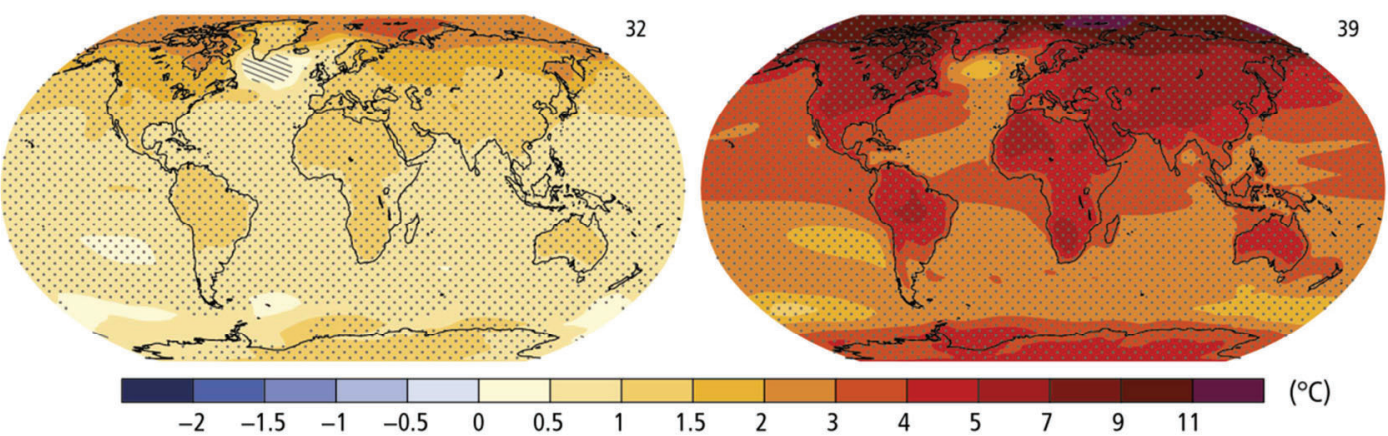

b)

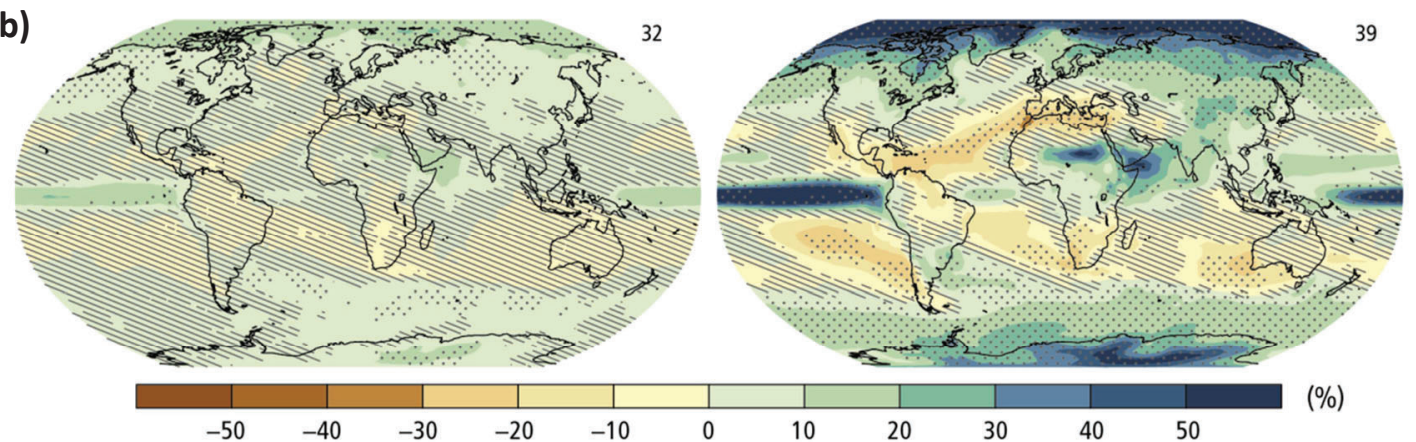

Figure 4. Change in a) average surface temperature and b) change in average precipitation based on multi-model mean projections for 2081-2100 relative to 1986-2005 under the RCP2.6 (left) and RCP8.5 (right) scenarios (IPCC, 2014). 


\subsection{Climate change and agriculture}

Demand for agricultural products continues to raise due to the population growth and increased food consumption per capita, at the same time, due to this population increase, a continual decline in available land surface area, in hectares per person, is being observed (Fig. 5a). Alongside the increase in population, changes in diet, particularly due to the higher meat consumption in some developing countries, may exacerbate the demand for feed crops. Food quality should also be taken into account because it must provide all of the essential nutrients to maintain human health (Morales et al., 2020). In addition, food productivity and security faces threats from climate change and weather variability and needs immediate consideration (Kulkarni et al., 2018). Factors such as water availability, temperature, solar radiation or $\left[\mathrm{CO}_{2}\right]$ regulate metabolic processes in crops, determining their productivity and quality (Schmidhuber and Tubiello, 2007). According to Lesk et al. (2017), globally, it is estimated that losses of cereal production of 1,820 million $\mathrm{kg}$ have been caused by water scarcity during the past four decades. Temperature is another factor that largely determines yield. As it has been reported by Schlenker and Roberts (2009), under climate change scenarios, with a temperature rise equal to $1{ }^{\circ} \mathrm{C}$, crop productivity of maize and soybean might decrease over $50 \%$. Furthermore, as it was previously described, human activities are currently changing regional climatic factors and increasing the probability of climatic extremes (Fig. 5b). Climatic extremes such as heatwaves, droughts or floods have been shown to have a strong effect on crop productivity (Reichstein et al., 2013; Cogato et al., 2019). Consequently, despite technological advances, such as improved varieties or increased irrigation surface, climate is still a key factor in agricultural productivity and global agricultural productivity and the quality of these products are being (and will be) affected (Zandalinas et al., 2021). However, it is worth noting that, these effects are related to variability in local climates rather than in global climate patterns and are mediated by target factors such as the duration/intensity of the stress, plant genotype and developmental stage (Soares et al., 2019). Importantly, agriculture is releasing about $18 \%$ of the world GHG's (Poore and Nemecek, 2018; Fig. 2) and, consequently, suffers the consequences of climate change and causes them at the same time. As such, agriculture faces enormous challenges: meeting society's growing food demands while facing the effects of climatic disturbances and simultaneously reducing its own environmental impact (Foley et al., 2011). Nowadays, one of the greatest challenges 
facing agricultural research is to understand agro-physiological and metabolic responses of crops to new climatic scenarios with the ultimate aim to have an environment friendly agriculture able to face the increasing demand for safe and secure food.
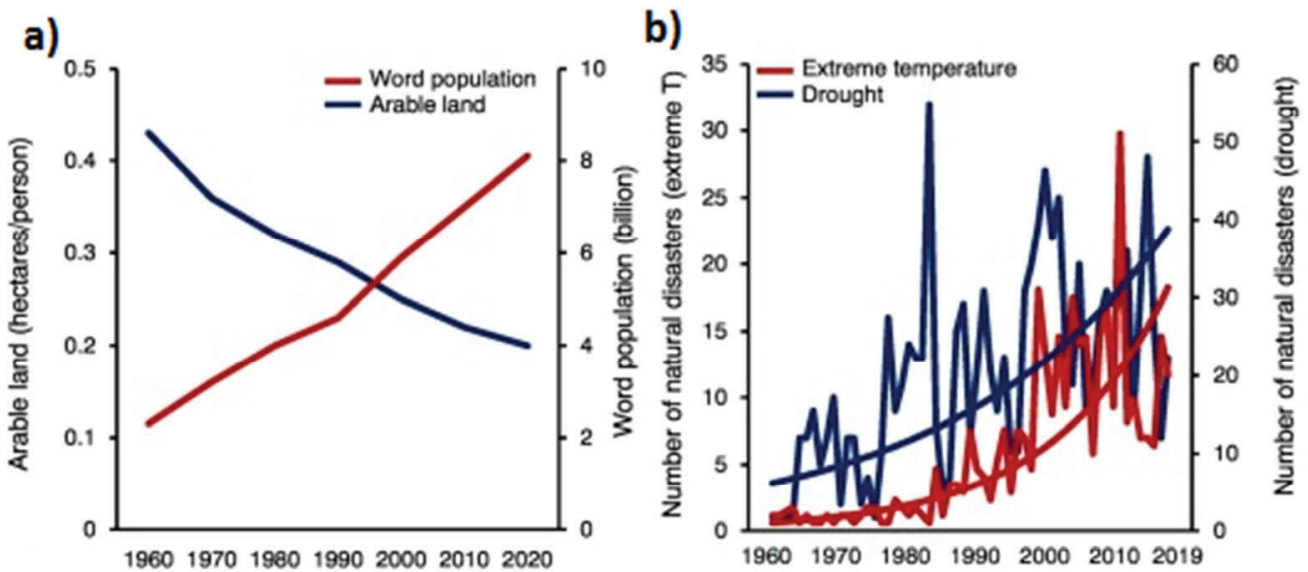

Figure 5. Main factors affecting agricultural productivity: a) Changes in world population and the availability of arable agricultural land; b) Global frequency of droughts and extreme temperature episodes. Modified from Zandalinas et al. (2021).

\section{Main pressures of climate change in agriculture}

Climate change affects directly agricultural crop production via: i) effects of increasing $\left[\mathrm{CO}_{2}\right]$ on crop productivity, ii) effects of temperature, precipitation, radiation, humidity etc. on crop development and growth, and iii) damages caused by extreme events such as extreme heatwaves, droughts and flooding (Fig. 6). Additionally, there are indirect effect such as changes in weeds, pest and diseases, environmental pollution or degradation and changes of crop distribution (Olesen et al., 2011). The latter are out of the scope of the present work and here, we shall focus on effects of increasing $\left[\mathrm{CO}_{2}\right]$ and extreme events related to rising $\left[\mathrm{CO}_{2}\right]$ and changes in precipitation and temperature patterns: droughts and heatwaves.

Droughts and heatwaves, defined as short-term extreme high temperature (Wahid et al., 2007), are the two major abiotic stresses affecting agricultural systems and farm productivity in southern Europe. Additionally, the combined effects of two or more stresses on our agricultural systems often occur together and are expected to increase (Vautard et al., 2007; IPCC, 2014), causing crop failures worldwide and lead to food insecurity. However, unlike individual stresses, little is known about how crops respond to a combination of two or more of these stresses (Awasthi et al., 2014). The 
responses of plants to stress combination is unique and involve many gene expression leading to physiologic and metabolic changes that are not observed in the response to each of the different stresses applied separately (Zandalinas et al., 2021). This emphasizes the need to understand the effect of abiotic stress alone or combined to identify traits that confer tolerance under these conditions as a valuable tool for crop improvement under future climatic conditions (Cohen et al., 2020).

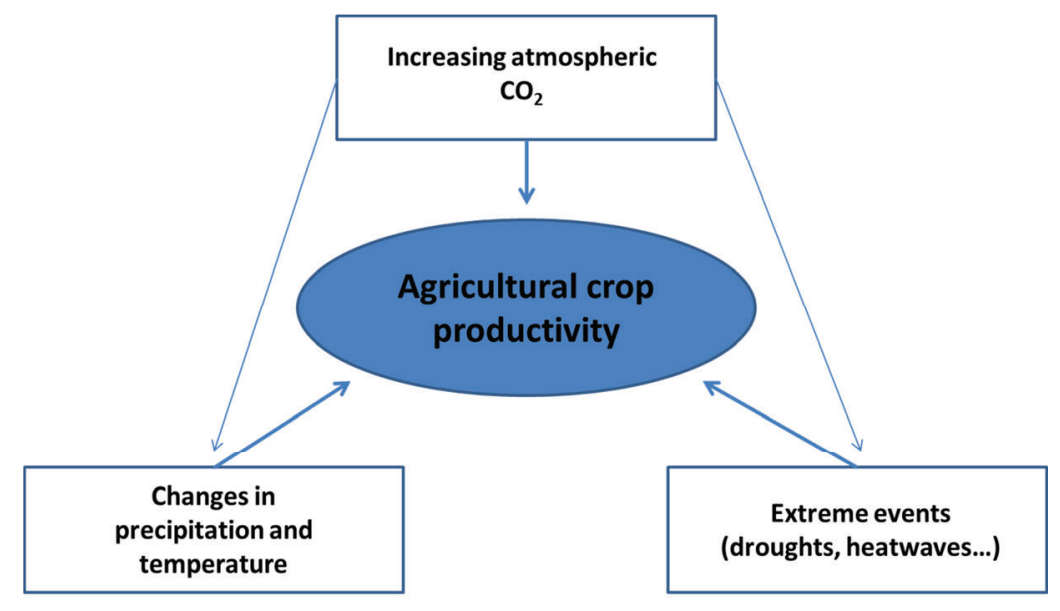

Figure 6. Direct effects of climate change on crop productivity.

\section{Increasing $\left[\mathrm{CO}_{2}\right]$}

It has been well documented that elevated $\mathrm{CO}_{2}$ concentration $\left(\mathrm{e}\left[\mathrm{CO}_{2}\right]\right)$ enhances $\mathrm{C}$ fixation by stimulating photosynthesis with the consequent increase in plant growth and yield (Soares et al., 2019), although increases in crop yield are generally lower than photosynthetic enhancement (Tubiello et al., 2007). This positive effect in agriculture has been denoted as " $\mathrm{CO}_{2}$ fertilization effect" and has already been observed in crop plants, from cereals or legumes (Ainsworth and Rogers, 2007; Högy and Fangmeier, 2008) to vegetables (Jin et al. 2009; Dong et al. 2018). Nonetheless, substantial differences can be found on $\mathrm{CO}_{2}$ fertilization among species, with $\mathrm{C}_{3}$ plants being more responsive to this effect than $\mathrm{C}_{4}$ plants (Fuhrer, 2003). Additionally, under e $\left[\mathrm{CO}_{2}\right]$, increased photosynthesis along with decreased stomatal conductance $\left(\mathrm{g}_{\mathrm{s}}\right)$ often results in higher crop water-use efficiency (WUE) (Soba et al., 2020a). However, the magnitude and persistence of these effects are unclear. Although the initial stimulation of net photosynthesis associated with $\mathrm{e}\left[\mathrm{CO}_{2}\right]$ is sometimes retained, some species fail to sustain the initial, maximal stimulation. This phenomenon is called "photosynthetic acclimation" (Aranjuelo et al., 2011). This acclimation may be due to stomatal 
limitations, thus decreasing intercellular $\left[\mathrm{CO}_{2}\right]\left(C_{i}\right)$ as a result of stomatal closure, or to biochemical limitations, such as changes in the maximum carboxylation rate $\left(V_{c, \max }\right)$ of Rubisco (ribulose-1,5-bisphosphate carboxylase/oxygenase) and the rate of photosynthetic electron transport $\left(J_{\max }\right)$ (Vicente et al., 2017). However, in legumes, due to the fact that this family is capable to form nodules, which are a strong $\mathrm{C}$ sink, it has been reported that legumes maintain high rates of photosynthesis under $\mathrm{e}\left[\mathrm{CO}_{2}\right]$, even after long-term treatment (Bernacchi et al., 2006; Arenque et al., 2014).

Previous studies (Loladze 2014; Myers et al., 2014; Weigel, 2014) also found that, $\mathrm{e}\left[\mathrm{CO}_{2}\right]$ has the potential to influence seed mineral concentration and thereby impact human and animal nutrition. According to meta-analyses studies carried out by Loladze (2014) and Myers (2014), e[ $\left.\mathrm{CO}_{2}\right]$ could reduce seed mineral concentration of several row crops such as soybean (Glycine max), wheat (Triticum aestivum), and rice (Oryza sativa) (Loladze, 2014; Myers et al., 2014). These studies concluded that e[CO $\left.\mathrm{CO}_{2}\right]$ will especially reduce zinc $(\mathrm{Zn})$ and iron $(\mathrm{Fe})$ concentration thereby affecting food nutritional value and contributing to malnourishment in undeveloped countries. Mechanisms responsible for decreased seed mineral concentration are not yet clear, and two hypotheses have been proposed to explain this phenomenon: (i) reduced transpiration as a result of stomatal closure under $\mathrm{e}\left[\mathrm{CO}_{2}\right]$ may interfere with the uptake of nutrients by roots and movement within the plant (McGrath and Lobell, 2013); and (ii) a dilution effect from increased seed mass production could contribute to reduce mineral concentrations observed under $\mathrm{e}\left[\mathrm{CO}_{2}\right]$, suggesting that $\mathrm{e}\left[\mathrm{CO}_{2}\right]$ changes the equilibrium among plant carbon metabolism and nutrient uptake. Together with this mineral reduction, $\mathrm{e}\left[\mathrm{CO}_{2}\right]$ has generally been shown to decrease the concentration in protein in grains of many crops (Myers et al., 2014).

\section{Drought}

Drought is considered to be the most limiting factor on plant growth and crop productivity in agricultural systems (Bray, 1997; Cattivelli et al., 2008). Agriculture is by far the biggest global user of freshwater resources and consequently highly vulnerable to climate change. Precipitation patterns and extreme events (droughts) are particularly important for rain-fed agriculture, which represents the major part of total crop surface. Yield reduction induced by drought has been observed in many crops 
species, and their detrimental effects mainly depend on the growth stage and the duration and intensity of the stress.

At the physiological level, although drought impedes growth and productivity of crops at both vegetative and reproductive stages, damage during the reproductive growth stage is often more severe (Farooq et al., 2017). During the vegetative stage, drought stress greatly reduce plant growth and development. Growth is mainly determined by cell division and cell elongation. Under drought stress, reductions of photoassimilates and metabolites required for cell division are observed. Likewise, reduced turgor pressure due to a decrease in water uptake inhibited cell elongation. As a result, impaired mitosis and reduced cell elongation and expansion result in diminished crop growth under water scarcity (Farooq et al., 2009). Reduced growth and leaf expansion, together with impaired photosynthetic machinery, oxidative stress and stomatal related limitations (stomatal closure) results in reduced photosynthesis and subsequent crop yield reduction. At agronomical level, drought stress during the reproductive growth stage leads to major yield reductions compared to vegetative stages, which is mainly due to a decrease in photosynthetic efficiency and synthesis/translocation of assimilates to flowers (causing poor pollination and higher rates of flower abortion) and, during grain filling, poor cell division resulting in fewer and smaller seeds (Farooq et al., 2017; Du et al., 2020). Additionally, reduced transpiration rate due to drought reduces the total nutrient uptake and their diminished tissue concentrations which may affect yield quality (Shegal et al., 2018) and change leaf biochemistry, with a decrease in maximum carboxylation velocity $\left(V_{\text {cmax }}\right)$, indicating inhibition of Rubisco activity, as shown in Medicago truncatula (Araujo et al., 2015).

When subjected to drought (or other abiotic stress) plant is required to perceive and then react to the signals in a highly coordinated and interactive manner, developing changes at multiple organization levels, from morphological to gene expression. In this sense, phytohormones play a central role in the perception of drought, triggering signal transduction cascades. Their fluctuation coordinate the regulation of growth response under stress conditions (Archarya and Assman, 2009; Wilkinson and Davies, 2010; Du et al., 2013). During drought stress, abscisic acid (ABA) is the primary phytohormone that triggers short-term responses. Under water restriction, these changes in the level of endogenous phytohormones induced changes in gene expression affecting the synthesis, 
production and accumulation of several metabolites as an osmoregulatory response, such as carbohydrates, amino acids and organic acids, in different organ plants (Valliyodan and Nguyen, 2006; Sanchez et al., 2012). Together with phytohormones, several studies have also shown that reactive oxygen species (ROS) play a key role as molecular signals under abiotic stresses. However, ROS are better known to cause oxidative damages, which leads to enhanced peroxidation of membrane lipids together with degradation of nucleic acids, and both structural and functional proteins (Farooq et al., 2009). To avoid this damage, plants have evolved a highly efficient antioxidative defense system that modulates ROS in many stress situations including drought and heatwaves (Apel and Hirt, 2004).

\section{Heatwave}

A heatwave is defined as a short period of extreme high temperature (Haworth et al., 2018). Due to high thermal sensitivity of many enzymatic reactions involved in carbon gain and growth regulation, heatwave plays a major role in regulating plant performance (Li et al., 2020). The susceptibility to high temperatures in plants varies with the stage of plant development, although heat stress affects to a certain extent all vegetative and reproductive stages. High wave impairs the photosynthetic apparatus by disrupting photosynthetic pigments, inhibiting activity of photosystem II and deactivating various enzymes involved in photosynthetic carbon reactions (Law et al., 2001; Chavan et al., 2019), resulting in significant decreases in relative growth rate and net assimilation. During anthesis, the number of pollen grains, their composition and viability, ovule viability and post-fertilization processes are highly sensitive to high temperature, leading to decreased flower set percentage and, at the end, to losses in final crop yield (Djanaguiraman et al. 2013). Likewise during grain filling, heatwaves affect duration of grain filling and grain quality. In cereals and legumes, reductions in seed starch, oil content and protein has been observed under heat stress conditions (Maestri et al., 2002). Similarly to drought, and other abiotic stresses, immediately after exposure to high temperatures and perception of signals mediated by phytohormones, changes occur at the molecular level altering the expression of genes leading to the synthesis of stress-related metabolites in response. 


\section{Interaction of various abiotic stresses}

Although plant responses to a single abiotic stress are relatively well known, our knowledge of plant performance under a more complex environment where multiple stresses co-occur is fragmentary. Nonetheless, the occurrence of two (or more) abiotic stresses together is expected to increase in the near future (IPCC, 2014). Plant responses to multiple stresses are usually not predictable from single factor studies since previous works show that we cannot extrapolate plant responses to stress combinations simply by the addition of individual responses and, that the combination of drought and heatwave, for example, has a more severe impact on physiology and yield than drought or heatwave taken separately (Mittler, 2006; Balfagón et al., 2020). For example, under heatwave, the transpiration rate increases as stomata open in order to reduce leaf temperature (Nahar et al., 2016). On the contrary, when heatwave is combined with drought, stomata closure would occur in order to avoid water loss with the consequence of increasing leaf temperature (Farooq et al., 2017). In addition, stomatal closure lowers $C_{i}$, decreasing the supply of $\mathrm{CO}_{2}$ and leading to a reduction in net photosynthesis $\left(A_{n}\right)$. As shown, heatwave and drought combination might have an additional detrimental effect on plant physiology compared to the effect of the individual stresses (Zandalinas et al., 2018). On the other hand, some authors suggest that crop response to future $\left[\mathrm{CO}_{2}\right]$ could partially offset negative effects of other abiotic stresses such as heatwave or drought (Lobel and Gourdji, 2012; Roy et al., 2016; Abdelhakim et al., 2021) due to the reduction in $g_{s}$. In addition, drought and heat combination can also shorten the life cycle, affecting negatively seed yield and a variety of yield components such as harvest index, seed number or size (Awasthi et al., 2014; Zandalinas et al., 2020). Thus, under abiotic stress combination the physiological and metabolic adjustments are dynamic and dependent on stress type and severity as well as the species and cultivar. Therefore, due to the described knowledge gap, understanding combined stresses and their relation with legume performance is demanding more attention to crop improvement for future climatic conditions. 


\subsection{Legumes, as a target crop to study climate change}

\section{Legume agronomic importance}

The legume family (Fabaceae, syn. Leguminosae) comprises over 750 genera and 19,000 species ranging from small herbs to large trees and represents the third largest family of Angiosperms (Mousavi-Derazmahalleh et al., 2018). This family includes important grain and forage species, in fact have accompanied farmers since the Neolithic revolution, the very onset of farming practices of mankind. The Leguminosae are second to cereal crops in agricultural importance based on area harvested and total production (Graham and Vance, 2003), covering 14\% of the total cultivated land worldwide (FAOSTAT, 2020). This family includes warm-season legumes, such as soybean (Glycine max), common bean (Phaseolus vulgaris), cowpea (Vigna unguiculata) and cool-season legumes, such as alfalfa (Medicago sativa), pea (Pisum sativum), lentil (Lens culinaris), chickpea (Cicer arietinum), and broad bean (Vicia faba).

Grain legumes provide about one-third of all dietary protein nitrogen and onethird of processed vegetable oil (mainly soybean and peanut) for human consumption (Graham and Vance, 2003). With seeds containing at least $20-40 \%$ of protein, legumes are the perfect complement to cereals, the primary source of carbohydrates, in particular among low-income families or people avoiding meat for religious or ethical reasons (Young et al., 2003). Cereal seed proteins are deficient in Lys, unlike in legumes, which are deficient in sulfur-containing amino acids and Trp, presents in cereals (Wang et al., 2003). Additionally, legumes contain substances beneficial to health such as antioxidants, saponins, folate, lignans, and dietary fibre, having the potential to offer protection against some cancers, diabetes, and obesity (Mousavi-Derazmahalleh et al., 2018). Also, grain and forage legumes are also rich sources of dietary protein fiber and energy for animal feeding. In spite of their importance, legumes are generally underexploited in agriculture (Foyer et al. 2016), probably due to the reputation among farmers of these crops being low-yielding. For instance, during the Green Revolution (1950-1980), the global production of pulses increased by $60 \%$ whereas cereal production almost tripled in the same period (Robinson et al., 2019).

In the Western world, protein intake is dominated by meat and dairy products. However, animal protein production has effects on the environment being responsible

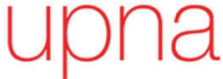


for an important part of anthropogenic greenhouse gas emissions, including $9 \%$ of emitted carbon dioxide, $35-40 \%$ of emitted methane and $65 \%$ of emitted nitrous oxide (Robinson et al. 2019). With a global demand for food rising due to the population growth and increased food consumption per capita, a dietary shift from high meat consumption to more plant-based foods are desirable, to target more sustainable food production (Poore and Nemecek, 2018). Nevertheless, as meat consumption is not predicted to disappear but to increase in the next years, more climate adapted sources of animal feed are also required (Hopkins and Del Prado, 2007; Kulkarni et al., 2018).

Legume, with both human food and forage potential, are suitable crops for agriculture. In addition to being a useful source of carbohydrates, protein and micronutrients, pulses grow in a wide range of climates and soil types. In terms of carbon footprint, the volume of GHG's released by the cultivation of legumes is significantly lower compared to other crops (five to seven times lower per unit area) (Stagnari et al. 2017) and the carbon reduction is much bigger when compared with animal products (Poore and Nemecek, 2018). However, between the characteristics of legumescultivation, the most important is their capacity to fix atmospheric nitrogen through symbioses with rhizobial bacteria within their root nodules (Aranjuelo et al., 2014). Based on these attributes, it is tempting to claim that legumes are one of the most promising components of the Climate Smart Agriculture concept (FAO, 2013; Araujo et al., 2015) This would be consistent with recommendations from the EAT-Lancet report, which highlighted the urgent need for increased consumption of plant-based foods to sustain population and planetary health (EAT-Lancet Commission, 2019) (Fig. 7). 


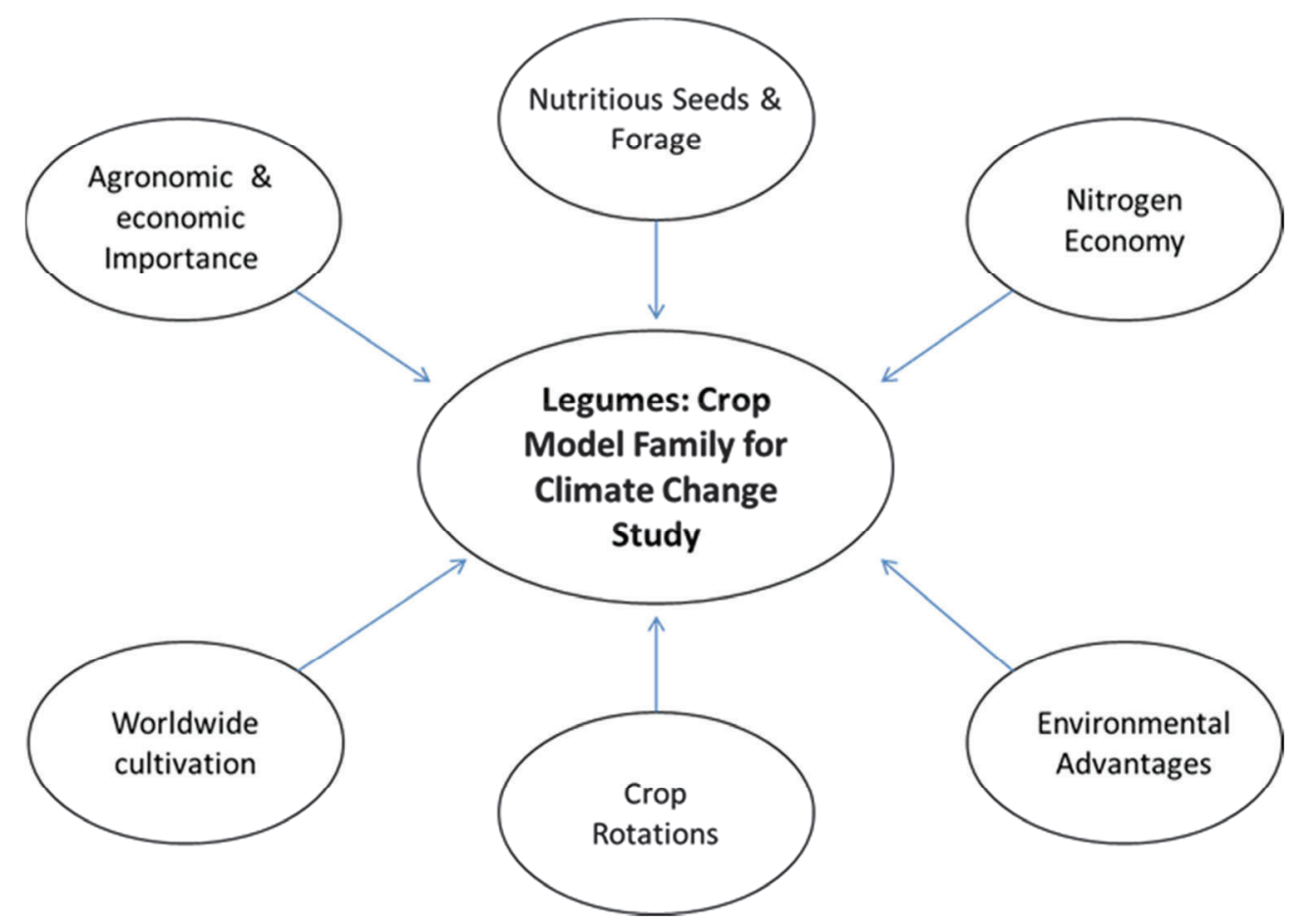

Figure 7. Legumes as a model crop family

\section{Biological $N_{2}$ fixation}

Nitrogen $(\mathrm{N})$ is an essential macronutrient and second most important element after carbon and, after water, the most critical growth limiting factor for plants and crop production. Nitrogen comprised between 1 and 5\% of total crop dry weight, and is an important constituent in amino acids, proteins, nucleic acids, chlorophyll and other metabolites. Therefore, farmers use synthetic $\mathrm{N}$ fertilizers, which are produced through the Haber-Bosch process, to improve their crop yield; however, in some cases, excessive application of $\mathrm{N}$ fertilizer has resulting in $\mathrm{N}$ cycle disturbance, groundwater contamination with nitrates and more GHG's emissions during the manufacture and application (Adams et al., 2018). Nevertheless, legumes are self-supporters of nitrogen fertilization through atmospheric nitrogen fixation in root nodules via the symbiosis with rhizobia bacteria. The symbiotic relationship between the plant and bacteria takes place in the root nodules. There is a tight dependency on $\mathrm{C}$ and $\mathrm{N}$ metabolism between bacteroids and the plant. While the host provides photoassimilates, which supply the energy and $\mathrm{C}$ skeletons required by the bacteroid to fix $\mathrm{N}_{2}$ by nitrogenase $\left(N_{\text {ase }}\right)$, the bacteroid supply all or part of $\mathrm{N}$ required by the legume (Larrainzar et al., 2009). Biological N fixation (BFN) by legume crops ranges from 21 to $389 \mathrm{~kg} \mathrm{ha}^{-1}$ (Raza et al., 
2020) and is mainly dependent on crop species and variety, bacteria strain and environmental factors (Aranjuelo et al., 2014; Sanz-Saez et al., 2019). This capacity of the legumes to fix atmospheric $\mathrm{N}$ reduces the need for chemical fertilizer use, helping to reduce GHG's production, mainly $\mathrm{CO}_{2}$, which is emitted during $\mathrm{N}$ fertilizer manufacture, and $\mathrm{N}_{2} \mathrm{O}$, from the denitrification of the applied $\mathrm{N}$ fertilizer (Reay et al., 2012). Between 40 Tg N (Galloway et al., 2008) and 50-70 Tg N (Herridge et al., 2008) are estimated to be fixed by legumes in agricultural systems annually; additionally, another 3 to $5 \mathrm{Tg} \mathrm{N}$ are fixed by legumes in natural ecosystems (Smil, 1999). Part of N fixed by nodules is released in the soil after crop harvest and together with the release of high-quality organic matter into the soil (Stagnari et al. 2017) legumes help to enrich the soil for the next crop, therefore being an important family in crop rotation. The estimated amounts of $\mathrm{N}$ fixed from atmospheric $\mathrm{N}$ in legume/grass pastures in the world range from 13 to $682 \mathrm{~kg} \mathrm{~N}^{-1}$ year $^{-1}$ (Ledgard and Steele, 1992). For instance, alfalfa plants have the ability to fix up to $350 \mathrm{~kg} \mathrm{~N} \mathrm{ha}^{-1}$ year $^{-1}$ (Carlsson and Huss-Danell, 2003) and soybean is estimated to fix on average $79 \mathrm{~kg} \mathrm{~N} \mathrm{ha}^{-1}$ year $^{-1}$ (Salvagiotti et al., 2008).

\section{Soybean and alfalfa: important crops in current and near future agriculture.}

For the present thesis two different legumes has been chosen: soybean (Glycine $\max ($ L.) Merr.) and alfalfa (Medicago sativa L.). These two legumes were selected for their contrasting characteristic. While soybean is a tropical pulse legume, alfalfa is a temperate forage legume. Additionally, regarding nodules, legumes are generally grouped into two groups, namely determinate and indeterminate, based on whether a persistent meristem is formed. Soybean represents the first group (determinate nodules) and alfalfa has indeterminate nodules. However, one characteristic was basic for their selection, both species are the most cultivated legumes and are widely grown worldwide (Graham and Vance, 2003). Therefore, due to their economic importance and worldwide cultivation, the study of climate change effects in these two crops is required in order to ensure adequate legume availability products for food and feed (Stagnari et al., 2017) (Fig. 6).

Soybean

Soybean, is the fourth most important food crop and the most cultivated legume, with 349 million tons produced in 2018 (FAOSTAT, 2020) being the most traded 
agricultural commodity, accounting for over $10 \%$ of the total value of the global exchange. This legume is an important source of high quality protein and oil for human and livestock consumption (Ainsworth et al., 2012). Additionally, it contains a considerable amount of carbohydrates, amino acids, and minerals that contribute to its nutritional value (Medic et al., 2014). Soybean is cultivated mainly at latitudes 20-50 $\mathrm{N}$ and $10-40^{\circ} \mathrm{S}$ (Leff et al., 2004), suggesting a wide adaptability towards different environments and climates. However, that degree of adaptability may not be enough under the influence of climate change and factors such as drought and heatwaves can lead to reduced soybean production worldwide (Li et al., 2017).

\section{Alfalfa}

Alfalfa, a perennial legume crop, is the most cultivated forage legume in the world, and the most frequent and commercially source of forage and feed in many countries (Annicchiarico et al., 2015). For example, it is the third or fourth most valuable crop in the U.S. (U.S. Department of Agriculture, National Agricultural Statistics Service). The combination of high quality forage (Radović et al., 2009), capacity to fix atmospheric nitrogen by symbiotic relationships with Ensifer genus bacteria, and the expected rise of forage crops due to increases in the global demand for feed products (Hopkins and Del Prado, 2007), make this crop interesting for food security and environmental conservation. Alfalfa is the basic component in feeding program mainly for ruminants animal, dairy cattle as well as for beef cattle, horses, sheep, but also for other classes of livestock. Due to these benefits, alfalfa is grown throughout the dry tropical and temperate regions of the world (Kulkarni et el., 2018). However, beside their rapid recovery after cutting and longevity, alfalfa, like other legume crops, shows variable production rates, mostly due to abiotic factors such as drought (Daryanto et al. 2015). 


\subsection{Effects of climate change on legumes}

As described before, legumes are a significant source of plant based proteins in humans and livestock diet, and due to their agronomic characteristic also a sustainable food. However, legume production is threatened by various abiotic stresses which are expected to increase in number and severity with climate change (IPCC, 2014). Additionally, when compared with cereals, the other key crop family, the greater sensitivity of legumes to various abiotic stresses and comparatively lower yield made that the cultivation as well as research on legumes have always been under-prioritized as compared to cereal crops (Naeem et al., 2020). Therefore, to tackle this situation, there is a need to investigate effects of climate change associated with greenhouse gas emissions, such as water stress, increased temperature, and $\mathrm{e}\left[\mathrm{CO}_{2}\right]$ and the needing for several future agricultural adaptations to ensure adequate legume availability for food and feed production (Hopkins and Del Prado, 2007; Araújo et al., 2015).

\section{Leaf and nodule under changing environmental conditions}

\section{Elevated atmospheric $\left[\mathrm{CO}_{2}\right]$}

Extensive studies of legume responses to $\mathrm{e}\left[\mathrm{CO}_{2}\right]$ have shown that, depending on the interaction with other environmental parameters, elevated $\mathrm{CO}_{2}$ might reduce stomatal conductance $\left(\mathrm{g}_{\mathrm{s}}\right)$ and enhance photosynthesis rate $\left(A_{n}\right)$ with a stimulation of water use efficiency (WUE), growth and yield (Ainsworth et al., 2002; Aranjuelo et al., 2005; Ainsworth and Rogers, 2007; Erice et al., 2014; Soba et al., 2020a). Such responses are due to the fact that, for $\mathrm{C}_{3}$ plants, atmospheric $\left[\mathrm{CO}_{2}\right]$ concentration is suboptimal. As a consequence, the projected increase of atmospheric $\left[\mathrm{CO}_{2}\right]$ levels is expected to have a "fertilizer" effect, which will result in greater plant growth. In a meta-analysis summarizing 111 studies in soybean, Ainsworth et al. (2002) showed that $\mathrm{e}\left[\mathrm{CO}_{2}\right]$ increased canopy photosynthetic rate (59\%) more than total biomass $(39 \%)$ or total seed weight $(24 \%)$. Based in these results, some authors suggest that legume response to future $\left[\mathrm{CO}_{2}\right]$ could partially offset other negative aspects of global change, such as drought or high temperature (Lobell and Gourdji, 2012). However, in some crops the initial stimulation due to $\mathrm{e}\left[\mathrm{CO}_{2}\right]$ is retained after certain time (Aranjuelo et al., 2011) due to stomatal and biochemical limitations (Vicente et al., 2017). Despite that, legume family form nodules in symbiosis with bacteria of the genus Rhizobia, which provide access to atmospheric $\mathrm{N}_{2}$, through biological nitrogen fixation (BNF). 
According to Kaschuk et al. (2009), bacteroids can consume between 4 to $11 \%$ of the carbohydrates fixed through photosynthesis and, therefore, high rates of photosynthesis have been shown to be maintained in legumes under $\mathrm{e}\left[\mathrm{CO}_{2}\right]$, even after long-term treatment (Bernacchi et al., 2006; Arenque et al., 2014), avoiding C sink-limitation (Ainsworth et al., 2004). In addition, the plant demand for $\mathrm{N}$ likely increases under $\mathrm{e}\left[\mathrm{CO}_{2}\right]$ and, hence, symbiotic $\mathrm{N}_{2}$ fixation has been considered as the most influential factor affecting plant $\mathrm{N}$ uptake and productivity under e[ $\left.\mathrm{CO}_{2}\right]$ (Ainsworth et al., 2003). Due to the greater availability of photo-assimilates in plants under e $\left[\mathrm{CO}_{2}\right]$, it is expected that under $\mathrm{e}\left[\mathrm{CO}_{2}\right]$ legumes can develop more and larger roots and nodules allowing more $\mathrm{N}_{2}$ to be fixed, making legumes an advantageous crop family in impoverish agricultural soils under future climate conditions (Stagnari et al., 2017). However, some studies show that although plant level $\mathrm{N}_{2}$ fixation increased under $\mathrm{e}\left[\mathrm{CO}_{2}\right]$, the larger photoassimilate availability did not contribute to increase specific nodule $\mathrm{N}_{2}$ fixation, probably due to a deteriorated respiratory mechanism (Aranjuelo et al., 2008; 2014).

\section{Drought and high temperature}

Exposure to droughts and periods of extreme heat, or heatwaves, have been identified as the climate variables that most negatively affect plant growth and development, causing significant yields losses on a global scale (Deryng et al., 2014; Herritt and Fritschi, 2020). In the case of legumes, the effects of heat (Nahar et al., 2016) and water (Farooq et al., 2009; Soba et al., 2019) stresses on have been studied widely in isolation, but their potential combined impact is less clearly defined (Awasthi et al., 2014).

In terms of productivity, both water and temperature stresses are detrimental to legume grain yield at all growth stages. However, damage during the reproductive stages, flowering and pod formation and filling, are the major reason for yield loss (Pushpavalli et al., 2015; Sehgal et al., 2018). Yield losses during reproductive stages has been directly linked to a decrease in photosynthetic performance, resulting in a poor synthesis/translocation of assimilates to flowers and pods that causes a poor pollination and higher rates of flower abortion and, during pod and grain filling, poor cell division resulting in fewer and smaller seeds both in high temperature (Djanaguiraman and Prasad, 2010; Puteh et al., 2013) and water stress (Farooq et al., 2017; Du et al., 2020). On the other hand, in forage legumes, such as alfalfa, productivity losses by these 
stresses are mainly due to the previously described inhibition of cell elongation and, therefore, reduction in aerial biomass (Soba et al., 2019). Moreover, lower protein content and mineral impoverishment have also been detected in aboveground organs of $\mathrm{N}_{2}$ fixing alfalfa (Sanz-Saez et al., 2012) and soybean plants (Myers et al., 2014, Soba et al., 2020a) under different climate change conditions. Consequently, they might determine the value of nutritional diet and the quality of animal and human consumption in the short/medium term future (Sanz-Sáez et al., 2012). As it has been previously observed, legume responses to a single abiotic in terms of quality are relatively well known. In contrast, our knowledge of legume quality under multiple stresses co-occurs is fragmentary. Drought in combination with heat stress at seed filling adversely affects seed size and seed yield in various crops, including legumes (Awasthi et al., 2014; Hamidou et al., 2013; Shegal et al., 2019; Choukri et al., 2020). However, no information is available on the individual and combined effects of heat and water stress during seed filling on the qualitative aspects of legume seeds (Shegal et al., 2018).

Additionally, both stresses decrease $A_{n}$, due to not only an increase of internal resistance to $\mathrm{CO}_{2}$ diffusion, caused by stomata closure, but also due to an increase in photodamage of the photosystem II (PSII), formation of ROS, and an increase of leaf temperature, thus favoring photorespiration (Prasad et al., 2008, Molero and Aranjuelo, 2017; Ergo et al., 2018). Inhibition of PSII activity disables enzymes of the Calvin cycle, reduces Rubisco activity and increases oxidative damage by enhancing ROS production (Mendez-Espinosa et al., 2019; Balfagón et al., 2020), compromising plant photosynthesis and carbon assimilation.

Abiotic stresses require plants to perceive and react to these signals in a highly coordinated and interactive manner (Soba et al., 2019). Phytohormones play a central role in the perception of abiotic stresses, triggering interactions between the signal transduction cascades. Between them, abscisic acid (ABA) is the primary phytohormone that triggers short-term responses, such as stomatal closure (Dodd, 2013), in order to reduce the transpiratory rate and, consequently, the water consumed by the plant under stresses like drought or heatwave. Changes in endogenous phytohormones induce changes in gene expression that affect the synthesis, production and accumulation of several metabolites as part of an osmoregulatory response, such as carbohydrates, amino acids and organic acids, in different plant organs (Sanchez et al., 
2012) in order to decrease the osmotic potential ( $\Psi$ s) allowing the maintenance of water absorption and turgidity pressure (Molero and Aranjuelo, 2007). All these changes affect $\mathrm{N}$ and $\mathrm{C}$ metabolism that have been demonstrated to play a very important role in drought (Aranjuelo et al., 2015; Larrainzar et al., 2009) and heat stress (Nahar et al., 2016) response and in productivity.

At the nodule level, BNF is especially sensitive to water stress with a rapid inhibition of $N_{\text {ase }}$ activity (Zahran, 1999). In fact, inhibition of BNF has been shown to precede photosynthesis inhibition in drought stressed legumes (Durand et al., 1987). The reported decrease in $N_{\text {ase }}$ activity has been associated with different mechanisms such as (i) reduction of photoassimilates to the bacteroid; (ii) accumulation of nitrogen compounds in the nodule (iii) decreased permeability of $\mathrm{O}_{2}$; and (iv) oxidative stress (Aranjuelo et al., 2014). However, nodule functioning under heat, and in special under combined stresses, has not been characterized in detail, highlighting the necessity to conduct further studies considering these factors (Aranjuelo et al., 2014).

Due to their intense biochemical activity, legume nodules are at high risk of damage as a result of the generation of ROS (Gogorcena et al., 1995). Although ROS may play an essential role in redox signaling, they may also disrupt biological membranes and cause cellular damage (Apel and Hirt, 2004). To avoid this damage, nodules possess an array of antioxidants that modulate ROS levels, which suggests an important connection between $\mathrm{N}_{2}$ fixation and antioxidants (Becana et al., 2010; Soba et al., 2020b). Phytohormones play a central role in the perception of abiotic stresses, triggering interaction between the signal transduction cascades. In nodules, several authors have shown the importance of phytohormones during their formation and development (reviewed by Liu et al., 2018). However, in mature nodules, the factors that orchestrate nodule perception and responses under abiotic stresses related to phytohormones have received much less attention.

On the other hand, nodule metabolism under water restrictions is highly dependent on the metabolism of other organs (Molero et al., 2019). For example, in alfalfa plants it was shown that nodule metabolism performance (characterized via proteomics and metabolic profile analyses) was tightly linked to the impact of drought on leaf metabolism (Aranjuelo et al., 2011). These results showed that deleterious effects of drought on nodules also conditioned leaf responsiveness and highlighted the 
importance of taking into account the whole plant as a system. Nevertheless, metabolite exchange, organ signalling mechanisms, and the coordination of their changes between nodules and other plant organs are still not clear. 
upna

Universidad pubilica de Navara 
" II. OBJECTIVES

upna 
upna

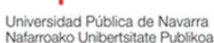




\section{OBJECTIVES}

The main objective of the present thesis was to go in depth in the knowledge of the legume physiological, biochemical and metabolic responses to abiotic stresses and events associated with climate change (elevated $\mathrm{CO}_{2}$, drought and heatwave) with special emphasize in the relation leaf-nodule. This main objective was divided in different sub-objectives:

i) Analyze the response of soybean cultivars with different WUE (due to different cultivar stomatal closure) to future $\mathrm{CO}_{2}$ scenarios (Chapter 1). For this sub-objective we centered in:

a. Photosynthetic performance at leaf and canopy level.

b. Seed yield and seed quality parameters (mineral composition).

ii) Evaluate physiological, hormonal and metabolic response to water stress at whole plant level of two alfalfa cultivars with contrasting origins and responses to drought (Chapter 2).

iii) Confirm the presence of vitamin $\mathrm{E}$ in nodules of different legumes and examine its possible function as an antioxidant in legume nodules to modulate lipid peroxidation under drought (Chapter 3)

iv) Study the effects of combined water stress and heatwave during early reproductive stages in soybean on leaf and nodule tissues and on final seed yield (Chapter 4$)$. 


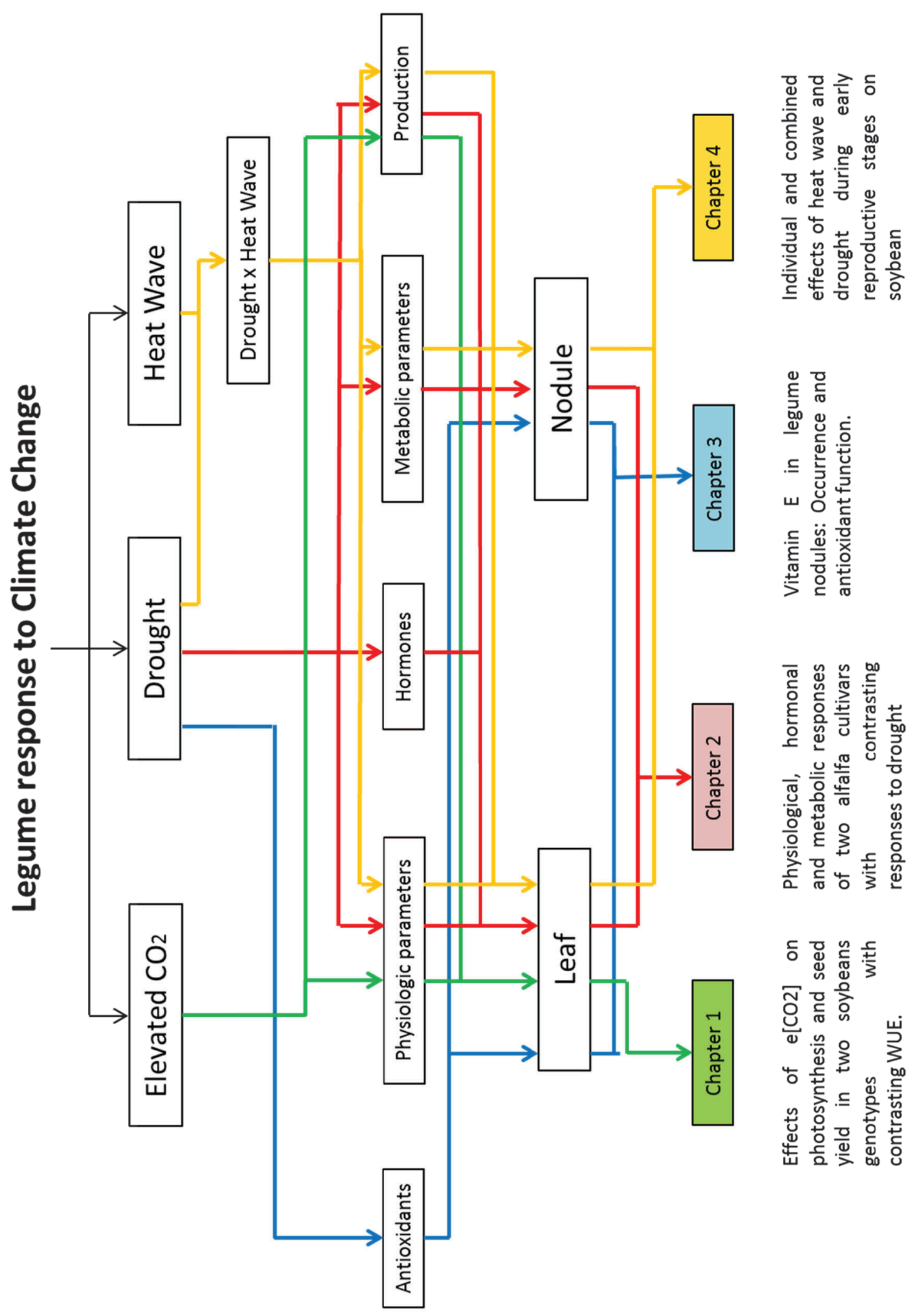


upna

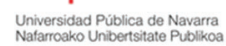


" III. CHAPTER 1

upna 
upna

Universicad Publica de Navara
Natarsaako Unibersitate Publikoa 


\title{
Effects of elevated $\left[\mathrm{CO}_{2}\right]$ on photosynthesis and seed yield parameters in two soybean genotypes with contrasting water use efficiency
}

\author{
David Soba $^{\mathrm{a}}$, Tianchu Shu ${ }^{\mathrm{b}}$, G. Brett Runion ${ }^{\mathrm{c}}$, Stephen A. Prior ${ }^{\mathrm{c}}$, Felix B. Fritschi ${ }^{\mathrm{d}}$, Iker Aranjuelo ${ }^{\mathrm{a}}$, \\ Alvaro Sanz-Saez ${ }^{\mathrm{b}, *}$ \\ ${ }^{\mathrm{a}}$ Instituto de Agrobiotecnología (IdAB), Consejo Superior de Investigaciones Científicas (CSIC)-Gobierno de Navarra, Av. Pamplona 123, 31192, Mutilva, Spain \\ ${ }^{\mathrm{b}}$ Department of Crop, Soil and Environmental Sciences, Auburn University, Auburn, AL, 36849, USA \\ ${ }^{\mathrm{c}}$ U.S. Department of Agriculture-Agricultural Research Service, National Soil Dynamics Laboratory, Auburn, AL, 36832, USA \\ ${ }^{\mathrm{d}}$ Division of Plant Sciences, University of Missouri, Columbia, MO, USA
}

\section{A R T I C L E I N F O}

\section{Keywords:}

Glycine max

Genotypes

Leaf and canopy

Gas exchange

Stomatal conductance

\begin{abstract}
A B S T R A C T
The predicted increase in atmospheric $\mathrm{CO}_{2}$ concentration $\left[\mathrm{CO}_{2}\right]$ is expected to enhance photosynthesis and seed yield in crops such as soybean [Glycine $\max ($ L.) Merr.]. However, future breeding for high water use efficiency (WUE) could interfere with the amount of carbon (C) fixed by leaves and seed mineral composition under elevated $\left[\mathrm{CO}_{2}\right]$ due to lower stomatal conductance $\left(\mathrm{g}_{\mathrm{s}}\right)$. In the present study, two genotypes with contrasting WUE were grown in open top chambers (OTC) under ambient (410 ppm; $\mathrm{a}_{[}\left[\mathrm{CO}_{2}\right]$ ) and elevated (610 ppm; e $\left[\mathrm{CO}_{2}\right]$ ). In order to test performance of both cultivars to changing $\mathrm{CO}_{2}$ conditions, growth, photosynthetic performance (leaf and canopy level) and seed mineral composition were analyzed. The low WUE genotype had a greater response to e $\left[\mathrm{CO}_{2}\right]$ in terms of leaf daily photosynthetic $\mathrm{C}$ gain due to greater $\mathrm{g}_{\mathrm{s}}$, which was compensated in the high WUE genotype by an increase in leaf area (LA). However, in the low WUE genotype, improved daily photosynthetic $\mathrm{C}$ gain did not translate into greater biomass or seed yield $\left[\mathrm{CO}_{2}\right]$ response compared to the high WUE genotype, suggesting better assimilate partitioning by the high WUE genotype. In terms of seed composition, the high WUE genotype generally had lower mineral concentrations at e $\left[\mathrm{CO}_{2}\right]$ compared to a $\left[\mathrm{CO}_{2}\right]$, but greater total amounts of nutrient (due to higher seed yield) under e[ $\left[\mathrm{CO}_{2}\right]$ compared to the low WUE genotype. Findings presented here highlight importance of genetic variation in soybean response to future atmospheric $\left[\mathrm{CO}_{2}\right]$ which should be considered when breeding for future climates.
\end{abstract}

\section{Introduction}

Atmospheric $\left[\mathrm{CO}_{2}\right]$ has strongly increased from $\sim 280 \mathrm{ppm}$ to $\sim 410$ ppm between pre-industrial times and the present (CO2.earth, 2020), and if current trends in emissions continue, atmospheric $\left[\mathrm{CO}_{2}\right]$ could reach 600 ppm by 2050 (IPCC, 2013). Soybean [Glycine max (L.) Merr.] is the fourth most important crop globally in terms of seed production (i.e., 353 million tons produced in 2017; FAOSTAT, 2020) and is an important source of protein for human and livestock consumption (Ainsworth et al., 2012). Extensive studies of soybean responses to elevated $\mathrm{CO}_{2}$ concentrations $\left(\mathrm{e}\left[\mathrm{CO}_{2}\right]\right.$ ) have shown that $\mathrm{e}\left[\mathrm{CO}_{2}\right]$ may reduce stomatal conductance $\left(\mathrm{g}_{\mathrm{s}}\right)$ and enhance photosynthesis, water use efficiency (WUE), and growth and yield (Rogers et al., 1983a, 1983c, 1984; Sionit et al., 1984; Ainsworth et al., 2002; Ainsworth and Rogers, 2007; Prior et al., 2010). Some authors suggest that soybean responses to future $\left[\mathrm{CO}_{2}\right]$ could partially offset other negative aspects of global change, such as drought or high temperature (Lobell and Gourdji, 2012). Therefore, this important potential benefit should be investigated to identify genotypes with better response to e $\left[\mathrm{CO}_{2}\right]$ and the mechanisms contributing to this responsiveness (Aspinwall et al., 2015).

Bishop et al. (2015) studied 18 soybean genotypes under fully open air conditions and noted that seed yield response to $\mathrm{e}\left[\mathrm{CO}_{2}\right]$ differed among genotypes and that genotypes displaying the greatest seed yield response to e $\left[\mathrm{CO}_{2}\right]$ also had large increases in total biomass. Recently, Sanz-Sáez et al. (2017) studied two soybean cultivars with contrasting yield response to $\mathrm{e}\left[\mathrm{CO}_{2}\right]$ and showed that greater photosynthetic capacity showed as higher light conversion efficiency likely contributed to higher seed yields under both ambient and e $\left[\mathrm{CO}_{2}\right]$.

Under e $\left[\mathrm{CO}_{2}\right]$, increased photosynthesis along with decreased $\mathrm{g}_{\mathrm{s}}$ results in higher intrinsic WUE, defined as photosynthetic carbon gain per unit of water transpired (Rogers et al., 1983a; Passioura, 2004;

\footnotetext{
* Corresponding author.

E-mail address: sanz@auburn.edu (A. Sanz-Saez).
} 
Prior et al., 2010; Gilbert et al., 2011). This increase in WUE under e $\left[\mathrm{CO}_{2}\right]$ could imply that soybean may be less sensitive to drought conditions under future atmospheric $\left[\mathrm{CO}_{2}\right]$. However, previous research with commercial soybean cultivars under free air $\mathrm{CO}_{2}$ enrichment (FACE) and open top chambers (OTC) conditions showed that the expected stimulation of yield at $\mathrm{e}\left[\mathrm{CO}_{2}\right]$ could decrease and even become negative with increasing drought stress, mainly due to greater stomatal closure when compared with plants grown at ambient $\left[\mathrm{CO}_{2}\right]\left(\mathrm{a}\left[\mathrm{CO}_{2}\right]\right)$ (Li et al., 2013; Gray et al., 2016). These authors suggest that a decrease in photosynthesis and, therefore, in biomass accumulation and yield at $\mathrm{e}\left[\mathrm{CO}_{2}\right]$ under water stress conditions, may be due to a reduction in $\mathrm{g}_{\mathrm{s}}$ that would reduce leaf intercellular $\left[\mathrm{CO}_{2}\right]\left(\mathrm{C}_{\mathrm{i}}\right)$. This indicates that e $\left[\mathrm{CO}_{2}\right]$ may not always counteract drought-induced reduction in soybean seed yield as previously thought (Lobell and Gourdji, 2012). Consequently, breeding for high WUE cultivars based on lower stomatal conductance, as proposed to offset the negative effects of future water limited conditions (Condon et al., 2004), could have a negative effect on biomass and seed yield under $\mathrm{e}\left[\mathrm{CO}_{2}\right]$.

In addition to the above mentioned physiological changes, e $\left[\mathrm{CO}_{2}\right]$ has the potential to influence seed mineral concentration and thereby impact human and animal nutrition (Weigel, 2014). Recently, two meta-analysis assessments noted that $\mathrm{e}\left[\mathrm{CO}_{2}\right]$ could reduce seed mineral concentration of several row crops such as soybean, wheat (Triticum aestivum), and rice (Oryza sativa) (Loladze, 2014; Myers et al., 2014). These studies concluded that $\mathrm{e}\left[\mathrm{CO}_{2}\right]$ will especially reduce $\mathrm{Zn}$ and $\mathrm{Fe}$ concentrations thereby affecting food nutritional value and contributing to malnourishment in undeveloped countries. The mechanisms responsible for decreased seed mineral concentration are not yet clear, however, two hypotheses have been proposed to explain this phenomenon: (1) reduced transpiration as a result of stomatal closure under $\mathrm{e}\left[\mathrm{CO}_{2}\right]$ may interfere in the uptake of nutrients by roots and movement within the plant (McGrath and Lobell, 2013); and (2) a dilution effect from increased seed mass production could contribute to reduced mineral concentrations observed under e $\left[\mathrm{CO}_{2}\right]$ (Singh et al., 2016). Additionally, the effect of $\mathrm{e}\left[\mathrm{CO}_{2}\right]$ on soybean seed mineral composition is not clear and may be greatly influenced by genotype (Myers et al., 2014; Li et al., 2018; Soares et al., 2019). Although several researchers have previously discussed the transpiration and dilution hypotheses, they have not been experimentally tested. Consequently, assessing plant growth or nutrient uptake of contrasting WUE genotypes under $\mathrm{e}\left[\mathrm{CO}_{2}\right]$ can be useful in elucidating nutritional impacts and might offer guidelines for cultivar selection to meet needs of future climatic scenarios.

With this in mind, we hypothesized that in future $\mathrm{CO}_{2}$ scenarios, breeding for high WUE genotypes could reduce the amount of $\mathrm{C}$ fixed by leaves, therefore yield, and alter seed nutrient levels due to greater stomatal closure. Using two soybean genotypes with contrasting WUE under ambient and elevated $\left[\mathrm{CO}_{2}\right]$, we tested this hypothesis by examining: a) photosynthetic performance at leaf and canopy levels; and b) seed mineral concentration and content. These two genotypes were among 373 diverse soybean genotypes initially tested by Dhanapal et al. (2015) for WUE using the carbon isotope ratio $\left(\delta^{13} \mathrm{C}\right)$ technique; the two selected genotypes showed consistent differences in $\delta^{13} \mathrm{C}$ (thus WUE) across four environments (two years and two locations).

\section{Materials and methods}

\subsection{Plant material and experimental conditions}

Two maturity group IV soybean genotypes previously selected (Dhanapal et al., 2015) for high WUE (Pi398223) and low WUE (Pi567201) were used in our study. Pi398223 (hereafter referred to as High_WUE) was annotated in the Germplasm Resources Information Network on 1972, and Pi567201 (hereafter referred to as Low_WUE) in 1993. Seeds of both genotypes were first obtained from the USDA soybean germplasm collection and then increased at University of
Missouri, Columbia. High_WUE and Low_WUE were among 373 diverse soybean genotypes that were tested in four environments (two years and two locations) by Dhanapal et al. (2015), and consistently were among the high and low WUE extremes as assessed by the carbon isotope ratio $\left(\delta^{13} \mathrm{C}\right)$ technique.

The current study was conducted at the soil bin facilities of the USDA-ARS National Soil Dynamics Laboratory, Auburn, Alabama (Batchelor, 1984). The bin used for the experimental setup was exactly as described by Runion et al. (2008). Open top chambers (Rogers et al., 1983b), encompassing $7.3 \mathrm{~m}^{2}$ of ground surface area, were used to achieve a target $\left[\mathrm{CO}_{2}\right]$ of ambient $(\sim 420 \mathrm{ppm})$, plus $200 \mathrm{ppm}$ (elevated $\left[\mathrm{CO}_{2}\right]$ ) during daylight hours via delivery and monitoring systems described by Mitchell et al. (1995). Season mean values were $427.3 \pm 0.23 \mathrm{ppm}$ for ambient $\left[\mathrm{CO}_{2}\right]$; and $631.1 \pm 0.45 \mathrm{ppm}$ for the elevated. There were 4 replicate chambers of each $\mathrm{CO}_{2}$ level for a total of 8 experimental plots. Each OTC held 2 containers of each genotype in order to have two sub-replicates for each plot. The experiment was conducted as a split plot design with $\mathrm{CO}_{2}$ level as the main plot factor and genotype as the split plot factor; the four blocks were distributed along the length of the soil bin. Prior to analysis, data from the two containers in each plot were averaged to yield one value per plot. Two additional containers of each genotype per OTC were also maintained until maturity (R8) and harvested for seed yield parameters.

\subsection{Crop growth and harvest}

The High_WUE and Low_WUE genotypes were sown into 20-liter black containers filled with commercial growth media (Pro-Mix BMX, Premier Tech, Quebec, Canada). Seeds were inoculated with commercial Bradyrhizobium japonicum (N-dure, Verdesian Inc., Cary, NC, USA) to ensure good nodulation. Containers were placed in OTCs immediately after sowing on 16 May. All containers were connected to a drip irrigation system that applied $3.8 \mathrm{~L}$ of water once every two days during the first three weeks, and every day afterwards to avoid drought stress. One liter of Evans minus-N solution (Evans, 1974) was applied to each container twice weekly. Physiological measurements were performed during plant reproductive growth coinciding with R3-R6 stages (Fehr et al., 1971). Experimental site meteorological conditions during the study are presented in Supplemental Fig. 1.

At mid seed fill (R5; 1 August 2019), eight plants per genotype and $\mathrm{CO}_{2}$ level (16 total) were destructively harvested and separated into root, shoot, leaves, and pods. Leaf area (LA) was measured using a LI3100 leaf area meter (LICOR Biosciences, Lincoln, NE, USA). Afterwards, all plant organs were oven dried for at least $72 \mathrm{~h}$ at $60{ }^{\circ} \mathrm{C}$ prior to dry weight (DW) determinations.

At maturity (R8; 5 September 2019), another eight plants per genotype and $\mathrm{CO}_{2}$ level were harvested. Grain and aboveground biomass were collected and dried as above to determine DW. Additional calculations included thousand grain weight (TGW) and harvest index (HI; ratio between seed weight and aboveground DW). Since soybean loses all leaves at maturity, a variation of $\mathrm{HI}$ was calculated (seed weight at R8 divided by aboveground DW at R5) in order to account for leaf biomass.

\subsection{Leaf gas exchange measurements}

Diurnal measurements of leaf instantaneous photosynthetic $\mathrm{CO}_{2}$ assimilation (A) and $\mathrm{g}_{\mathrm{s}}$ were measured using a LI-6400 Portable Photosynthesis System (LI-COR Biosciences, Lincoln, NE, USA). Measurements were made on the most recently fully expanded leaf at the top of the canopy three times during early pod (R3), full pod (R4), and seed filling (R5). Gas exchange was measured every $\approx 2 \mathrm{~h}$ from sunrise to sunset on 2 plants per genotype and OTC. Dark leaf respiration was measured $2 \mathrm{~h}$ after sunset. Before each measurement time point, light intensity was recorded by a photosynthetic photon flux density meter (LI-190; LICOR Biosciences, Lincoln, NE, USA), 
temperature was monitored by an onsite weather station, and relative humidity was maintained between $60 \%$ and $70 \%$. Conditions in the leaf cuvette were then set to match ambient environmental conditions, with the $\left[\mathrm{CO}_{2}\right]$ in the cuvette set to match either ambient $(\sim 410 \mathrm{ppm})$ or elevated $(\sim 610 \mathrm{ppm}) \mathrm{CO}_{2}$ treatments. Total daily $\mathrm{CO}_{2}$ uptake $\left(A^{\prime}\right)$ and water loss by transpiration $\left(g_{s}{ }^{\prime}\right)$ was estimated by integrating the areas under the curves formed by the different diurnals measures of $\mathrm{A}$ and $\mathrm{g}_{\mathrm{s}}$ for each individual plant and time point measured, as calculated in Sanz-Saez et al. (2017). The diurnal photosynthetic curve is shown in Supplemental Fig. 4.

In addition, maximum rates of Rubisco carboxylation $\left(\mathrm{Vc}_{\max }\right)$ and RuBP regeneration rate $\left(\mathrm{J}_{\max }\right)$ were estimated from the response of $A$ to intercellular $\left[\mathrm{CO}_{2}\right]\left(\mathrm{C}_{\mathrm{i}}\right)$ as previously described (Ainsworth et al., 2007). Briefly, A- $c_{i}$ curves were measured when plants were at beginning pod development (R3, 15 July), and the beginning of seed filling (R5, 26 July) according to growth stages defined by Fehr et al. (1971). Photosynthesis was initially measured at the growth $\left[\mathrm{CO}_{2}\right]$ (ambient, $410 \mathrm{ppm}$ or elevated, $610 \mathrm{ppm}$ ), and then $\left[\mathrm{CO}_{2}\right]$ was reduced stepwise to the lowest concentration of $50 \mathrm{ppm}$, followed by a stepwise increase to the highest concentration of $1500 \mathrm{ppm}$. A total of 11 measurements per curve were recorded. During measurements, the block temperature was set at $28{ }^{\circ} \mathrm{C}$ and PPFD was set at saturated light conditions (1,750 $\mu \mathrm{mol} \mathrm{m} \mathrm{m}^{-2} \mathrm{~s}^{-1}$ ). Variables $\mathrm{Vc}_{\max }$ and $\mathrm{J}_{\max }$ were calculated using equations developed by Sharkey et al. (2007).

\subsection{Canopy photosynthesis}

A modular transparent custom chamber was designed as a closed system to measure total canopy photosynthesis. The chamber consisted of a base module to hold the container and seal the chamber, an intermediate transparent module to adjust chamber height, and a top module with ceiling and all sensors and tube fittings (Supplemental Fig. 2a). The chamber footprint is $0.25 \mathrm{~m}^{2}(0.5 \mathrm{~m} \times 0.5 \mathrm{~m})$ and it has a total volume of $0.268 \mathrm{~m}^{3}$. To avoid leaks, all junctions between parts were sealed with foam gaskets. Both the middle and top modules had 4 fans to ensure air mixing. The top module contains a temperature sensor (LI-1000-8, LI-COR Biosciences, Lincoln, NE, USA) placed under the side frame, a PAR sensor (LI-190, LI-COR Bioscience, Lincoln, NE, USA) on top of the frame, and $5 \mathrm{~m}$ of polytetra-fluoroethylene (PTFE) tubing that connects the custom chamber inlet and outlet fittings to the LI-8100 (LI-COR Bioscience, Lincoln, NE, USA) that serves as $\mathrm{CO}_{2}$ analyzer and also measures temperature and PAR. For purposes of this study, $\mathrm{CO}_{2}$ fluxes were calculated as temporal changes in $\mathrm{CO}_{2}$ concentration of air passing through a closed loop in the canopy chamber. Measurements were performed within $90 \mathrm{~s}$ to avoid chamber overheating. Temperatures were not observed to increase more than $1{ }^{\circ} \mathrm{C}$ during measurements.

The $\mathrm{CO}_{2}$ evolution data were analyzed using Soil-Flux-Pro software (LI-COR Biosciences, Lincoln, NE, USA) by fitting a linear regression line to the $\mathrm{CO}_{2}$ evolution in the chamber, which provides normalized sum of square residuals of the fits and $\mathrm{R}^{2}$ values. The first $10 \mathrm{~s}$ of each measurement were eliminated to avoid increased errors associated with chamber closure. An example $\mathrm{CO}_{2}$ curve from these measurements can be seen in Supplemental Fig. 2. Whole plant canopy photosynthesis measurements were made once at the end of pod filling (R5, 25 July).

\subsection{C isotopic composition $\left(\delta^{13} C\right)$}

Above ground biomass from samples collected at R5 (leaves, stems, and pods) were ground to pass a $1 \mathrm{~mm}$ screen, weighed into tin capsules, and shipped to the UC-Davis Stable Isotopes Facility (Davis, California, USA) for C isotope analysis. Samples were analyzed using an isotope ratio mass spectrometer (IsoPrime, Elementar France, Villeurbanne) coupled to an elemental analyser (EA3000, EuroVector, Milan, Italy). The ${ }^{13} \mathrm{C} /{ }^{12} \mathrm{C}$ ratio (R) in plant material was calculated using the $\delta$ notation $\left(\delta^{13} \mathrm{C}\right.$, carbon isotope composition) with respect to
Vienna Pee Dee Belemnite calcium carbonate (V-PDB), with an analytical precision of $0.1 \%$.

$\delta^{13} \mathrm{C}$ accuracy was monitored using international secondary standards of known ${ }^{13} \mathrm{C} /{ }^{12} \mathrm{C}$ ratios (IAEA-CH7 polyethylene foil, IAEA-CH6 sucrose, and USGS-40 glutamic acid, IAEA, Austria), and internal controls of known ${ }^{13} \mathrm{C} /{ }^{12} \mathrm{C}$ ratios (i.e., Bovine liver, peach leaves, and nylon 5).

\subsection{Seed mineral composition analysis}

Seeds collected at maturity (R8) were ground and sent to Waters Agricultural Laboratories Inc. (Camila, GA) for mineral analysis. Concentrations of $\mathrm{N}, \mathrm{P}, \mathrm{K}, \mathrm{Mg}, \mathrm{Ca}, \mathrm{S}, \mathrm{B}, \mathrm{Zn}, \mathrm{Mn}, \mathrm{Fe}$, and $\mathrm{Cu}$ were determined using an Inductively Coupled Plasma Mass Spectroscopy (ICPMS). Mineral content (element amount in total seed mass) was calculated by multiplying mineral concentration by total seed weight per plant. Carbon dioxide response values in seed mineral concentration and seed total mineral content for each genotype are presented as the coefficient response of each trait in e $\left[\mathrm{CO}_{2}\right] / \mathrm{a}\left[\mathrm{CO}_{2}\right]$.

\subsection{Statistical analysis}

Data analysis was conducted using the mixed model procedures of SAS (PROC MIXED, SAS 9.4, Cary, NC, USA; Littell et al., 1996). The $\mathrm{CO}_{2}$ treatments and the genotypes were considered as fixed effects, while blocks were considered as random effect. When the main effect of $\mathrm{CO}_{2}$ treatment and/or genotype, or their interaction was significant, least square means post-hoc tests were performed to compare means (LSMEANS, SAS 9.4, SAS Institute, Cary, NC, USA). Seed mineral concentration and total mineral content expressed as coefficient response to $\mathrm{e}\left[\mathrm{CO}_{2}\right]$ for each trait were analyzed as e $\left[\mathrm{CO}_{2}\right] / \mathrm{a}\left[\mathrm{CO}_{2}\right]$.

\section{Results}

\subsection{Biomass and plant performance}

To confirm that the WUE of the two genotypes was different, the carbon isotopic ratio $\left(\delta^{13} \mathrm{C}\right)$ of aboveground biomass was measured at R5 (Supplementary Fig. 3). The effect of e $\left[\mathrm{CO}_{2}\right]$ on $\delta^{13} \mathrm{C}$ was significant due to the fact that $\mathrm{CO}_{2}$ supplied in $\mathrm{e}\left[\mathrm{CO}_{2}\right]$ OTCs was depleted in ${ }^{13} \mathrm{C}$ (Erice et al., 2019). In both environments, the High_WUE genotype showed significantly lower $\delta^{13} \mathrm{C}$ in comparison to Low_WUE.

Biomass sampling was conducted at beginning of seed filling and harvest maturity. Results of statistical analysis regarding biomass accumulation, partitioning, and leaf and seed characteristics describing genotypes, $\mathrm{CO}_{2}$ levels (ambient, 410 ppm; elevated, $610 \mathrm{ppm}$ ) and their interaction effects are shown in Table S1. At R5, the High_WUE genotype produced more biomass than the Low-WUE, and exposure to e $\left[\mathrm{CO}_{2}\right]$ increased aboveground plant biomass by $53.0 \%$ and $36.3 \%$ in High_WUE and Low_WUE, respectively (Fig. 1). The same pattern was observed for leaf DW, but the increased in LA under e $\left[\mathrm{CO}_{2}\right]$ was only significant in High_WUE $(+46 \%)$. The $\mathrm{CO}_{2}$ level $\mathrm{x}$ genotype interactions found for aboveground DW and leaf DW point to the greater responsiveness of the high_WUE than the Low_WUE to $\mathrm{CO}_{2}$ level. The effects of genotype, $\left[\mathrm{CO}_{2}\right]$, and their interaction were significant for seed yield with increases of $100.8 \%$ and $64.8 \%$ in High_WUE and Low_WUE, respectively under e[ $\left[\mathrm{CO}_{2}\right]$ (Fig. 2). The TGW was increased under e $\left[\mathrm{CO}_{2}\right]$ only for Low_WUE. Harvest index calculated at maturity (HI_R8) showed a significant decrease under e[ $\left[\mathrm{CO}_{2}\right]$ when both genotypes were taken together. However, when HI was calculated using leaf and stem biomass from R5 (HI_R5, stage coinciding with maximum canopy coverage), the e $\left[\mathrm{CO}_{2}\right]$ treatment increased $\mathrm{HI}$ in the High_WUE genotype $(51.3 \%)$ but the $18.9 \%$ increase in the Low_WUE genotype was not significant. 

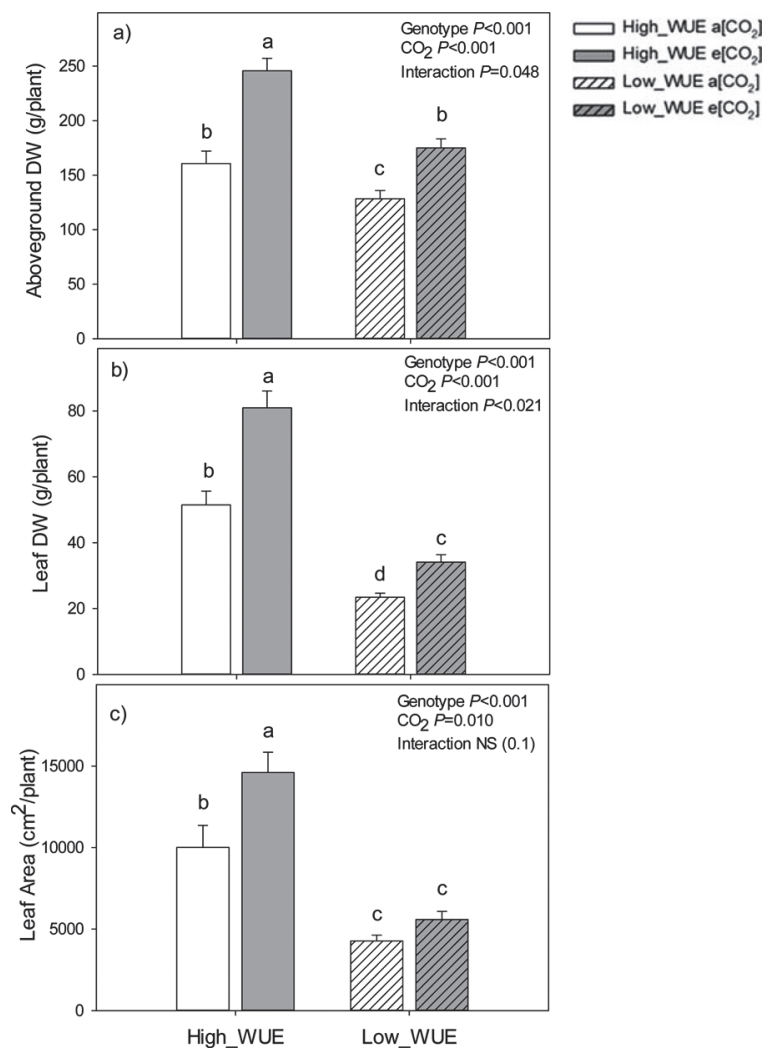

Fig. 1. Physiological parameters at the R5 growth stage: a) aboveground dry weight, b) leaf dry weight, and c) leaf area per plant measured in High_WUE and Low_WUE genotypes grown under ambient and elevated $\left[\mathrm{CO}_{2}\right]$. The bar chart shows the average of four replicate OTC's for each treatment $(n=4)$ Results of statistics are shown (two-way ANOVA, $P<0.05$ ). Letters indicate significant differences between treatments or genotypes (Tukey post hoc test $P<0.05)$. NS, not significant.

\subsection{Leaf photosynthesis}

Diurnal measurements of leaf photosynthesis were made three times during pod filling (R3, R4, and R5). Daily photosynthetic C gain $\left(A^{\prime}\right)$ and daily water loss by stomatal conductance $\left(g_{s}{ }^{\prime}\right)$ was estimated by integrating areas under the $\mathrm{A}$ and $\mathrm{g}_{\mathrm{s}}$ curves, respectively (Fig. 3). Supplementary Fig. 4 shows photosynthesis and $g_{s}$ data of individual time points. Genotypes differed at each measurement time, and a positive $A^{\prime}$ response to e $\left[\mathrm{CO}_{2}\right]$ was found in Low_WUE at beginning pod development (R3) and beginning of seed filling (R5). In contrast, no differences were found in High_WUE between $\mathrm{CO}_{2}$ levels at any of the three measurement dates (Fig. 3a). Genotypes differed in $g_{s}{ }^{\prime}$ at R3, R4, and R5, with consistently greater $g_{s}{ }^{\prime}$ in the Low_WUE. Both genotypes showed reductions in $g_{s}{ }^{\prime}$ under e $\left[\mathrm{CO}_{2}\right]$ during pod filling (R3 and R4), but not during seed filling. $V c_{\max }$ and $J_{\max }$ were greater in Low_WUE at beginning of pod filling with a significant increase in $V c_{\max }$ at the $P<0.1$ level under e $\left[\mathrm{CO}_{2}\right]$ when both genotypes were taken into account. In contrast, no differences were found between genotypes or $\mathrm{CO}_{2}$ levels at R5 (Fig. 4).

\subsection{Canopy photosynthesis}

Canopy photosynthesis measurements were made during seed filling. In comparison with $\mathrm{a}\left[\mathrm{CO}_{2}\right]$, the $\mathrm{e}\left[\mathrm{CO}_{2}\right]$ treatment increased canopy photosynthesis by 37.1 and $76.3 \%$ in High_WUE and Low_WUE, respectively. However, no differences between the two genotypes were observed (Fig. 5a). When canopy photosynthesis was expressed on a LA basis, effects of genotype, $\mathrm{CO}_{2}$, and their interaction all were significant (Table S2). When expressed per LA, canopy

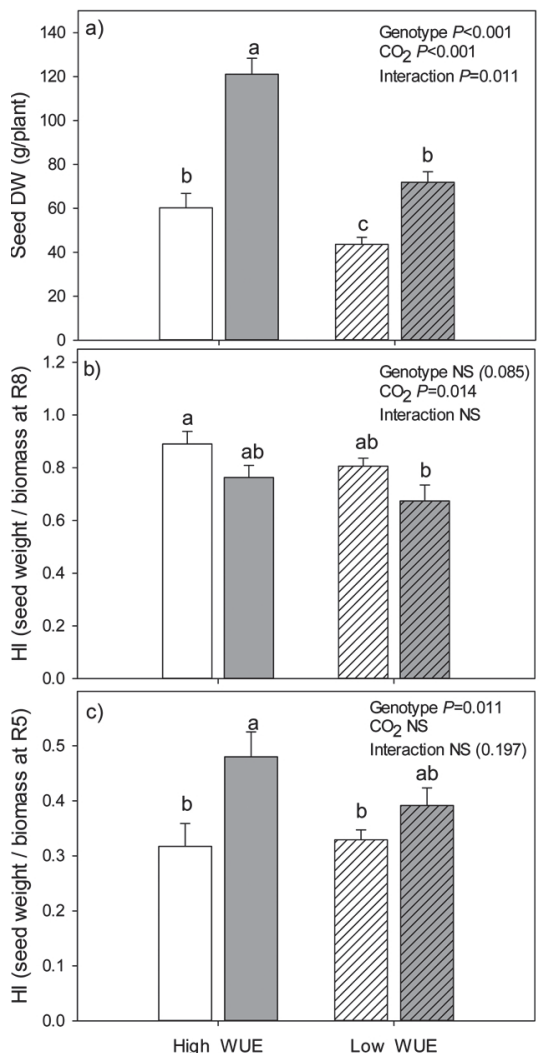

$\square$ High_WUE a[C $\left.\mathrm{CO}_{2}\right]$ $\square$ High_WUE e[CO एבC Low_MUE a[CO $\left.\mathrm{CO}_{2}\right]$ [D] Low_WUE e[ $\left[\mathrm{CO}_{2}\right]$

Fig. 2. Physiological parameters at maturity: a) seed dry weight, b) harvest index (HI) measured as the ratio between seed yield and aboveground biomass at R8 growth stage, and c) harvest index (HI) measured as the ratio between seed yield and aboveground biomass at R5 measured in High_WUE and Low_WUE genotypes grown under ambient and elevated $\left[\mathrm{CO}_{2}\right]$. The bar chart shows the average of four replicate OTC's for each treatment $(n=4)$. Results of statistics are shown (two-way ANOVA, $P<0.05$ ). Letters indicate significant differences between treatments or genotypes (Tukey post hoc test $P<0.05$ ). NS, not significant.

photosynthesis in Low_WUE was greater in both $\mathrm{CO}_{2}$ environments compared to High_WUE, and an increase of $55.3 \%$ was measured under $\mathrm{e}\left[\mathrm{CO}_{2}\right]$ (Fig. 5b). Unlike Low_WUE, canopy photosynthesis in High_WUE was similar at both $\mathrm{CO}_{2}$ levels when expressed per LA, which was similar to the observations for leaf-level photosynthesis (Fig. 3).

\subsection{Seed mineral concentration and content}

Mineral composition in mature seeds showed that $\mathrm{e}\left[\mathrm{CO}_{2}\right]$ reduce concentrations of $\mathrm{Ca}$ and $\mathrm{B}(\mathrm{P}<0.05)$ and $\mathrm{P}$ and $\mathrm{Zn}(\mathrm{P}<0.1)$ in High_WUE, and for Zn in Low_WUE (Fig. 6a). Seed mineral nutrient concentrations were significant higher in Low_WUE compared to High_WUE, except for N, P and S (Table S3), and in the case of Fe the reverse case (significant greater content in High_WUE genotype) was observed. The interaction effect was significant for $\mathrm{Ca}, \mathrm{B}$, and Fe (Table S4). Iron concentration was significantly increased in High_WUE in response to e $\left[\mathrm{CO}_{2}\right]$, but remained unchanged in Low_WUE. In the case of $\mathrm{Ca}$ and $\mathrm{B}$ concentrations were lower in $\mathrm{e}\left[\mathrm{CO}_{2}\right]$ in High_WUE but did not differ between $\mathrm{CO}_{2}$ levels in Low_WUE.

When comparing total mineral content of soybean seed (mineral concentration $\mathrm{x}$ total seed weight), the main effects of genotype and $\left[\mathrm{CO}_{2}\right]$ were significant for all minerals and the interaction was significant for $\mathrm{K}, \mathrm{Mg}, \mathrm{S}, \mathrm{Zn}$, and Fe (Table S4). All minerals followed the same trend and could be arranged in the following order: High_WUE at e $\left[\mathrm{CO}_{2}\right]>$ Low_WUE at e $\left[\mathrm{CO}_{2}\right]>$ High_WUE at a $\left[\mathrm{CO}_{2}\right]>$ Low_WUE at $\mathrm{a}\left[\mathrm{CO}_{2}\right]$ (Table S3). In all cases, the percent change between ambient and elevated $\left[\mathrm{CO}_{2}\right]$ was greater in High_WUE, primarily due to the 


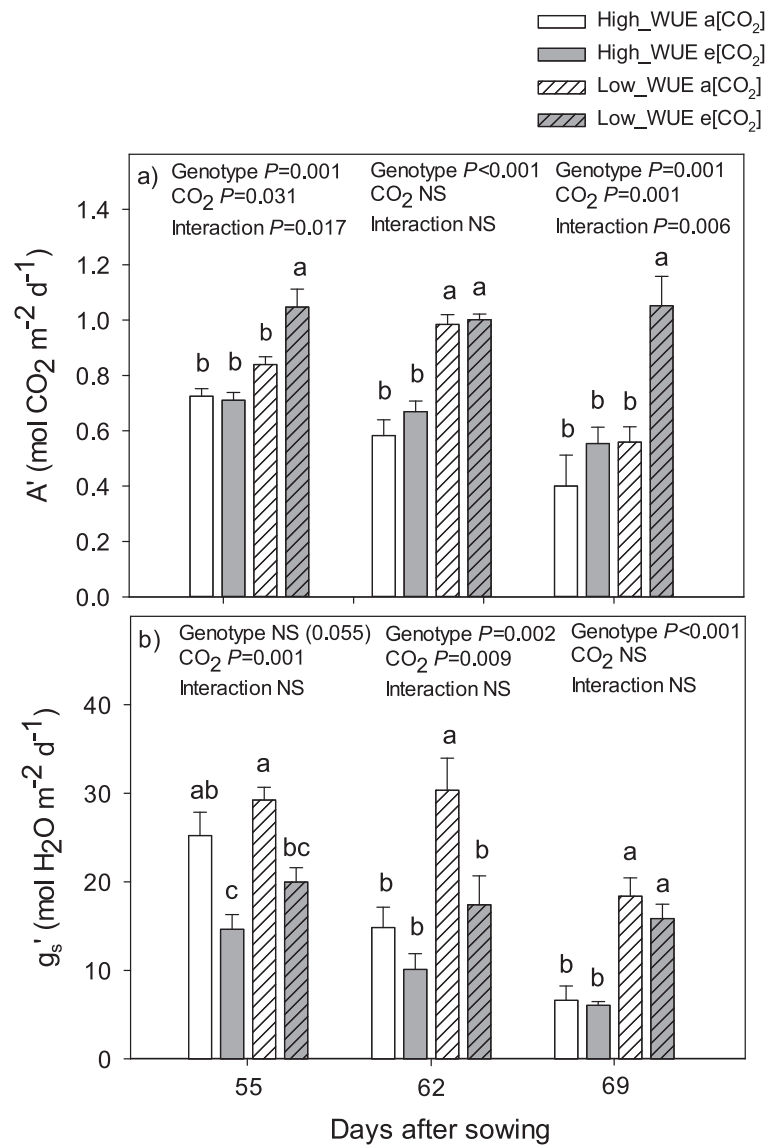

Fig. 3. Leaf photosynthetic parameters: a) daily photosynthetic $\mathrm{C}$ gain $\left(A^{\prime}\right)$ and b) daily water loss by stomata measured in High_WUE and Low_WUE genotypes grown under ambient and elevated $\left[\mathrm{CO}_{2}\right]$. The bar chart shows the average of four replicate OTC's for each treatment $(\mathrm{n}=4)$. Results of statistics are shown (two-way ANOVA, $P<0.05$ ). Letters indicate significant differences between treatments or genotypes (Tukey post hoc test $P<0.05$ ). NS, not significant.

greater response in total seed weight of this genotype to $e\left[\mathrm{CO}_{2}\right]$ (Fig. 6b).

\section{Discussion}

In plants with $\mathrm{C}_{3}$ photosynthetic metabolism, there may be two main responses to the predicted increase in atmospheric $\left[\mathrm{CO}_{2}\right]$ : (1) increased photosynthesis, and (2) reduced stomatal conductance. Other effects of e $\left[\mathrm{CO}_{2}\right]$ on plants, such as increased WUE or changes in seed mineral composition, are derived from these two fundamental responses (Long et al., 2004; Ainsworth and Rogers, 2007). Breeding for greater WUE can enhance yield in certain environments (Condon et al., 2004; Gilbert et al., 2011; Sinclair, 2012) but may have significant limitations since lower $g_{s}$ will influence leaf $C_{i}$ (Earl, 2002), thereby diminishing $\mathrm{C}$ fixed by photosynthesis. With this hypothesis in mind, the present study analyzed the effects of future atmospheric $\left[\mathrm{CO}_{2}\right]$ on photosynthetic performance (at leaf and canopy levels) and seed mineral composition in two soybean genotypes previously identified to contrast in WUE (Dhanapal et al., 2015). In the present study, genotype WUE differences were confirmed using $\delta^{13} \mathrm{C}$ as a surrogate measure of WUE (Farquhar et al., 1982; Dhanapal et al., 2015). At the R5 stage, the High_WUE genotype had less negative $\delta^{13} \mathrm{C}$ in both $\left[\mathrm{CO}_{2}\right]$ treatments, which is correlated with a higher WUE, compared with the Low_WUE genotype (Fig. S3)

Better assimilate supply, measured by enhanced $\mathrm{C}$ acquisition, may occur in plants from increased photosynthetic efficiency of $C$ fixation per unit of area, or by increased light interception from increased LA

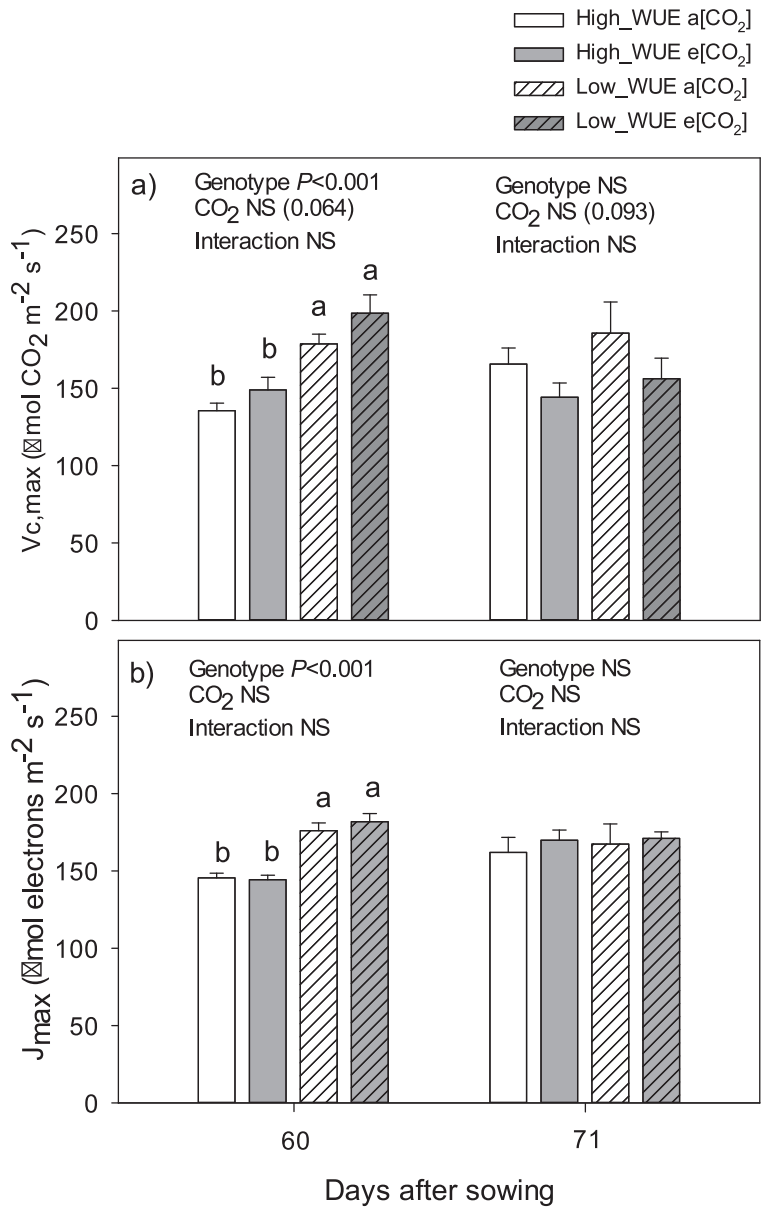

Fig. 4. a) Maximum rate of Rubisco carboxylation $\left(V c_{\max }\right)$ and b) RuBP regeneration rate $\left(\mathrm{J}_{\max }\right)$ measured in High_WUE and Low_WUE genotypes grown under ambient and elevated $\left[\mathrm{CO}_{2}\right]$. The bar chart shows the average of four replicate OTC's for each treatment $(n=4)$. Results of statistics are shown (twoway ANOVA, $P<0.05$ ). Letters indicate significant differences between treatments or genotypes (Tukey post hoc test $P<0.05$ ). NS, not significant.

(Evans, 2013). To distinguish between these factors, two types of photosynthesis measurements were made: (1) diurnal leaf-level measurements throughout pod filling, combined with A-Ci curves to estimate $\mathrm{Vc}_{\max }$ and $\mathrm{J}_{\max }$; and (2) whole plant canopy-level measurements during seed filling. Estimated by integrating the area under the leaf photosynthetic curve throughout the day, the first assessment yields daily photosynthetic C fixed per unit of leaf area. The second assessment was taken as the integration of $\mathrm{C}$ assimilation by the whole plant canopy divided by total plant LA.

In the present study, $\mathrm{A}^{\prime}$ of the Low_WUE was responsive to $\mathrm{e}\left[\mathrm{CO}_{2}\right]$ at two out of three measurement times whereas the High_WUE was not responsive to e $\left[\mathrm{CO}_{2}\right]$ at any of the measurements (Fig. 3a). The higher calculated daily photosynthetic C gain per unit leaf area of Low_WUE was probably due to the greater stomatal conductance observed at each assessment (Fig. 3b; Supplemental Fig. S4). A positive relationship between stomatal opening and photosynthesis was documented in a study using 38 Chinese soybean cultivars released over a period of 82 years (Liu et al., 2012). Another reason for the higher A' and e $\left[\mathrm{CO}_{2}\right]$ stimulation observed in Low_WUE may be the greater $\mathrm{Vc}_{\max }$ and $\mathrm{J}_{\max }$ observed in this genotype at the beginning of pod filling (Fig. 4), which indicates lower biochemical limitations of photosynthesis in this genotype (Morales et al., 2020). This improvement in photosynthesis reflected by increased $\mathrm{Vc}_{\max }$ and $\mathrm{J}_{\max }$ previously has been modelled in soybean by Bernacchi et al. (2013) and demonstrated in a FACE facility by Sanz-Sáez et al. (2017).Is important to note that these gas exchange 


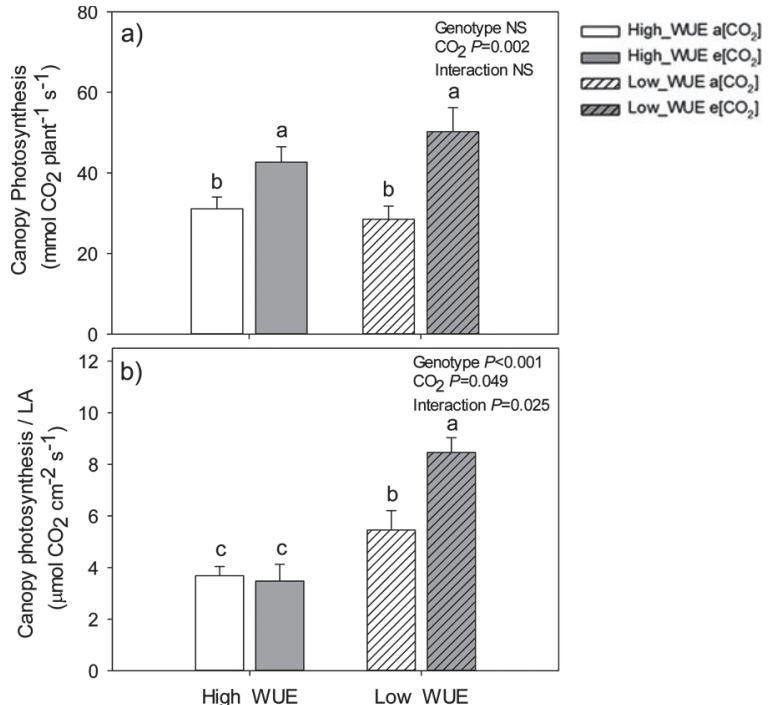

Fig. 5. Canopy photosynthesis measures: a) per plant and b) per leaf area (LA) measured in High_WUE and Low_WUE genotypes grown under ambient and elevated $\left[\mathrm{CO}_{2}\right]$. The bar chart shows the average of four replicate OTC's for each treatment $(n=4)$. Results of statistics are shown (two-way ANOVA, $P<0.05)$. Letters indicate significant differences between treatments or genotypes (Tukey post hoc test $P<0.05$ ). NS, not significant.
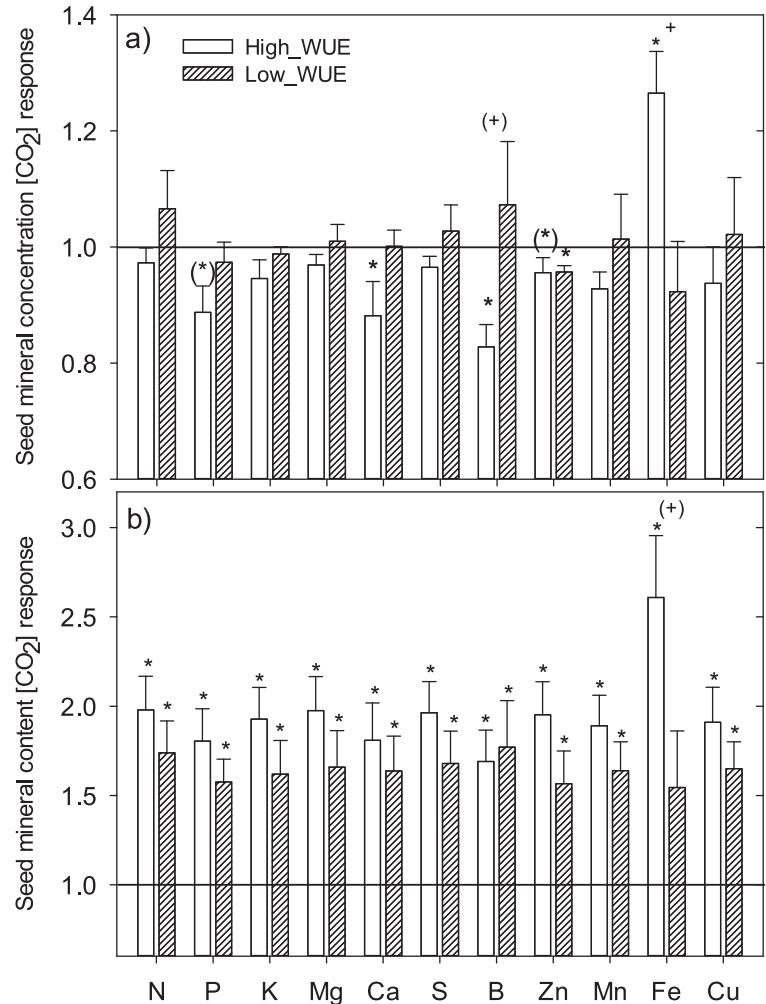

Fig. 6. a) Mineral concentration and b) total mineral content in soybean seeds from High_WUE (plain) and Low_WUE (striped) genotypes grown under ambient and elevated $\left[\mathrm{CO}_{2}\right] . \mathrm{CO}_{2}$ response values are the mean value of each mineral in $\mathrm{e}\left[\mathrm{CO}_{2}\right] / \mathrm{a}\left[\mathrm{CO}_{2}\right]$. The bar chart shows the average of four replicate OTC's for each treatment $(n=4)$. Bars with asterisk indicate significant effects of $\left[\mathrm{CO}_{2}\right]$ for each genotype tested by ANOVA test. Significance level is based upon the difference between the $\mathrm{CO}_{2}$ treatments, although the data presented are the ratio $\left(\mathrm{e}\left[\mathrm{CO}_{2}\right] / \mathrm{a}\left[\mathrm{CO}_{2}\right]\right) .(*) P<0.10 ; * P<0.05$. Cross between bars for the same mineral indicate significant effects of genotype for $\mathrm{CO}_{2}$ response (e $\left[\mathrm{CO}_{2}\right] / \mathrm{a}\left[\mathrm{CO}_{2}\right]$ ) tested by ANOVA test $(+) P<0.10 ;+P<0.05$. measurements were performed in plants that were fully irrigated, therefore Low_WUE cultivars were able to maximize their photosynthetic performance. We expect that under future water restrictions imposed by global change, the response of the cultivars may have been different due to the possible drought tolerance of the High_WUE cultivar; however this was not the scope of this study.

Our data seem to indicate that the High_WUE genotype compensated for lower daily photosynthetic $\mathrm{C}$ assimilation by producing more LA to increase light interception (Fig. 1c). Increased LA in High_WUE in response to e[$\left[\mathrm{CO}_{2}\right]$, helps explain why canopy photosynthesis was similar in both genotypes (Fig. 5a). To estimate average plant photosynthetic performance per unit leaf area for each genotype, canopy photosynthesis was divided by LA. Results from this calculation exhibited a trend similar to diurnal leaf measurements, confirming the higher daily photosynthetic $\mathrm{C}$ gain and positive effect of e $\left[\mathrm{CO}_{2}\right]$ on photosynthetic rate in Low_WUE.

Better leaf photosynthetic performance in Low_WUE under e $\left[\mathrm{CO}_{2}\right]$ could predict increases in biomass and total seed weight compared to the High_WUE genotype. In a meta-analysis summarizing 111 studies, Ainsworth et al. (2002) showed that e[ $\left[\mathrm{CO}_{2}\right]$ increased canopy photosynthetic rate (59\%) more than total biomass (39\%) or total seed weight $(24 \%)$. However, in our study a greater increase in photosynthesis compared to seed yield at e $\left[\mathrm{CO}_{2}\right]$ was only observed in the Low_WUE genotype; e $\left[\mathrm{CO}_{2}\right]$ increased canopy photosynthesis by $76 \%$, total seed weight by $65 \%$, and aboveground biomass by $35 \%$. In contrast, seed yield of High_WUE was doubled (101\%) by e $\left[\mathrm{CO}_{2}\right]$ while the canopy photosynthesis increase was only $37 \%$, indicating a genotype specific response to e $\left[\mathrm{CO}_{2}\right]$. At R5, High_WUE showed greater biomass response to $\mathrm{e}\left[\mathrm{CO}_{2}\right]$, which translated into more pods and higher total seed weight at maturity compared to Low_WUE. These results agree with those of Bishop et al. (2015) and Kumagai et al. (2015) who reported that cultivars with the strongest biomass response to $\left[\mathrm{CO}_{2}\right]$ produced greater seed yield. Our data suggest that the greater biomass $\mathrm{CO}_{2}$ response of High_WUE was primarily due to greater leaf $(\sim 55 \%)$ and shoot $(\sim 35 \%)$ biomass response relative to Low_WUE. Enhanced leaf area production under $\mathrm{e}\left[\mathrm{CO}_{2}\right]$ has been observed previously in soybean (Rogers et al., 1983a, 1984; Prior et al., 1991, 2003) and other $C_{3}$ crops such as rice and wheat (Ainsworth and Long, 2005; Dermody et al., 2006; Srinivasan et al., 2016), and has been negatively correlated with yield (Liu et al., 2012; Srinivasan et al., 2016) and photosynthesis (Liu et al., 2012). In contrast, here, greater LA production of High_WUE compensated a lack of change in daily photosynthetic $\mathrm{C}$ gain in this genotype.

Yield is the product of total dry matter accumulation (assimilate supply) and the partitioning of assimilates to harvestable parts measured by $\mathrm{HI}$ (Kumudini, 2002). Total seed weight response to e[ $\left[\mathrm{CO}_{2}\right]$ was greater in High_WUE compared to Low_WUE (101\% and $65 \%$, respectively) (Fig. 2a). This seed yield response to e $\left[\mathrm{CO}_{2}\right]$ was greater than previous reports which indicate a yield response ranging from 10 to $95 \%$ (Ziska et al., 1998; Kumagai et al., 2015; Bunce, 2015; Bishop et al., 2015; Li et al., 2019). The HI determined at R8 revealed a decrease in the amount of biomass and energy partitioned to seed under e $\left[\mathrm{CO}_{2}\right]$ (Fig. 2b). However, $\mathrm{HI}$ determined at R8 underestimates total dry matter accumulated since it does not account for weight of abscised leaves (Morrison et al., 1999). When calculated as the ratio between total seed weight at R8 and aboveground biomass at R5, HI showed a significant increase under $\mathrm{e}\left[\mathrm{CO}_{2}\right]$ in the High_WUE genotype whereas it was not affected in Low_WUE (Fig. 2c). The greater amount of biomass and energy partitioned from leaves to seeds could partially explain the greater increase in seed yield in High_WUE in response to e $\left[\mathrm{CO}_{2}\right]$. These results suggest that selection for high WUE cultivars does not necessarily translate to lower yield benefit under e $\left[\mathrm{CO}_{2}\right]$ provided that a genotype is able to compensate for no or limited enhancement in photosynthesis per leaf area (due to lower $\mathrm{g}_{\mathrm{s}}$ ) by increasing LA and greater nutrient remobilization from leaves to seed.

Some studies have suggested that increased biomass and lower 
transpiration under e $\left[\mathrm{CO}_{2}\right]$ may affect the nutritional value of soybean seeds (Prior et al., 2008; Myers et al., 2014; Singh et al., 2016; Li et al., 2018). Therefore, alterations in plant growth or nutrient uptake and utilization under $\mathrm{e}\left[\mathrm{CO}_{2}\right]$ in cultivars with contrasting WUE may lead to differences in seed nutritional attributes. Understanding the impact of e $\left[\mathrm{CO}_{2}\right]$ on seed composition may offer opportunities for quality improvements under future climatic scenarios. In our experiment, changes in mineral concentration were mainly due to differences between genotypes rather than between $\mathrm{CO}_{2}$ treatments (Table S4). When both genotypes were taken together, $\mathrm{e}\left[\mathrm{CO}_{2}\right]$ consistently reduced seed $\mathrm{Zn}$ concentration only $(-4.5 \% ; P=0.007)$, while there was an interaction between $\mathrm{e}\left[\mathrm{CO}_{2}\right]$ and genotype for $\mathrm{Ca}, \mathrm{B}$, and $\mathrm{Fe}$. Zinc is an essential mineral for the human immune system and adequate dietary amounts are required to avoid stunted growth in children (Brown et al., 2001). Our observed reduction in soybean seed $\mathrm{Zn}$ concentration is in accordance with Myers et al. (2014) who reported a significant Zn reduction of $5.1 \%(P<0.001)$ under $\mathrm{e}\left[\mathrm{CO}_{2}\right]$. The significant treatment interaction indicated that $\mathrm{e}\left[\mathrm{CO}_{2}\right]$ reduced nutrient concentrations only in the High_WUE genotype for $\mathrm{Ca}(P=0.044)$ and $\mathrm{B}(P=0.002)$ (Fig. 6). The observed higher Fe concentration under $\mathrm{e}\left[\mathrm{CO}_{2}\right]$ in the High_WUE genotype was in contrast to earlier reports of no $\mathrm{CO}_{2}$ effect (Prior et al., 2008; Soares et al., 2019) or decreased Fe concentration in soybean (Myers et al., 2014; Li et al., 2018) and was in opposition to the dilution effect. However, this increase was in accordance with Singh et al. (2016) and may be due to a continuous supply of Fe in nutrient solution and more root growth under $\mathrm{e}\left[\mathrm{CO}_{2}\right]$ (Table S1) that facilitated Fe acquisition for increased seed Fe concentration (Wiersma, 2005) or higher enzymatic activities that require $\mathrm{Fe}$ as a cofactor for redox reactions as proposed by Pérez-López et al. (2014) in barley seedlings.

In addition to concentration data, seed mineral content (seed mineral concentration $\mathrm{x}$ total seed weight) was assessed. Observed higher mineral content in soybeans grown under $\mathrm{e}\left[\mathrm{CO}_{2}\right]$ is in agreement with previous reports (Prior et al., 2008; Singh et al., 2016) (Table 1). Increased nutrient content has been attributed to greater total seed production under e[CO $\mathrm{CO}_{2}$ (Rogers et al., 1999; Singh et al., 2016). Thus, the greater responsiveness of High_WUE to $\mathrm{e}\left[\mathrm{CO}_{2}\right]$ resulted in greater total seed weight which translated into higher mineral content compared to Low_WUE (Fig. 6). The observed $\mathrm{CO}_{2}$ x genotype interaction for mineral content (i.e., $\mathrm{N}, \mathrm{K}, \mathrm{Mg}, \mathrm{S}, \mathrm{Zn}$ and $\mathrm{Fe}$ ) may be attributable to different $\mathrm{CO}_{2}$ effects on mineral concentration in the two genotypes (e.g., Fe), but in most cases was likely due to the lower stimulatory effect of e $\left[\mathrm{CO}_{2}\right]$ on Low_WUE total seed weight (e.g., $\mathrm{Zn}, \mathrm{Mg}, \mathrm{Ca}$ ); a combination of these factors could explain this interaction in other cases (e.g., N, S).

Therefore, the general trend of lower mineral concentration and greater total amount of nutrients under e $\left[\mathrm{CO}_{2}\right]$ in High_WUE compared to Low_WUE, primarily was due to a higher seed yield $\mathrm{CO}_{2}$ response which resulted in greater total amounts of nutrients distributed throughout greater seed mass (dilution effect). It is important to note that a restriction in nutrient uptake due to lower $g_{s}$ and transpiration was not observed in this study, as the total amounts of nutrients in seed at $\mathrm{e}\left[\mathrm{CO}_{2}\right]$ were significantly higher in High_WUE despite lower $\mathrm{g}_{\text {s }}$ per leaf area than in Low_WUE in both $\mathrm{CO}_{2}$ environments (Fig. S4). Since root system biomass under $\mathrm{e}\left[\mathrm{CO}_{2}\right]$ was not different between genotypes (Table S1), greater nutrient uptake could be due to a greater LA that compensated for the lower transpiration per leaf area (i.e., canopy photosynthesis assessment) and allowed for bigger root-shoot flux of nutrients, when plants were maintained at fully irrigation conditions.

\section{Conclusions}

Our data showed that High_WUE had lower daily photosynthetic C gain, probably due to diffusive (lower $\mathrm{g}_{\mathrm{s}}$ ) and biochemical (lower $\mathrm{Vc}_{\max }$ and $\mathrm{J}_{\mathrm{max}}$ ) related limitations. This were compensated, in High_WUE genotype, with a greater LA, equating photosynthesis at canopy level, which at the end resulted in a greater seed yield in this genotype, especially under $\mathrm{e}\left[\mathrm{CO}_{2}\right]$. Our findings demonstrate important soybean intraspecific variations in physiological responses to future atmospheric $\left[\mathrm{CO}_{2}\right]$ and, in opposition to our initial hypothesis, showed that, under proper irrigation, selection for higher WUE does not necessarily mean selecting against a greater yield response at e[ $\left.\mathrm{CO}_{2}\right]$. Such finding, linked with the strategy to promote the development of more resource efficient crops, could be of great relevance for near future breeding programs. Further, the fact that the current study was carried out only with two contrasting WUE genotypes, remarks that more research needs to be done to test if the findings described in this study is a general trend, or if different traits that codify for distinct WUE can influence the yield response at elevated $\left[\mathrm{CO}_{2}\right]$.

\section{Funding}

David Soba is the recipient of a PhD grant supported by the Public University of Navarra, and was the recipient of a travel grant from the same institution. This project was partially funded by the Alabama Soybean Farmers Association, the Alabama agricultural experiment station and the Hatch program of the National Institute of Food and agriculture, U.S. department of Agriculture.

\section{CRediT authorship contribution statement}

David Soba: Conceptualization, Data curation, Formal analysis, Investigation, Methodology, Writing - original draft. Tianchu Shu: Formal analysis, Investigation, Methodology, Writing - review \& editing. G. Brett Runion: Data curation, Formal analysis, Funding acquisition, Writing - review \& editing. Stephen A. Prior: Formal analysis, Funding acquisition, Project administration, Resources, Supervision, Writing - review \& editing. Felix B. Fritschi: Formal analysis, Writing - review \& editing. Iker Aranjuelo: Conceptualization, Formal analysis, Writing - review \& editing. Alvaro Sanz-Saez: Conceptualization, Data curation, Formal analysis, Funding acquisition, Investigation, Methodology, Project administration, Resources, Supervision, Writing - original draft.

\section{Declaration of Competing Interest}

The authors declare that they have no known competing financial interest or personal relationship that could have appeared to influence the work reported in this paper.

\section{Acknowledgements}

The authors would like to thank the technical help during the experiment of Mr. Robert Icenogle and Barry Dorman from the USDA-ARS and all the collaborators at the Crop Physiology Lab at Auburn University.

\section{Appendix A. Supplementary data}

Supplementary material related to this article can be found, in the online version, at doi:https://doi.org/10.1016/j.envexpbot.2020. 104154.

\section{References}

Ainsworth, E.A., Long, S.P., 2005. What have we learned from 15 years of free-air $\mathrm{CO}_{2}$ enrichment (FACE)? A meta-analytic review of the responses of photosynthesis, canopy properties and plant production to rising $\mathrm{CO}_{2}$. New Phytol. 165, 351-372.

Ainsworth, E.A., Rogers, A., 2007. The response of photosynthesis and stomatal conductance to rising $\left[\mathrm{CO}_{2}\right]$ : mechanisms and environmental interactions. Plant Cell Environ. 30, 258-270.

Ainsworth, E.A., Davey, P.A., Bernacchi, C.J., Dermody, O.C., Heaton, E. A., Moore, D.J. Long, S.P., 2002. A meta-analysis of elevated $\left[\mathrm{CO}_{2}\right]$ effects on soybean (Glycine max) physiology, growth and yield. Global Change Biol. 8, 695-709.

Ainsworth, E.A., Rogers, A., Leakey, A.D.B., Heady, L.E., Gibon, Y., Stitt, M., Schurr, U., 2007. Does elevated atmospheric $\left[\mathrm{CO}_{2}\right]$ alter diurnal $\mathrm{C}$ uptake and the balance of $\mathrm{C}$ 
and $\mathrm{N}$ metabolites in growing and fully expanded soybean leaves? J. Exp. Bot. 58, 579-591.

Ainsworth, E.A., Yendrek, C.R., Skoneczka, J.A., Long, S.P., 2012. Accelerating yield potential in soybean: potential targets for biotechnological improvement. Plant Cell Environ. 35, 38-52.

Aspinwall, M.J., Loik, M.E., Resco de Dios, V., Tjoelker, M.G., Payton, P.R., Tissue, D.T., 2015. Utilizing intraspecific variation in phenotypic plasticity to bolster agricultural and forest productivity under climate change. Plant Cell Environ. 38, 1752-1764.

Batchelor Jr., J.A., 1984. Properties of Bin Soils at the National Soil Dynamics Lab. Paper No. 218. ARS-USDA, Auburn, AL.

Bernacchi, C.J., Bagley, J.E., Serbin, S.P., Ruiz-Vera, U.M., Rosenthal, D.M., VanLoocke, A., 2013. Modelling $C_{3}$ photosynthesis from the chloroplast to the ecosystem. Plant Cell Environ. 36, 1641-1657.

Bishop, K.A., Betzelberger, A.M., Long, S.P., Ainsworth, E.A., 2015. Is there potential to adapt soybean (Glycine max Merr.) to future $\left[\mathrm{CO}_{2}\right]$ ? An analysis of the yield response of 18 genotypes in free-air $\mathrm{CO}_{2}$ enrichment. Plant Cell Environ. 38, 1765-1774.

Brown, K.H., Wuehler, S.E., Peerson, J.M., 2001. The importance of zinc in human nutrition and estimation of the global prevalence of zinc deficiency. Food Nutr. Bull. 22 113-12.

Bunce, J.A., 2015. Elevated carbon dioxide effects on reproductive phenology and seed yield among soybean cultivars. Crop Sci. 55, 339-343.

CO2.earth, 2020. $\mathrm{CO}_{2}$ Earth: A Pro Oxygen Website. Victoria, British Columbia, Canada. https://www.co2.earth.

Condon, A.G., Farquhar, G.D., Rebetzke, G.J., Richards, R.A., 2004. Breeding for high water-use efficiency. J. Exp. Bot. 55, 2447-2460.

Dermody, O., Long, S.P., DeLucia, E.H., 2006. How does e[ $\left[\mathrm{CO}_{2}\right]$ or ozone affect the leaf-area index of soybean when applied independently? New Phytol. 169, 145-155.

Dhanapal, A.P., Ray, J.D., Singh, S.K., Hoyos-Villegas, V., Smith, J.R., Purcell, L.C., et al., 2015. Genome-wide association study (GWAS) of carbon isotope ratio ( $813 \mathrm{C})$ in diverse soybean [Glycine $\max$ (L.) Merr.] genotypes. Theor. Appl. Gent 128, 73-91.

Earl, H.J., 2002. Stomatal and non-stomatal restrictions to carbon assimilation in soybean (Glycine $\max$ ) lines differing in drought use efficiency. Environ. Exp. Bot. 48 (3), 237-246.

Erice, G., Sanz-Sáez, A., González-Torralba, J., Méndez-Espinoza, A.M., Urretavizcaya, I., Nieto, M.T., Serret, M.D., Araus, J.L., Irigoyen, J.L., Aranjuelo, I., 2019. Impact of elevated $\mathrm{CO}_{2}$ and drought on yield and quality traits of a historical (Blanqueta) and a modern (Sula) durum wheat. J. Cereal Sci. 87, 194-201.

Evans, H.J., 1974. Symbiotic nitrogen fixation in legume nodules. In: Moore, M.J. (Ed.), Research Experiences in Plant Physiology. Springer-Verlag, NY, pp. 417-426.

Evans, J.R., 2013. Improving photosynthesis. Plant Physiol. 162 (4), 1780-1793.

FAOSTAT, 2020. ProdStat. Core Production Data Base, Electronic Resource. http:// faostat.fao.org/.

Farquhar, G.D., O’Leary, M.H., Berry, J.A., 1982. On the relationship between carbon isotope discrimination and the intercellular carbon-dioxide concentration in leaves. Aust. J. Plant Physiol. 9, 121-137.

Fehr, W.R., Caviness, C.E., Burmood, D.T., Pennington, J.S., 1971. Stage of development descriptions for soybeans, Glycine $\max$ (L.) Merr. Crop Sci. 11, 929-931.

Gilbert, M.E., Zwieniecki, M.A., Holbrook, N.M., 2011. Independent variation in photosynthetic capacity and stomatal conductance leads to differences in intrinsic water use efficiency in 11 soybean genotypes before and during mild drought. J. Exp. Bot. $62,2875-2887$.

Gray, S.B., Siebers, M., Locke, A.M., et al., 2016. Intensifying drought eliminates the expected benefits of elevated [CO2] for soybean. Nat. Plants 2, 16132.

IPCC, 2013. Summary for policymakers. In: Stocker, T.F., Qin, D., Plattner, G.-K., Tignor, M., Allen, S.K., Boschung, J., Nauels, A., Xia, Y., Bex, V., Midgley, P.M. (Eds.), Climate Change 2013: The Physical ScienceBasis. Contribution of Working Group I to the Fifth Assessment Report of the Intergovern-Mental Panel on Climate Change. Cambridge University Press, Cambridge, UK and New York, NY, USA, pp. 3-29.

Kumagai, E., Aoki, N., Masuya, Y., Shimono, H., 2015. Phenotypic plasticity conditions the response of soybean seed yield to elevated atmospheric $\mathrm{CO}_{2}$ concentration. Plant Physiol. 169, 2021-2029.

Kumudini, S., 2002. Trials and tribulations: a review of the role of assimilate supply in soybean genetic yield improvement. Field Crops Res. 75, 211-222.

Li, D., Liu, H., Oiao, Y., Wang, Y., Cai, Z., Dong, B., Shi, C., Liu, Y., Li, X., Liu, M., 2013. Effects of elevated $\mathrm{CO} 2$ on the growth, seed yield, and water use efficiency of soybean (Glycine max (L.) Merr.) under drought stress. Agric. Water Manag. 129, 105-112.

Li, Y.S., Yu, Z.H., Jin, J., Zhang, Q.Y., Wang, G.H., Liu, C.K., Wu, J.J., Wang, C., Liu, X.B., 2018. Impact of e[ $\left[\mathrm{CO}_{2}\right]$ on seed quality of soybean at the fresh edible and mature stages. Front. Plant Sci. 9 1413-1413.

Li, Y., Yu, Z., Yang, S., Jin, J., Wang, G., Liu, C., Herbert, S.J., Liu, X., 2019. Soybean intraspecific genetic variation in response to elevated $\mathrm{CO}_{2}$. Arch. Agron. Soil Sci. 65 (12), 1733-1744.

Littell, R.C., Milliken, G.A., Stroup, W.W., Wolfinger, R.D., 1996. SAS System for Mixed Models. SAS Institute, Inc., Cary, NC.

Liu, G., Yang, C., Xu, K., Zhang, Z., Li, D., Wu, Z., Chen, Z., 2012. Development of yield and some photosynthetic characteristics during 82 years of genetic improvement of soybean genotypes in northeast China. Aust. J. Crop Sci. 6, 1416-1422.

Lobell, D.B., Gourdji, S.M., 2012. The influence of climate change on global crop productivity. Plant Physiol. 160, 1686-1697.

Loladze, I., 2014. Hidden shift of the ionome of plants exposed to elevated $\mathrm{CO}_{2}$ depletes minerals at the base of human nutrition. eLife 3, e02245.

Long, S.P., Ainsworth, E.A., Rogers, A., Ort, D.R., 2004. Rising atmospheric carbon dioxide: plants FACE the future. Annu. Rev. Plant Biol. 55, 591-628.

McGrath, J.M., Lobell, D.B., 2013. Reduction of transpiration and altered nutrient allocation contribute to nutrient decline of crops grown in e $\left[\mathrm{CO}_{2}\right]$ concentrations. Plant Cell Environ. 36, 697-705.

Mitchell, R.J., Runion, G.B., Prior, S.A., Rogers, H.H., Amthor, J.S., Henning, F.P., 1995. Effects of nitrogen on Pinus palustris foliar respiratory responses to elevated atmospheric $\mathrm{CO}_{2}$ concentration. J. Exp. Bot. 46, 1561-1567.

Morales, F., Ancín, M., Fakhet, D., González-Torralba, J., Gámez, A.L., Seminario, A. Soba, D., Ben Mariem, S., Garriga, M., Aranjuelo, I., 2020. Photosynthetic metabolism under stressful growth conditions as a bases for crop breeding and yield improvement. Plants 9, 88.

Morrison, M.J., Voldeng, H.D., Cober, E.R., 1999. Physiological changes from 58 years of genetic improvement of short-season soybean cultivars in Canada. Agron. J. 91, 685-689.

Myers, S.S., Zanobetti, A., Kloog, I., et al., 2014. Increasing $\mathrm{CO}_{2}$ threatens human nutrition. Nature 510, 139-142.

Passioura, J.B., 2004. Water-use efficiency in farmers' fields. In: Bacon, M. (Ed.), WaterUse Efficiency in Plant Biology. Blackwell, Oxford, pp. 302-321.

Pérez-López, U., Miranda-Apodaca, J., Mena-Petite, A., Muñoz-Rueda, A., 2014. Responses of nutrient dynamics in barley seedlings to the interaction of salinity and carbon dioxide enrichment. Environ. Exp. Bot. 99, 86-99.

Prior, S.A., Rogers, H.H., Sionit, N., Patterson, R.P., 1991. Effects of elevated atmospheric $\mathrm{CO}_{2}$ on water relations of soya bean. Agric., Ecosyst. Environ. 35, 13-25.

Prior, S.A., Torbert, H.A., Runion, G.B., Rogers, H.H., 2003. Implications of elevated $\mathrm{CO}_{2}-$ induced changes in agroecosystem productivity. J. Crop Prod. 8, 217-244.

Prior, S.A., Runion, G.B., Rogers, H.H., Torbert, H.A., 2008. Effects of atmospheric $\mathrm{CO}_{2}$ enrichment on crop nutrient dynamics under no-till conditions. J. Plant Nutr. 31, 758-773.

Prior, S.A., Runion, G.B., Rogers, H.H., Arriaga, F.J., 2010. Elevated atmospheric carbon dioxide effects on soybean and sorghum gas exchange in conventional and no-tillage systems. J. Environ. Qual. 39, 596-608.

Rogers, H.H., Bingham, G.E., Smith, J.M., Surano, K.A., 1983a. Responses of selected plant species to elevated carbon dioxide in the field. J. Environ. Qual. 11, 569-574.

Rogers, H.H., Heck, W.W., Heagle, A.S., 1983b. A field technique for the study of plant responses to elevated carbon dioxide concentrations. Air Pollut. Control Assn. J. 33, $42-44$

Rogers, H.H., Thomas, J.F., Bingham, G.E., 1983c. Response of agronomic and forest species to elevated atmospheric carbon dioxide. Science 220, 428-429.

Rogers, H.H., Cure, J.D., Thomas, J.F., Smith, J.M., 1984. Influence of elevated $\mathrm{CO}_{2}$ on growth of soybean plants. Crop Sci. 24, 361-366.

Rogers, H.H., Runion, G.B., Prior, S.A., Torbert, H.A., 1999. Response of plants to elevated atmospheric $\mathrm{CO}_{2}$ : root growth, mineral nutrition, and soil carbon. In: Luo, Y., Mooney, H.A. (Eds.), Carbon Dioxide and Environmental Stress. Academic Press, San Diego, California, pp. 215-244.

Runion, G.B., Price, A.J., Prior, S.A., Rogers, H.H., Torbert, H.A., Gjerstad, D.H., 2008 Effects of elevated atmospheric $\mathrm{CO}_{2}$ on a $\mathrm{C}_{3}$ and a $\mathrm{C}_{4}$ invasive weed. Bot. Res. J. 1 (3), $56-62$.

Sanz-Sáez, A., Koester, R.P., Rosenthal, D.M., Montes, C.M., Ort, D.R., Ainsworth, E.A., 2017. Leaf and canopy scale drivers of genotypic variation in soy-bean response to elevated carbon dioxide concentration. Glob. Change Biol. 23, 3908-3920.

Sharkey, T.D., Bernacchi, C.J., Farquhar, G.D., Singsaas, E.L., 2007. Fitting photosynthetic carbon dioxide response curves for $\mathrm{C}_{3}$ leaves. Plant Cell Environ. 30, $1035-1040$.

Sinclair, T.R., 2012. Is transpiration efficiency a viable plant trait in breeding for crop improvement? Funct. Plant Biol. 39, 359-365.

Singh, S.K., Barnaby, J.Y., Reddy, V.R., Sicher, R.C., 2016. Varying response of the concentration and yield of soybean seed mineral elements, carbohydrates, organic acids, amino acids, protein, and oil to phosphorus starvation and $\mathrm{CO}_{2}$ enrichment Front. Plant Sci. 7, 1967. https://doi.org/10.3389/fpls.2016.01967.

Sionit, N., Rogers, H.H., Bingham, G.E., Strain, B.R., 1984. Photosynthesis and stomatal conductance with $\mathrm{CO}_{2}$-enrichment of container- and field-grown soybeans. Agron. J. 76, 447-451.

Soares, J., Deuchande, T., Valente, L.M., Pintado, M., Vasconcelos, M.W., 2019. Growth and nutritional responses of bean and soybean genotypes to $\left[\mathrm{CO}_{2}\right]$ in a controlled environment. Plants 8, 465. https://doi.org/10.3390/plants8110465.

Srinivasan, V., Kumar, P., Long, S.P., 2016. Decreasing, not increasing, leaf area will raise crop yields under global atmospheric change. Global Change Biol. 23, 1626-1635.

Weigel, H.J., 2014. Plant quality declines as $\mathrm{CO}_{2}$ levels rise. Elife 3, e03233.

Wiersma, J.V., 2005. High rates of Fe-EDDHA and seed iron concentrations suggest partial solutions to iron deficiency in soybean. Agron. J. 97, 924-934.

Ziska, L.H., Bunce, J.A., Caulfield, F., 1998. Intraspecific variation in seed yield of soybean (Glycine $\max$ ) in response to increased atmospheric carbon dioxide. Aust. J. Plant Physiol. 25 (7), 801-807. 


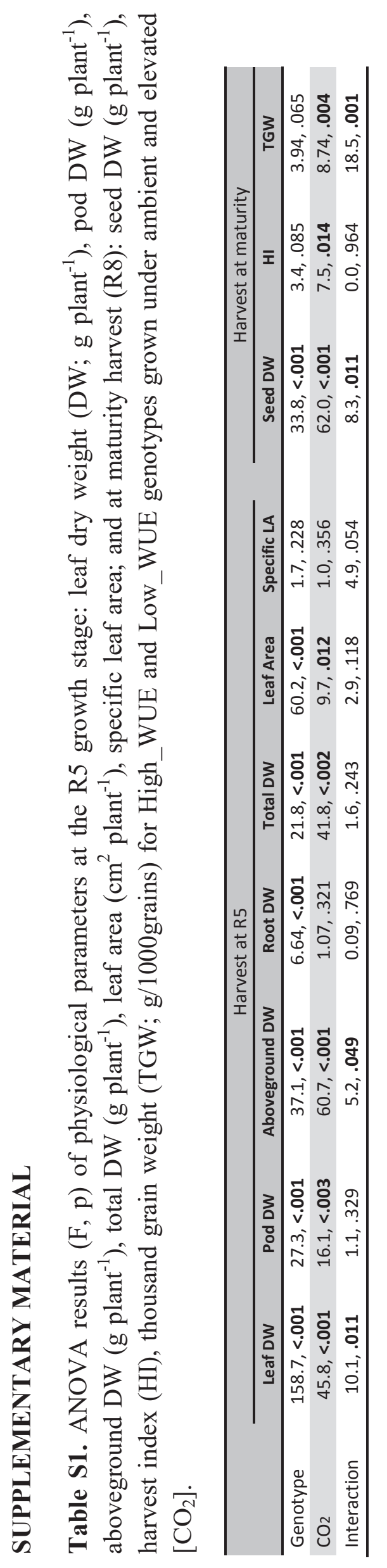




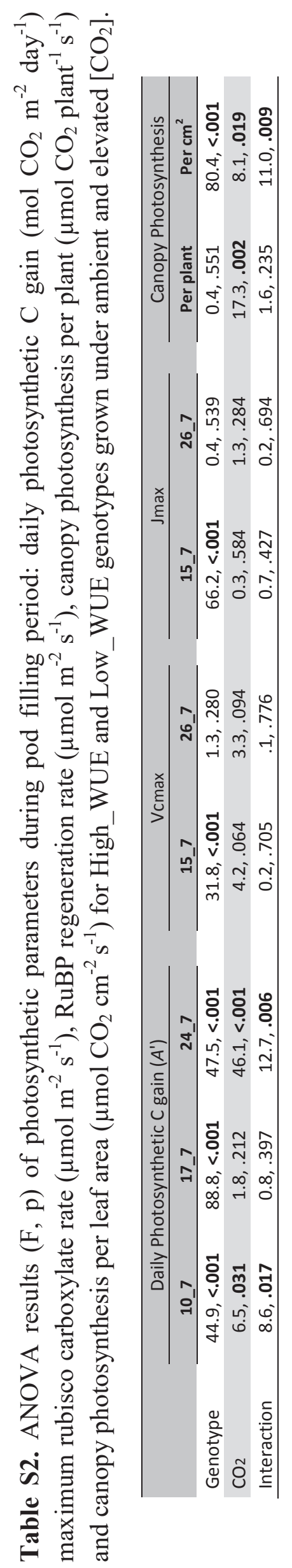




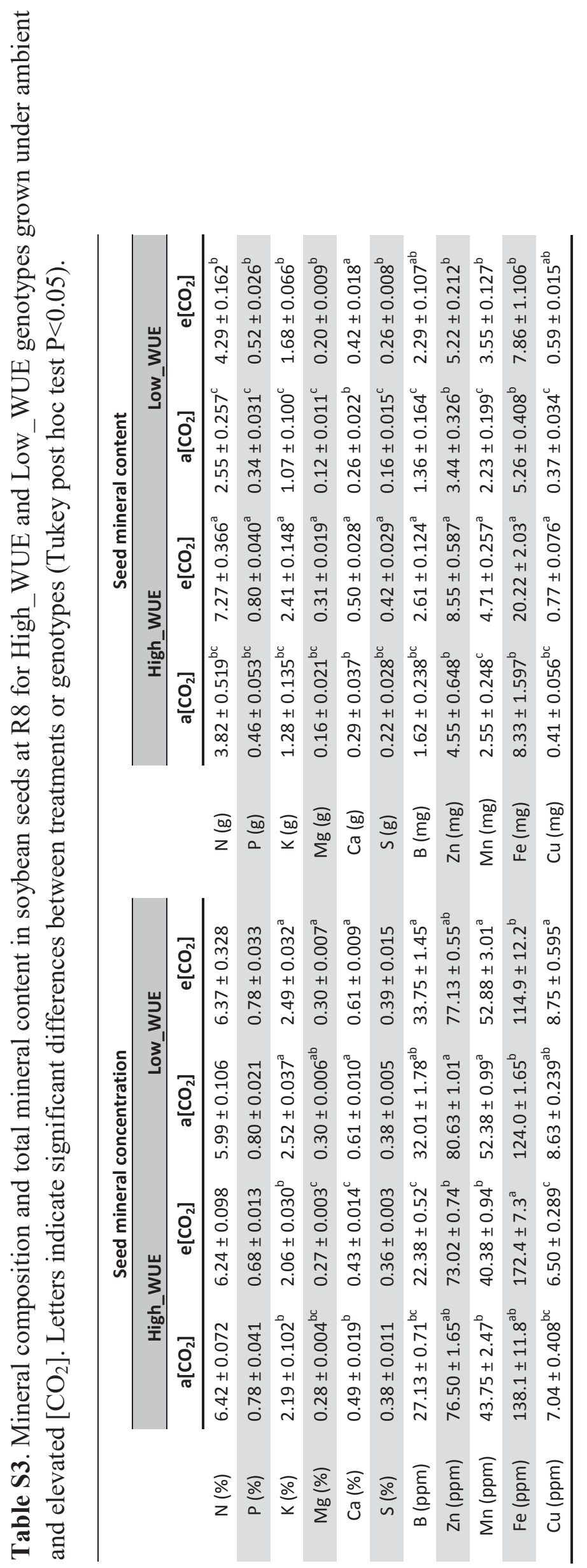




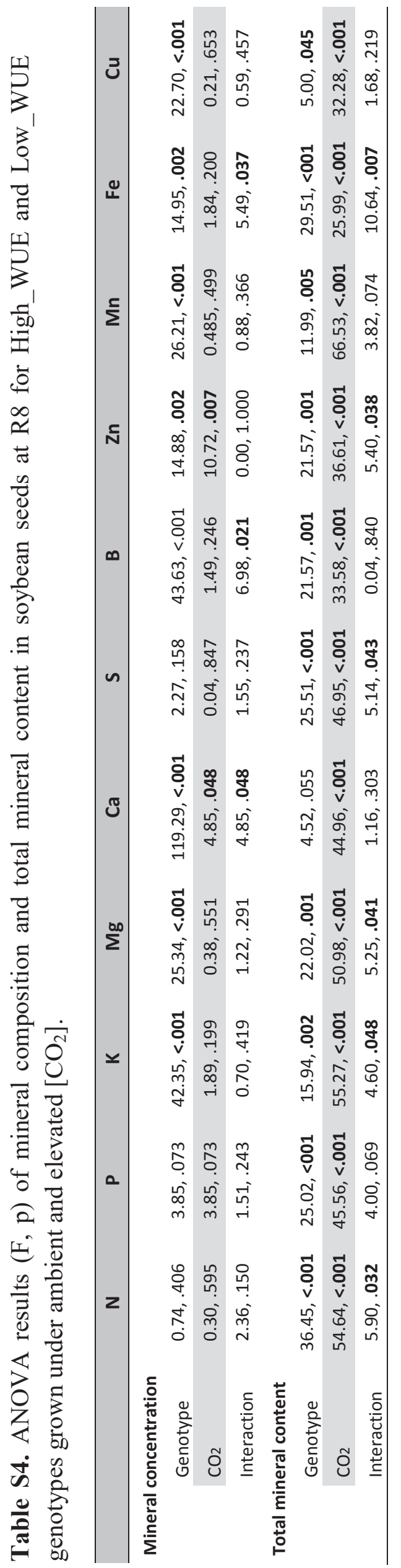




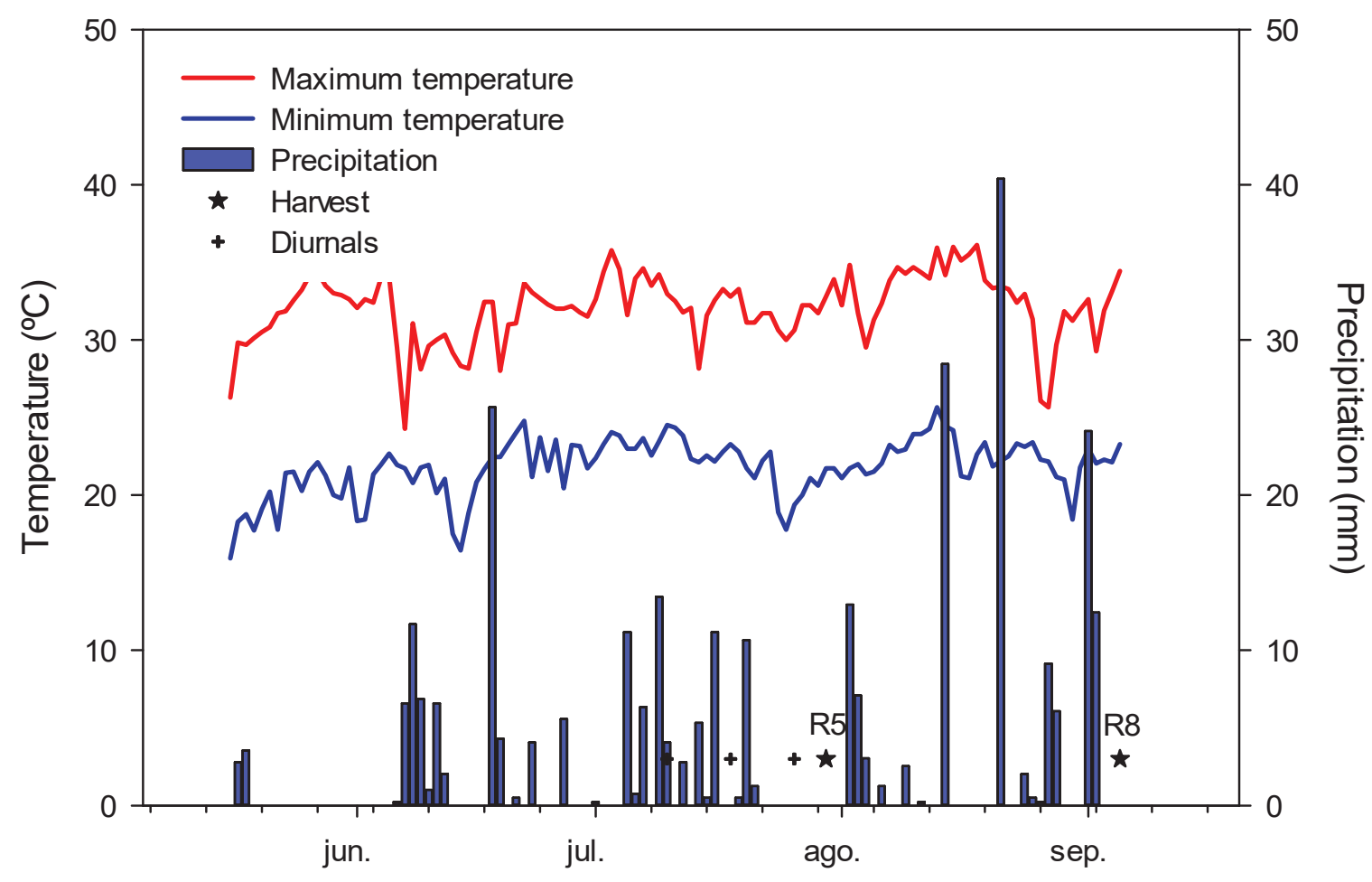

Figure S1 Daily measures of meteorological conditions from planting to crop maturity (maximum, minimum temperature, and precipitation) at U.S. Department of Agriculture-Agricultural Research Service National Soil Dynamics Laboratory, Auburn, Alabama, USA. 


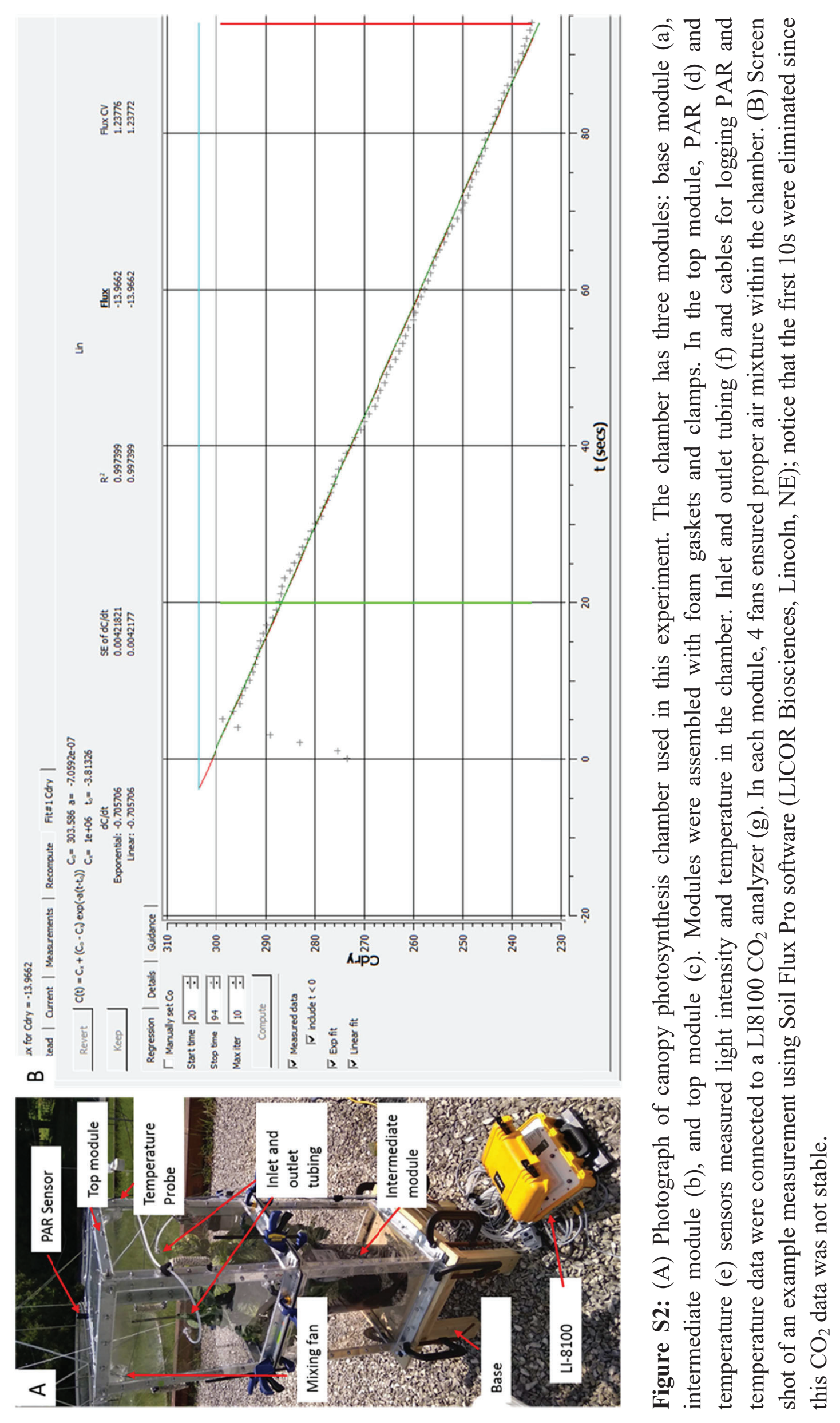




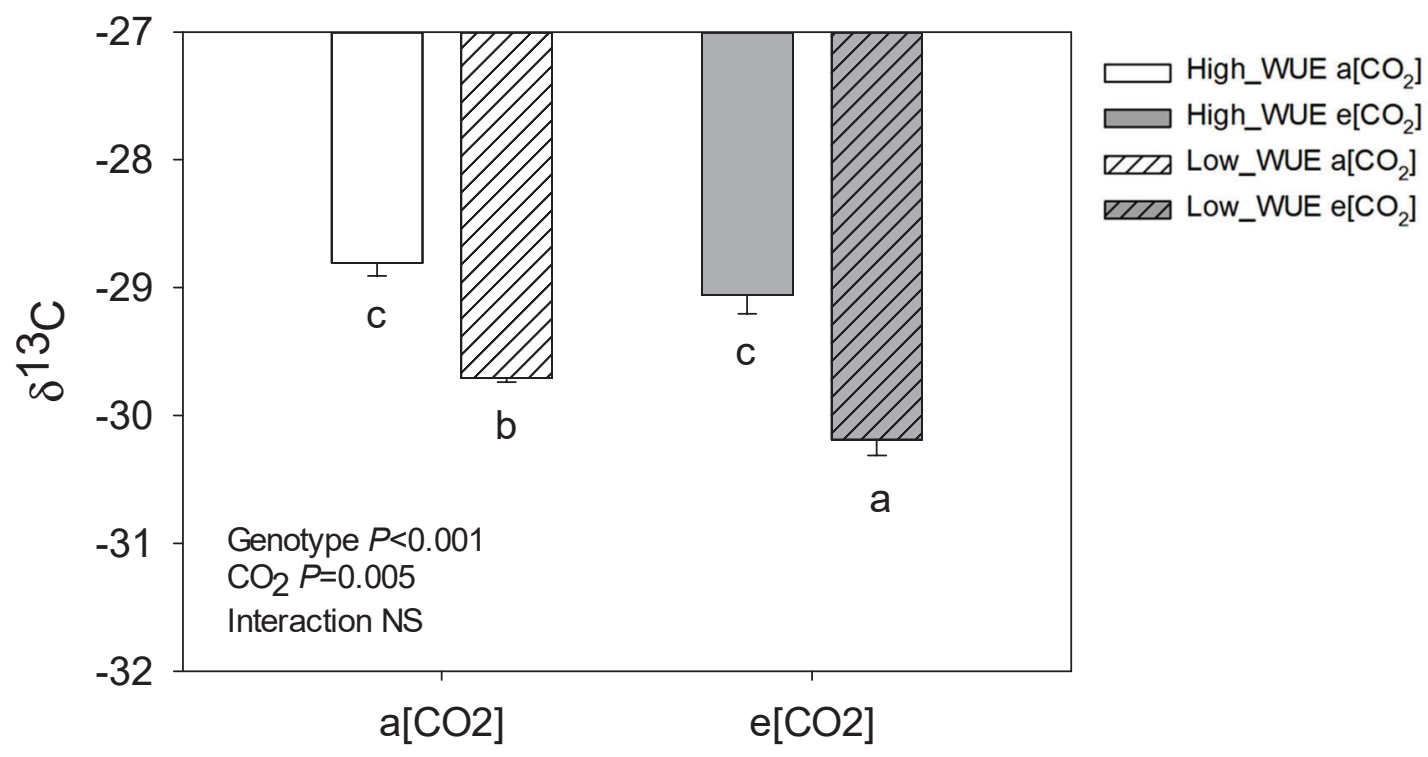

Figure S3. Carbon isotopic composition $\left(\delta^{13} \mathrm{C}\right)$ measured in High_WUE and Low_WUE genotypes grown under ambient and elevated $\left[\mathrm{CO}_{2}\right]$. The bar chart shows the average of four replicate OTC's for each treatment $(n=4)$. Results of statistics are shown (two-way ANOVA, $P<0.05$ ). Letters indicate significant differences between treatments or genotypes (Tukey post hoc test $P<0.05$ ). 


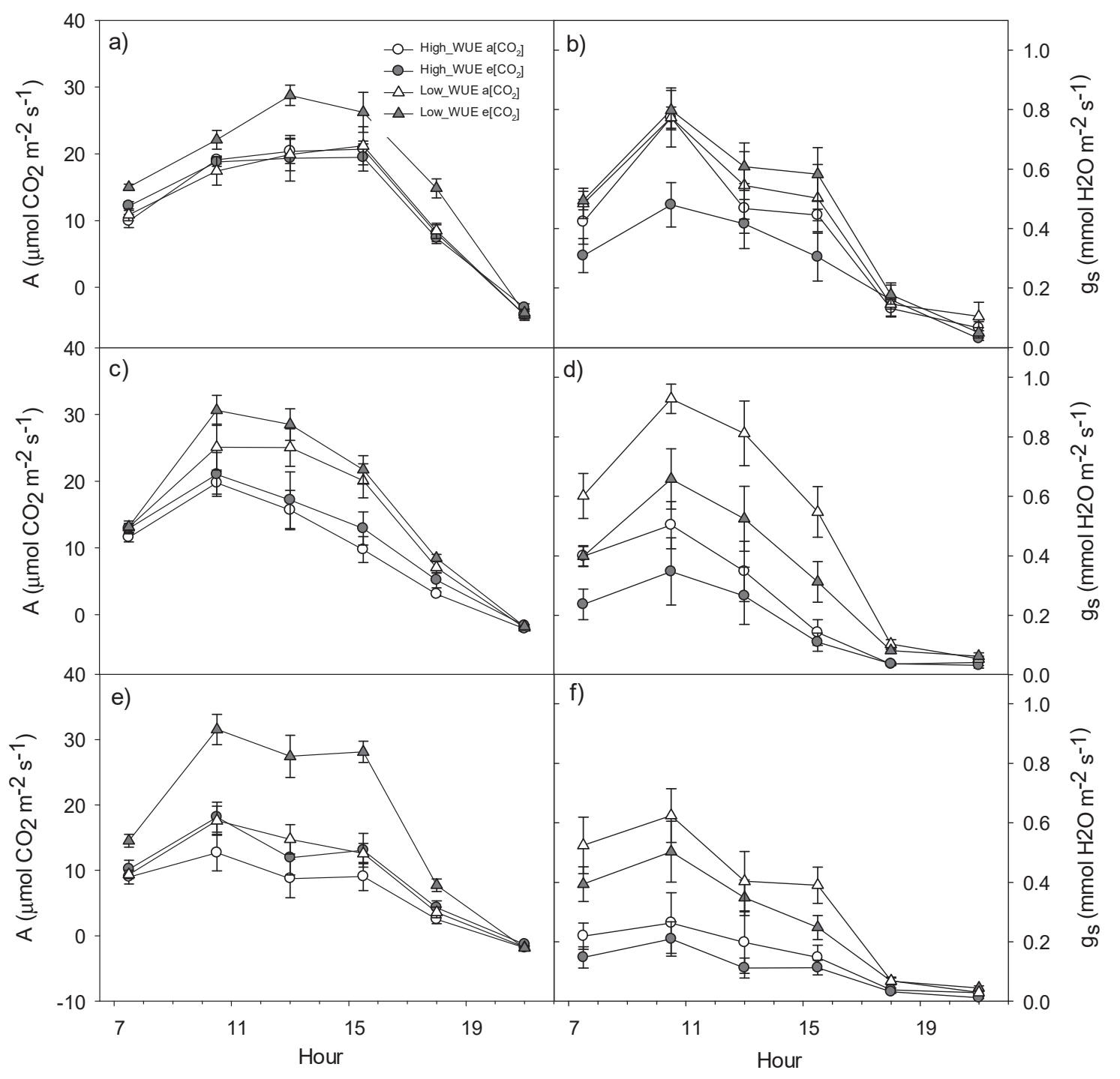

Figure S4. Leaf photosynthetic parameters: a), c), e) photosynthesis (A) and b), d), f) stomatal conductance $\left(\mathrm{g}_{\mathrm{s}}\right)$ measured in High_WUE and Low_WUE genotypes grown under ambient and elevated $\left[\mathrm{CO}_{2}\right]$. Measures taken at the $\mathrm{R} 3$ growth stage were a) and b), while those at the R4 growth stage were c) and d), and R5 growth stage were e) and f). 
upna

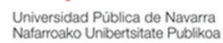


"IV.CHAPTER 2

upna 
upna

Universicad Publica de Navara
Natarsaako Unibersitate Publikoa 


\title{
Physiological, Hormonal and Metabolic Responses of two Alfalfa Cultivars with Contrasting Responses to Drought
}

\author{
David Soba ${ }^{1}$, Bangwei Zhou ${ }^{2}$, Cesar Arrese-Igor ${ }^{3}$, Sergi Munné-Bosch ${ }^{4}(\mathbb{D})$ and Iker Aranjuelo ${ }^{1, *}$ \\ 1 Instituto de Agrobiotecnología (IdAB), Consejo Superior de Investigaciones Científicas-Gobierno de \\ Navarra, 31006 Mutilva, Spain; david.soba@unavarra.es \\ 2 Key Laboratory of Vegetation Ecology, Ministry of Education, Institute of Grassland Science, \\ Northeast Normal University, Changchun 130024, China; 9-973@163.com \\ 3 Department of Sciences, Institute for Multidisciplinary Research in Applied Biology, \\ Universidad Pública de Navarra, E-31006 Pamplona, Spain; cesarai@unavarra.es \\ 4 Department of Evolutionary Biology, Ecology and Environmental Sciences, Faculty of Biology, \\ University of Barcelona, 08028 Barcelona, Spain; smunne@ub.edu \\ * Correspondence: iker.aranjuelo@csic.es; Tel.: +34-948-168-015
}

Received: 30 September 2019; Accepted: 14 October 2019; Published: 15 October 2019

check for updates

\begin{abstract}
Alfalfa (Medicago sativa L.) is frequently constrained by environmental conditions such as drought. Within this context, it is crucial to identify the physiological and metabolic traits conferring a better performance under stressful conditions. In the current study, two alfalfa cultivars (San Isidro and Zhong $\mathrm{Mu}$ ) with different physiological strategies were selected and subjected to water limitation conditions. Together with the physiological analyses, we proceeded to characterize the isotopic, hormone, and metabolic profiles of the different plants. According to physiological and isotopic data, Zhong Mu has a water-saver strategy, reducing water lost by closing its stomata but fixing less carbon by photosynthesis, and therefore limiting its growth under water-stressed conditions. In contrast, San Isidro has enhanced root growth to replace the water lost through transpiration due to its more open stomata, thus maintaining its biomass. Zhong Mu nodules were less able to maintain nodule $\mathrm{N}_{2}$ fixing activity (matching plant nitrogen $(\mathrm{N})$ demand). Our data suggest that this cultivar-specific performance is linked to Asn accumulation and its consequent N-feedback nitrogenase inhibition. Additionally, we observed a hormonal reorchestration in both cultivars under drought. Therefore, our results showed an intra-specific response to drought at physiological and metabolic levels in the two alfalfa cultivars studied.
\end{abstract}

Keywords: alfalfa; drought; hormones; metabolites; N/C metabolism; nodule; physiology

\section{Introduction}

Forage legumes are important in agricultural systems as feed sources for livestock. Among them, alfalfa (Medicago sativa L.) is the most cultivated forage legume in the world [1] and one of the most widely distributed forage crops from Patagonia to Siberia. The combination of high quality forage [2], the capacity to fix atmospheric nitrogen by symbiotic relationships with Ensifer genus bacteria, and the expected rise of forage crops due to increases in the global demand for ruminant products [3], make this crop interesting for food security and environmental conservation. However, alfalfa, like other legume crops, shows changeable production rates, mostly due to abiotic factors such as drought [4].

Drought is considered to be the most limiting factor for plant growth and crop productivity in agricultural systems [5,6]. In nitrogen fixing legumes, production limitations due to drought can be partially explained by the sensitivity of biological nitrogen fixation (BNF) to water deficit 
conditions $[7,8]$. In fact, inhibition of BNF has been shown to precede photosynthesis inhibition in drought stressed legumes [9,10]. The following mechanisms were described [11] as being responsible for inhibition of BNF in legumes: inadequate oxygen supply, carbon $(\mathrm{C})$ shortage, nitrogen (N) feedback, and the role of oxidative stress. On the other hand, nodule metabolism under water restrictions is highly dependent on the metabolism of other organs [12]. For example, in alfalfa plants it was shown that nodule metabolism performance (characterized via proteomics and metabolic profile analyses) was tightly linked to the impact of drought on leaf metabolism [13]. These results showed that deleterious effects of drought on nodules also conditioned leaf responsiveness and highlighted the importance of taking into account the whole plant as a system. Nevertheless, metabolite exchange, organ signalling mechanisms, and the coordination of their changes between nodules and other plant organs are still not clear.

Abiotic stresses require plants to perceive and react to these signals in a highly coordinated and interactive manner, adapting at multiple organizational levels including morphological, physiological, and biochemical adjustments, as well as coordinating alterations in gene expression. Phytohormones play a central role in the perception of abiotic stresses, triggering interactions between the signal transduction cascades [14]. Abscisic acid (ABA) is the primary phytohormone that triggers short-term responses, such as stomatal closure, and long-term responses like favouring maintenance of root growth to optimize water uptake $[15,16]$. Other phytohormones such as auxin, cytokinin, gibberellins, jasmonic acid, and salicylic acid and their mutual interaction have also been suggested as being involved in abiotic stress [17,18]. At the legume nodule level, several authors have shown the importance of phytohormones in nodule formation and development (reviewed by reference [19] and more recently by reference [20]), contributing greatly to our current understanding of plant-microbe interactions. Cytokinin and local accumulation of auxin can promote nodule development [21-23]. Ethylene, jasmonic acid, ABA, and gibberellic acid all negatively regulate infection thread formation and nodule development $[20,24]$. However, in mature nodules, the factors that orchestrate nodule responses under abiotic or biotic stresses related to phytohormones have received much less attention.

Under water restriction, these changes in the level of endogenous phytohormones induce changes in gene expression that affect the synthesis, production and accumulation of several metabolites as part of an osmoregulatory response, such as carbohydrates, amino acids and organic acids, in different plant organs [25]. Several studies have clearly demonstrated that $\mathrm{N}$ and $\mathrm{C}$ metabolism plays a very important role in the water stress response $[12,26,27]$. It has been suggested that some amino acids can be transported from shoots to nodules as systemic signals for BNF under drought conditions $[8,28]$ and that amino acids can represent an alternative source of $C$ and energy for the bacteroid [29]. Further, stomatal closure and the resulting lower transpiration may involve alterations in long-distance transport of $\mathrm{N}$ compounds between underground and aerial plant tissues, provoking an accumulation of $\mathrm{N}$ compounds in nodules of plants under water stress [8]. However, it has been shown that artificial alterations of plant transpiration do not produce a decline in the rates of nitrogen fixation or an accumulation of $\mathrm{N}$ compounds in nodules of pea plants [30]. Therefore, it is important to understand this complex exchange of $\mathrm{N}$ and $\mathrm{C}$ metabolites between plants and nodules, especially under stress conditions.

Alfalfa is cultivated under very diverse climatic conditions around the planet, so different genotypes exposed to drought stress have revealed phenotypic variation that influences their productivity under abiotic stresses. However, the current understanding of these stress-adaptive mechanisms is relatively limited. Therefore, to reveal the key features of drought stress tolerance mechanisms in alfalfa plants, physiological, hormonal, and metabolic approaches were performed in leaves, roots, and nodules of two alfalfa cultivars with different origins and with contrasting drought responses. 


\section{Results}

\subsection{Preliminary Study}

A preliminary study was conducted to choose two varieties with contrasting origins and drought responses. For this purpose, eight varieties comprising four from Spain and four from China were grown in control and drought conditions. Measures of biomass, mineral composition and gas exchange determinations were taken and are shown in Table S1. We observed that San Isidro and Zhong Mu were the two varieties with the greatest differences in behaviour under water-stressed conditions, and therefore, these two cultivars were chosen for the study.

\subsection{Water Limitation Effects on Plant Growth}

Agro-physiological differences between cultivars are shown in Figures 1-3 after suppression of irrigation until 15\% of the full substrate water-holding capacity was reached. While shoot biomass decreased in the Zhong Mu under water shortage, root biomass increased in San Isidro (Figure 1a). The relative water content (RWC) was reduced in roots and, especially, in nodules for both varieties, yet the decrease in leaf water content was only significant for San Isidro (Figure 1b). The N percentage in all studied organs was reduced under water stress in both varieties (Figure 1c). The BNF efficiency under water-stressed conditions was significantly lower in both cultivars. However, drought significantly reduced the $\mathrm{N}$ yield in terms of biomass in Zhong $\mathrm{Mu}$ alone (Figure 2).

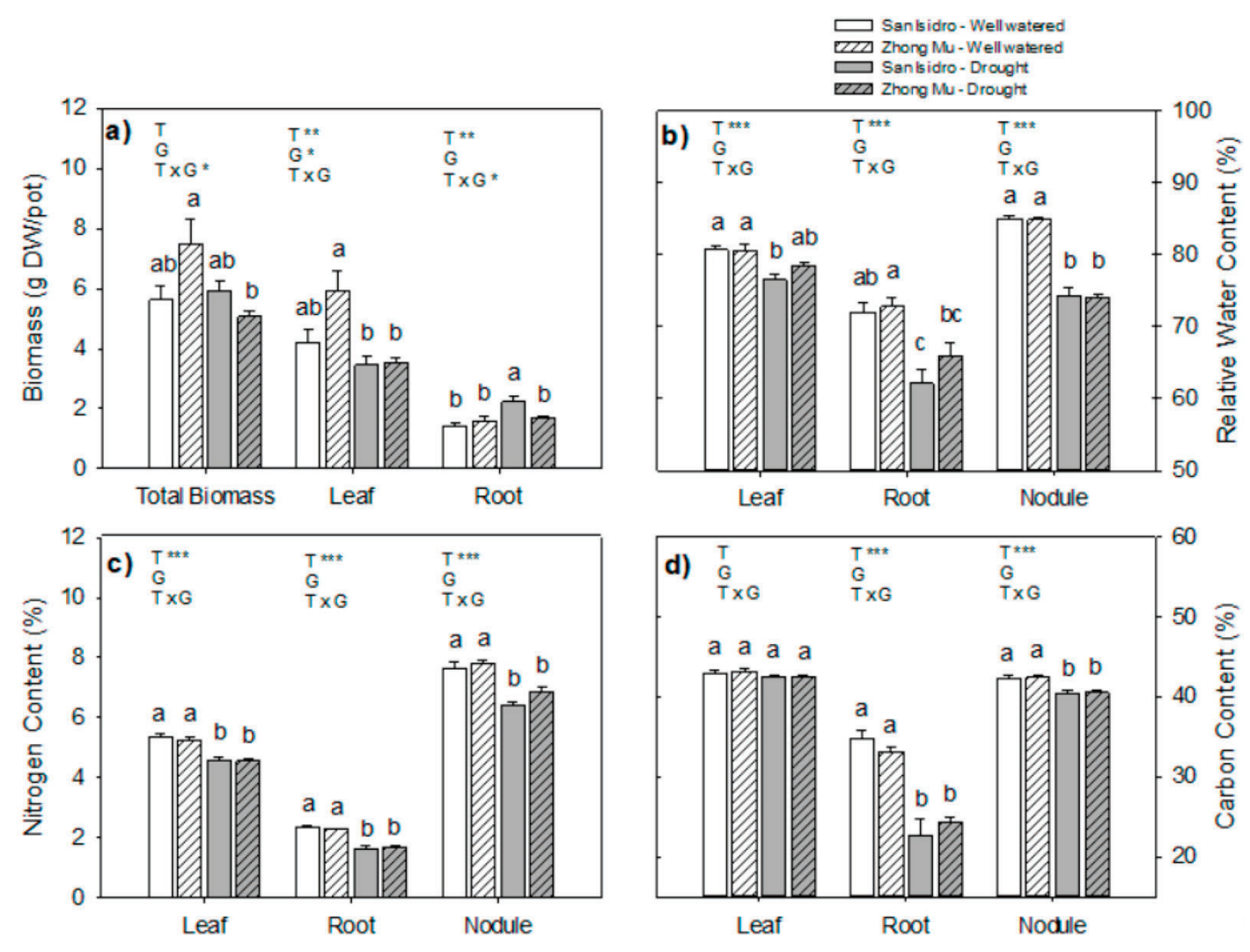

Figure 1. Agro-physiological parameters under control and drought conditions in two cultivars of Medicago sativa: San Isidro and Zhong Mu. (a) Dry biomass (g DW/pot); (b) relative water content (\%); (c) nitrogen content (\%) and (d) carbon content (\%). Each value represents the mean \pm SE $(n=6)$. The different letters indicate significant differences $(p<0.05)$. Asterisks indicate significant differences: ${ }^{*} p<0.05,{ }^{* *} p<0.01,{ }^{* * *} p<0.001$, in the two-way ANOVA for water-stress and cultivars. 

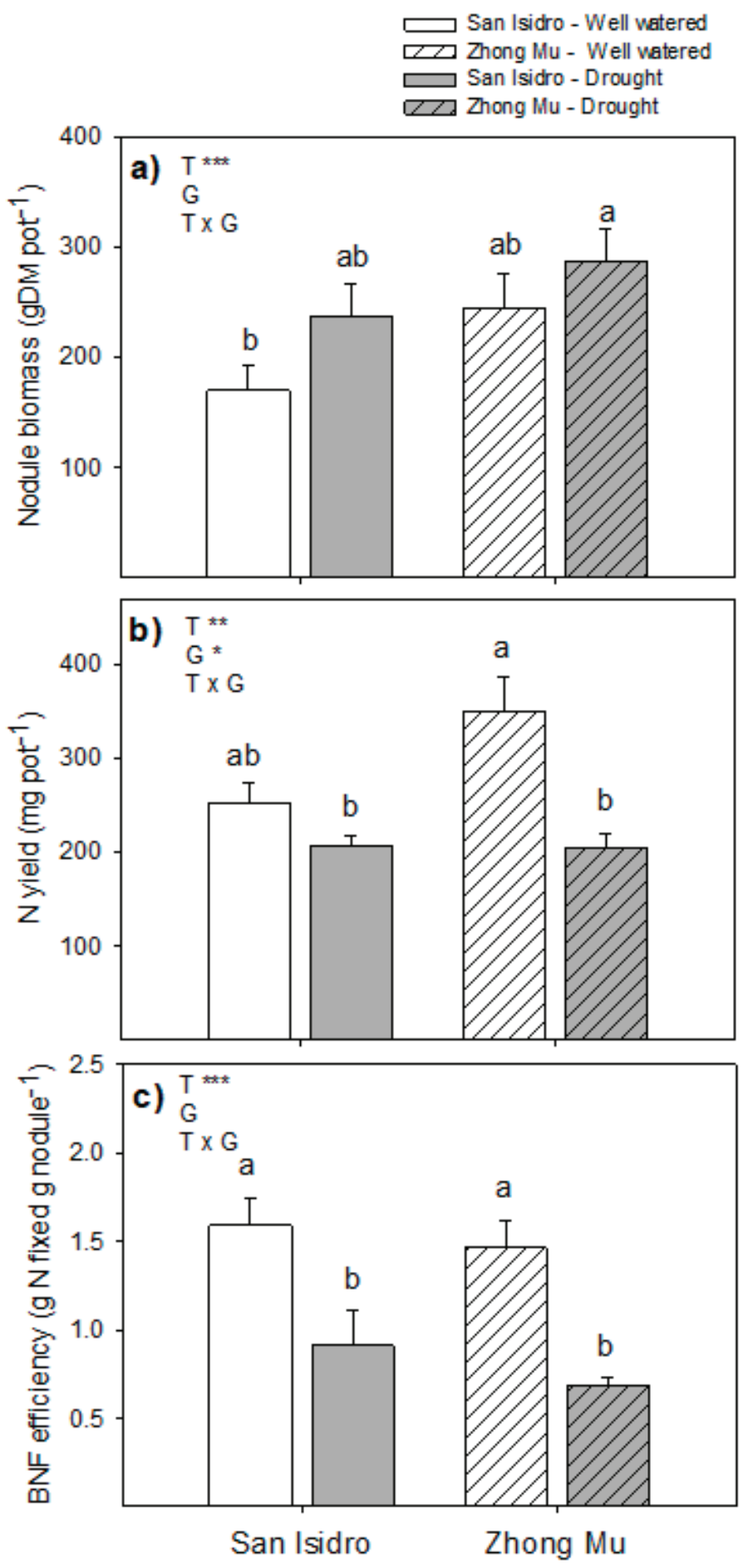

Figure 2. (a) Nodule biomass; (b) N yield per pot and (c) biological nitrogen fixation (BNF) efficiency under control and drought conditions in two cultivars of Medicago sativa: San Isidro and Zhong Mu. Each value represents the mean $\pm \mathrm{SE}(n=6)$. The different letters indicate significant differences $(p<0.05)$. Asterisks indicate significant differences: ${ }^{*} p<0.05,{ }^{* *} p<0.01,{ }^{* * *} p<0.001$, in the two-way ANOVA for water-stress and cultivars.

All of the gas exchange determinations: photosynthetic rates (A), transpiration (E), stomatal conductance $\left(\mathrm{g}_{\mathrm{s}}\right)$ and substomatic $\mathrm{CO}_{2}$ concentration $\left(\mathrm{C}_{\mathrm{i}}\right)$ were found to be significantly lower in the plants under water suppression but no differences between varieties were found in the treatments (Table S2). Isotopic discriminations of ${ }^{13} \mathrm{C}$ were analyzed in leaves and roots and a decreases in both 
varieties and their organs were found (Figure 3). Oxygen isotope fractions $\left(\delta^{18} \mathrm{O}\right)$ were also analyzed in leaves and roots. Differences were only found in leaves, with a significant increase in $\delta^{18} \mathrm{O}$ under water stress in Zhong Mu (Figure 3).

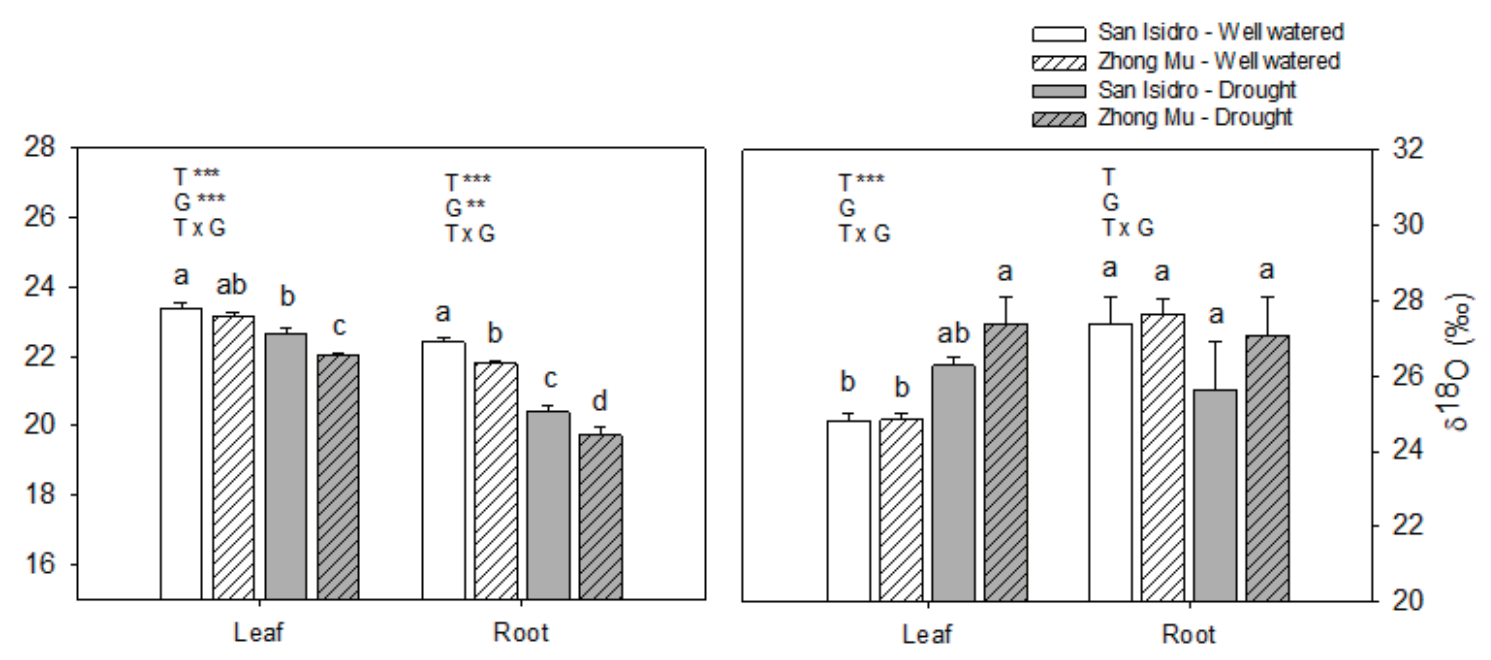

Figure 3. Carbon isotope discrimination $\left(\Delta^{13} \mathrm{C}\right)$ and oxygen isotope composition $\left(\delta^{18} \mathrm{O}\right)$ in leaves and roots under control and drought condition in two cultivars of Medicago sativa: San Isidro and Zhong $\mathrm{Mu}$. Each value represents the mean $\pm \mathrm{SE}(n=6)$. The different letters indicate significant differences $(p<0.05)$. Asterisks indicate significant differences: ${ }^{*} p<0.05,{ }^{* *} p<0.01,{ }^{* * *} p<0.001$, in the two-way ANOVA for water-stress and cultivars.

\subsection{Hormones}

The hormone quantitation was normalized to the dry weight (DW) of samples so as to avoid any discrepancy due to changes in relative water content under drought conditions. Three endogenous stress-related phytohormones were studied (ABA, salicylic acid (SA), and JA) (Figure 4). The ABA and JA contents were two orders of magnitude larger than the rest of the phytohormones studied. The most responsive phytohormone to drought was $\mathrm{ABA}$, showing differences between treatments in all organs, but the difference between cultivars was only significant for leaves, which were the organs with the highest content. JA, which was the most abundant phytohormone, changed between treatments and cultivars only in the nodules. Their JA content decreased under water stress by $84.5 \%$ in San Isidro and by $63.3 \%$ in $\mathrm{Zhong} \mathrm{Mu}$, and the Treatment $\times$ Genotype $(\mathrm{T} \times \mathrm{G})$ interaction was also significant. By contrast, SA contents increased with water shortage in leaves and roots but not in nodules with no difference between cultivars.

The four cytokinins studied are shown in Figure 5. Trans-zeatin (Z) was affected by the cultivar in roots and by drought in nodules, whereas its precursor, trans-zeatin riboside (ZR) did not differ between cultivars and was not affected by drought in leaves and nodules. There was no isopentenyl adenine (2iP) detected in nodules of alfalfa plants, and it was unaltered in roots, but, in leaves, the differences between treatments and varieties were significant. The endogenous isopentenyladenosine (IPA) content was significantly decreased in leaves and nodules under water limitation, especially in San Isidro.

The indole-3-acetic acid (IAA) content in leaves of San Isidro was higher than in Zhong Mu, especially in control conditions. The IAA content in roots of both cultivars and leaves of San Isidro was decreased under drought. Among the gibberellins analyzed, gibberellin $1\left(\mathrm{GA}_{1}\right)$ was below the limit of detection in all organs studied. However, gibberellin $4\left(\mathrm{GA}_{4}\right)$ showed an interesting response in nodules under water stress, being 3.5-fold higher in the nodules of both varieties under drought compared to control conditions (Figure 6). 


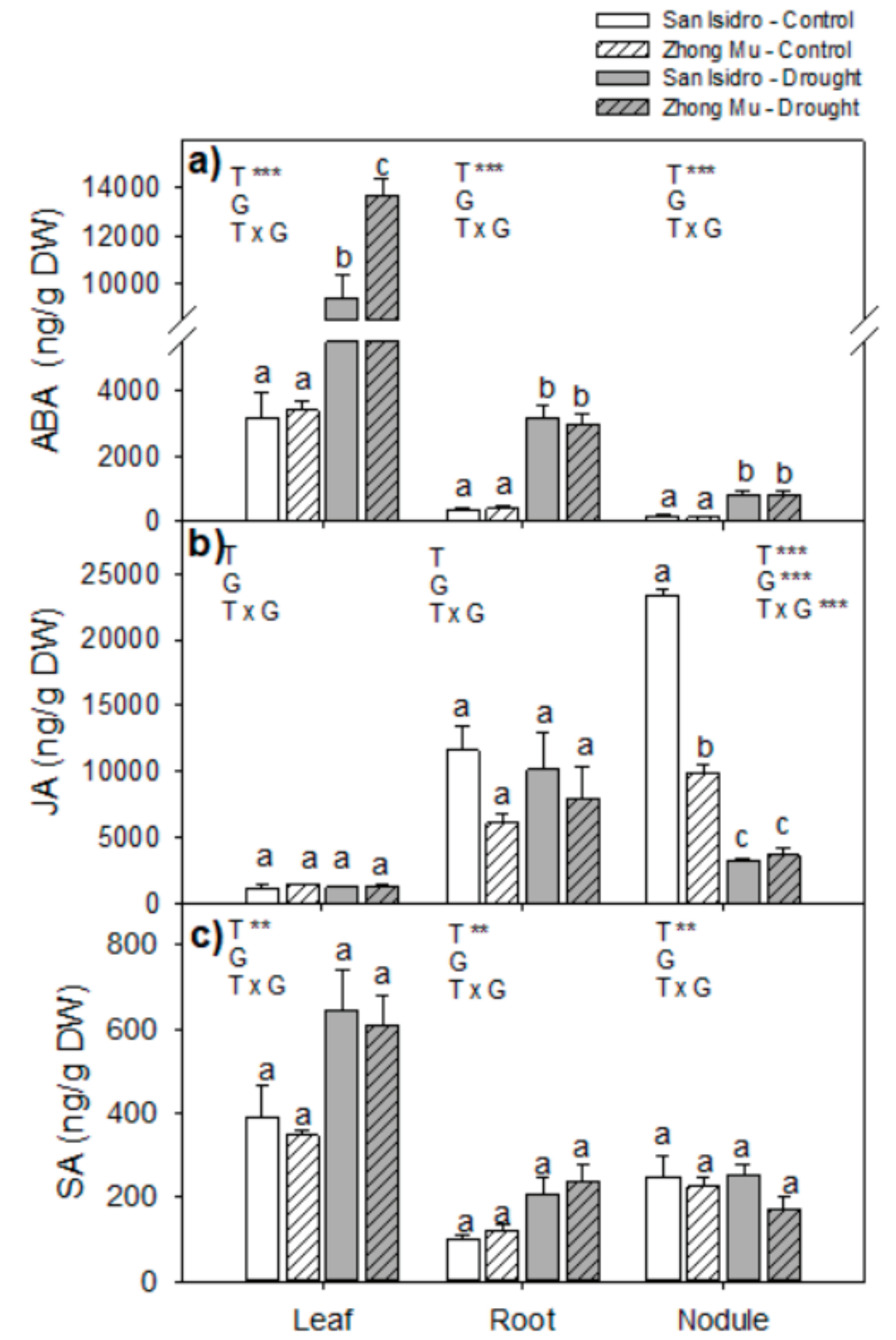

Figure 4. Stresses related hormones: (a) Abscisic acid (ABA); (b) jasmonic acid (JA) and (c) salicylic acid (SA) content in leaves, roots and nodules under control and drought condition in two cultivars of Medicago sativa: San Isidro and Zhong Mu. Each value represents the mean \pm SE $(n=6)$. The different letters indicate significant differences $(p<0.05)$. Asterisks indicate significant differences: ${ }^{*} p<0.05,{ }^{* *} p<0.01,{ }^{* * *} p<0.001$, in the two-way ANOVA for water-stress and cultivars. 


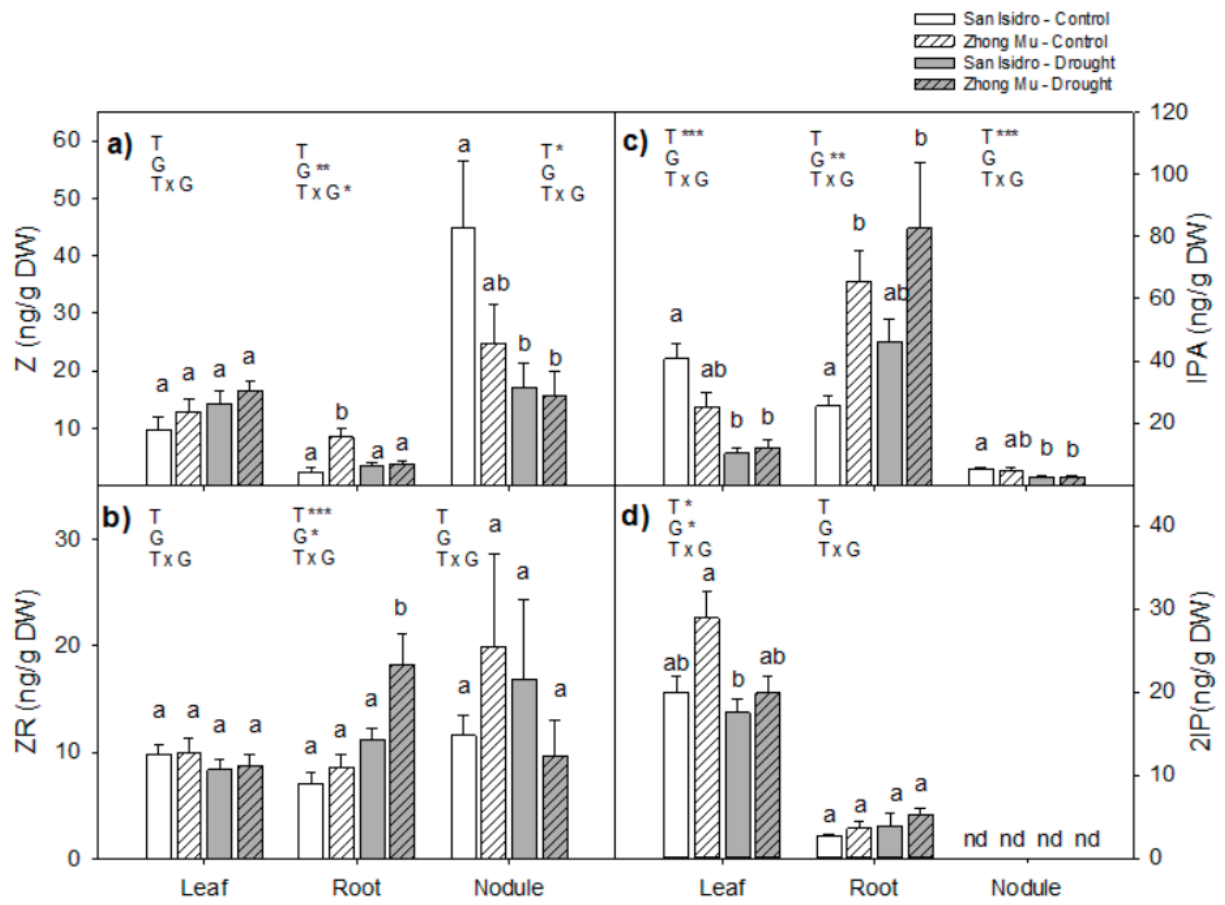

Figure 5. Cytokinins content in leaves, roots and nodules under control and drought condition in two cultivars of Medicago sativa: San Isidro and Zhong Mu: (a) trans-zeatin (Z), (b) trans-zeatin riboside $(\mathrm{ZR}),(\mathbf{c})$ isopentenyladenosine (IPA) and (d) isopentenyl adenine (2iP). Each value represents the mean $\pm \mathrm{SE}(n=6)$. The different letters indicate significant differences $(p<0.05)$. Asterisks indicate significant differences: ${ }^{*} p<0.05,{ }^{* *} p<0.01,{ }^{* * *} p<0.001$, in the two-way ANOVA for water-stress and cultivars.

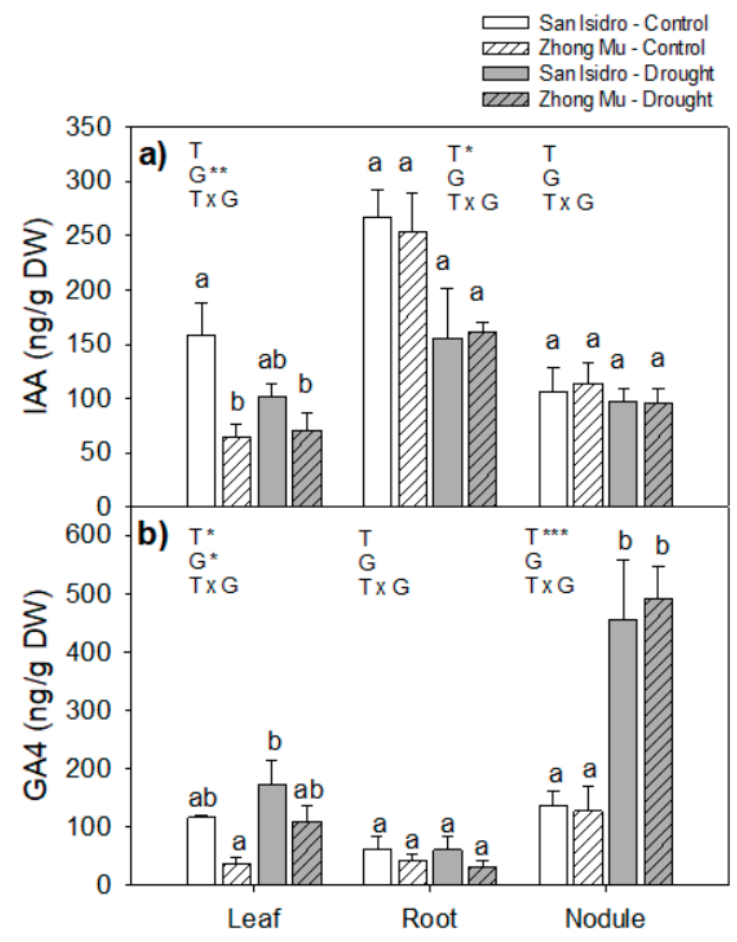

Figure 6. (a) Indole-3-acetic acid acid (IAA) and (b) gibberellin $4\left(\mathrm{GA}_{4}\right)$ content in leaves, roots and nodules under control and drought condition in two cultivars of Medicago sativa: San Isidro and Zhong $\mathrm{Mu}$. Each value represents the mean \pm SE $(n=6)$. The different letters indicate significant differences $(p<0.05)$. Asterisks indicate significant differences: ${ }^{*} p<0.05,{ }^{* *} p<0.01$, ${ }^{* * *} p<0.001$, in the two-way ANOVA for water-stress and cultivars. 


\subsection{Amino Acids and Sugars}

Overall, 19 amino acids were quantitated in control and water-stressed plants in different plant organs. The quantitation was normalized to the dry weight (DW) of samples so as to avoid any discrepancy due to changes in relative water content under drought conditions. Significant differences in amino acids between treatments and varieties are shown in Table 1. Significant differences could be seen in amino acids involved in long-distance transport of $\mathrm{N}$ and osmoregulatory functions.

Three carbohydrates (glucose, fructose, and sucrose) were studied at the whole plant level (Figure 7). In leaves, the glucose concentration increased under water stress in both varieties, and fructose also increased in San Isidro but not in Zhong Mu. In contrast, the sucrose content in leaves was reduced in Zhong Mu under drought conditions. In roots under water stress, glucose was 8-fold higher in San Isidro and 4-fold higher in Zhong $\mathrm{Mu}$, and the interaction between treatment and genotype was also strong $(p=0.000)$. Root sucrose content was reduced $(-24 \%)$ under drought in San Isidro but unchanged in Zhong Mu. In nodules, the main sugar was sucrose, which was 2-fold higher in both cultivars under water limitation.

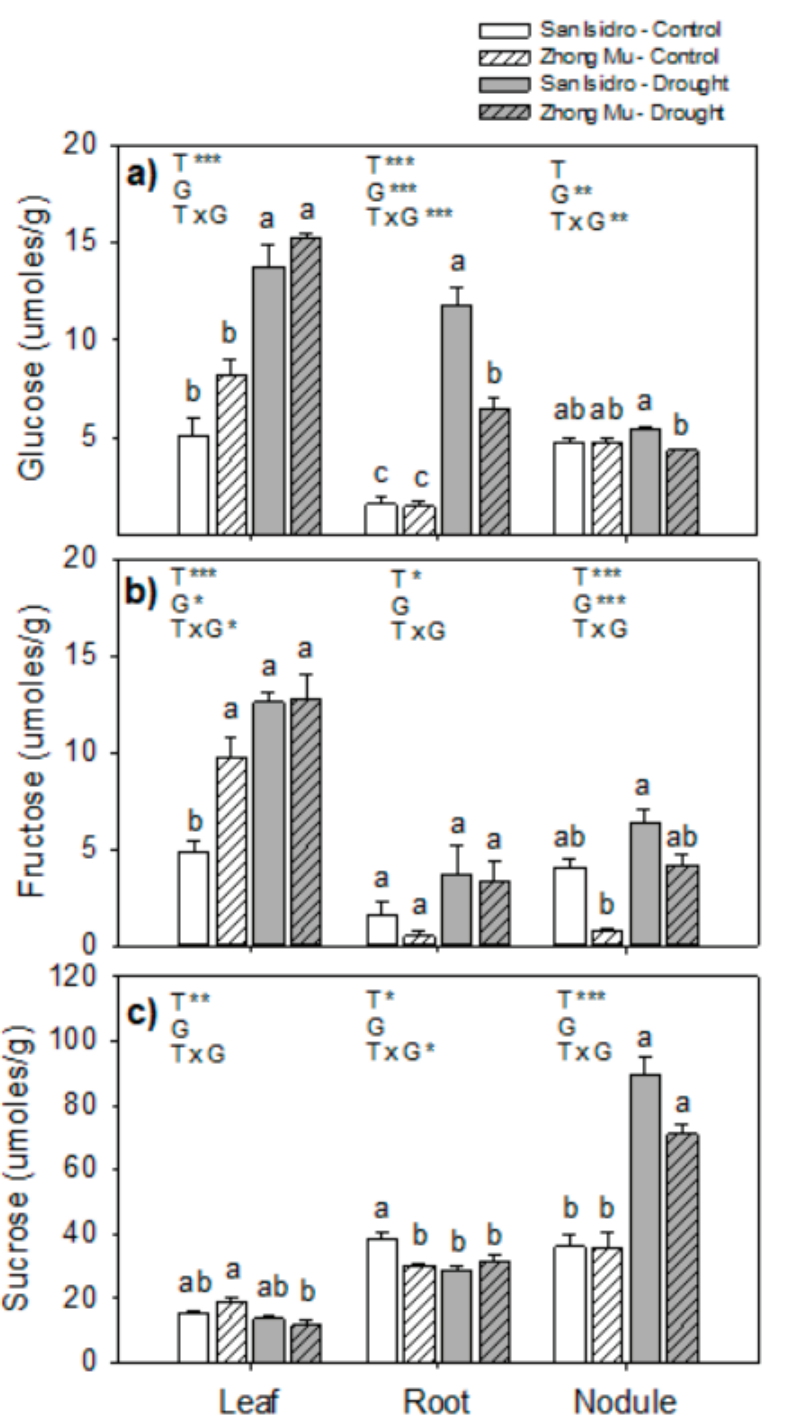

Figure 7. Soluble sugars content in leaves, roots and nodules under control and drought condition in two cultivars of Medicago sativa: San Isidro and Zhong Mu: (a) glucose, (b) fructose, (c) sucrose. Each value represents the mean $\pm \operatorname{SE}(n=6)$. The different letters indicate significant differences $(p<0.05)$. Asterisks indicate significant differences: ${ }^{*} p<0.05,{ }^{* *} p<0.01,{ }^{* * *} p<0.001$, in the two-way ANOVA for water-stress and cultivars. 


\section{Discussion}

During recent decades, the physiological and metabolic mechanisms underlying the responsiveness of alfalfa plants subjected to drought stress have been extensively studied in shoots. However, comparatively less information is available on other organs such as nodules. In the current study, the consequences of water restriction on growth, hormonal profile, and primary metabolism in alfalfa plants (leaves and roots) and nodules were characterized together in two cultivars with contrasting drought response strategies.

Biomass, mineral composition, and gas exchange data were used for the selection of two cultivars between a pool of 8 different cultivars from Spain and China (Table S1). On the basis of this data, San Isidro, a cultivar grown in Spain, and Zhong $\mathrm{Mu}$, from China, were chosen for the study. The cultivars were chosen for their contrasting drought response, mainly in biomass and gas exchange measures.

As observed in the preliminary study, this work identified considerable variation in the drought response within the selected varieties. Cultivars with contrasting responses to water stress are a rich resource and the study of the genetic diversity generates information to breed for increased yield under changing climate scenarios [31]. The current study aims to identify the agro-physiological, metabolite, and hormone profile parameters linked to the different responses to waters stress conditions.

\subsection{Drought Induces Different Agrophysiological Responses between Cultivars}

The study of the physiological mechanisms involved in the response to water limitation showed two different strategies in the cultivars analyzed. On the one hand, Zhong Mu maintained high RWC by closing stomata with the consequence of biomass growth inhibition. On the other hand, San Isidro maintained its biomass growth, replacing the water lost by transpiration with a more developed root system. A decrease in shoot growth is one of the most rapid effects of water shortage. It should also be noted that roots play an important role in adaptation to water limitation. When subjected to water stress, an enhanced root system has been described as improving plant water extraction from the soil [32]. As a consequence, the increase in the root/shoot ratio is a conserved response among plants exposed to water limitation [5,33], increasing the allocation of the plant's resources from shoots to roots, reducing the evaporative surface area and improving water uptake from the soil [5,34,35]. In our study, the root/shoot ratio was enhanced in both cultivars, but each variety underwent different developmental changes to achieve this increase. In San Isidro the ratio was increased following an enhancement of the roots, whereas in Zhong Mu the aerial biomass was reduced. At the nodule level, when both varieties were considered together, nodule dry weight was slightly but significantly higher under drought; this is in accordance with the significant increase observed in alfalfa nodules under drought [12] and suggests that an increase in nodulation compensates for the lower nodule efficiency observed under this stress conditions (Figure 2).

Maintenance of a constant RWC by closing stomata has been described as another physiological mechanism in drought-tolerant cultivars in many legumes and other crops [36]. However, our data showed a significant decrease in water content in all of the organs studied in both cultivars under drought, without differences between cultivars. Carbon isotope discrimination $\left(\Delta^{13} C\right)$ has been described as a good indicator of water status, providing long-term information on the transpiration efficiency of plants and as an indicator of water use efficiency (WUE) [37-39]. Given that leaves and roots of Zhong Mu maintained lower $\Delta^{13} \mathrm{C}$ under water-stressed conditions, we could assume that this cultivar had lower transpiration and greater WUE during biomass formation compared to San Isidro, and this was in accordance with the observed leaf RWC. These leaf RWC and $\Delta^{13} \mathrm{C}$ results were also in agreement with the oxygen isotope ratio $\left(\delta^{18} \mathrm{O}\right)$ (Figure 3). Some authors [40-43] have suggested that the $\delta^{18} \mathrm{O}$ of plant material reflects the evaporative conditions under which the material was formed, showing a negative relationship between the $\delta^{18} \mathrm{O}$ of leaves and stomatal conductance. In our experiment, the $\delta^{18} \mathrm{O}$ of leaves showed increased values under water limitation in both cultivars 
but it was only statistically significant in Zhong Mu. In line with the authors cited previously, this data could indicate lower stomatal conductance in Zhong Mu leaves.

Therefore, taking the physiological and isotopic data together, we observed two strategies to deal with water deficit. While San Isidro fixed more carbon, maintaining its aerial biomass under drought and promoting its root system for increased water uptake from the soil to compensate for water lost by transpiration, Zhong Mu reduced its water loss through transpiration by closing stomata and therefore fixed less carbon. Consequently, we have in both cultivars a trade-off between saving water and capturing carbon.

\subsection{Drought Caused Hormonal Reorchestration at the Whole Plant Level}

Under environmental stresses like drought, plants respond by changing the levels of endogenous phytohormones, playing a central role in the rapid orchestration of the stress response. ABA has been proven as the main phytohormone involved in abiotic stresses, provoking the rapid closure of stomata after perception of stress [44]. After water deprivation, the endogenous levels of ABA in leaves were three-fold higher in San Isidro and four-fold higher in Zhong Mu. These results are in agreement with the isotopic data that suggested a lower stomatal conductance in Zhong Mu plants exposed to drought. Roots under drought also produce ABA, which is rapidly transported from roots to shoots where it is accumulated in the apoplast of leaf guard cells $[14,45,46]$. The lower ABA content observed in roots compared with leaves indicates efficient ABA transport from roots to shoots. At the nodule level, in Pisum sativum it has been shown that an exogenous ABA supply stimulated an abrupt decrease in the nitrogenase activity of nodules, caused by the decrease in leghemoglobin levels [47]. Thus, the observed increase in ABA content under drought might have an effect on nodule oxygen diffusion and lead to the decline in nitrogen fixation.

Salicylic acid is also accumulated in plants under drought stress and is involved in inducing drought tolerance by regulating several physiological processes through signalling, for example, leaf senescence [48]. Our data showed a small accumulation of salicylic acid under drought in leaves and roots, although without differences between the cultivars. In contrast, jasmonic acid was strongly reduced in nodules under drought with the greater reduction observed for San Isidro. Jasmonic acid has been reported to be a negative regulator in the initial moments of nodulation [49,50]. Our results could suggest a cultivar-specific enhancement of nodulation under water limitation that compensates for the decrease in nitrogenase activity.

In San Isidro nodules a significant decrease was found in the cytokinins, zeatin, and IPA, implying a cultivar-specific trend for these two hormones. Recently, several authors have speculated about a direct connection between cytokinins and nitrogen fixation metabolism [51-53]. Additionally, it has been demonstrated that a decreased level of cytokinins accelerates nodule senescence and thus causes a gradual decline in nitrogenase activity throughout nodule development [52]. Cytokinins are often considered ABA antagonists [54,55], so a reduction in cytokinins might amplify responses to increasing levels of ABA [56]. Therefore, the observed reduction in cytokinins in San Isidro nodules may be in accordance with the increased levels of ABA under drought, reducing the nitrogen fixation efficiency in this cultivar, and suggesting that a hormonal cross-talk coordinates the drought response.

It has been reported that reduced levels of gibberellins decrease the number of nodules and this suggests that nodule formation is strictly controlled by the gibberellin concentration $[24,57]$. Our observed four-fold increase in gibberellin contents in nodules under drought conditions might involve an enhancement of nodule formation in both varieties, as was observed for jasmonic acid. This is in accordance with the observed enhancement of nodule biomass under water-stressed conditions.

\subsection{Drought Induces Lower $N_{2}$ Fixation, and Cultivar Differences could be Explained by N Feedback}

The decrease in \% $\mathrm{N}$ indicates that, under water limitation, the nodules (all plant $\mathrm{N}$ was provided by the nodules) were not efficient enough to supply the required $\mathrm{N}$ and to solve the $\mathrm{N}$ availability problems. The strong relationship between $\mathrm{N}_{2}$ fixation in legumes and the physiological status of the 
host plant has been described in several studies [12,26,58-62]. The greater decrease of $\mathrm{N}$ biomass yield and BNF efficiency between treatments in Zhong Mu showed a more limiting nodule functioning in this cultivar. Deleterious effects of drought on nodule performance have been described previously in alfalfa, and several mechanisms have been suggested for the inhibition of nitrogen fixation in legumes: carbon shortage, nitrogen feedback, inadequate oxygen supply and the role of oxidative stress $[11-13,27,61,63]$.

Sucrose is the principal form of photoassimilates for long-distance transport. Leaf sucrose concentration is determined by several factors including the rate of photosynthesis, the rate of sucrose hydrolysis (to glucose and fructose), and the rate of sucrose export to other organs [64]. In our experiment, the decrease in leaf sucrose concentration between treatments was only significant in Zhong Mu. Conversely, larger differences between treatments in glucose and fructose content in leaves were found in San Isidro, which suggested a lower rate of photosynthesis (as shown before) or/and higher rate of sucrose export to other organs in Zhong Mu plants (Figure 7). Contrastingly, the root sucrose decrease in San Isidro might be related with the larger increase in root glucose content or with the greater (but not significant) accumulation of sucrose in nodules of this cultivar. The accumulation of sucrose under drought stress has been widely reported in nodules of alfalfa and other legumes and was mainly attributed to the inhibition of SS activity $[60,65]$. Our data showed a similar accumulation of sucrose in nodules under water shortage in both cultivars, indicating that sucrose accumulation in nodules is not a good measure to distinguish drought tolerance between genotypes.

Leaf nitrogenous metabolites (Asn, Asp, Glu) were decreased by water limitation, probably due to the inhibition of nitrogenase activity (Table 1 and Figure 2). The depletion at the leaf level of these amino acids suggests that under drought conditions there was a remobilisation of $\mathrm{N}$ from the leaf towards reserve organs, mainly the primary root $[13,66]$. The accumulation of Pro might serve to stabilize the protein structure and is associated with an osmoregulatory function in response to drought [67]. High levels of proline in nodules have been observed [18] to have a protective role against reactive oxygen species (ROS). Within this context, the increased levels registered in drought-stressed plants suggest that these nodules could have been subjected to oxidative stress. Accumulation of ROS is another mechanism that might play a role in the drought-induced inhibition of $\mathrm{N}_{2}$ fixation. It should be highlighted that Pro accumulation under drought has been described as an important characteristic for distinguishing drought tolerance between cultivars [68]. Nevertheless, in our work the enhancement of Pro under water shortage was similar in both cultivars, indicating that Pro is not the prime cause for distinct drought tolerance in either cultivar, as similarly observed in nodules of two contrasting drought-tolerant peanut cultivars [33]. In addition, gamma-aminobutyric acid (GABA) is an amino acid with a protective function against ROS, and which acts during osmoregulation and as a signalling molecule [69]. The accumulations of GABA in nodules and roots of San Isidro plants were larger than in Zhong Mu.

Asn is the main N-transporter in alfalfa, and Asn accumulation in nodules has been implicated in $\mathrm{N}$ feedback, promoting the inhibition of symbiotic $\mathrm{N}_{2}$ fixation $[8,27,28]$. According to these studies, accumulation of Asn and other $\mathrm{N}_{2}$ fixation products in nodules is due to the lower aboveground $\mathrm{N}$ demand. In leaves, the Asn content was significantly lower under water limitation in San Isidro but not in Zhong Mu. Such differences suggest a higher consumption of Asn in San Isidro that resulted in a higher demand and lower nodule accumulation of Asn compared to Zhong Mu. This accumulation of Asn in Zhong Mu nodules could have been involved in the observed lower $\mathrm{N}_{2}$ fixation efficiency. Additionally, another reason to explain the greater accumulation of Asn in Zhong Mu nodules is its lower transpiration rate, as observed previously with the $\Delta^{13} \mathrm{C}$ and $\delta^{18} \mathrm{O}$ data. It has been noted [8] that lower transpiration may involve alterations in long-distance transport of $\mathrm{N}$ compounds between underground and aerial plant tissues, provoking an accumulation of $\mathrm{N}$ compounds in nodules of plants under water stress. However, recently, examination of the influence of transpiration on long-distance metabolite transport and its effects on the drought-induced inhibition of symbiotic nitrogen fixation 
in pea nodules under artificial reduction of plant transpiration has not revealed any accumulation of $\mathrm{N}$ compounds [30].

\section{Materials and Methods}

\subsection{Plant Material and Experimental Design}

The experiments were conducted with two alfalfa (Medicago sativa L.) cultivars, San Isidro and Zhong Mu, currently cultivated in Spain and China, respectively. These two contrasting cultivars were chosen during a previous experiment between eight alfalfa cultivars (four from Spain and four from China). The design was similar in both experiments. Seeds were germinated in Petri dishes and after germination, the plants were transplanted to $6 \mathrm{~L}$ black pots (four plants per pot) containing a substrate filled with 2:1 $(v / v)$ perlite/vermiculite. The experiment was conducted with six pots of each combination in a controlled greenhouse at $25 / 18 \cdot{ }^{\circ} \mathrm{C}$ (day/night) under natural daylight. The greenhouse was located at the Institute of Agrobiotechnology (IdAB) $\left(42^{\circ} 47^{\prime} \mathrm{N}, 1^{\circ} 37^{\prime} \mathrm{W}\right.$; Pamplona, Spain).

During the second week, plants were inoculated twice with Ensifer meliloti strain 102F34. To ensure that the sole $\mathrm{N}$ source was $\mathrm{N}_{2}$ fixed by nodules, the plants were watered with an $\mathrm{N}$-free nutrient solution with the following composition (mEq/L): $\mathrm{KH}_{2} \mathrm{PO}_{4}, 2 ; \mathrm{MgSO}_{4}, 1.5 ; \mathrm{KCl}, 3 ; \mathrm{CaCl}_{2}, 1.5 ; \mathrm{Na}$-FeEDTA, 0.12; and microelements as recommended [70], twice a week. When plants were 62 days old, half of the plants (randomly selected) were exposed to drought conditions by withholding watering), while the others were maintained in optimal water conditions. Suppression of irrigation was maintained for 15 days until $15 \%$ of the full substrate water-holding capacity was reached, while control plants were maintained at $90 \%$ full substrate water-holding capacity. At this point, gas exchange measurements were carried out, and then plants were collected and separated into apical shoot, primary root and nodules and were immediately frozen in liquid $\mathrm{N}$ and stored at $-80^{\circ} \mathrm{C}$ for further analyses. A subsample of each organ was separated and dried in an oven for $48 \mathrm{~h}$ at $60^{\circ} \mathrm{C}$ in order to determine dry weight. The water status of the plants was evaluated by measuring the leaf, root and nodule RWC according to [71].

Biological $\mathrm{N}$ fixation efficiency (BNF efficiency) was calculated as the quotient between biomass $\mathrm{N}$ yield per plant and nodule dry matter per plant.

\subsection{Gas Exchange and Chlorophyll Fluorescence Determinations}

Gas exchange measurements were carried out with a Li-Cor 6400 portable gas exchange photosynthesis system (LI-COR, Lincoln, NE, USA) on healthy and fully expanded apical leaves under conditions similar to growth conditions $\left(400 \mu \mathrm{mol} \mathrm{m}{ }^{-2} \mathrm{~s}^{-1} \mathrm{PPFD}, 25^{\circ} \mathrm{C}\right)$. Photosynthetic $\mathrm{CO}_{2}$ assimilation (A) was determined using equations developed by reference [72]. Stomatal conductance (gs) was determined as described by reference [73].

\subsection{Hormone Profiling}

Leaf, root, and nodule samples were ground in liquid nitrogen using a mix ball and $100 \mathrm{mg}$ sample (fresh weight) was homogenised with methanol:isopropanol:acetonitrile (50:49:1) using ultrasonication for $30 \mathrm{~min}\left(4^{\circ} \mathrm{C}\right)$. After centrifuging at $14,000 \times \mathrm{g}$ for $10 \mathrm{~min}$ at $4{ }^{\circ} \mathrm{C}$, the supernatant was collected and the pellet re-extracted with the same solvent until it was colourless. Supernatants were pooled and filtered with $0.22 \mu \mathrm{m}$ PTFE filters (Phenomenex, Torrance, CA, USA), transferred to HPLC vials and injected into a UHPLC-MS/MS. Endogenous hormones including abscisic acid (ABA), salicylic acid (SA), jasmonic acid (JA), the auxin indole-3-acetic acid (IAA), the cytokinins trans-zeatin and trans-zeatin riboside, isopentenyl adenosine (IPA) and 2-isopentenyl adenine (2iP), and gibberellin $4\left(\mathrm{GA}_{4}\right)$, were separated using an elution gradient on a reverse-phase UHPLC system and quantified using tandem mass spectrometry in multiple reaction monitoring mode exactly as described [74]. UHPLC/ESI-MS/MS equipment with an Aquity UPLCTM Sistem (Waters, Milford, MA, USA) quaternary pump equipped with and autosampler coupled to an API 3000 triple quadrupole mass spectrometer 
(PE Sciex, Concord, Ont., Canada) was used for analyses. Deuterium-labelled compounds were used as internal standards for quantification.

\subsection{Free Amino Acid and Sugar Determinations}

For the free amino acid determination, frozen plant tissues were ground to a fine powder in liquid nitrogen and a sub-sample was lyophilised. Lyophilised plant tissue $(20 \mathrm{mg})$ was homogenised in $400 \mu \mathrm{L}$ of $80 \%$ ethanol and mixed using a vortex, incubated at $80^{\circ} \mathrm{C}$ for $1 \mathrm{~h}$, and centrifuged at $14,000 \times \mathrm{g}$ and $4{ }^{\circ} \mathrm{C}$ for $10 \mathrm{~min}$ and the pellet was completely dehydrated. The pellet was re-suspended in $100 \mu \mathrm{L}$ of milli-Q water, centrifuged at $14,000 \times g$ and $4{ }^{\circ} \mathrm{C}$ for $10 \mathrm{~min}$, and the supernatant was collected. The amino acid content in the supernatant was determined by high performance liquid chromatography (HPLC) (Waters Corporation, Barcelona, Spain) after derivatization with a ACCQ-Fluor ${ }^{\mathrm{TM}}$ Reagent kit (Waters, Milford, MA, USA) based in borate buffer, acetonitrile and, AQC derivatizing reagent (6-aminoquinolyl-N-hydroxysuccinimidyl carbamate) as previously described [75].

For soluble sugars determinations, lyophilised plant tissue $(25 \mathrm{mg})$ was homogenised in $0.5 \mathrm{~mL}$ of $100 \%$ ethanol, then another $0.5 \mathrm{~mL}$ of $80 \%$ ethanol was added and mixed using a vortex. The sample was incubated at $70{ }^{\circ} \mathrm{C}$ for $90 \mathrm{~min}$, centrifuged at $14,000 \times \mathrm{g}$ for $10 \mathrm{~min}$ and the supernatant collected. The supernatant was used to determine glucose, fructose, and sucrose content with an ionic chromatographer (ICS-3000, Thermo Scientific ${ }^{\mathrm{TM}}$, Waltham, MA, USA).

\subsection{Carbon and Nitrogen Content}

The $\mathrm{C}$ and $\mathrm{N}$ content in leaf, root and nodule samples were determined based on sample dynamic combustion, using an elemental analyzer (FlashEA1112, ThermoFinnigan, Waltham, MA, USA) equipped with a MAS200R autosampler. The sample was weighed in a tin capsule (MX5 microbalance, Mettler-Toledo, Columbus, OH, USA) and introduced into a quartz reactor filled with WO3 and copper and heated at $1020^{\circ} \mathrm{C}$. The combustion gas mixture was carried by a helium flow to a WO3 layer to achieve a complete quantitative oxidation, following by a reduction step in a copper layer to reduce nitrogen oxides and $\mathrm{SO}_{3}$ to $\mathrm{N}_{2}$ and $\mathrm{SO}_{2}$. The resulting components, $\mathrm{N}_{2}, \mathrm{CO}_{2}, \mathrm{H}_{2} \mathrm{O}$, and $\mathrm{SO}_{2}$ were separated in a chromatographic column (Porapak 2m, Santa Clara, CA, USA) and detected with a thermal conductivity detector.

\subsection{Carbon ${ }^{13} \mathrm{C}$ Discrimination and Oxygen Isotopic Composition Analyses $\left({ }^{13} \mathrm{C}\right.$ and $\delta^{18} \mathrm{O}$ Respectively)}

Leaf and root samples $(\approx 0.1 \mathrm{~g})$ were selected to determinate the $\mathrm{C}$ isotopic composition $\left(\delta^{13} \mathrm{C}\right)$ using an elemental analyser (EA1108; Carlo Erba Instrumentazione, Milan, Italia) coupled to an isotope ratio mass spectrometer (Delta C; Finnigan, Mat., Bremen, Germany) operating in continuous flow mode. The $\delta^{13} \mathrm{C}$ values were transformed to discrimination values $\left(\Delta^{13} \mathrm{C}\right)$ according to [38], where air $\delta^{13} \mathrm{C}=-8 \%$ in Vienna Pee Dee Belemnite (V-PDB):

$$
\Delta^{13} C=\frac{\delta \text { air }-\delta \text { plant }}{1-\frac{\delta \text { plant }}{1000}}
$$

A MAT253 isotope ratio mass spectrometer coupled through a Conflo III to a high temperature conversion/elemental analyser (TC/EA) (all of them from Thermo Scientific ${ }^{\mathrm{TM}}$, Waltham, MA, USA) was used for ${ }^{18} \mathrm{O} /{ }^{16} \mathrm{O}$ isotope ratio measurement. Samples were weighed out $(0.6 \mathrm{mg})$ into $5 \times 3.3 \mathrm{~mm}$ silver capsules (Lüdi, Switzerland). Samples were thermally decomposed to CO in a glassy carbon reactor. The reactor consisted of an outer ceramic tube and an inner glassy carbon tube filled with glassy carbon granulate, and silver, and quartz wool (Elemental Microanalysis). The reactor temperature was set to $1450{ }^{\circ} \mathrm{C}$ and the post-reactor gas chromatography (GC) column was maintained at $65^{\circ} \mathrm{C}$ (He flow rate $90 \mathrm{~mL} / \mathrm{min}$ ). The ${ }^{18} \mathrm{O} /{ }^{16} \mathrm{O}$ isotope ratios are reported as $\delta^{18} \mathrm{O}$ values (\%) relative to Vienna Standard Mean Ocean Water (V-SMOW). The measured $\delta^{18} \mathrm{O}$ values were normalized to the VSMOW 
scale using the contemporaneously analyzed standards IAEA- $601\left(\delta^{18} \mathrm{O}_{\mathrm{VSMOW}}=23.3 \pm 0.3 \%\right.$ o $)$ and IAEA- $602\left(\delta^{18} \mathrm{O}_{\text {VSMOW }}=71.4 \pm 0.5 \%\right.$ o $)$. The SD for measurements was $\pm 0.4 \%$.

\subsection{Statistics}

Statistical analyses were performed with IBM SPSS Statistics for Windows, Version 20.0. (IBM Corp. Armonk, NY, USA). Differences among well-watered and drought treatments were evaluated with two way Analyses of Variance (ANOVA), with treatment being one fixed factor and variety the other fixed factor. Tukey' post hoc tests were used to determine statistical differences between treatments and varieties. All data were tested for normality (Kolmogorov-Smirnof test) and homogeneity of variances (Levene's test). The resulting P-values were considered to be statistically significant at $p<0.05$. Asterisks indicate significant differences: ${ }^{*} p<0.05,{ }^{* *} p<0.01,{ }^{* * *} p<0.001$, in the two-way ANOVA for water-stress and cultivars.

\section{Conclusions}

Plant response to water limitation is a trade-off between saving water by reducing transpiration and capturing carbon through photosynthesis. This response could be different between genotypes within the same crop species. In our study, two different strategies were observed in two alfalfa cultivars selected in a previous experiment. According to physiological and isotopic data, Zhong $\mathrm{Mu}$ has a water-saver strategy via a more conservative response: reducing of water loss by closing stomata and fixing less carbon by photosynthesis, thus limiting its growth under water limitation. In contrast, San Isidro promoted root growth to enhance water uptake to replace water lost through transpiration due to its more open stomata, allowing a greater rate of carbon to be fixed and maintaining biomass under drought. ABA was found in higher concentrations under drought in Zhong Mu leaves than in San Isidro leaves, supporting the physiological and isotopic data. The root nodule response to water deficit was also different between cultivars. Data on the biomass $\mathrm{N}$ yield and BNF efficiency indicated a lower capacity to supply the required $\mathrm{N}$ in Zhong $\mathrm{Mu}$. Our data suggest that this cultivar-specific decrease in nitrogen fixation is caused by a nitrogenase inhibition due to an N-feedback, which was manifested in the accumulation of Asn in nodules exposed to water shortage. On the other hand, the accumulation of sucrose, proline, and ABA in nodules of both cultivars might implicate carbon shortage, oxidative stress, and inadequate oxygen supply to the bacteroids, thereby reducing the $\mathrm{N}$ fixed.

Supplementary Materials: Supplementary materials can be found at http://www.mdpi.com/1422-0067/20/20/ 5099/s1.

Author Contributions: Conceptualization, I.A., B.Z. and C.A.-I.; methodology, I.A., B.Z. and S.M.-B.; formal analysis, I.A., D.S., B.Z. and S.M.-B.; resources, I.A., C.A.-I. and S.M.-B.; writing-original draft preparation, D.S.; writing-review and editing, D.S., I.A., C.A.-I. and S.M.-B.

Funding: This work was supported by the i-COOP-suelos y legumbres (2016SU0016) call funded by the National Research Council. David Soba is the recipient of a PhD grant supported by the Public University of Navarra

Conflicts of Interest: The authors declare no conflict of interest. 


\section{Abbreviations}

$\begin{array}{ll}\text { N } & \text { Nitrogen } \\ \text { BNF } & \text { Biological nitrogen fixation } \\ \text { C } & \text { Carbon } \\ \text { ABA } & \text { Abscisic acid } \\ \text { RWC } & \text { Relative water content } \\ \text { A } & \text { Photosynthetic rates } \\ \text { E } & \text { Transpiration } \\ \text { gs }_{\text {s }} & \text { Stomatal conductance } \\ \mathrm{C}_{\mathrm{i}} & \text { Substomatic } \mathrm{CO}_{2} \text { concentration } \\ \text { SA } & \text { Salicylic acid } \\ \text { JA } & \text { Jasmonic acid } \\ \text { Z } & \text { Trans-zeatin } \\ \text { ZR } & \text { Trans-zeatin riboside } \\ \text { IAA } & \text { Indole-3-acetic acid } \\ \text { GA } 1 & \text { Gibberellin } 1 \\ \text { GA } & \text { Gibberellin } 4 \\ \text { IPA } & \text { Isopentenyl adenosine } \\ \text { 2iP } & \text { Isopentenyl adenine } \\ \text { DW } & \text { Dry weight } \\ \Delta^{13} \mathrm{C} & \text { Carbon isotope discrimination } \\ \Delta^{18} \mathrm{O} & \text { Oxygen isotope ratio } \\ \text { WUE } & \text { Water use efficiency } \\ \text { SS } & \text { Sucrose synthase } \\ \text { ROS } & \text { Reactive oxygen species } \\ \text { GABA } & \text { Gamma-aminobutyric acid } \\ \text { Asn } & \text { Asparagine } \\ \text { Asp } & \text { Aspartic acid } \\ \text { Glu } & \text { Glutamic acid } \\ \text { Pro } & \text { Proline } \\ & \end{array}$

\section{References}

1. Annicchiarico, P.; Barrett, B.; Brummer, E.C.; Julier, B.; Marshall, A.H. Achievements and challenges in improving temperate perennial forage legumes. Crit. Rev. Plant Sci. 2015, 34, 327-380. [CrossRef]

2. Radović, J.; Sokolović, D.; Marković, J. Alfalfa-most important perennial forage legume in animal husbandry. Biotech. Anim. Husb. 2009, 25, 465-475. [CrossRef]

3. Steinfeld, H.; Gerber, P.; Wassenaar, T.D. Livestock's Long Shadow: Environmental Issues and Options; FAO: Rome, Italy, 2006.

4. Daryanto, S.; Wang, L.; Jacinthe, P.A. Global synthesis of drought effects on food legume production. PLoS ONE 2015, 10, 6. [CrossRef] [PubMed]

5. Bray, E.A. Plant responses to water deficit. Trends Plant Sci. 1997, 2, 48-54. [CrossRef]

6. Cattivelli, L.; Rizza, F.; Badeck, F.W.; Mazzucotelli, E.; Mastrangelo, A.M.; Francia, E.; Marè, C.; Tondelli, A.; Stanca, A.M. Drought tolerance improvement in crop plants: An integrated view from breeding to genomics. Field Crops Res. 2008, 105, 1-14. [CrossRef]

7. Serraj, R.; Sinclair, T.R. Inhibition of nitrogenase activity and nodule oxygen permeability by water deficit. J. Exp. Bot. 1996, 47, 1067-1073. [CrossRef]

8. Serraj, R.; Vadez, V.; Sinclair, T.R. Feedback regulation of symbiotic $\mathrm{N}_{2}$ fixation under drought stress. Agronomie 2001, 21, 621-626. [CrossRef]

9. Durand, J.L.; Sheehy, J.E.; Minchin, F.R. Nitrogenase activity: Photosynthesis and nodule water potential in soybean plants experiencing water-deprivation. J. Exp. Bot. 1987, 38, 311-321. [CrossRef]

10. Djekoun, A.; Planchon, C. Water status effect on dinitrogen fixation and photosynthesis in soybean. Agron. J. 1991, 83, 316-322. [CrossRef] 
11. Aranjuelo, I.; Arrese-Igor, C.; Molero, G. Nodule performance within a changing environmental context. J. Plant Physiol. 2014, 171, 1076-1090. [CrossRef]

12. Molero, G.; Tcherkez, G.; Roca, R.; Mauve, C.; Cabrera-Bosquet, L.; Araus, J.L.; Nogués, S.; Aranjuelo, I. Do metabolic changes underpin physiological responses to water limitation in alfalfa (Medicago sativa) plants during a regrowth period? Agric. Water Manag. 2019, 212, 1-11. [CrossRef]

13. Aranjuelo, I.; Molero, G.; Erice, G.; Avice, J.C.; Nogués, S. Plant physiology and proteomics reveals the leaf response to drought in alfalfa (Medicago sativa L.). J. Exp. Bot. 2011, 62, 111-123. [CrossRef] [PubMed]

14. Wilkinson, S.; Davies, W.J. Drought, ozone, ABA and ethylene: New insights from cell to plant to community. Plant Cell Environ. 2010, 33, 510-525. [CrossRef] [PubMed]

15. Dodd, I.C. Abscisic acid and stomatal closure: A hydraulic conductance conundrum? New Phytol. 2013, 197, 6-8. [CrossRef] [PubMed]

16. Sah, S.K.; Kambham, R.R.; Li, J. Abscisic acid and abiotic stress tolerance in crop plants. Front. Plant Sci. 2016, 7, 571. [CrossRef] [PubMed]

17. Xiong, L.; Schumaker, K.S.; Zhu, J.K. Cell signaling during cold, drought, and salt stress. Plant Cell. 2002, 14, S165-S183. [CrossRef] [PubMed]

18. Defez, R.; Andreozzi, A.; Dickinson, M.; Charlton, A.; Tadini, L.; Pesaresi, P.; Bianco, C. Improved drought stress response in alfalfa plants modulated by an IAA over-producing rhizobium strain. Front. Microbiol. 2017, 8, 2466. [CrossRef]

19. Ferguson, B.J.; Mathesius, U. Phytohormone regulation of legume-rhizobia interactions. J. Chem. Ecol. 2014, 40, 770-790. [CrossRef]

20. Liu, H.; Zhang, C.; Yang, J.; Yu, N.; Wang, E. Hormone modulation of legume-rhizobial symbiosis. J. Integr. Plant Biol. 2018, 60, 632-648. [CrossRef]

21. Suzaki, T.; Ito, M.; Kawaguchi, M. Genetic basis of cytokinin and auxin functions during root nodule development. Front. Plant Sci. 2013, 4, 42. [CrossRef]

22. Ng, J.L.P.; Hassan, S.; Truong, T.T.; Hocart, C.H.; Laffont, C.; Frugier, F.; Mathesius, U. Flavonoids and auxin transport inhibitors rescue symbiotic nodulation in the Medicago truncatula cytokinin perception mutant cre1. Plant Cell. 2015, 27, 2210-2226. [CrossRef] [PubMed]

23. Fisher, J.; Gaillard, P.; Fellbaum, C.R.; Subramanian, S.; Smith, S. Quantitative 3D imaging of cell level auxin and cytokinin response ratios in soybean roots and nodules. Plant Cell Environ. 2018, 41, 2080-2092. [CrossRef] [PubMed]

24. Ferguson, B.J.; Foo, E.; Ross, J.J.; Reid, J.B. Relationship between gibberellin, ethylene and nodulation in Pisum sativum. New Phytol. 2011, 189, 829-842. [CrossRef]

25. Sanchez, D.H.; Schwabe, F.; Erban, A.; Udvardi, M.K.; Kopka, J. Comparative metabolomics of drought acclimation in model and forage legumes. Plant Cell Environ. 2012, 35, 136-149. [CrossRef] [PubMed]

26. Aranjuelo, I.; Molero, G.; Erice, G.; Aldasoro, J.; Arrese-Igor, C.; Nogués, S. Effect of shoot on remobilization of carbon and nitrogen during regrowth of nitrogen-fixing alfalfa. Physiol. Plant 2015, 153, 91-104. [CrossRef]

27. Larrainzar, E.; Wienkoop, S.; Scherling, C.; Kempa, S.; Ladrera, R.; Arrese-Igor, C.; Weckwerth, W.; Gonzalez, E.M. Carbon metabolism and bacteroid functioning are involved in the regulation of nitrogen fixation in Medicago truncatula under drought and recovery. Mol. Plant Microbe Interact. 2009, 22, 1565-1576. [CrossRef]

28. King, C.A.; Purcell, L.C. Inhibition of $\mathrm{N}_{2}$ fixation in soybean is associated with elevated ureides and amino acids. Plant Physiol. 2005, 137, 1389-1396. [CrossRef]

29. Lodwig, E.; Poole, P. Metabolism of rhizobium bacteroids. Crit. Rev. Plant Sci. 2003, 22, 37-78. [CrossRef]

30. Aldasoro, J.; Larrainzar, E.; Arrese-Igor, C. Application of anti-transpirants temporarily alleviates the inhibition of symbiotic nitrogen fixation in drought-stressed pea plants. Agric. Water Manag. 2019, 213, 193-199. [CrossRef]

31. Sinclair, T.R.; Nogueira, M.A. Selection of host-plant genotype: The next step to increase grain legume $\mathrm{N}_{2}$ fixation activity. J. Exp. Bot. 2018, 69, 3523-3530. [CrossRef]

32. Wu, Y.; Cosgrove, D.J. Adaptation of roots to low water potentials by changes in cell wall extensibility and cell wall proteins. J. Exp. Bot. 2000, 51, 1543-1553. [CrossRef] [PubMed]

33. Furlam, A.L.; Bianucci, E.; Castro, S.; Dietz, K.J. Metabolic features involved in drought stress tolerance mechanisms in peanut nodules and their contribution to biological nitrogen fixation. Plant Sci. 2017, 263, 12-22. [CrossRef] [PubMed] 
34. Liu, F.; Andersen, M.N.; Jacobsen, S.E.; Jensen, C.R. Stomatal control and water use efficiency of soybean (Glycine max L. Merr.) during progressive soil drying. Environ. Exp. Bot. 2005, 54, 33-40. [CrossRef]

35. Jongrungklanga, N.; Toomsana, B.; Vorasoot, N.; Jogloy, S.; Boote, K.J.; Hoogenboom, G.; Patanothaia, A. Rooting traits of peanut genotypes with different yield responses to pre-flowering drought stress. Field Crop. Res. 2011, 120, 262-270. [CrossRef]

36. Silvente, S.; Sobolev, A.P.; Lara, M. Metabolite adjustments in drought tolerant and sensitive soybean genotypes in response to water stress. PLOS ONE. 2012, 7, 6. [CrossRef]

37. Farquhar, G.D.; Richards, R.A. Isotopic composition of plant carbon correlates with water-use efficiency of wheat genotypes. Aust. J. Plant Physiol. 1984, 11, 539-552. [CrossRef]

38. Farquhar, G.D.; Ehleringer, J.R.; Hubick, K.T. Carbon isotope discrimination and photosynthesis. Annu. Rev. Plant Physiol. 1989, 40, 503-537. [CrossRef]

39. Yousfi, S.; Serret, M.D.; Márquez, A.J.; Voltas, J.; Araus, J.L. Combined use of $\delta^{13} \mathrm{C}, \delta^{18} \mathrm{O}$ and $\delta^{15} \mathrm{~N}$ tracks nitrogen metabolism and genotypic adaptation of durum wheat to salinity and water deficit. New Phytol. 2012, 194, 230-244. [CrossRef]

40. Barbour, M.M.; Fischer, R.A.; Sayre, K.D.; Farquhar, G.D. Oxygen isotope ratio of leaf and grain material correlates with stomatal conductance and yield in irrigated, field-grown wheat. Aust. J. Plant Physiol. 2000, 27, 625-637.

41. Barbour, M.M.; Farquhar, G.D. Relative humidity- and ABA-induced variation in carbon and oxygen isotope ratios of cotton leaves. Plant Cell Environ. 2000, 23, 473-485. [CrossRef]

42. Del Pozo, A.; Matus, I.; Serret, M.D.; Araus, J.L. Agronomic and physiological traits associated with breeding advances of wheat under high-productive Mediterranean conditions. The case of Chile. Environ. Exp. Bot. 2014, 103, 180-189. [CrossRef]

43. Cabrera-Bosquet, L.; Molero, G.; Nogués, S.; Araus, J.L. Water and nitrogen conditions affect the relationships of $\delta^{13} \mathrm{C}$ and $\delta^{18} \mathrm{O}$ with gas exchange and growth in durum wheat. J. Exp. Bot. 2009, 60, 1633-1644. [CrossRef] [PubMed]

44. Schroeder, J.I.; Allen, G.J.; Hugouvieux, V.; Kwak, J.M.; Waner, D. Guard cell signal transduction. Annu. Rev. Plant Physiol. Plant Mol. Biol. 2001, 52, 627-658. [CrossRef] [PubMed]

45. Zhang, J.; Davies, W.J. Sequential responses of whole plant water relations towards prolonged soil drying and the mediation by xylem sap ABA concentration in the regulation of stomatal behaviour of sunflower plants. New Phytol. 1989, 113, 167-174. [CrossRef]

46. Jia, W.; Zhang, J.; Zhang, D.P. Metabolism of xylem-delivered ABA in relation to ABA flux and concentration in leaves of maize and Commelina communis. J. Exp. Bot. 1996, 47, 1085-1091. [CrossRef]

47. González, E.M.; Gálvez, L.; Royuela, M.; Aparicio-Tejo, P.M.; Arrese-Igor, C. Insights into the regulation of nitrogen fixation in pea nodules: Lessons from drought, abscisic acid and increased photoassimilate availability. Agronomie 2001, 21, 607-613. [CrossRef]

48. Abreu, M.E.; Munné-Bosch, S. Photo- and antioxidant protection and salicylic acid accumulation during post-anthesis leaf senescence in Salvia lanigera grown under Mediterranean climate. Physiol. Plant. 2007, 131, 590-598. [CrossRef]

49. Nakagawa, T.; Kawaguchi, M. Shoot-applied MeJA suppresses root nodulation in Lotus japonicus. Plant Cell Physiol. 2006, 47, 176-180. [CrossRef]

50. Sun, J.; Cardoza, V.; Mitchell, D.M.; Bright, L.; Oldroyd, G.; Harris, J.M. Crosstalk between jasmonic acid, ethylene and Nod factor signaling allow integration of diverse inputs for regulation of nodulation. Plant J. 2006, 46, 961-970. [CrossRef]

51. Chen, Y.; Chen, W.; Li, X.; Jiang, H.; Wu, P.; Xia, K.; Yang, Y.; Wu, G. Knockdown of LjIPT3 influences nodule development in Lotus japonicus. Plant Cell Physiol. 2014, 55, 183-193. [CrossRef]

52. Boivin, S.; Kazmierczak, T.; Brault, M.; Wen, J.; Gamas, P.; Mysore, K.S.; Frugier, F. Different cytokinin CHK receptors regulate nodule initiation as well as later nodule developmental stages in Medicago truncatula. Plant Cell Environ. 2016, 39, 2198-2209. [CrossRef] [PubMed]

53. Reid, D.E.; Heckmann, A.B.; Novak, O.; Kelly, S.; Stougaard, J. CYTOKININ OXIDASE/DESHYDROGENASE3 maintains cytokinin homeostasis during root and nodule development in Lotus japonicus. Plant Physiol. 2016, 170, 1060-1074. [CrossRef] [PubMed]

54. Cowan, A.K.; Cairns, A.L.P.; Bartels-Rahm, B. Regulation of abscisic acid metabolism: Towards a metabolic basis for abscisic acid-cytokinin antagonism. J. Exp. Bot. 1999, 50, 595-603. [CrossRef] 
55. Pospíšilová, J.; Synková, H.; Rulcová, J. Cytokinins and water stress. Biol. Plant. 2000, 43, 321-328. [CrossRef]

56. Davies, W.J.; Zhang, J. Root signals and the regulation of growth and development of plants in drying soil. Annu. Rev. Plant Physiol. Plant Mol. Biol. 1991, 42, 55-76. [CrossRef]

57. Ferguson, B.J.; Ross, J.J.; Reis, J. Nodulation Phenotypes of gibberellin and brassinosteroid mutants of Pea. Plant physiol. 2005, 138, 2396-2405. [CrossRef] [PubMed]

58. Aranjuelo, I.; Irigoyen, J.J.; Sánchez-Díaz, M. Effect of elevated temperature and water availability on $\mathrm{CO}_{2}$ exchange and nitrogen fixation of nodulated alfalfa plants. Environ. Exp. Bot. 2007, 59, 99-108. [CrossRef]

59. Aranjuelo, I.; Irigoyen, J.J.; Sánchez-Díaz, M.; Nogués, S. Carbon partitioning in $\mathrm{N}_{2}$ fixing Medicago sativa plants exposed to different $\mathrm{CO}_{2}$ and temperature conditions. Funct. Plant Biol. 2008, 35, 306-317. [CrossRef]

60. Gálvez, L.; González, E.M.; Arrese-Igor, C. Evidence for carbon flux shortage and strong carbon/nitrogen interactions in pea nodules at early stages of water stress. J. Exp. Bot. 2005, 56, 2551-2561. [CrossRef]

61. Schulze, J. How are nitrogen fixation rates regulated in legumes? J. Plant Nutr. Soil Sci. 2004, 167, $125-137$. [CrossRef]

62. Serraj, R. Effects of drought stress on legume symbiotic nitrogen fixation: Physiological mechanisms. Indian J. Exp. Biol. 2003, 41, 1136-1141. [PubMed]

63. Naya, L.; Ladrera, R.; Ramos, J.; González, E.M.; Arrese-Igor, C.; Minchin, F.R.; Becana, M. The response of carbon metabolism and antioxidant defenses of alfalfa nodules to drought stress and to the subsequent recovery of plants. Plant Physiol. 2007, 144, 1104-1114. [CrossRef] [PubMed]

64. Egli, D.B.; Ramseur, E.L.; Zhen-wen, Y.; Sullivan, E.H. Source-sink alterations affect the number of cells in soybean cotyledons. Crop. Sci. 1989, 29, 732-735. [CrossRef]

65. González, E.M.; Gordon, A.J.; James, C.L.; Arrese-Igor, C. The role of sucrose synthase in the response of soybean nodules to drought. J. Exp. Bot. 1995, 46, 1515-1523. [CrossRef]

66. Gordon, A.J.; Minchin, F.R.; James, C.L.; Komina, O. Sucrose synthase in legume nodules is essential for nitrogen fixation. Plant Physiol. 1999, 120, 867-877. [CrossRef]

67. Zhang, J.Y.; Cruz de Carvalho, M.H.; Torres-Jerez, I.; Kang, Y.; Allen, S.N.; Huhman, D.V.; Tang, Y.; Murray, J.; Sumner, L.W.; Udvardi, M.K. Global reprogramming of transcription and metabolism in Medicago truncatula during progressive drought and after rewatering. Plant Cell Environ. 2014, 37, 2553-2576. [CrossRef]

68. Turkan, I.; Bor, M.; Özdemir, F.; Koca, H. Differential responses of lipid peroxidation and antioxidants in the leaves of drought-tolerant $P$. acutifolius Gray and drought-sensitive P. vulgaris L. subjected to polyethylene glycol mediated water stress. Plant Sci. 2005, 168, 223-231. [CrossRef]

69. Michaeli, S.; Fromm, H. Closing the loop on the GABA shunt in plants: Are GABA metabolism and signaling entwined? Front. Plant. Sci. 2015, 6, 419. [CrossRef]

70. Hoagland, D.R.; Arnon, D.I. The water-culture method for growing plants without soil. Calif. Agric. Exp. Stn. 1950, 347, 1-32.

71. Weatherley, P. Studies in the water relations of the cotton plant. 1. The field measurement of water deficits in leaves. New Phytol. 1950, 49, 81-97. [CrossRef]

72. Caemmerer, S.; Farquhar, G.D. Some relationships between the biochemistry of photosynthesis and the gas exchange of leaves. Planta 1981, 153, 376-387. [CrossRef] [PubMed]

73. Harley, P.C.; Loreto, F.; Di Marco, G.; Sharkey, T.D. Theoretical considerations when estimating the mesophyll conductance to $\mathrm{CO}_{2}$ flux by the analysis of the response of photosynthesis to $\mathrm{CO}_{2}$. Plant Physiol. 1992, 98, 1429-1436. [CrossRef] [PubMed]

74. Müller, M.; Munné-Bosch, S. Rapid and sensitive hormonal profiling of complex plant samples by liquid chromatography coupled to electrospray ionization tandem mass spectrometry. Plant Meth. 2011, 7, 37. [CrossRef] [PubMed]

75. Cohen, S.A.; Michaud, D.P. Synthesis of a fluorescent derivatizing reagent, 6-aminoquinolyl-N-hydroxysuccinimidyl carbamate, and its application for the analysis of hydrolysate amino acids via high-performance liquid chromatography. Anal. Biochem. 1993, 211, 279-287. [CrossRef]

(C) 2019 by the authors. Licensee MDPI, Basel, Switzerland. This article is an open access article distributed under the terms and conditions of the Creative Commons Attribution (CC BY) license (http://creativecommons.org/licenses/by/4.0/). 
upna

Universicad Publica de Navara
Natarsaako Unibersitate Publikoa 
"V.CHAPTER 3

upna

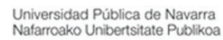


upna

Universicad Publica de Navara
Natarsaako Unibersitate Publikoa 


\title{
Vitamin E in legume nodules: Occurrence and antioxidant function
}

\author{
David Soba ${ }^{\mathrm{a}}$, Maren Müller ${ }^{\mathrm{b}, \mathrm{c}}$, Iker Aranjuelo ${ }^{\mathrm{a}}$, Sergi Munné-Bosch ${ }^{\mathrm{b}, \mathrm{c}, *}$ \\ ${ }^{a}$ Instituto de Agrobiotecnología (IdAB), Consejo Superior de Investigaciones Científicas-Gobierno de Navarra, Spain \\ ${ }^{\mathrm{b}}$ Department of Evolutionary Biology, Ecology and Environmental Sciences, Faculty of Biology, University of Barcelona, Barcelona, Spain \\ ${ }^{\mathrm{c}}$ Institute of Nutrition and Food Safety, University of Barcelona, Barcelona, Spain
}

\section{A R T I C L E I N F O}

\section{Keywords:}

Glycine max

Medicago sativa

Pisum sativum

Soybean

Alfalfa

Pea plants

Fabaceae

Legumes

Tocopherols

Vitamin E

\begin{abstract}
A B S T R A C T
Although the biosynthesis and function of tocochromanols in leaves and seeds have been extensively studied, their occurrence and function in underground tissues, such as roots and nodules, is very poorly understood. Here, we performed a comparative study of the presence of tocochromanols in different plant organs (leaves, roots and nodules) of three legumes (soybean, alfalfa and pea plants). Additionally, we measured variations in tocochromanols as a function of the severity of water stress and evaluated their relationship with the extent of membrane lipid peroxidation and nodule performance (as indicated by thiobarbituric acid-reactive substances assay and ${ }^{15} \mathrm{~N}$ isotope labeling, respectively). Results showed the presence of endogenous tocopherols, mainly $\alpha$ tocopherol, in the three studied organs of the three legumes. Nodules showed higher concentrations of $\alpha$-tocopherol than roots, but lower than leaves. $\alpha$-Tocopherol content increased under water shortage in nodules, roots and leaves of soybean as well as in roots of alfalfa, but not in the other plant systems. A strong negative correlation between $\alpha$-tocopherol and thiobarbituric acid-reactive substances contents was found for roots and especially for nodules. Furthermore, nodule $\alpha$-tocopherol content positively correlated with nodule $\mathrm{N}_{2}$ fixation (estimated by ${ }^{15} \mathrm{~N}$ isotope labeling). We conclude that $\alpha$-tocopherol is a major antioxidant found in legume nodules.
\end{abstract}

\section{Introduction}

Better understanding of legume crops' biology is a priority nowadays for food security and environmental conservation. Moreover, the new scenario of global change is predicted to increase plant exposure to abiotic stresses, which is expected to negatively affect crop production in different regions (Schmidhuber and Tubiello, 2007). In this scenario, legume plants may be exposed to an increased oxidative stress caused by more unpredictable drought events (Moran et al., 1994). Legumerhizobia symbiosis plays an essential role in nitrogen assimilation in economically important crops, such as alfalfa (Medicago sativa), pea (Pisum sativum) and soybean (Glycine max) plants, and the process of nitrogen fixation is essential to keep nutrient homeostasis not only during nitrogen deficiency, but also under other abiotic stress conditions, such as drought, which may lead to a nutrient unbalance. While some legumes (such as alfalfa and pea plants) develop indeterminate nodules, which are characterized by a nodule meristem that persists and newly divided (i.e. uninfected) cells are continuously formed at the elongating nodule tip, others (such as soybean) show determinate nodules where the tissue matures synchronously, with all infected cells at approximately the same stage of differentiation, and meristematic tissues are lacking (Crawford et al., 2015). Plants have evolved a highly efficient antioxidative defense system that modulate reactive oxygen species (ROS) levels in many developmental and stress situations, including drought. Although ROS may play an essential role in redox signaling, they may also disrupt biological membranes and cause cellular damage (Apel and Hirt, 2004). Lipid peroxidation is the oxidative degradation of lipids in a process in which free radicals "steal" electrons from membrane lipids by a free radical chain reaction mechanism, eventually resulting in cellular damage Farmer and Mueller (2013). Among a number of antioxidants, tocochromanols comprise a class of lipid-soluble molecules ( $\alpha$-, $\beta$-, $\gamma$-, $\delta$-tocopherols and tocotrienols, also known as vitamin E, but also plastochromanol-8, Kruk et al., 2014). Vitamin E plays a major role in avoiding the negative effects of ROS in lipid membranes by inhibiting the propagation of lipid peroxidation through the direct scavenging of lipid peroxyl radicals but also by quenching/scavenging singlet oxygen (Boonnoy et al., 2018; Muñoz and Munné-Bosch, 2019). While the ROS elimination function is also performed by other antioxidants, such as carotenoids (Havaux et al., 2005), the inhibition of the propagation of lipid peroxidation is exclusive to tocopherols, $\alpha$-tocopherol being the most efficient compound (Muñoz and Munné-Bosch, 2019). Beyond its antioxidant role, new

\footnotetext{
${ }^{*}$ Corresponding author. Institute of Nutrition and Food Safety, University of Barcelona, Barcelona, Spain.

E-mail address: smunne@ub.edu (S. Munné-Bosch).
} 
biological functions of vitamin $\mathrm{E}$ in plants, related to various physiological processes, have emerged in recent years, from alterations of photo-assimilate export in leaves (Hofius et al., 1999; Sattler et al., 2004; Maeda et al., 2006) to maintenance of seed viability during quiescence and germination (Sattler et al., 2004), and the regulation of leaf senescence (Abbasi et al., 2009). Nonetheless, its role in other physiological processes, in particular their possible functions in underground organs, remains very poorly understood (Muñoz and MunnéBosch, 2019).

Legume root nodules are sites of intense biochemical activity and consequently are at high risk of damage as a result of the generation of ROS (Gogorcena et al., 1995). Although nodules possess an array of antioxidants that modulate ROS levels, which suggests an important connection between $\mathrm{N}_{2}$ fixation and antioxidants (Becana et al., 2010), lipid peroxidation was found to be elevated in nodules of alfalfa (Naya et al., 2007), pigeon pea (Swaraj et al., 1995), soybean (Evans et al., 1999) and beans (Gogorcena et al., 1997) subjected to drought, suggesting lipid membrane damage. However, vitamin E in nodules has been studied only by Evans et al. (1999) during soybean nodule ageing, in which study, the presence of $\alpha$-tocopherol was determined by highperformance liquid chromatography (HPLC), but not confirmed by mass spectrometry (MS). Yet, very little is known about the occurrence and function of vitamin $\mathrm{E}$ in nodules. Here, we aimed at confirming the presence of vitamin $\mathrm{E}$ in soybean nodules, studying its presence in other legume nodules (alfalfa and pea plants) and examining its possible antioxidant function in nodules, to modulate lipid peroxidation under water stress, by performing a comparative study using nodules, roots and leaves from three legumes (soybean, alfalfa and pea plants). We found that, not only is $\alpha$-tocopherol the major accumulator of vitamin $\mathrm{E}$ in nodules of the three studied legumes, but that it negatively and positively correlates with lipid peroxidation and nodule performance, respectively, thus suggesting a protective antioxidant role against stress.

\section{Results and discussion}

\subsection{Vitamin E presence in underground tissues of different legumes}

Tocochromanols play an essential role as antioxidants in photosynthetic organisms, protecting membranes against ROS, a function exerted together with carotenoids (Maeda and DellaPenna, 2007; Falk and Munné-Bosch, 2010; Muñoz and Munné-Bosch, 2019). But at the same time, they are the only antioxidant capable of reacting with lipid peroxyl radicals and therefore of modulating the extent of lipid peroxidation in biological membranes (Falk and Munné-Bosch, 2010; Muñoz and Munné-Bosch, 2019). They have been extensively studied in photosynthetic organs and seeds, however, little attention has been paid to their occurrence and function in roots and nodules. With the exception of the first enzyme involved in tocochromanol synthesis, $p$ hydroxyphenylpyruvate dioxygenase, the successive key limiting enzymes are all membrane-bound, localized in the plastid membrane and/ or plastoglobuli (Garcia et al., 1999; Vidi et al., 2006). Although plastids are almost ubiquitously present in all plant cells, and virtually all plant tissues have the capacity to synthesize tocochromanols, only Evans et al. (1999) thus far, have described the presence of $\alpha$-tocopherol in nodules, using HPLC, without confirming the identity of this compound by other means. In our study, the presence of vitamin $\mathrm{E}$ in nodules was determined by HPLC and later independently confirmed by HPLC-MS/MS (Fig. 1A). Among the nine tocochromanols examined (the four tocopherol and four tocotrienol homologues $[\alpha, \beta, \gamma$ and $\delta]$ together with plastochromanol-8 [PC-8]), only $\alpha$-tocopherol was found in all three organs of the three studied species. $\alpha$-Tocopherol represented, in all cases (all species and in all organs), over 75\% of total tocochromanol content, being the only tocochromanol in roots and nodules of soybean and pea plants. $\beta$-Tocopherol was the second most abundant tocochromanol in legumes, being present in leaves of soybean and alfalfa and in nodules of alfalfa (Fig. 1B). Plastochromanol-8 was only found in very small amounts in leaves, but not in underground tissues. Pea nodules might also contain $\alpha$ - and $\gamma$-tocotrienol in small amounts but this could not be confirmed by LC-MS/MS (Fig. 1A), therefore requiring further investigation. In any case, our results indicate that the tocochromanol pathway in the three studied species is predominantly diverted to the formation of $\alpha$-tocopherol, and that other tocochromanols play, at best, a very minor role. The predominance of $\alpha$-tocopherol in the accumulation of tocochromanols in the photosynthetic tissues of plants has been extensively reported (Szymanska and Kruk, 2008; Falk and Munné-Bosch, 2010), but remains very poorly studied in relation to underground tissues. This study shows the occurrence of vitamin E in nodules of three different legume genera, suggesting the broad presence of vitamin $\mathrm{E}$ in this specific legume tissue. The accumulation of $\alpha$-tocopherol in nodules was lower than in leaves, but much higher compared to roots (Fig. 1B), thus indicating that nodule formation from root tissue specifically increases $\alpha$-tocopherol accumulation. In addition, strong interspecific differences were found in $\alpha$-tocopherol accumulation in nodules, being lower in soybean $\left(3.3 \mu \mathrm{g} \mathrm{gDW}^{-1}\right)$, which has determinate nodules, than in alfalfa $\left(41.8 \mu \mathrm{gDW}^{-1}\right)$ and pea $(19.8 \mu \mathrm{g}$ $\mathrm{gDW}^{-1}$ ), both with indeterminate nodules. It is known that $\alpha$-tocopherol is synthesized in plastids (Vidi et al., 2006) and that it protects thylakoid membrane lipids from ROS generated from photosynthesis (Havaux et al., 2005). Legume nodules are non-photosynthetic, which might partly constrain nodule tocopherol accumulation, as proposed for potato tubers (Crowell et al., 2008). The same may occur in roots, where $\alpha$-tocopherol content was even lower than in nodules (10.6, 2.7 and $2.1 \mu \mathrm{gDW}^{-1}$ in pea, soybean and alfalfa, respectively). In this tissue, another reason for the lower accumulation of $\alpha$-tocopherol could be the lower risk of oxidative damage in roots, compared to nodules and leaves (Escudero et al., 1996). It is interesting to note that indeterminate nodules (from alfalfa and pea plants) showed much higher concentrations of $\alpha$-tocopherol than those of determinate nodules (soybean). This suggests that the nodule meristem, which persists and continuously produces newly divided (i.e. uninfected) cells at the elongating nodule tip, plays a key role in the production of pro-plastids that will continuously form nodule plastids containing high contents of tocopherols for an adequate protection of the nodule from oxidative stress. Alternatively, it is also tempting to speculate that meristems make indeterminate nodules stronger sinks than determinate nodules for source (leaves) to sink (nodule) remobilization of vitamin E, or its precursors, through the phloem (for a hypothetical model of this process, see Muñoz and Munné-Bosch, 2019; see also Pellaud and MèneSaffrané, 2017 for the possible role of precursors), an aspect that warrants further investigation.

\subsection{Vitamin $E$ reduces the extent of lipid peroxidation in nodules}

Changes in foliar $\alpha$-tocopherol levels under water stress conditions have been extensively reported previously (Munné-Bosch, 2005). Whereas drought-tolerant plants usually show increased $\alpha$-tocopherol contents, sensitive ones display tocopherol losses, leading to oxidative damage. Here, we studied how water limitation influences $\alpha$-tocopherol content in underground tissues, especially in the nodules, in comparison to roots (excluding nodules) and leaves. Relative water content (RWC), used as a measure of water stress severity, decreased under stress in all studied organs and species (Fig. 2A). Nodules and roots were the most affected organs and alfalfa the species with the greatest observed decrease in the RWC (Fig. 2A). Nodule performance, as estimated by ${ }^{15} \mathrm{~N}$ isotope labeling $\left(\delta^{15} \mathrm{~N}\right)$, also decreased under water deficit conditions in the three species (Fig. 2B). Increased $\alpha$-tocopherol content was observed in soybean leaves, roots and nodules, and only in this legume did $\alpha$-tocopherol accumulation increased under waterlimited conditions (Fig. 3). This stress-induced increase in $\alpha$-tocopherol accumulation in nodules should imply lower lipid peroxidation and membrane damage; therefore, TBARS accumulation was expected to be 


\section{(A) NODULES}

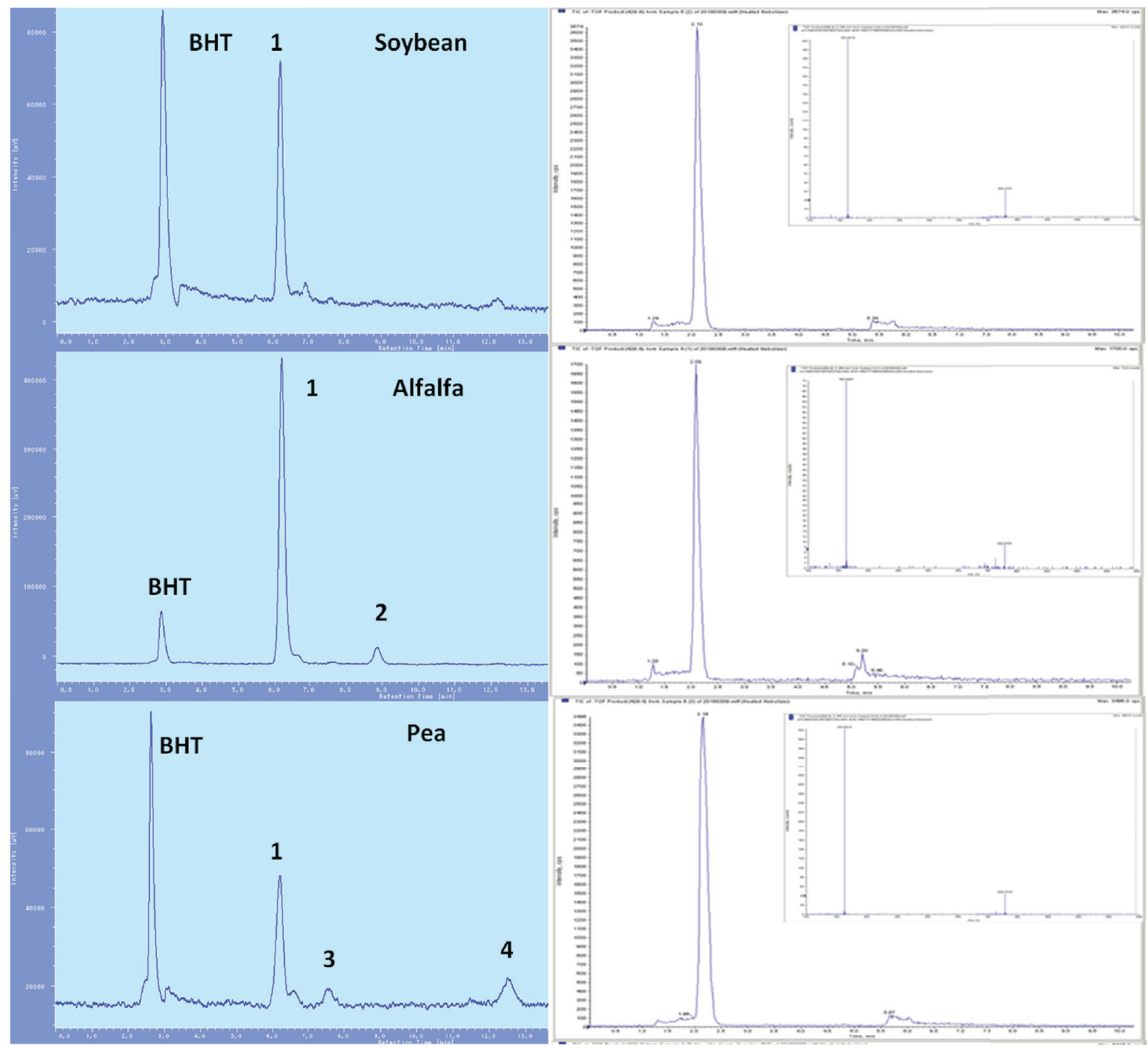

(B)

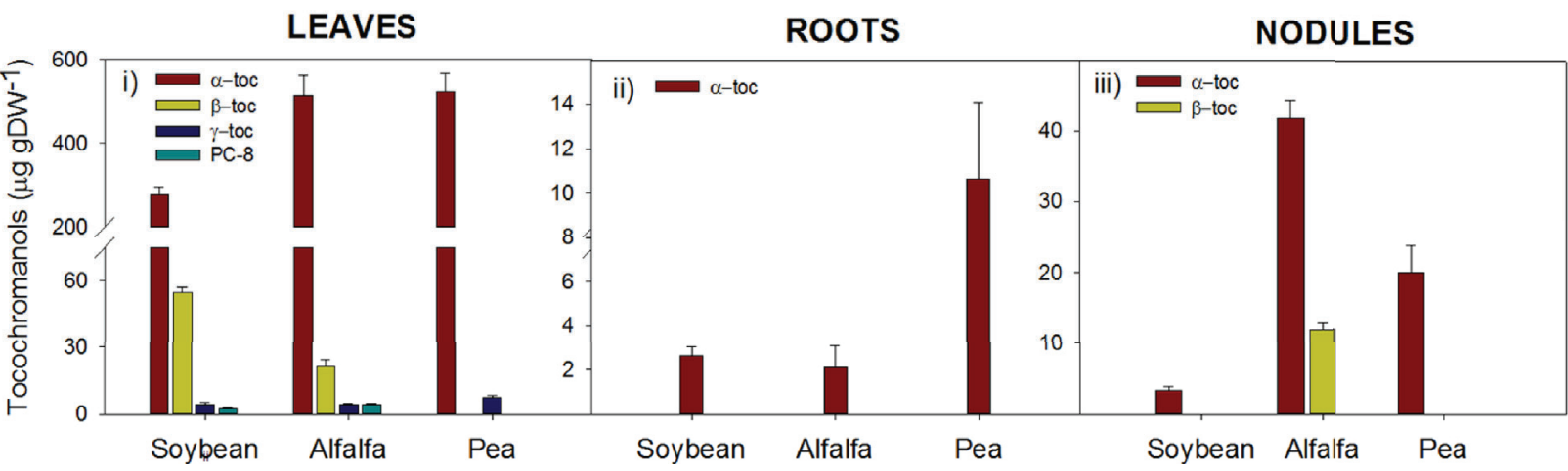

Fig. 1. Identification and quantification of tocochromanols in legume nodules. (A) HPLC chromatograms (left) and LC-MS/MS identification (right) of $\alpha$-tocopherol in nodules of soybean, alfalfa and pea plants. Precursor and product ion $\mathrm{m} / \mathrm{z}$ used for LC-MS/MS identification was 430/163.1) $\alpha$-tocopherol, 2) $\beta$-tocopherol, 3) unknown, 4) unknown. (B) Quantification of tocochromanols in leaves, roots and nodules of three studied legumes (soybean, alfalfa and pea plants). Data represent the mean \pm SE of $n=10$. Although peaks 3 and 4 found in pea nodules co-eluted with $\alpha$ - and $\gamma$-tocotrienol, respectively, in the HPLC chromatogram, they could not be confirmed by LC-MS/MS. BHT, butylated hydroxytoluene.

lower than in alfalfa and pea. However, soybean was the studied legume with the larger TBARS content in nodules (Fig. 4); this could be related to the presence of the aforementioned determinate nodules and the consequent low steady level of $\alpha$-tocopherol in this species (Fig. 3).
On the other hand, nodules of alfalfa and pea did not change their nodule $\alpha$-tocopherol accumulation during water stress (Fig. 3). Nonetheless, TBARS content also remained constant under drought, and lower than in soybean (Fig. 4). The fact that soybean has determinate 
(A)
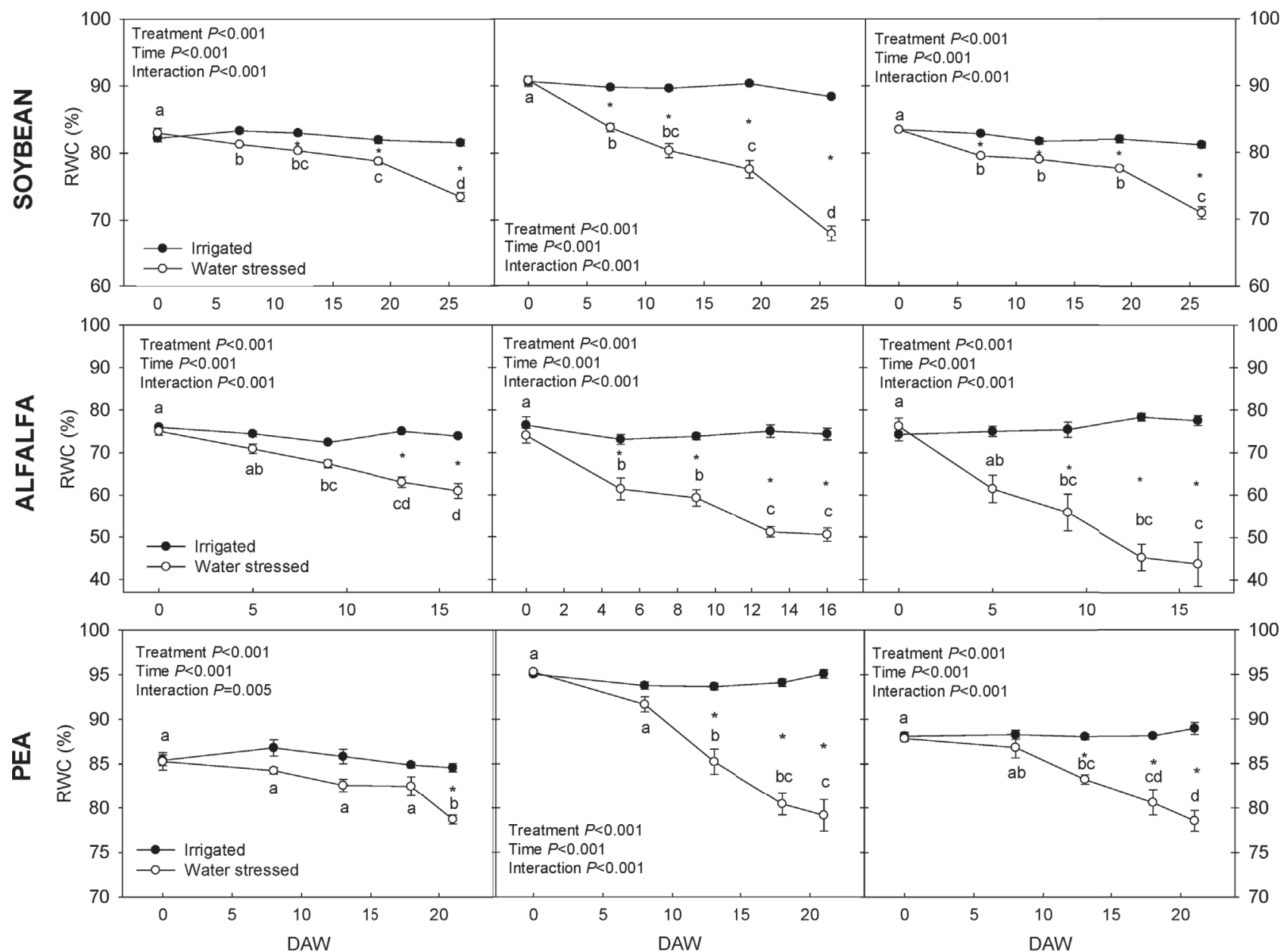

(B)

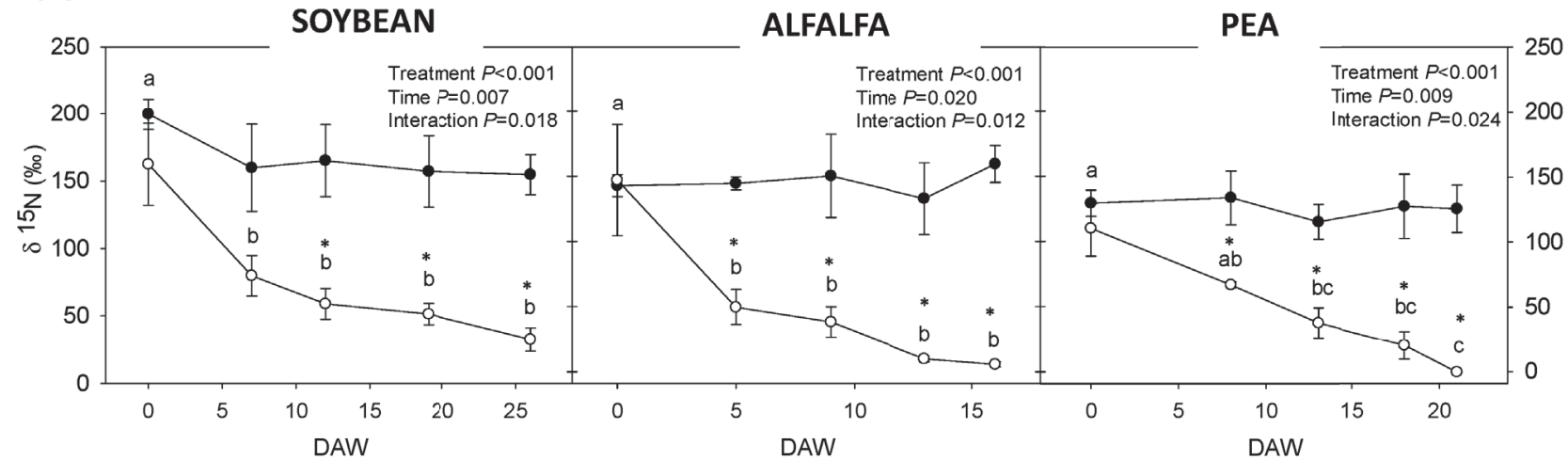

Fig. 2. Water deficit stress effects on the relative water content of leaves, roots and nodules and ${ }^{15} \mathrm{~N}$ isotope labeling in nodules of soybean, alfalfa and pea plants. (A) Relative water content (RWC) of leaves, roots and nodules of soybean, alfalfa and pea plants (from top to bottom). Data correspond to the mean \pm SE of $n=5$ individuals. Results of statistics are shown (two-way ANOVA, $P<0.05)$. (B) ${ }^{15} \mathrm{~N}$ isotope labeling $\left(\delta^{15} \mathrm{~N}\right)$ in nodules of irrigated and water-stressed plants in soybean, alfalfa and pea. Data correspond to the mean \pm SE of $n=4$. Results of statistics are shown (two-way ANOVA, $P<0.05$ ). An asterisk indicates significant differences between water-stressed and irrigated plants. Letters indicate significant differences over time in water-stressed plants (Tukey posthoc test $P<0.05)$. NS, not significant. DAW, days after water withdrawal in water-stressed plants.

nodules, in contrast to alfalfa and pea which have indeterminate nodules, may therefore be one of the major factors explaining the differences in vitamin $\mathrm{E}$ and its response to drought stress.

To evaluate the relationship between vitamin $\mathrm{E}$ and the extent of lipid peroxidation in legumes, a correlation analysis between $\alpha$-tocopherol accumulation and TBARS levels was carried out for the three studied organs of the three species (Fig. 5). In nodules, when all data were pooled together, we observed that the correlation between $\alpha$-tocopherol and TBARS was strongly significant and negative $(\mathrm{r}=-0.767 ; P<0.001)$ (Fig. 5A). These results showed that in general greater tocopherols levels implied lower lipid peroxidation, thus supporting the idea that $\alpha$-tocopherol acts as an antioxidant in nodules, protecting against lipid peroxidation and thereby avoiding membrane damage caused by ROS. Similarly, in roots, pea plant was 

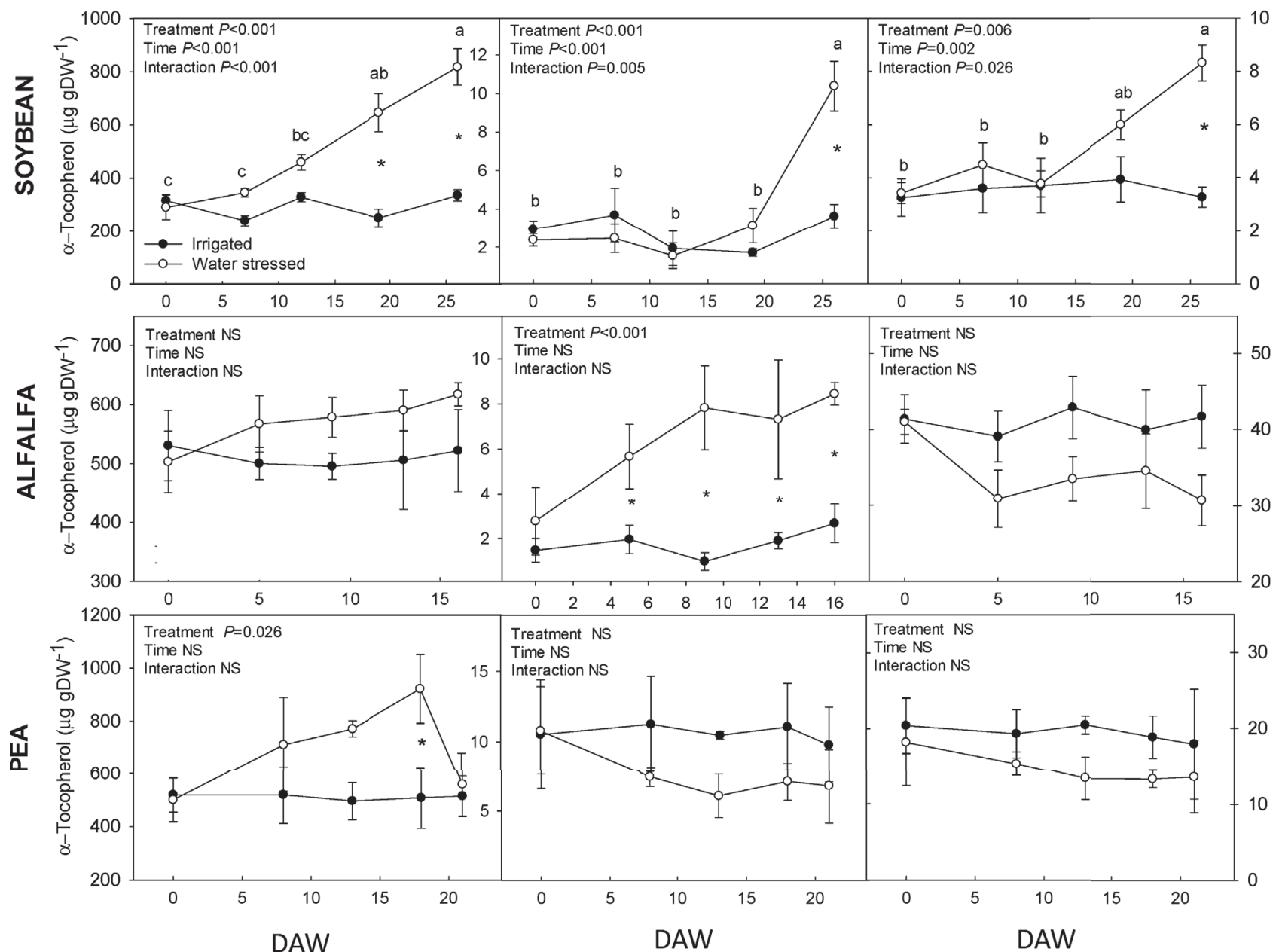

Fig. 3. Differential effects of water deficit stress on $\alpha$-tocopherol content of leaves, roots and nodules of soybean, alfalfa and pea plants. $\alpha$-Tocopherol content in leaves, roots and nodules of soybean, alfalfa and pea plants (from top to bottom). Data correspond to the mean \pm SE of $n=5$ individuals. Results of statistics are shown (two-way ANOVA, $P<0.05$ ). An asterisk indicates significant differences between water-stressed and irrigated plants. Letters indicate significant differences over time in water-stressed plants (Tukey posthoc test $P<0.05$ ). NS, not significant. DAW, days after water withdrawal in water-stressed plants.

the species with the highest content of $\alpha$-tocopherol $(\sim 10-12 \mu \mathrm{g}$ $\mathrm{gDW}^{-1}$ ) and, at the same time, where the lipid peroxidation was lower compared with the other two species, suggesting an active role for $\alpha$ tocopherol in protecting against lipid peroxidation. This observation was confirmed when the correlation between $\alpha$-tocopherol and TBARS in the roots of the three studied species was analyzed, producing a significant and negative correlation $(\mathrm{r}=-0.490 ; P<0.001)$ (Fig. 5A). Interestingly, this correlation was not observed for leaves, which may be attributed to the fact that chloroplasts have additional and more complex mechanisms of antioxidant protection compared to plastids of roots and nodules.

Before harvest, the root/nodule zone was enriched with ${ }^{15} \mathrm{~N}_{2}$, therefore, the higher the labeled ${ }^{15} \mathrm{~N}$ incorporation (measured as stable ${ }^{15} \mathrm{~N}$ isotope composition $\left(\delta^{15} \mathrm{~N}\right)$ ) in nodule tissue, the greater the biological nitrogen fixation. We used this parameter as a measure of nodule performance, showing a significant drop in all species under drought conditions (Fig. 2B). Nodule nitrogen fixation is inhibited under drought conditions due to, among other reasons, the effect of oxidative damage (Naya et al., 2007; Aranjuelo et al., 2014). When data on $\alpha$-tocopherol and nodule performance $\left(\delta^{15} \mathrm{~N}\right)$ were pooled together, the correlation was significant and positive, but weak $(r=0.284$, $P=0.021$ ) (Fig. 5B). Interestingly, this correlation was much stronger when data from alfalfa nodules, alone, were considered $(r=0.663$, $P<0.001)$. This means that an increase in nodule performance, and therefore of nodule nitrogen fixation, occurred when $\alpha$-tocopherol contents were enhanced, particularly in alfalfa. Taken together, results support the idea that vitamin $\mathrm{E}$ acts as a powerful antioxidant in legume nodules, protecting plastids against membrane lipid peroxidation, and may promote nodule performance in legumes.

\section{Conclusions}

It is concluded that (i) tocochromanols are present in underground tissues of contrasting legume genera, mainly in the $\alpha$-tocopherol form, (ii) the variation in $\alpha$-tocopherol content under drought conditions depends on the plant species, organ studied and type of nodule, and (iii) $\alpha$-tocopherol might protect legume nodules against lipid peroxidation and eventually improve their performance. Further research is needed, however, to better understand the regulatory mechanisms governing the accumulation of vitamin $\mathrm{E}$ in these non-photosynthetic tissues.

\section{Experimental}

\subsection{Plant material, treatments and sampling}

The experiment was conducted on three legume species: soybean (Glycine max L.), alfalfa (Medicago sativa L.) and pea plants (Pisum sativum L.). Seeds were germinated in Petri dishes and after germination 

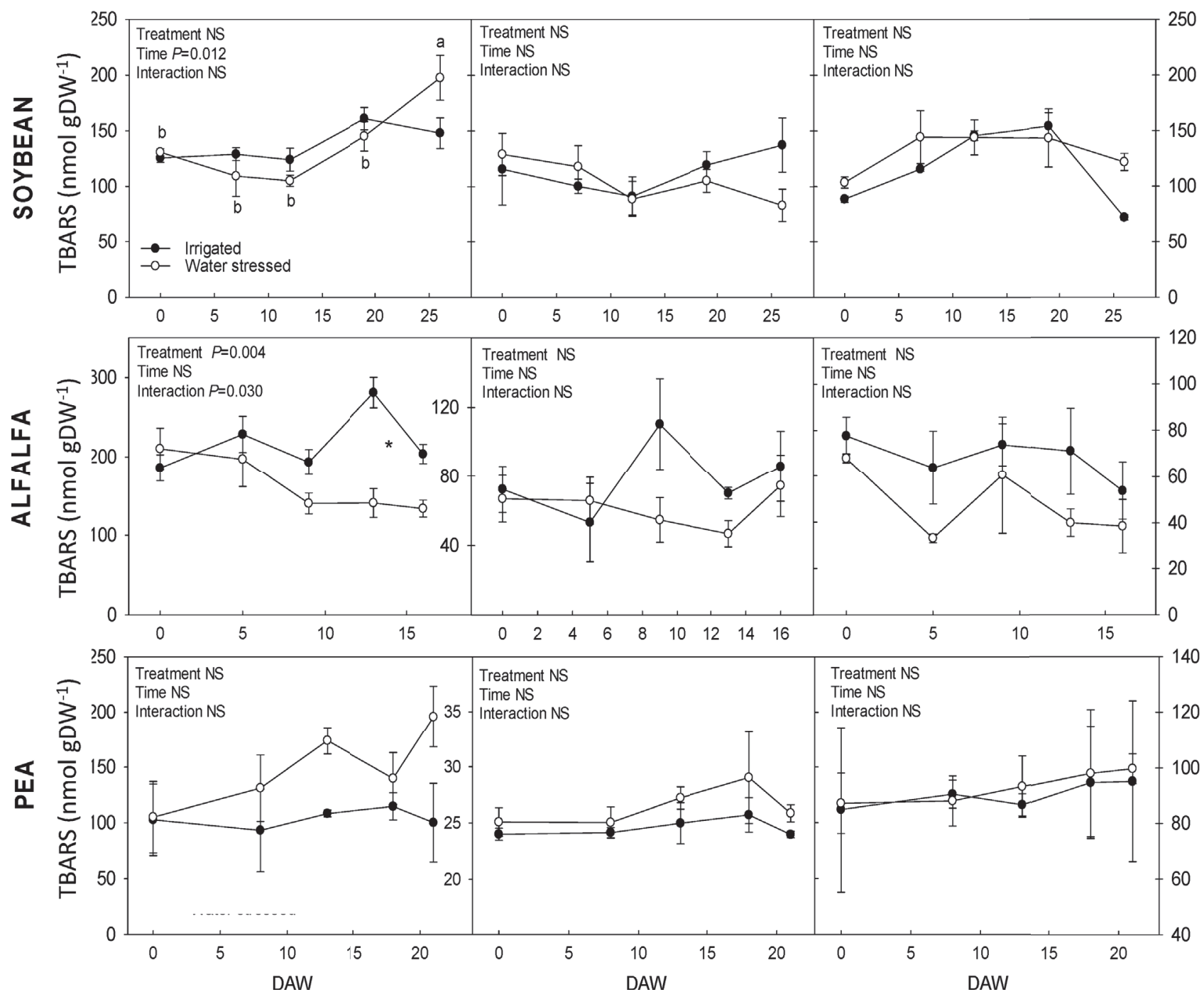

Fig. 4. Differential effects of water deficit stress on the extent of lipid peroxidation, estimated as thiobarbituric acid-reactive substances (TBARS) content, in leaves, roots and nodules of soybean, alfalfa and pea plants (from top to bottom). Data correspond to the mean \pm SE of $n=5$ individuals. Results of statistics are shown (two-way ANOVA, $P<0.05$ ). An asterisk indicates significant differences between water-stressed and irrigated plants. Letters indicate significant differences over time in water-stressed plants (Tukey posthoc test $P<0.05$ ). NS, not significant. DAW, days after water withdrawal in water-stressed plants.

the plants were transplanted to $3 \mathrm{~L}$ black pots containing a substrate filled with 2:1 (v/v) perlite/vermiculite. Four plants per pot were grown in the case of alfalfa and two plants per pot for soybean and pea. Two weeks after sowing, plants were inoculated twice with their symbiotic bacteria. To ensure that the sole $\mathrm{N}$ source was $\mathrm{N}_{2}$ fixed by nodules, the plants were watered twice a week with an $\mathrm{N}$-free nutrient solution with the following composition (mEq/L): $\mathrm{KH}_{2} \mathrm{PO}_{4}, 2 ; \mathrm{MgSO}_{4}$, 1.5; KCI, 3; $\mathrm{CaCl}_{2}, 1.5$; NaFeEDTA, 0.12; and microelements as recommended by Hoagland and Arnon (1950). When soybean and pea plants were 43-days old and alfalfa plants were 74-days old, half of the plants (randomly selected) were exposed to drought conditions by withholding watering, whereas the others were maintained in optimal water conditions. The experiment was conducted on six pots of each combination, with two treatments (control and drought) and sample collection at five points after water withdrawal. During the whole experiment, the plants were grown in a controlled greenhouse at $25 / 18{ }^{\circ} \mathrm{C}$ (day/night), under natural daylight, at the Institute of Agrobiotechnology (42.80 N, $1.66 \mathrm{~W}$; Pamplona, Spain). For tocochromanol and TBARS analysis, samples of leaves, roots and nodules were collected on five different days after the water suppression (these days were different for each species). The samples were immediately frozen in liquid nitrogen and stored at $-80{ }^{\circ} \mathrm{C}$ until analysis. A subsample of each organ was separated and dried in an oven for $48 \mathrm{~h}$ at $60{ }^{\circ} \mathrm{C}$, in order to determine dry weight and nitrogen isotope fraction $\left(\delta^{15} \mathrm{~N}\right)$.

\subsection{Water status, isotope labeling and determination of $\delta^{15} \mathrm{~N}$}

The water status of organs was evaluated by measuring the leaf, root and nodule RWC as described (Cela et al., 2011). Before harvesting, three pots of each treatment were selected for ${ }^{15} \mathrm{~N}_{2}$ labeling. The pots containing these plants were placed within a hand-made labeling chamber and closed hermetically. $25 \mathrm{~mL}$ of ${ }^{15} \mathrm{~N}_{2}$ enriched at 98 ATOM $\%$, provided by Cambridge Isotope Laboratories, Inc. (Andover, USA), was then injected into the root zone using a gas syringe (SGE Analytical Science Pty. Ltd., Australia). The injection of enriched ${ }^{15} \mathrm{~N}_{2}$ was conducted $4 \mathrm{~h}$ before harvest and $3 \mathrm{~h}$ after the beginning of the daily light period, coinciding with the period of largest $\mathrm{N}_{2}$ fixation activity. Nonlabeled plants were maintained at ambient $\mathrm{N}_{2}$ air conditions. Measurements of stable ${ }^{15} \mathrm{~N}$ isotope ratios were performed using a continuous-flow isotope-ratio mass spectrometer Deltaplus 
(A)
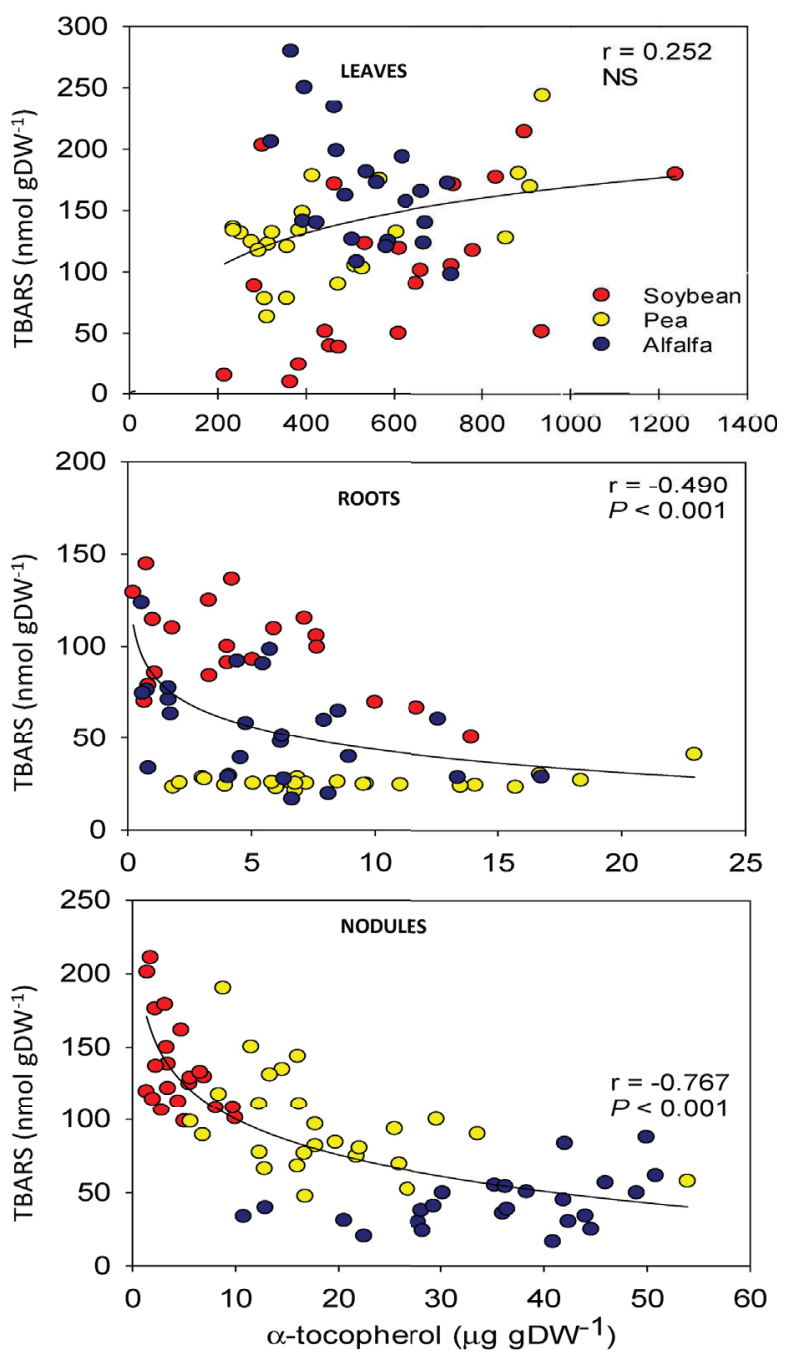

(B)

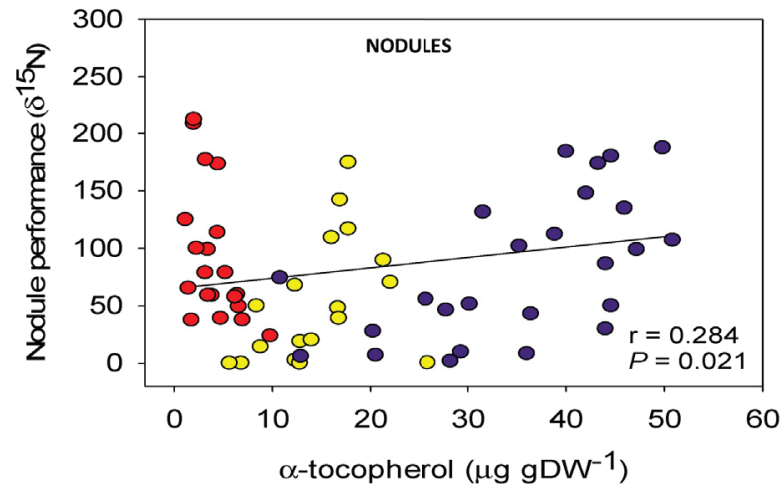

Fig. 5. Correlation analyses between $\alpha$-tocopherol contents, lipid peroxidation and nodule performance in soybean, alfalfa and pea plants. (A) Pearson's correlation analysis between $\alpha$-tocopherol and thiobarbituric acid-reactive substances (TBARS) contents in leaves, roots and nodules. (B) Pearson's correlation analysis between $\alpha$-tocopherol and nodule performance, as estimated by ${ }^{15} \mathrm{~N}$ isotope labeling $\left(\delta^{15} \mathrm{~N}\right)$ in nodules. $P$ values and correlation coefficients $(\mathrm{r})$ are shown.

(ThermoFinnigan) coupled to an elemental analyzer FlashEA1112 (ThermoFinniganInstruments) through a Conflo II interface (ThermoFinnigan).

\subsection{Tocochromanol contents and lipid peroxidation}

For analyses of tocochromanol content, leaf, root and nodule samples (100 mg) were ground in liquid nitrogen and extracted for $30 \mathrm{~min}$ with cold methanol (v/v) containing $0.01 \%(\mathrm{w} / \mathrm{v})$ butylated hydroxytoluene (BHT) using ultrasonication. After centrifuging at $6.000 \mathrm{~g}$ for $10 \mathrm{~min}$ at $4{ }^{\circ} \mathrm{C}$, the supernatant was collected and the pellet re-extracted again with the same solvent; then, supernatants were pooled, filtered, and injected into the HPLC. Tocochromanols were separated isocratically on a normal-phase HPLC system using a fluorescent detector, as described. Identification of tocochromanols was confirmed by LCMS/MS. The MS acquisition was performed using negative ionization between $\mathrm{m} / \mathrm{z} 100$ and 650 , with the Turbo Ionspray source. In addition, QqToF was used to obtain product ion information. The MS parameters were: ion spray voltage, -4200 ; declustering potential (DP), -40 ; focusing potential (FP), -150 ; declustering potential two (DP2), -10 ; ion release delay (IRD), $6 \mathrm{~V}$; ion release width (IRW), $5 \mathrm{~ms}$; nebulizer gas, 50 (arbitrary units); curtain gas, 60 (arbitrary units), and auxiliary gas $\mathrm{N} 2,6000 \mathrm{~cm} 3 \mathrm{~min}-1$ heated at $500{ }^{\circ} \mathrm{C}$.

The extent of lipid peroxidation was estimated by measuring the levels of malondialdehyde in leaves, roots and nodules, following the TBARS assay, considering the effect of potential interfering compounds, as described (Hodges et al., 1999).

\subsection{Statistical analysis}

Statistical analyses were performed with IBM SPSS Statistics for Windows, Version 20.0. (IBM Corp. Armonk, NY). Statistical differences between measurements of the different treatments and times were evaluated with analyses of variance (ANOVA). Tukey post hoc tests were used to determine statistical differences between treatments. The significance of correlations was tested using Pearson's correlation analysis. Differences were considered to be statistically significant at $P<0.05$.

\section{Author contributions}

D.S. and S.M.-B. designed research with the help of I.A. and M.M.; D.S. and M.M. performed research; D.S. and M.M. analyzed data with the help of I.A. and S.M.-B.; and D.S. and S.M.-B. wrote the paper.

\section{Declaration of competing interest}

The authors declare no competing interests.

\section{Acknowledgements}

We thank the Serveis Científico-tècnics and Serveis de Camps Experimentals (University of Barcelona, Spain) for technical support, and Christopher Evans for English correction of the text. D.S. is a recipient of a PhD fellowship from the Public University of Navarra. This work was supported by the Spanish Government (BFU2015-64001-P/ MINECO/FEDER grant) and the Catalan Government (ICREA Academia award given to S.M.-B.)

\section{References}

Abbasi, A.R., Saur, A., Hennig, P., Tschiersch, H., Hajirezaei, M., Hofius, D., Sonnewald, U., Voll, L.M., 2009. Tocopherol deficiency in transgenic tobacco (Nicotiana tabacum L.) plants leads to accelerated senescence. Plant Cell Environ. 32, 144-157.

Apel, K., Hirt, H., 2004. Reactive oxygen species: metabolism, oxidative stress, and signal transduction. Annu. Rev. Plant Biol. 55, 373-399.

Aranjuelo, I., Arrese-Igor, C., Molero, G., 2014. Nodule performance within a changing environmental context. J. Plant Physiol. 171, 1076-1090.

Becana, M., Matamoros, M.A., Udvardi, M., Dalton, D.A., 2010. Recent insights into antioxidant defenses of legume root nodules. New Phytol. 188, 960-977.

Boonnoy, P., Kartunnen, M., Wong-ekkabut, J., 2018. Does $\alpha$-tocopherol flip-flop help to protect membranes against oxidation? J. Phys. Chem. B 122, 10362-10370. 
Cela, J., Chang, C., Munné-Bosch, S., 2011. Accumulation of $\gamma$ - rather than $\alpha$-tocopherol alters ethylene signaling gene expression in the vte4 mutant of Arabidopsis thaliana. Plant Cell Physiol. 52, 1389-1400.

Crawford, N.M., Kahn, M.L., Leustek, T., Long, S.R., 2015. Nitrogen and sulfur. In: Buchanan, B.B., Gruissem, W., Jones, R.L. (Eds.), Biochemistry and Molecular Biology of Plants. American Society of Plant Biologists, Rockville, MA.

Crowell, E.F., McGrath, J.M., Douches, D.S., 2008. Accumulation of vitamin E in potato (Solanum tuberosum) tubers. Transgenic Res. 17, 205-217.

Escudero, P.R., Minchin, F.R., Gogorcena, Y., Iturbe-Ormaetxe, I., Klucas, R.V., Becana, M., 1996. Involvement of activated oxygen in nitrate-induced senescence of pea root nodules. Plant Physiol. 110, 1187-1195.

Evans, P.J., Gallesi, D., Mathieu, C., Hernández, M.J., de Felipe, M., Halliwell, B., Puppo, A., 1999. Oxidative stress occurs during soybean nodule senescence. Planta 208 , 73-79.

Falk, J., Munné-Bosch, S., 2010. Tocochromanol functions in plants: antioxidation and beyond. J. Exp. Bot. 61, 1549-1566.

Farmer, E.E., Mueller, M.J., 2013, ROS-mediated lipid peroxidation and RES-activated signaling. Annu. Rev. Plant Biol. 64, 429-450.

Garcia, I., Rodgers, M., Pepin, R., Hsieh, T.F., Matringe, M., 1999. Characterization and subcellular compartmentation of recombinant 4-hydroxyphenylpyruvate dioxygenase from Arabidopsis in transgenic tobacco. Plant Physiol. 119, 1507-1516.

Gogorcena, Y., Gordon, A.J., Escudero, P.R., Minchin, F.R., Witty, J.F., Moran, J.F. Becana, M., 1997. $\mathrm{N}_{2}$ fixation, carbon metabolism, and oxidative damage of darkstressed common bean plants. Plant Physiol. 113, 1193-1201.

Gogorcena, Y., Iturbe-Ormaetxe, I., Escuredo, P.R., Becana, M., 1995. Antioxidant defenses against activated oxygen in pea nodules subjected to water stress. Plant Physiol. 108, 753-759.

Havaux, M., Eymery, F., Porfirova, S., Rey, P., Dörmann, P., 2005. Vitamin E protects against photoinhibition and photooxidative stress in Arabidopsis thaliana. Plant Cell $17,3451-3469$.

Hoagland, D.R., Arnon, D.I., 1950. The water-culture method for growing plants without soil. California Agricult. Exp. Stat. 347, 1-32

Hodges, D.M., DeLong, J.M., Forney, C.F., Prange, R.K., 1999. Improving the thiobarbituric acid-reactive-substances assay for estimating lipid peroxidation in plant tissues containing anthocyanin and other interfering compounds. Planta 207, 604-611.

Hofius, D., Hajirezaei, M., Geiger, M., Tschiersch, H., Melzer, M., Sonnewald, U., 1999.
RNAi-mediated tocopherol deficiency impairs photoassimilate export in transgenic potato plants. Plant Physiol. 135, 1256-1268.

Kruk, J., Szymanska, R., Cela, J., Munné-Bosch, S., 2014. Plastochromanol-8: fifty years of research. Phytochemistry 108, 9-16.

Maeda, H., Song, W., Sage, T.L., DellaPenna, D., 2006. Tocopherols play a crucial role in low-temperature adaptation and phloem loading in Arabidopsis. Plant Cell 18, $2710-2732$.

Maeda, H., DellaPenna, D., 2007. Tocopherol functions in photosynthetic organism. Curr. Opin. Plant Biol. 10, 260-265.

Moran, J.F., Becana, M., Iturbe-Ormaetxe, I., Frechilla, S., Klucas, R.V., Aparicio-Tejo, P., 1994. Drought induces oxidative stress in pea plants. Planta 194, 346-352.

Munné-Bosch, S., 2005. The role of $\alpha$-tocopherol in plant stress tolerance. J. Plant Physiol. $162,743-748$.

Muñoz, P., Munné-Bosch, S., 2019. Vitamin E in plants: biosynthesis, transport, and function. Trends Plant Sci. https://doi.org/10.1016/j.tplants.2019.08.006.

Naya, L., Ladrera, R., Ramos, J., González, E.M., Arrese-Igor, C., Minchin, F.R., Becana, M., 2007. The response of carbon metabolism and antioxidant defenses of alfalfa nodules to drought stress and to the subsequent recovery of plants. Plant Physiol. $144,1104-1114$.

Pellaud, S., Mène-Saffrané, L., 2017. Metabolic origins and transport of vitamin E biosynthetic precursors. Front. Plant Sci. 8, 1959.

Sattler, S.E., Gilliland, L.U., Magallanes-Lundback, M., Pollard, M., DellaPennaa, D., 2004. Vitamin E is essential for seed longevity and for preventing lipid peroxidation during germination. Plant Cell 16, 1419-1432.

Schmidhuber, J., Tubiello, F.N., 2007. Global food security under climate change. Proc. Natl. Acad. Sci. U.S.A. 104, 19703-19708.

Swaraj, K., Dhandi, S., Sheokand, S., 1995. Relationship between defense mechanism against activated oxygen species and nodule functioning with progress in plant and nodule development in Cajanus cajan L Mill sp. Plant Sci. 112, 65-74.

Szymanska, R., Kruk, J., 2008. Tocopherol content and isomers' composition in selected plant species. Plant Physiol. Biochem. 46, 29-33.

Vidi, P., Kanwischer, M., Baginsky, S., Austin, J.R., Csucs, G., Dörmann, P., Kessler, F., Bréhélin, C., 2006. Tocopherol cyclase (VTE1) localization and vitamin E accumulation in chloroplast plastoglobule lipoprotein particles. J. Biol. Chem. 281 $11225-11234$. 
upna

Universicad Publica de Navara
Natarsaako Unibersitate Publikoa 
"VI. CHAPTER 4

upna 
upna

Universidad Pubica ce Navaraa
Natarsacko Unibersitate Publikoa 


\title{
Additive effect of heatwave and water stresses on soybean seed yield is caused by impaired carbon assimilation at pod formation but not at flowering
}

\author{
David Soba ${ }^{1}$, Cesar Arrese-Igor ${ }^{2}$, Iker Aranjuelo $^{1^{*}}$ \\ ${ }^{1}$ Instituto de Agrobiotecnología (IdAB), Consejo Superior de Investigaciones Científicas \\ (CSIC)-Gobierno de Navarra, Av. Pamplona 123, 31192, Mutilva, Spain. \\ ${ }^{2}$ Institute for Multidisciplinary Research in Applied Biology (IMAB), Universidad Pública de \\ Navarra (UPNa), Campus Arrosadia, Pamplona, 31006, Spain \\ *Corresponding autor e-mail: iker.aranjuelo@csic.es
}

\section{Abstract}

Heatwave (HW) combined with water stress (WS) are critical environmental factors negatively affecting crop development, particularly, during reproductive stages. This study aimed to quantify the individual and combined effects of HW and WS during early reproductive stages on leaf and nodule functioning and their relation with final soybean seed yield (SY). For this purpose, during flowering (R2) and pod formation (R4) soybean (Glycine max L. Merr) plants were exposed to different temperature (ambient $-25^{\circ} \mathrm{C}$ versus $\mathrm{HW}-40^{\circ} \mathrm{C}$ ) and water availability capacity versus WS-20\% of the field capacity). HW, WS and their interacting impact on yield depended on the phenological stage at which the stress was applied being more affected at R4. On gas exchange, HS alone did not show a clear effect, while WS severely impaired photosynthetic machinery, especially when combined with HS. Impaired photoassimilates supply at flowering caused flower abortion and a significant reduction of final SY on interacting stresses and WS. On the other hand, at pod formation (R4), decreased leaf performance caused additive effect on SY by decreasing pod setting and seed size in combined stresses but not when the stresses occurs alone. At nodule level, WS (alone or in combination with HW) caused nodule impairment reflected in a lower leaf N. Such response was linked with a poor malate supply to the bacteroids and the consequent feed-back inhibition process caused by nitrogenous compounds accumulation. In summary, our study remarked that sensitivity of soybean to interacting heat and water stresses is highly conditioned by the phenologic stage in which it occurs, 
being R4 stage (still pod setting and starting of grain filling) a critical moment. To our knowledge this is the first work integrating combined stresses at early reproductive stages on soybean.

Keywords: heatwave, water stress, interacting stresses, C and $\mathrm{N}$ metabolism, photosynthesis, nodule, soybean.

\section{INTRODUCTION}

Soybean (Glycine $\max$ (L.) Merr.) is the most cultivated legume with over 124.9 million hectares worldwide and the fourth most important crop in terms of seed production (i.e., 349 million tons produced in 2018) (FAOSTAT, 2020). This legume is a rich source of high quality proteins and oil for livestock and human consumption (Ainsworth et al., 2012; Medic et al., 2014). However, soybean production is severely limited by several abiotic factors (Raza et al., 2020; Ostmeyer et al., 2020). Among them, exposure to periods of extreme heat, or heatwaves, is recurrent in the main soybean production area (Deryng et al., 2014; Perkins, 2015; Herritt and Fritschi, 2020). Additionally, since great part of the cultivation area is rainfed, lack of precipitation is the other limiting factor affecting soybean production (Liu et al., 2004).

Indeed, high-temperature and water stress are the most influential climate variables that negatively affect plant growth and development, causing significant yield losses on a global scale (Matiu et al., 2017). In legumes, the effects of heat (Nahar et al., 2016) and water (Farooq et al., 2009) stresses on have been studied widely in isolation, but their potential combined impact is less clearly defined (Awasthi et al., 2014). Plant responses to heat and water stress have much in common and mainly depend on the growth stage and the duration and intensity of the stress (Farooq et al., 2017). Overall, at leaf level, both stresses decrease photosynthesis rate, due not only to an increase of internal resistance to $\mathrm{CO}_{2}$ diffusion caused by stomatal closure, but also due to an increase in photodamage of the photosystem II (PSII) and an increase of leaf temperature, thus favoring ribulose-1,5-bisphosphete carboxylase/oxigenase (Rubisco) oxygenase activity (Prasad et al., 2008, Ergo et al., 2018). At legume nodule level, water stress has been widely reported to decrease nitrogenase activity by reducing carbohydrate and $\mathrm{O}_{2}$ availability to the bacteroid and by increasing accumulation of $\mathrm{N}$ compound and oxidative stress (Aranjuelo et al., 2008; Larrainzar et al., 2009; Soba et

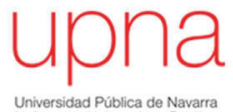


al., 2019). However nodule functioning under heat, and in special under combined stresses, has not been characterized in detail, highlighting the necessity to conduct further studies considering these factors (Aranjuelo et al., 2014).

In terms of productivity, both stresses impair legume grain yield at all growth stages. However, damage during the reproductive stages, flowering and pod formation and filling, are the major reason for yield loss (Pushpavalli et al., 2014; Sehgal et al., 2018). Yield losses during reproductive stages has been directly linked to a decrease in photosynthetic performance, resulting in a poor synthesis/translocation of assimilates to flowers and pods that causes a poor pollination and higher rates of flower abortion and, during pod and grain filling, poor cell division resulting in fewer and smaller seeds both in high temperature (Puteh et al., 2013; Djanaguiraman and Prasad, 2010; Bhandari et al., 2016) and water stress (Farooq et al., 2017; Du et al., 2020). Additionally, number of pollen grains, their composition and viability is highly sensitive to high temperature (Djanaguiraman et al. 2013) and water stress (Al-Ghzawi et al., 2009), leading to decreased pod set percentage. As a final consequence, both stresses negatively affects seed yield (SY) and their components such as number of pods per plant (PN), number of seeds (SN) or thousand seed weight (TSW) (Egli et al., 2005; Puteh et al., 2013).

As shown, the influence on physiological and metabolic processes of heat and water stress as single-stress factors on soybean are well documented; however, studies focused on the effects of combined stresses, especially short periods of extreme heat (heatwaves), are scarce. Nonetheless, this two abiotic stresses often occur together and is expected to increase in the near future (Schär et al., 2004; Vautard et al., 2007; IPCC, 2014). Previously works show that pathways regulating plant responses to heat and water stress are largely distinct (Rizhsky et al., 2004) and that we cannot extrapolate plant responses to stress combinations simply by the addition of responses to the two single stresses (Mittler, 2006; Ahmed et al., 2013; Zandalinas et al., 2018). In general, a more severe impact on physiology and yield in heat and water stress combination has been shown when compared to heat or water stress alone (Balfagón et al., 2020). This emphasizes the need to study this stresses combination to identify traits that confer tolerance to heat and water stress in order to develop more tolerant varieties (Rizhsky et al., 2004; Zandalinas et al., 2018; Cohen et al., 2021). In legumes, the effects on physiological and yield parameters of heat and water stress in combination have been 
studied in some species, e.g., peanut (Arachis hypogea L.) (Hamidou et al., 2013), chickpea (Cicer arietinum L.) (Canci and Toker, 2009; Awasthi et al., 2014), lentil (Lens culinaris Medikus) (Sehgal et al., 2017) and soybean (Jumrani and Singh, 2018; Ergo et al., 2018). However, the specific effect of heatwave alone or in combination with water deficit has not been addressed yet. Additionally, great part of the combination stresses studies have been focus on grain filling period (R5) and there is a lack of studies during the previous key reproductive stages, from the beginning flowering to full pod formation (R1-R4). Finally, in legumes, nodule performance under combined stresses and their relation with flowering and seed formation is a clear gap demanding more attention.

Therefore, understanding the effect of heatwave, water stress and their interaction at flowering and full pod stages on developmental and biochemical processes at leaf and nodule level is valuable to grain yield improvement for future climatic conditions. With this in mind, the present study aimed to i) analyse the effects of heatwave and water stress (alone or in combination) on soybean leaf and nodule performance during flowering and pod formation; ii) link these effects on leaf and nodule functioning at these specific stages with final soybean seed yield.

\section{MATERIALS AND METHODS}

\subsection{Plant Material and Experimental Design}

The experiment was conducted with Sumatra soybean cultivar (Glycine max (L.) Merr.). Sumatra is a maturity group I cultivar and is the cultivar for human consumption most cultivated in Spain. Seeds were germinated in Petri dishes and, after germination, the plants were transplanted to $3 \mathrm{~L}$ black pots (one plant per pot) containing a substrate filled with 2:1 $(v / v)$ perlite/vermiculite. The experiment was conducted with ten pots of each combination ( 80 pots in total) in a controlled greenhouse at $25 / 18 \cdot{ }^{\circ} \mathrm{C}$ (day/night) under natural daylight. The greenhouse was located at the Institute of Agrobiotechnology (IdAB) $\left(42^{\circ} 47^{\prime} \mathrm{N}, 1^{\circ} 37^{\prime} \mathrm{W}\right.$; Pamplona, Spain).

During the first and second week, plants were inoculated twice with commercial Bradyrhizobium japonicum. To ensure that the sole $\mathrm{N}$ source was $\mathrm{N}_{2}$ fixed by nodules, the plants were watered with an $\mathrm{N}$-free nutrient solution exactly as described in Soba et

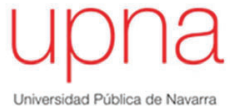


al. (2019) and microelements as recommended by Hoagland and Arnon (1950), twice a week.

At full flowering (R2) (Fehr et al., 1971) half of the plants (randomly selected) were subdivided in 4 groups (Control, heatwave (HW), water stress (WS) and heatwave $\mathrm{x}$ water stress combination (HW $\mathrm{x}$ WS). Ten replications per treatment and developmental stage were used, five replications for biomass, biochemical and metabolic measurements just after the treatment and five replications for yield and yield parameters at maturity. In water stressed plants, suppression of irrigation was maintained for 7 days until $20 \%$ of the full substrate water-holding capacity was reached, while plants in well irrigated groups were maintained at full substrate waterholding capacity. Heatwave treatments were carried out in a chamber (Fitoclima, 1200 PLH, Aralab Bio, Portugal). Growth chamber conditions were set to $14 \mathrm{~h}$ of light $(1,000$ $\mu \mathrm{mol} \mathrm{m} \mathrm{m}^{-2}$ ) and $25^{\circ} \mathrm{C}$ and $50 \%$ relative humidity during the light hours (6 am to $8 \mathrm{pm}$ ) and $18^{\circ} \mathrm{C}$ and $70 \%$ relative humidity in the dark. Temperatures were increased from 18 to $25^{\circ} \mathrm{C}, 1 \mathrm{~h}$ after lights were turned on and returned to 18 from $25^{\circ} \mathrm{C}, 1 \mathrm{~h}$ after lights were turned off. Plants were grown in these similar greenhouse conditions for three additional days in order to a proper chamber acclimation. At that time, maintaining photoperiod and humidity, temperature treatment was initiated, which was imposed as follows: the temperature was increased gradually from $30^{\circ} \mathrm{C}$ at $6: 00$ am to reach 40 by 9:00 am and held at these temperatures until 5:00 pm. Then, the temperature was reduced from 40 to $30^{\circ} \mathrm{C}$ from 5:00 pm to $8: 00 \mathrm{pm}$ and maintained at $30^{\circ} \mathrm{C}$ until $6: 00$ am. As elevated temperatures that occur during the growing season in the field often come in the form of heatwaves generally lasting a few days, temperature treatments were imposed over the course of 4 days. At the end of the different treatments, half of the plants were randomly selected for the intermediate harvest; gas exchange measurements were carried out, and then plants were collected and separated into leaves, shoot, roots and nodules and were immediately frozen in liquid $\mathrm{N}$ and stored at $-80{ }^{\circ} \mathrm{C}$ for further analyses. A subsample of each organ was separated and dried in an oven for $48 \mathrm{~h}$ at $60{ }^{\circ} \mathrm{C}$ in order to determine dry weight (DW). The other half of the plants of each treatment was maintained until maturity harvest under control condition in the greenhouse. At maturity harvest (R8), aboveground biomass, yield and yield components such as PN, SN and TSW were recorded.

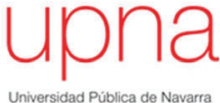


The same four treatments and set of measures were carried out during full pod stage (R4) with the other half of the plants.

\subsection{Gas exchange and chlorophyll fluorescence determinations}

Gas exchange and chlorophyll fluorescence were measured at the end of the different treatments (imposed at R2 and R4 developmental stages). The former were carried out with a Li-Cor 6400 portable gas exchange photosynthesis system (LI-COR, Lincoln, NE, USA) on healthy and fully expanded apical leaves. The measurements were carried out at the end of the treatments under conditions similar to growth conditions $\left(1000 \mu \mathrm{mol} \mathrm{m}{ }^{-2} \mathrm{~s}^{-1}\right.$, and $\left.400 \mu \mathrm{mol} \mathrm{mol}^{-1} \mathrm{CO}_{2}\right)$ and block temperature depending of the group (control and WS; $25^{\circ} \mathrm{C}$ and $\mathrm{HW}$ and $\mathrm{HW} \times \mathrm{WS} ; 40^{\circ} \mathrm{C}$ ). Photosynthetic $\mathrm{CO}_{2}$ assimilation $\left(A_{n}\right)$ was determined using equations developed by von Caemmerer and Farquhar (1981). Stomatal conductance $\left(g_{s}\right)$ was determined as described by Harley et al. (1992). Plants were dark-adapted for 50 min before dark respiration $\left(R_{\mathrm{D}}\right)$ measurements (Nogués et al., 2004).

Fluorescence parameters were measured with a fluorescence chamber (LFC 6400-40; LI-COR) coupled to the Li-Cor 6400. Light-adapted variables included electron transport rate (ETR), quantum yield of photosystem II photochemistry (ФPSII), photochemical quenching $(q P)$, non-photochemical quenching $(q N)$. Leaves were then dark-adapted for $20 \mathrm{~min}$ and maximum quantum yield of PSII photochemistry $\left(F_{\mathrm{v}} / F_{\mathrm{m}}\right)$ were measured.

\subsection{Leaf and grain nitrogen content}

The nitrogen $(\mathrm{N})$ content in leaf samples were determined based on sample dynamic combustion, using an elemental analyzer (FlashEA1112, ThermoFinnigan, Waltham, Massachusetts, USA) equipped with a MAS200R autosampler. The sample was weighed in a tin capsule (MX5 microbalance, Mettler-Toledo, Columbus, Ohio, USA) and introduced into a quartz reactor filled with $\mathrm{WO}_{3}$ and copper and heated at $1020^{\circ} \mathrm{C}$. The combustion gas mixture was carried by a helium flow to a $\mathrm{WO}_{3}$ layer to achieve a complete quantitative oxidation, following by a reduction step in a copper layer to reduce nitrogen oxides and $\mathrm{SO}_{3}$ to $\mathrm{N}_{2}$ and $\mathrm{SO}_{2}$. The resulting components, $\mathrm{N}_{2}$,

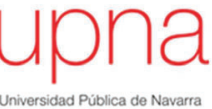


$\mathrm{CO}_{2}, \mathrm{H}_{2} \mathrm{O}$, and $\mathrm{SO}_{2}$ were separated in a chromatographic column (Porapak 2m, Santa Clara, California, USA) and detected with a thermal conductivity detector.

\subsection{Chlorophyll and anthocyanins content}

Chlorophyll (Chl) and anthocyanins (Anth) content was estimated using a portable non-destructive a DUALEX sensor (Dualex Scientific, Force A, France). The chlorophyll is given in $\mu \mathrm{g} / \mathrm{cm}^{2}$ in the range of $5-80 \mu \mathrm{g} / \mathrm{cm}^{2}$. Anthocyanins content are given in relative absorbance units from 0 to 1.5 .

\subsection{Organic acids determinations}

For oxalic, oxaloacetic, malic, citric and succinic acid extraction, leaf and nodule fresh weight frozen material was ground to a fine powder in liquid nitrogen with a pestle and mortar and $50 \mathrm{mg}$ was weight and resuspended in $500 \mu \mathrm{l}$ of $\mathrm{HClO}_{4} 1 \mathrm{M}$, left at $4{ }^{\circ} \mathrm{C}$ for $30 \mathrm{~min}$ and centrifuged for $15 \mathrm{~min}$ at $14,000 \mathrm{~g}$ at $4^{\circ} \mathrm{C}$. Organic acids contents from supernatants were then determined by HPLC. Chromatographic separation was performed using a Waters Alliance HPLC system (Waters, Mildford, MA, USA) and a Synergi Hydro-RP $80 \AA$ Å column ( 250 x $4.6 \mathrm{~mm}$ i.d., particle size $=4 \mu \mathrm{m}$; Phenomenex $)$ with a flow of $0.8 \mathrm{ml} / \mathrm{min}$ mobile phase $\left(20 \mathrm{mM} \mathrm{KH}_{2} \mathrm{PO}_{4}\right.$, adjusted to $\mathrm{pH} 2.9$ with concentrated $\mathrm{H}_{3} \mathrm{PO}_{4}$ ) and $40{ }^{\circ} \mathrm{C}$ column temperature. The total run time per sample was $20 \mathrm{~min}$. Organic acids were monitored at $210 \mathrm{~nm}$ and quantified based on standard calibration curves generated with authentic oxalic, oxaloacetic, malic, citric and succinic acids (Sigma-Aldrich). Before statistic analysis quantification was normalized to DW in order to avoid any discrepancy due to changes in tissue water content.

\subsection{Free amino acid and sugar determinations}

Free amino acid and soluble sugars determinations were carried out in leaf and nodule samples. For amino acids frozen plant tissues were ground to a fine powder in liquid nitrogen and a sub-sample was lyophilised. Lyophilised plant tissue $(20 \mathrm{mg})$ was homogenised in $400 \mu \mathrm{L}$ of $80 \%$ ethanol and mixed using a vortex, incubated at $80{ }^{\circ} \mathrm{C}$ for $1 \mathrm{~h}$, and centrifuged at $14,000 \mathrm{~g}$ and $4{ }^{\circ} \mathrm{C}$ for $10 \mathrm{~min}$ and the pellet was completely dehydrated. The pellet was re-suspended in $100 \mu \mathrm{L}$ of milli-Q water, centrifuged at $14,000 \mathrm{~g}$ and $4{ }^{\circ} \mathrm{C}$ for $10 \mathrm{~min}$, and the supernatant was collected. The amino acid content in the supernatant was determined by high performance liquid chromatography

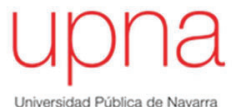


(HPLC) (Waters Corporation, Barcelona, Spain) after derivatization with a ACCQFluor $^{\mathrm{TM}}$ Reagent kit (Waters, Milford Massachusetts, USA) based in borate buffer, acetonitrile and, AQC derivatizing reagent (6-aminoquinolyl-n-hydroxysuccinimidyl carbamate) as previously described (Cohen and Michaud, 1993).

For sucrose (Suc), glucose (Glu) and fructose (Fru) determinations, lyophilised plant tissue $(25 \mathrm{mg}$ ) was homogenised in $0.5 \mathrm{~mL}$ of $100 \%$ ethanol, then another $0.5 \mathrm{~mL}$ of $80 \%$ ethanol was added and mixed using a vortex. The sample was incubated at 70 ${ }^{\circ} \mathrm{C}$ for $90 \mathrm{~min}$, centrifuged at $14,000 \mathrm{~g}$ for $10 \mathrm{~min}$ and the supernatant collected. The supernatant was used to determine Suc, Glu and Fru content with an ionic chromatographer (ICS-3000, Thermo Scientific ${ }^{\mathrm{TM}}$, Waltham, Massachusetts, USA). Starch was determined in leaf pellets after ethanol extraction, using the amyloglucosidase test kit (R-BiopharmAG, Darmstadt, Germany).

\subsection{Statistical analysis}

Statistical analyses were performed with IBM SPSS Statistics for Windows, Version 20.0. (IBM Corp. Armonk, NY, USA). Statistical differences between measurements of the different treatments were evaluated with two ways Analyses of Variance (ANOVA). Tukey' post hoc tests were used to determine statistical differences between treatments at R2 and R4 independently. All data were tested for normality (Kolmogorov-Smirnof test) and homogeneity of variances (Levene's test). The resulting $P$-values were considered to be statistically significant at $p<0.05$. Asterisks indicate significant differences: $* p<0.05, * * p<0.01$, in the two-way ANOVA for treatments and developmental stages.

\section{RESULTS}

\subsection{Biomass and yield parameters}

Biomass parameters in soybean (measured at the end of the stresses periods at R2 and R4) were significantly affected by temperature and water stress. Phenological stage (P) and water treatment (W) were the two main factors influencing biomass and were always significant (with the exception of WS in root DW). However, heat treatment $(\mathrm{H})$ influenced only leaf and nodule biomass. None of the interactions were significant for any biomass parameter. Overall, at flowering, the water regimen had a stronger effect on biomass than heatwave; however, at pod formation only the 
combination of stresses had significant effect, except for nodule biomass (Fig. 1 and Table S1). For instance, total biomass was reduced by $45.0 \%$ and $39.1 \%$ at R2 and R4 respectively when both stressed were applied in combination. Leaf and nodule biomass were the treatments with the greatest reduction under the studied stressed. Finally, root/shoot ratio showed significant increases under combined stresses (Table S1)

Phenological stage has not effect on SY or its components, only seed $n^{\circ}$ per pod and harvest index (HI) showed significant differences between stages. Seed yield, SN and PN exhibited significant differences among water regimen, heat treatment and the interaction DxH. Other important yield component such as TSW did not showed significant differences between treatment or stages but showed significant DxW interaction (Table S1). When episodes of heat and water stress occurred concomitantly SY decreased at both R2 and R4 stage (33.2\% and 54.3\%, respectively) $(p<0.05)$ in comparison to the control. Similarly, WS plants at both stage and HW plants at R4 also reduced their SY (Fig. 2 and Table S1).

\subsection{Gas exchange and chlorophyll fluorescence}

Photosynthetic rate and $g_{s}$ were found to be significantly lower in the plants under water stress and plants under combined heat and water stresses. This decrease was found when the stresses were applied both at R2 and R4. However, no significantly differences were found when heat stress occurs alone (Table 1). Transpiration $\left(T_{r}\right)$ values in plants under HW were significantly higher than control ones and the values of WS and HWxWS plants significantly lower; therefore, higher water use efficiency (WUE) values were found in water stressed treatments. Higher vapor pressure deficit (VPDL) and leaf temperature ( $T^{\mathrm{a}}$ leaf) values $(p<0.05)$ were found in plants under heatwave (and their combination with water stress) at both stages. On the other hand, highest $R_{D}$ values were found in plants subjected to heatwave alone followed by plants under combined stresses (Table 1).

Among the chlorophyll fluorescence parameters, phenological stage had not significant effect in any of the parameters. The parameters for light acclimated light: $\mathrm{F}_{\mathrm{v}}{ }^{\prime} / \mathrm{F}_{\mathrm{m}}{ }^{\prime}, \phi P S I I$, ETR, $q P$ and $q N$ were significantly reduced under WS (alone or combined with HW). Heatwave has not significant effect in any treatment except for $\mathrm{F} v^{\prime} / \mathrm{Fm}^{\prime}$ which was significant reduced when compared to control plants. The dark-




adapted parameter $\mathrm{F} v / \mathrm{Fm}$ did not shown differences between stages or treatments (Table $1)$.

Finally, Chl and Anth pigments showed antagonistic trends with higher Chl content in leaves of HW plants whereas in these plants Anth showed the lowest values. In both pigments the interaction $\mathrm{WxH}$ was significant (Table 1).

\subsection{Carbohydrates}

Three carbohydrates: Suc, Glu and Fru were studied in leaves and nodules; additionally, starch was analyzsed in leaves (Table 2). In leaves, carbohydrates concentration generally decreased under water stress and, especially, when water and heat stresses were combined, particularly at flowering (Table 2). In nodules, the main sugar was Suc, which was significantly higher in both stages when the stresses were applied alone or in combination. Starch content was analyzsed in leaves showing similar trend at both developmental stages, with significant decreases under heat stress but in particular under water stress and their combination with heat.

\subsection{Organic acids}

In leaves, WS alone only reduced significantly, compared to control plants, the levels of citrate and malate during flowering. However, when combined with HW, reductions in these two dicarboxylic acids were significant at both stages; additionally succinate was also reduced at R2 stage. On the other hand, HW alone has not significant effect on leaf organic acids.

In nodules, water stress reduced, in comparison with control nodules, the content of citrate, malate and succinate at flowering. When combined with HW the reduction was general in both phenological stages, except for oxaloacetate (OAA) at flowering. Significant lower levels of OAA and malate were observed in plant suffering HW at bot stages.

\subsection{Amino acids}

Overall, 18 amino acids were quantitated in leaf and nodule tissue in the four different water and heat treatments and two phenological stages. The quantitation was normalized to the DW of samples so as to avoid any discrepancy due to changes in relative water content under WS conditions. Significant differences in amino acids 
between treatments and phenological stage are shown in Table 3. In leaves at flowering, a greater accumulation of amino acids were found in plants under heatwave and interacting stresses; on the contrary, at R4, water stressed leaves were found to have the greatest contents of photorespiration related amino acids (serine (Ser) and glycine (Gly)) and osmoprotectant amino acids (proline (Pro)). On the other hand, in nodules, significant differences could be seen mainly in amino acids involved in long-distance transport of $\mathrm{N}$ (aspartate (Asp) and asparagine (Asn)), osmoregulatory functions $(\gamma-$ aminobutyric acid (GABA)) and branched-chain amino acid (isoleucine (Ile), leucine (Leu) and valine (Val)).

\section{DISCUSSION}

Physiological and metabolic mechanisms underlying SY responsiveness of soybean plants subjected to high temperature or water stress have been extensively studied; however, much less information is available on combined heatwave and water stressed, while under field conditions, these stresses often occur in combination (Schär et al., 2004; Vautard et al., 2007). Additionally, scant information currently exists about the effect of interacting stresses in nodule performance and their implication in plant fitness and seed yield. In the current study, physiological, biochemical and metabolic consequences of short periods of extreme heat, heatwave (HW), water stress (WS) and their combination (HW x WS) during reproductive period (flowering (R2) and full pod (R4)) were studied in leaves and nodules of soybean plants and their effect on SY was analyzsed.

\subsection{Leaf function}

\section{Photosynthetic performance}

Leaves have a primary role in the production and transport of photoassimilates to the seed and therefore, leaf function is close related with final SY (Hodgson et al., 2017). At flowering, as observed in SY, leaf biomass significantly decreased in plants under WS (alone or in combination with HW); however, under HW leaf reduction was not significant. Leaf biomass reductions under WS and HW x WS treatments were 48.1 and $61.7 \%$, respectively. These reductions are higher than the observed reductions in total biomass, $42.3 \%$ for WS and 52.4\% for HW x WS. When the stresses occurs during full pod formation, only the combination of stresses significantly reduced both, leaf and

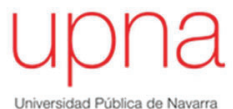


total biomass (51.6 and 39.1\%, respectively). In all cases leaf biomass was the plant tissue most affected by the stresses (Fig. 1 and Table S1). Since plant photosynthetic capacity depends on the $A_{n}$ and photosynthetic area of the plant (Yin and Struik, 2017; Soba et al., 2020), this reduction are expected to negatively affect photoassimilate production by these plants.

Photosynthetic function in leaves was inhibited when WS (alone or in combination with HW) was imposed in both R2 and R4 stages, as indicated by sharp reductions in $A_{n}, g_{s}$ and $\mathrm{Chl}$ concentration (Table 1 and Fig. 4). However, in plants under HW, photosynthetic parameters were not affected at any developmental stage, conversely to previous studies in soybean (Vu et al., 1997; Jumrani and Singh, 2019). In plants under combined stresses, stomatal response to WS prevailed over that to HW in both key developmental stages. Therefore, in the balance between preventing water loss and protecting from over-heating seems that the prevention of water loss trough stomatal closure prevail over the effect of heat to cool leaf surface. Similar results in soybean have been shown recently by Katam et al. (2020). However, Jumrani and Singh (2019) found negative effects on photosynthesis under both temperature and water stresses. Our data suggest that plants under water scarcity suffer a sharp decrease in $g_{s}$ in order to reduce water loss though transpiration (Table 1), which lead to a reduction in $\mathrm{CO}_{2}$ uptake for photosynthesis and a reduction plant productivity (Lawson and Blatt, 2014; Awasthi et al. 2014). In plants under combined HW x WS, high vapor pressure deficit (VPDL) caused a supplementary source for stomatal closure (Lobell et al., 2014). An additional effect of lower $g_{s}$ is the observed increase in WUE (Table 1) as widely observed in crops (Gorthi et al., 2019). Maintenance of Chl in leaves is considered to be an important factor for maintaining higher $A_{n}$ and, hence, better yields under environmental stresses such as heat and water deficit (Borrell et al., 2000). The observed greater loss of Chl under WS or HS x WS plants compared to HW alone has been previously reported in bentgrass (Agrostis stolonifera L.) (McCann and Huang, 2007) and legumes such as chickpea (Awasthi et al., 2014) and soybean (Jumrani and Singh, 2019). Recently, loss of Chl in soybean leaves has been associated with Ndeficiency due to an impaired nodule functioning (Soba et al., 2021). This, together with a possible increase of reactive oxygen species (ROS) production, as suggested by chlorophyll florescence measures (Lim et al., 2007), are likely behind the lower Chl content in water stressed soybeans.

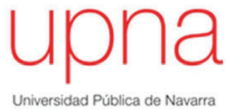


Soybean plants under WS (combined or not with heatwave), reduced ETR and ФPSII, compared to control conditions, in special during flowering stage. Nevertheless, increasing temperatures alone did not influenced ETR and ФPSII values, in accordance with the higher $A_{n}$ observed in this treatment. The present study would indicate that water regimen has a more pronounced effect on PSII function than heatwave. Similar results have been shown recently in tomato plants (Zhou et al., 2019) and olive trees (Haworth et al., 2018). On the other hand, Jumrani and Singh (2019) found in soybean significant decline in ETR and TPSII with both high temperature and water stress. Additionally, previous observations of the impact high temperatures when combined with water deficit indicate PSII inhibition to be more sensitive to heat stress than to water stress (Havaux, 1992; Martinazzo et al., 2013; Jumrani and Singh, 2019; Killi et al., 2020), in opposition to our observations. One possible explanation for this contrasting response could be the intrinsic nature of heatwave, short period of extreme high temperature (Haworth et al., 2018), in opposition to reported high temperature maintained during entire phases of plant growth in these experiments (Jumrani and Singh, 2019; Killi et al., 2020). Non-photochemical quenching $(q N)$ decreased at flowering under WS alone and in combination with HW; however, at R4, the decreased was only significant in HW x WS plants. Indicating that soybean under water regimen may not be able to dissipate thermally part of the absorbed light energy in PSII antennae in order to avoid photo-oxidative damage (Aranjuelo et al., 2005; Méndez-Espinoza et al., 2019) (Fig. 4). In addition to chemical protection, Anth are plant pigments known for their photoprotective role under stresses (Kovinich et al., 2015). In our study, when HW alone was compared to HW x WS combined stresses, could be seen a significant increase of Anth. Many studies have confirmed that plants accumulate Anth with certain photoprotective role in plants under different stresses (Hughes et al. 2005; Macar and Ekmekci, 2008; Moustaka et al. 2020).

Taking into account leaf biomass, gas exchange and chlorophyll florescence data, WS had dominant effect over HW, in especial when applied at flowering. The biochemical response of plant photosynthesis was similar in plants under both WS and HW x WS combination. This inhibition was caused by stomatal and non-stomatal limitations of photosynthesis. On the other hand, plants under HW were capable to maintain their leaf function without significant affections compared to control plants.

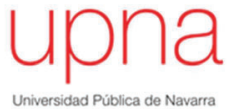




\section{Carbon and nitrogen metabolism}

The described decrease in photosynthetic performance under water regimen is translated into a lower synthesis of carbohydrates such as Suc and starch. Decreases in leaf Suc content are special relevant at flowering. Leaf Suc content is determined by several factors others than $A_{n}$, such as Suc export to flowers/pods or nodules (Egli et al., 1989). Since PN at physiological maturity seem to be reduced in plants under interacting stresses imposed at flowering (Fig. 2) but not the supply of Suc to the nodule (Table 2), we suggest that at this stage export of Suc to reproductive sink may be compromised by water scarcity, with the result of the significant increase in flower abortion (Al-Ghzawi et al., 2009). During R2 and R4, low starch concentration in leaves were found under WS (alone or in combination with HW) when compared to control or HW plants. This was indicating poor starch synthesis or/and high starch degradation in order to maintain Suc supply when $A_{n}$ are low (Ruan, 2014; Figueroa and Lunn, 2016).

Protection of photosynthesis from photoinhibition through photorespiration is well known, dissipating excess of light energy and hence reducing formation of ROS (Kozaki and Takeba, 1996) but also suppose a loss of C previously fixed by photosynthesis (Farquhar et al., 1980). The observed high levels of Gly and Ser and the increase in Gly/Ser ratio (data not shown) in soybean plants under HW (alone or combined with WS) has been related with increased photorespiratory activity under stress conditions (Novitskaya et al. 2002; Fahnenstich et al. 2008; Soba et al. 2021). Additionally, the most evident way of oxalate accumulation is the oxidation of glyoxylate (Yu et al., 2010; Igamberdiev et al., 2018) that can be formed during photorespiration. These two observations are suggesting higher levels of photorespiration during heatwave treatments as suggested in previous works (Peñuelas and Llusià, 2002; Prasad et al., 2008; Rollins et al., 2013), probably due to higher leaf temperature (Table 1) that increase oxygen solubility and their affinity by Rubisco (Brooks and Farquhar, 1985).

Leaf $\mathrm{N}$ content at R2 and R4 was significantly higher under heatwave than under water stress (Table 1). In accordance, leaf nitrogenous amino acids (Asp, Alanine (Ala)) were decreased by water limitation compared to heatwave (Table 3). Since nodules were the solely $\mathrm{N}$ source to the plants, lower leaf $\mathrm{N}$ and nitrogenous metabolites content may indicate an impaired nodule performance under water stress (Soba et al., 
2019). Additionally, another reason to explain the lower accumulation of Asp and Ala in WS and HW x WS leaves is its lower transpiration rate (Table 1). It has been noted that lower transpiration may involve alterations in long-distance transport of $\mathrm{N}$ compounds between underground and aerial plant tissues, provoking an accumulation of $\mathrm{N}$ compounds in nodules of plants under water stress (Serraj et al., 2001). The lower leaf $\mathrm{N}$ concentration could be involved in the observed lower Chl concentration in WS and combined stresses treatments, being another reason for impaired photosynthetic performance in both treatments (Evans, 1989; Xue et al., 2004; Sanz-Sáez et al., 2019).

\subsection{Nodule performance}

Together with leaves, nodule was the tissue more severely affected, in terms of biomass, by the occurrence of stresses (Fig. 1 and Table S1). Nodule biomass reduction was significant for the two stresses and their combination during R2 and R4, with reductions ranged from $\approx 40 \%$ when the stresses were applied alone to more than $50 \%$ when applied in combination.

Biological nitrogen fixation (BNF) in legume nodules is fueled by the $\mathrm{C}$ fixed through photosynthesis. Although photosynthesis is severely inhibited by WS (and their interaction with HW), limited supply of photosynthates to the nodules does not appear to be directly involved in nodule performance, given that all treatments promotes an accumulation of Suc in nodules (Table 2). The increase of nodule Suc under abiotic stress has been previously reported in legume nodules under water stress (González et al., 1995; Ramos et al., 1999; Gálvez et al., 2005); being mainly attributed to the inhibition of sucrose synthase (SS) activity (González et al., 1995; Gordón et al., 1999). The limited studies on high temperature and nodule performance also show that decreases in nodule functioning is not due to limited supply of carbohydrates (Aranjuelo et al., 2014). In our experiment, lower contents of malate and succinate in nodules of plants under HW, WS or combined stresses were observed. These two dicarboxylic acids are the main respiratory substrates to bacteroids and are produced by the cleavage of Suc by SS and the subsequent glycolytic activities, probably indicating that phosphoenolpyruvate carboxylase (PEPC) was also negatively affected (Lodwig and Poole, 2003). Malate and succinate contents have been shown to be limited in nodules of pea (Gálvez et al. 2005) and soybean (Ladrera et al. 2007) under water stress, probably due to this SS and/or PEPC down-regulation (González et al., 1995). 
Therefore, these observations reinforce the idea of an adequate supply of photoassimilates from leaves to nodules but a SS down-regulation provoking low provision of dicarboxylic acids which supply the energy and $\mathrm{C}$ skeletons required by the bacteroid to fix $\mathrm{N}_{2}$ by nitrogenase (Aranjuelo et al., 2014).

Additionally, under abiotic stresses, the lower leaf $\mathrm{N}$ demand has been described to cause amino acid accumulation in nodules, in these sense several compounds such as glutamine (Gln), Asn, Asp and ureides have been suggested to be involved in a $\mathrm{N}$ feedback mechanism (Serraj et al., 2001; King and Purcell, 2005; Larrainzar et al., 2009; Sulieman and Schulze, 2010; Aranjuelo et al., 2014; Soba et al., 2019). In our case, WS (alone or in combination with HW), caused an increase of Asn and Asp (Table 3), two of the most abundant amino acids in soybean nodules. Lower transpiration rates observed in both treatments (Table 1) may be involved in this specific amino acid accumulation through alterations in long-distance transport of $\mathrm{N}$ compounds between underground and aerial plant tissues (Serraj et al., 2001). Additionally, oxaloacetate could be used mostly to accumulate Asp/Asn, at the expenses of malate production.

In conclusion, nodule biomass was severely affected by HW, WS and their combined effect, similarly, nodule performance was also affected. On the one hand, under combination of HW and WS nodule functioning seem to be affected in a similarly way to WS alone but with more severe consequences. Under these condition nodule performance seems to be limited by i) poor respiratory activity to the bacteroids (due to a poor SS/PEPC activity, not to a reduced transport of photoassimilates from leaves to nodules) and ii) accumulation of nitrogenous compound (Asp and Asn), probably due to the reduced transpiration (Fig. 4). Both traits have been associated with a decrease of nitrogenase activity (Serraj et al., 1999). On the other hand, HW nodules seem to be affected by poor cleavage of Suc into malate, the main supply the energy and $\mathrm{C}$ skeletons required by the bacteroid, but high transpiration rates avoid $\mathrm{N}$-feedback due to amino acids accumulation. As a consequence, in WS treatment $\mathrm{N}$ availability at aboveground level (leaf $\mathrm{N}$ concentration; Table 1) was negatively affected in comparison with HW. However, in plants under combined heat and water stresses leaf $\mathrm{N}$ content was statistically similar to HW plants, probably due to concentration effect caused by lower leaf biomass and $\mathrm{N}$ demand. 


\subsection{Linking plant physiology and soybean seed yield}

Grain yield under HS, WS and their combination is the final manifestation of effect on physiological processes occurring during and after the stresses. In this sense, we observed similarities between biomass measurements at flowering and pod formation and final seed yield (Fig. 1 and 2). For example, when we analyzsed total biomass measured at R2 and R4 and final SY, we observed in both parameters a similar reduction in water stressed plants (alone or in combination with HW) at R2; however, at R4 an additive effect in both parameters was observed in plants under combined stresses. It is documented that the simultaneous occurrence of HW and WS may cause an additive effect with an impact on SY considerable larger than the single stress effects. This has been shown in cereals like barley (Rollins et al., 2013), wheat (Prasad et al., 2011) and legumes like soybean (Dornbos and Mullen, 1992, Jumrani and Singh, 2018). In our case, this was only observed when the stresses were applied during the grain filling period with a significant decrease of $54.3 \%$ when compared to control plants. This decrease were lower than ones observed in HW $(-25.4 \% ; p<0.05)$ and WS $(-24.4 \% ; p<0.05)$. On the other hand, similarly to that observed during flowering, Ergo et al. (2018), showed that the additive or multiplicative effect on soybean grain yield due to the interaction of both stresses was not observed. For instance, when applied at flowering WS (alone an in combination with HW) had a similar significant decrease (31.6\% and 33.2\%; respectively), and plants under HW showed a slight not significant decrease $(-9.9 \%)$. Similar results have been found in tomato (Nakishore and Farrel, 2016), groundnut (Hamidou et al., 2012; Awasthi et al., 2014), lentil (Sehgal et al., 2017). Furthermore, SY is mainly a function of pod numbers (PN), seed numbers (SN) and thousand seed weight (TSW) (Jumrani and Singh, 2018). In our case, reductions in SY was mainly due to PN and SN diminutions, which close follow the same trend that SY (Fig. 2). However, changes in TSW only explain seed yield variation in plant under water regimen at pod formation (R4). Similar results have been showed in heat and water stressed field-grown soybean (Ergo et al., 2018). Maintenance of TSW can be seen as a compensatory effect of HW plants due to a reduction in the SN (Andriani et al., 1991). Nevertheless, at pod formation plants under WS a slight (not significant) decrease and a great decrease $(p<0.001)$ in HW*WS was observed in TSW. In this sense, there is ample evidence supporting that heat stress episodes and/or water stress during grain filling decrease soybean SY mainly through decreases in TSW and to a

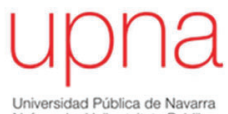


lesser extent in GN (Brevedan and Egli, 2003; Dornbos and Mullen, 1992; Rotundo and Westgate, 2010; Ergo et al., 2018). Seed weight can be modified until late seed filling which extends the capacity of soybean seeds to modify their weight in response to abiotic stresses (Borrás et al., 2004), like in this case the additive effect of HW x WS. However, in our case significant reductions in PN and SN were observed in plants subjected to heatwave. This result highlight that important pod and seed number diminutions can be expected at this developmental stage, due to a large overlapping of reproductive phases which was also accentuated by the indeterminate growth of the genotype used in this study. Earlier studies have shown that the end of the critical period for pod and seed number determination is close to grain filling stage (Board and Tan, 1995; Egli, 1997).

In our experiment we suggest that when the stresses were applied at flowering, decreased SY under water regimen is due to flower abortion caused by insufficient Suc supply from leaves (Farooq et al., 2017; Du et al., 2020). However, a correct photosynthetic performance in plants under HW allows maintaining SY similar to control plants. The other yield parameter, TSW was not affected under any treatment probably because photosynthetic machinery was able to recover from the stress during grain filling and the supply of photoassimilates were not affected. Therefore, as photosynthetic effects and reduction in sugar supply, were similar in water stressed plants and plants under combined effect (Table 1 and 2), the final SY were similar reduced and no additive effect was observed (Fig. 2). On the other hand, when applied at late pod formation, reductions in SY in plants under combined stresses were significantly higher compared with the other treatments. This SY reduction was due to diminutions in $\mathrm{PN}, \mathrm{SN}$ and TSW, suggesting a poor pod setting due to low photoassimilates supply and a low TSW of the formed seed that may indicate that the photosynthetic capacity of these plants may not be fully recovery when the stresses were ceased. The sum of reduced PN (and SN) and lower TSW observed in plants under combined stresses can help to explain the additive effect of heatwave and water stress in SY during late pod formation (Egli et al., 2005; Puteh et al., 2013). Additionally, we suggest that reductions of PN in this stage could done full pod formation as the most critical stage for SY determination, since later reduction in PN would not expected (pods are already formed) and only TSW should be modified (Brevedan and Egli, 2003; 
Dornbos and Mullen, 1992; Rotundo and Westgate, 2010; Ergo et al., 2018), in opposition of R4 where both, PN and TSW, can be altered by abiotic stresses.

\section{CONCLUSIONS}

Our studies have indicated that water stress had higher impact than heatwave on physiological and biochemical parameters and, when combined, effects were more similar to those of water stress than those of heatwave, in special when applied at flowering. Water stress, alone or combined with heatwave, negatively affected photosynthetic performance (caused by closed stomata and photodamage), resulting in impaired Suc and starch metabolism in leaves and reproductive organs during flowering and pod formation. Nodule functioning were affected by water stress and combined stresses due to poor carbon supply to the bacteriods and N-compounds accumulation that negatively leaf $\mathrm{N}$ content in water stressed plants. These whole-plant effects caused, at maturity, decrease in seed yield. At flowering, fewer flower setting reduced seed yield equally in water stress and combined stresses, but not in heatwave treatment. However, seed yield effect of heatwave and water stress at pod formation was exacerbate when both stresses were applied concomitantly, and were due to both less pod setting and smaller seeds. We suggest pod formation as critical moment for soybean production under combined abiotic stresses. 


\section{REFERENCES}

Ahmed, I.M., Dai, H., Zheng, W., Cao, F., Zhang, G., Sun, D., Wu, F., 2013. Genotypic differences in physiological characteristics in the tolerance to drought and salinity combined stress between Tibetan wild and cultivated barley. Plant Physiol. Biochem. 63, 49-60. /https://doi.org/10.1016/j.plaphy.2012.11.004

Ainsworth, E.A., Yendrek, C.R., Skoneczka, J.A., Long, S.P., 2012. Accelerating yield potential in soybean: potential targets for biotechnological improvement. Plant. Cell Environ. 35, 38-52. https://doi.org/10.1111/j.13653040.2011.02378.x

Al-Ghzawi, A.A.-M., Zaitoun, S., Gosheh, H., Alqudah, A., 2009. Impacts of drought on pollination of Trigonella moabitica (Fabaceae) via bee visitations. Arch. Agron. Soil Sci. 55, 683-692. https://doi.org/10.1080/03650340902821666

Andriani, J., Andrade, F., Suero, E.E., Dardanelli, J.L., 1991. Water deficits during reproductive growth of soybeans. I. Their effects on dry matter accumulation, seed yield and its components. https://doi.org/10.1051/agro:19910904

Aranjuelo, I., Arrese-Igor, C., Molero, G., 2014. Nodule performance within a changing environmental context. J. Plant Physiol. 171, 1076-1090. https://doi.org/10.1016/J.JPLPH.2014.04.002

Aranjuelo, I., Irigoyen, J.J., Sánchez-Díaz, M., Nogués, S., 2008. Carbon partitioning in $\mathrm{N}_{2}$ fixing Medicago sativa plants exposed to different $\mathrm{CO}_{2}$ and temperature conditions. Funct. Plant Biol. 35, 306-317.

Aranjuelo, I., Pérez, P., Hernández, L., Irigoyen, J.J., Zita, G., MartínezCarrasco, R., Sánchez-Díaz, M., 2005. The response of nodulated alfalfa to water supply, temperature and elevated $\mathrm{CO}_{2}$ : photosynthetic downregulation. Physiol. Plant. 123, 348-358. https://doi.org/10.1111/j.1399-3054.2005.00459.x

Awasthi, R., Kaushal, N., Vadez, V., Turner, N.C., Berger, J., Siddique, K.H.M., Nayyar, H., 2014. Individual and combined effects of transient drought and heat stress on carbon assimilation and seed filling in chickpea. Funct. Plant Biol. 41, 1148-1167.

Balfagón, D., Zandalinas, S.I., Mittler, R., Gómez-Cadenas, A., 2020. High temperatures modify plant responses to abiotic stress conditions. Physiol. Plant. 170, 335-344. https://doi.org/10.1111/ppl.13151

Bhandari, K., Sharma, K., H, B., Siddique, K., Gaur, P., Kumar, S., Nair, R., Nayyar, H., 2017. Temperature sensitivity of food legumes: a physiological insight. Acta Physiol. Plant. 39. https://doi.org/10.1007/s11738-017-2361-5

Board, J., Tan, Q., 1995. Assimilatory Capacity Effects on Soybean Yield Components and Pod Number. Crop Sci. - Crop SCI 35. https://doi.org/10.2135/cropsci1995.0011183X003500030035x

Borrás, L., Slafer, G., Otegui, M.E., 2004. Seed dry weight response to sourcesink manipulations in wheat, maize and soybean: A quantitative reappraisal. F. Crop. Res. 86, 131-146. https://doi.org/10.1016/j.fcr.2003.08.002 
Borrell, A.K., Hammer, G.L., Douglas, A.C.L., 2000. Does Maintaining Green Leaf Area in Sorghum Improve Yield under Drought? I. Leaf Growth and Senescence. Crop Sci. 40, 1026-1037. https://doi.org/10.2135/cropsci2000.4041026x

Brevedan, R.E., Egli, D.B., 2003. Short Periods of Water Stress during Seed Filling, Leaf Senescence, and Yield of Soybean. Crop Sci. 43, 2083-2088. https://doi.org/10.2135/cropsci2003.2083

Brooks, A., Farquhar, G.D., 1985. Effect of temperature on the $\mathrm{CO}_{2} / \mathrm{O}_{2}$ specificity of ribulose-1,5-bisphosphate carboxylase/oxygenase and the rate of respiration in the light. Planta 165, 397-406. https://doi.org/10.1007/BF00392238

Canci, H., Toker, C., 2009. Evaluation of Yield Criteria for Drought and Heat Resistance in Chickpea (Cicer arietinum L.). J. Agron. Crop Sci. 195, 47-54. https://doi.org/10.1111/j.1439-037X.2008.00345.x

Cohen, I., Zandalinas, S.I., Huck, C., Fritschi, F.B., Mittler, R., 2021. Metaanalysis of drought and heat stress combination impact on crop yield and yield components. Physiol. Plant. 171, 66-76. https://doi.org/10.1111/ppl.13203

Cohen, S.A., Michaud, D.P., 1993. Synthesis of a Fluorescent Derivatizing Reagent, 6-Aminoquinolyl-N-Hydroxysuccinimidyl Carbamate, and Its Application for the Analysis of Hydrolysate Amino Acids via High-Performance Liquid Chromatography. Anal. Biochem. 211, 279-287. https://doi.org/10.1006/abio.1993.1270

Deryng, D., Conway, D., Ramankutty, N., Price, J., Warren, R., 2014. Global crop yield response to extreme heat stress under multiple climate change futures. Environ. Res. Lett. 9, 34011. https://doi.org/10.1088/1748-9326/9/3/034011

Djanaguiraman, Prasad, P.V.V., 2010. Ethylene production under high temperature stress causes premature leaf senescence in soybean. Funct. Plant Biol. 37, 1071-1084. https://doi.org/10.1071/FP10089

Djanaguiraman, Prasad, P.V.V., Schapaugh, W., 2013. High Day- or Nighttime Temperature Alters Leaf Assimilation, Reproductive Success, and Phosphatidic Acid of Pollen Grain in Soybean [Glycine max (L.) Merr.]. Crop Sci. 53, 1594-1604. https://doi.org/10.2135/cropsci2012.07.0441

Dornbos, D.L., Mullen, R.E., 1992. Soybean seed protein and oil contents and fatty acid composition adjustments by drought and temperature. J. Am. Oil Chem. Soc. 69, 228-231. https://doi.org/10.1007/BF02635891

Du, Y., Zhao, Q., Chen, L., Yao, X., Zhang, W., Zhang, B., Xie, F., 2020. Effect of drought stress on sugar metabolism in leaves and roots of soybean seedlings. Plant Physiol. Biochem. 146, 1-12. https://doi.org/10.1016/j.plaphy.2019.11.003

Egli, D.B., 1997. Cultivar maturity and response of soybean to shade stress during seed filling. F. Crop. Res. 52, 1-8. https://doi.org/10.1016/S03784290(97)00005-1 
Egli, D.B., TeKrony, D.M., Heitholt, J.J., Rupe, J., 2005. Air Temperature During Seed Filling and Soybean Seed Germination and Vigor. Crop Sci. 45, 13291335. https://doi.org/10.2135/cropsci2004.0029

Ergo, V. V, Lascano, R., Vega, C.R.C., Parola, R., Carrera, C.S., 2018. Heat and water stressed field-grown soybean: A multivariate study on the relationship between physiological-biochemical traits and yield. Environ. Exp. Bot. 148, 1-11. https://doi.org/10.1016/j.envexpbot.2017.12.023

Evans, J.R., 1989. Photosynthesis and nitrogen relationships in leaves of C3 plants. Oecologia 78, 9-19. https://doi.org/10.1007/BF00377192

Fahnenstich, H., Scarpeci, T.E., Valle, E.M., Flügge, U.-I., Maurino, V.G., 2008. Generation of Hydrogen Peroxide in Chloroplasts of Arabidopsis Overexpressing Glycolate Oxidase as an Inducible System to Study Oxidative Stress. Plant Physiol. 148, 719 LP - 729. https://doi.org/10.1104/pp.108.126789

FAOSTAT, n.d. ProdStat. Core Production Data Base, Electronic resource. (2020). [WWW Document]. URL http://faostat.fao.org/ (accessed 4.23.20).

Farooq, M., Gogoi, N., Barthakur, S., Baroowa, B., Bharadwaj, N., Alghamdi, S.S., Siddique, K.H.M., 2017. Drought Stress in Grain Legumes during Reproduction and Grain Filling. J. Agron. Crop Sci. 203, 81-102. https://doi.org/10.1111/jac.12169

Farooq, M., Wahid, A., Kobayashi, N., Fujita, D., Basra, S.M.A., 2009. Plant drought stress: effects, mechanisms and management. Agron. Sustain. Dev. 29, 185212. https://doi.org/10.1051/agro:2008021

Farquhar, G.D., von Caemmerer, S., Berry, J.A., 1980. A biochemical model of photosynthetic $\mathrm{CO}_{2}$ assimilation in leaves of $\mathrm{C} 3$ species. Planta 149, 78-90. https://doi.org/10.1007/BF00386231

Fehr, W.R., Caviness, C.E., Burmood, D.T., Pennington, J.S., 1971. Stage of Development Descriptions for Soybeans, Glycine Max (L.) Merrill1. Crop Sci. 11, cropsci1971.0011183X001100060051x.

https://doi.org/10.2135/cropsci1971.0011183X001100060051x

Figueroa, C.M., Lunn, J.E., 2016. A Tale of Two Sugars: Trehalose 6-Phosphate and Sucrose. Plant Physiol. 172, 7-27. https://doi.org/10.1104/pp.16.00417

Flexas, J., Medrano, H., 2002. Drought-inhibition of Photosynthesis in C3 Plants: Stomatal and Non-stomatal Limitations Revisited. Ann. Bot. 89, 183-189. https://doi.org/10.1093/aob/mcf027

Gálvez, L., González, E.M., Arrese-Igor, C., 2005. Evidence for carbon flux shortage and strong carbon/nitrogen interactions in pea nodules at early stages of water stress. J. Exp. Bot. 56, 2551-2561. https://doi.org/10.1093/jxb/eri249

González, E.M., Gordon, A.J., James, C.L., Arrese-lgor, C., 1995. The role of sucrose synthase in the response of soybean nodules to drought. J. Exp. Bot. 46, 15151523. https://doi.org/10.1093/jxb/46.10.1515

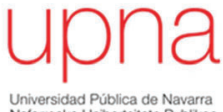


Gordon, A.J., Minchin, F.R., James, C.L., Komina, O., 1999. Sucrose synthase in legume nodules is essential for nitrogen fixation. Plant Physiol. 120, 867-878. https://doi.org/10.1104/pp.120.3.867

Gorthi, A., Volenec, J.J., Welp, L.R., 2019. Stomatal response in soybean during drought improves leaf-scale and field-scale water use efficiencies. Agric. For. Meteorol. 276-277, 107629. https://doi.org/10.1016/j.agrformet.2019.107629

Hamidou, F., Halilou, O., Vadez, V., 2013. Assessment of Groundnut under Combined Heat and Drought Stress. J. Agron. Crop Sci. 199, 1-11. https://doi.org/10.1111/j.1439-037X.2012.00518.x

Harley, P.C., Loreto, F., Di Marco, G., Sharkey, T.D., 1992. Theoretical Considerations when Estimating the Mesophyll Conductance to $\mathrm{CO}_{2}$ Flux by Analysis of the Response of Photosynthesis to $\mathrm{CO}_{2}$. Plant Physiol. 98, 1429 LP - 1436. https://doi.org/10.1104/pp.98.4.1429

Havaux, M., Strasser, R.J., 1992. Antagonistic effects of red and far-red lights on the stability of photosystem ii in pea leaves exposed to heat. Photochem. Photobiol. 55, 621-624. https://doi.org/10.1111/j.1751-1097.1992.tb04285.x

Haworth, M., Marino, G., Brunetti, C., Killi, D., De Carlo, A., Centritto, M., 2018. The Impact of Heat Stress and Water Deficit on the Photosynthetic and Stomatal Physiology of Olive (Olea europaea L.) - A Case Study of the 2017 Heat Wave. Plants . https://doi.org/10.3390/plants7040076

Herritt, M.T., Fritschi, F.B., 2020. Characterization of Photosynthetic Phenotypes and Chloroplast Ultrastructural Changes of Soybean (Glycine max) in Response to Elevated Air Temperatures. Front. Plant Sci. 6;11:153. https://doi.org/ $10.3389 /$ fpls.2020.00153

Hoagland, D.R., Arnon, D.I., 1950. The water-culture method for growing plants without soil. Calif. Agric. Exp. Stat. 347, 1-32.

Hodgson, J.G., Santini, B.A., Montserrat Marti, G., Royo Pla, F., Jones, G., Bogaard, A., Charles, M., Font, X., Ater, M., Taleb, A., Poschlod, P., Hmimsa, Y., Palmer, C., Wilson, P.J., Band, S.R., Styring, A., Diffey, C., Green, L., Nitsch, E., Stroud, E., Romo-Díez, A., de Torres Espuny, L., Warham, G., 2017. Trade-offs between seed and leaf size (seed-phytomer-leaf theory): functional glue linking regenerative with life history strategies ... and taxonomy with ecology? Ann. Bot. 120, 633-652. https://doi.org/10.1093/aob/mcx084

Huber, S., Rogers, H., Israel, D., 1984. Effects of $\mathrm{CO}_{2}$ enrichment on photosynthesis and photosynthate partitioning in soybean (Glycine max) leaves. Physiol. Plant. 62, 95-101.

Hughes, N.M., Neufeld, H.S., Burkey, K.O., 2005. Functional role of anthocyanins in high-light winter leaves of the evergreen herb Galax urceolata. New Phytol. 168, 575-587. https://doi.org/10.1111/j.1469-8137.2005.01546.x

Igamberdiev, A.U., Kleczkowski, L.A., 2018. The Glycerate and Phosphorylated Pathways of Serine Synthesis in Plants: The Branches of Plant Glycolysis Linking 
Carbon and Nitrogen Metabolism. Front. Plant Sci. 9, 318. https://doi.org/10.3389/fpls.2018.00318

IPCC, 2014. Climate Change 2014: Synthesis Report. Contribution of Working Groups I, II and III to the Fifth Assessment Report of the Intergovernmental Panel on Climate Change.

Jumrani, K., Bhatia, V.S., 2018. Impact of combined stress of high temperature and water deficit on growth and seed yield of soybean. Physiol. Mol. Biol. Plants 24, 37-50. https://doi.org/10.1007/s12298-017-0480-5

Jumrani, K., Bhatia, V.S., 2019. Interactive effect of temperature and water stress on physiological and biochemical processes in soybean. Physiol. Mol. Biol. Plants 25, 667-681. https://doi.org/10.1007/s12298-019-00657-5

Kalefetoğlu Macar, T., Ekmekçi, Y., 2008. PSII Photochemistry and Antioxidant Responses of a Chickpea Variety Exposed to Drought. Zeitschrift für Naturforsch. C 63, 583-594. https://doi.org/doi:10.1515/znc-2008-7-820

Katam, R., Shokri, S., Murthy, N., Singh, S.K., Suravajhala, P., Khan, M.N., Bahmani, M., Sakata, K., Reddy, K.R., 2020. Proteomics, physiological, and biochemical analysis of cross tolerance mechanisms in response to heat and water stresses in soybean. PLoS One 15, e0233905-e0233905. https://doi.org/10.1371/journal.pone.0233905

Killi, D., Raschi, A., Bussotti, F., 2020. Lipid Peroxidation and Chlorophyll Fluorescence of Photosystem II Performance during Drought and Heat Stress is Associated with the Antioxidant Capacities of C3 Sunflower and C4 Maize Varieties. Int. J. Mol. Sci. . https://doi.org/10.3390/ijms21144846

King, C.A., Purcell, L.C., 2005. Inhibition of $\mathrm{N}_{2}$ Fixation in Soybean Is Associated with Elevated Ureides and Amino Acids. Plant Physiol. 137, 1389-1396. https://doi.org/10.1104/pp.104.056317

Kovinich, N., Kayanja, G., Chanoca, A., Otegui, M.S., Grotewold, E., 2015. Abiotic stresses induce different localizations of anthocyanins in Arabidopsis. Plant Signal. Behav. 10, e1027850. https://doi.org/10.1080/15592324.2015.1027850

Kozaki, A., Takeba, G., 1996. Photorespiration protects C3 plants from photooxidation. Nature 384, 557-560. https://doi.org/10.1038/384557a0

Ladrera, R., Marino, D., Larrainzar, E., González, E.M., Arrese-Igor, C., 2007. Reduced carbon availability to bacteroids and elevated ureides in nodules, but not in shoots, are involved in the nitrogen fixation response to early drought in soybean. Plant Physiol. 145, 539-546. https://doi.org/10.1104/pp.107.102491

Larrainzar, E., Wienkoop, S., Scherling, C., Kempa, S., Ladrera, R., Arrese-Igor, C., Weckwerth, W., González, E.M., 2009. Carbon Metabolism and Bacteroid Functioning Are Involved in the Regulation of Nitrogen Fixation in Medicago truncatula Under Drought and Recovery. Mol. Plant-Microbe Interact. 22, 1565-1576. https://doi.org/10.1094/MPMI-22-12-1565 
Lawlor, D.W., 2002. Limitation to Photosynthesis in Water-stressed Leaves: Stomata vs. Metabolism and the Role of ATP. Ann. Bot. 89, 871-885. https://doi.org/10.1093/aob/mcf110

Lawson, T., Blatt, M.R., 2014. Stomatal Size, Speed, and Responsiveness Impact on Photosynthesis and Water Use Efficiency. Plant Physiol. 164, 1556 LP 1570. https://doi.org/10.1104/pp.114.237107

Lim, P.O., Kim, H.J., Gil Nam, H., 2007. Leaf Senescence. Annu. Rev. Plant Biol. 58, 115-136. https://doi.org/10.1146/annurev.arplant.57.032905.105316

Liu, F., Jensen, C., Andersen, M., 2004. Drought stress effect on carbohydrate concentration in soybean leaves and pods during early reproductive development: its implication in altering pod set. F. Crop. Res. 86, 1-13. https://doi.org/10.1016/S03784290(03)00165-5

Lobell, D.B., Roberts, M.J., Schlenker, W., Braun, N., Little, B.B., Rejesus, R.M., Hammer, G.L., 2014. Greater Sensitivity to Drought Accompanies Maize Yield Increase in the U.S. Midwest. Science (80). 344, 516 LP - 519. https://doi.org/10.1126/science.1251423

Lodwig, E., Poole, P., 2003. Metabolism of Rhizobium bacteroids. CRC. Crit. Rev. Plant Sci. 22, 37-78. https://doi.org/10.1080/713610850

Martinazzo, E.G., Ramm, A., Bacarin, M.A., 2012. The chlorophyll a fluorescence as an indicator of the temperature stress in the leaves of Prunus persica. Brazilian J. Plant Physiol. 24 (4). https://doi.org/10.1590/S1677-04202013005000001

Matiu, M., Ankerst, D.P., Menzel, A., 2017. Interactions between temperature and drought in global and regional crop yield variability during 1961-2014. PLoS One 12, e0178339.

McCann, S.E., Huang, B., 2007. Effects of Trinexapac-Ethyl Foliar Application on Creeping Bentgrass Responses to Combined Drought and Heat Stress. Crop Sci. 47, 2121-2128. https://doi.org/10.2135/cropsci2006.09.0614

Medic, J., Atkinson, C., Hurburgh Jr., C.R., 2014. Current Knowledge in Soybean Composition. J. Am. Oil Chem. Soc. 91, 363-384. https://doi.org/10.1007/s11746-013-2407-9

Méndez-Espinoza, A.M., Romero-Bravo, S., Estrada, F., Garriga, M., Lobos, G.A., Castillo, D., Matus, I., Aranjuelo, I., del Pozo, A., 2019. Exploring Agronomic and Physiological Traits Associated With the Differences in Productivity Between Triticale and Bread Wheat in Mediterranean Environments. Front. Plant Sci. 10: 404. http://dx.doi.org/10.3389/fpls.2019.00404

Mittler, R., 2006. Abiotic stress, the field environment and stress combination. Trends Plant Sci. 11, 15-19. https://doi.org/10.1016/j.tplants.2005.11.002

Moustaka, J., Tanou, G., Giannakoula, A., Adamakis, I.-D.S., Panteris, E., Eleftheriou, E.P., Moustakas, M., 2020. Anthocyanin accumulation in poinsettia leaves and its functional role in photo-oxidative stress. Environ. Exp. Bot. 175, 104065. https://doi.org/10.1016/j.envexpbot.2020.104065

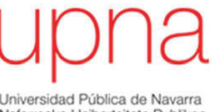


Murata, N., Takahashi, S., Nishiyama, Y., Allakhverdiev, S.I., 2007. Photoinhibition of photosystem II under environmental stress. Biochim. Biophys. Acta Bioenerg. 1767, 414-421. https://doi.org/10.1016/j.bbabio.2006.11.019

Nahar, K., Hasanuzzaman, M., Fujita, M., 2016. 12 - Heat stress responses and thermotolerance in soybean, in: Miransari, M. (Ed.), Abiotic and Biotic Stresses in Soybean Production. Academic Press, San Diego, pp. 261-284. https://doi.org/10.1016/B978-0-12-801536-0.00012-8

Nankishore, A., Farrell, A.D., 2016. The response of contrasting tomato genotypes to combined heat and drought stress. J. Plant Physiol. 202, 75-82. https://doi.org/10.1016/j.jplph.2016.07.006

Nogués, S., Tcherkez, G., Cornic, G., Ghashghaie, J., 2004. Respiratory Carbon Metabolism following Illumination in Intact French Bean Leaves Using ${ }^{13} \mathrm{C} /{ }^{12} \mathrm{C}$ Isotope Labeling. Plant Physiol. 136, 3245-3254. https://doi.org/10.1104/pp.104.048470

Novitskaya, L., Trevanion, S.J., Driscoll, S., Foyer, C.H., Noctor, G., 2002. How does photorespiration modulate leaf amino acid contents? A dual approach through modelling and metabolite analysis. Plant. Cell Environ. 25, 821-835. /https://doi.org/10.1046/j.1365-3040.2002.00866.x

Ostmeyer, T., Parker, N., Jaenisch, B., Alkotami, L., Bustamante, C., Jagadish, S.V.K., 2020. Impacts of heat, drought, and their interaction with nutrients on physiology, grain yield, and quality in field crops. Plant Physiol. Reports 25, 549-568. https://doi.org/10.1007/s40502-020-00538-0

Peñuelas, J., Llusià, J., 2002. Linking photorespiration, monoterpenes and thermotolerance in Quercus. New Phytol. 155, 227-237. https://doi.org/https://doi.org/10.1046/j.1469-8137.2002.00457.x

Perkins, S.E., 2015. A review on the scientific understanding of heatwavesTheir measurement, driving mechanisms, and changes at the global scale. Atmos. Res. 164-165, 242-267. https://doi.org/10.1016/j.atmosres.2015.05.014

Prasad, P.V. V, Staggenborg, S.A., Ristic, Z., 2008. Impacts of Drought and/or Heat Stress on Physiological, Developmental, Growth, and Yield Processes of Crop Plants, in: Response of Crops to Limited Water. John Wiley \& Sons, Ltd, pp. 301-355. https://doi.org/10.2134/advagricsystmodel1.c11

Prasad, P.V.V., Pisipati, S., Momčilović, I., Ristic, Z., 2011. Independent and Combined Effects of High Temperature and Drought Stress During Grain Filling on Plant Yield and Chloroplast EF-Tu Expression in Spring Wheat. J. Agron. Crop Sci. 197, 430-441. https://doi.org/10.1111/j.1439-037X.2011.00477.x

Pushpavalli, R., Zaman-Allah, M., Turner, N.C., Baddam, R., Rao, M. V, Vadez, V., 2015. Higher flower and seed number leads to higher yield under water stress conditions imposed during reproduction in chickpea. Funct. Plant Biol. 42, 162-174. doi: 10.1071/FP14135.

Puteh, A., Thuzar, M., Mondal, M., Abdullah, N.P.B., Halim, M., 2013. Soybean [Glycine $\max$ (L.) Merrill] seed yield response to high temperature stress during reproductive growth stages. Aust. J. Crop Sci. 7, 1472-1479. 
Ramos, M., GORDON, A., MINCHIN, F., Sprent, J., Parsons, R., 1999. Effect of Water Stress on Nodule Physiology and Biochemistry of a Drought Tolerant Cultivar of Common Bean (Phaseolus vulgaris L.). Ann. Bot. - ANN BOT 83, 57-63. https://doi.org/10.1006/anbo.1998.0792

Raza, A., Zahra, N., Hafeez, M.B., Ahmad, M., Iqbal, S., Shaukat, K., Ahmad, G., 2020. Nitrogen Fixation of Legumes: Biology and Physiology, in: Hasanuzzaman, M., Araújo, S., Gill, S.S. (Eds.), The Plant Family Fabaceae: Biology and Physiological Responses to Environmental Stresses. Springer Singapore, Singapore, pp. 43-74. https://doi.org/10.1007/978-981-15-4752-2_3

Rizhsky, L., Liang, H., Shuman, J., Shulaev, V., Davletova, S., Mittler, R., 2004. When defense pathways collide. The response of Arabidopsis to a combination of drought and heat stress. Plant Physiol. 134, 1683-1696. https://doi.org/10.1104/pp.103.033431

Rollins, J.A., Habte, E., Templer, S.E., Colby, T., Schmidt, J., von Korff, M., 2013. Leaf proteome alterations in the context of physiological and morphological responses to drought and heat stress in barley (Hordeum vulgare L.). J. Exp. Bot. 64, 3201-3212. https://doi.org/10.1093/jxb/ert158

Rotundo, J.L., Westgate, M.E., 2010. Rate and Duration of Seed Component Accumulation in Water-Stressed Soybean. Crop Sci. 50, 676-684. https://doi.org/https://doi.org/10.2135/cropsci2009.05.0240

Ruan, Y.-L., 2014. Sucrose Metabolism: Gateway to Diverse Carbon Use and Sugar Signaling. Annu. Rev. Plant Biol. 65, 33-67. https://doi.org/10.1146/annurevarplant-050213-040251

Sanz-Saez, A., Pérez-López, U., del-Canto, A., Ortiz-Barredo, A., Mena-Petite, A., Aranjuelo, I., Muñoz-Rueda, A., Lacuesta, M., 2019. Changes in environmental $\mathrm{CO}_{2}$ concentration can modify Rhizobium-soybean specificity and condition plant fitness and $\begin{array}{lllll}\text { productivity. } & \text { Environ. } & \text { Exp. } & \text { Bot. } & 162,\end{array}$ https://doi.org/10.1016/J.ENVEXPBOT.2019.01.013

Schär, C., Vidale, P.L., Lüthi, D., Frei, C., Häberli, C., Liniger, M.A., Appenzeller, C., 2004. The role of increasing temperature variability in European summer heatwaves. Nature 427, 332-336. https://doi.org/10.1038/nature02300

Sehgal, A., Sita, K., Kumar, J., Kumar, S., Singh, S., Siddique, K.H.M., Nayyar, H., 2017. Effects of Drought, Heat and Their Interaction on the Growth, Yield and Photosynthetic Function of Lentil (Lens culinaris Medikus) Genotypes Varying in Heat and Drought Sensitivity. Front. Plant Sci. 8:1776. https://doi.org/10.3389/fpls.2017.01776 .

Sehgal, A., Sita, K., Siddique, K.H.M., Kumar, R., Bhogireddy, S., Varshney, R.K., HanumanthaRao, B., Nair, R.M., Prasad, P.V.V., Nayyar, H., 2018. Drought or/and Heat-Stress Effects on Seed Filling in Food Crops: Impacts on Functional Biochemistry, Seed Yields, and Nutritional Quality. Front. Plant Sci. 9:1705. https://doi.org/10.3389/fpls.2018.01705 
Serraj, R., Vadez, V., Denison, R.F., Sinclair, T.R., 1999. Involvement of Ureides in Nitrogen Fixation Inhibition in Soybean. Plant Physiol. 119, 289-296. https://doi.org/10.1104/pp.119.1.289

Serraj, R., Vadez, V., Sinclair, T., 2001. Feedback regulation of symbiotic $\mathrm{N}_{2}$ fixation under drought stress. Agronomie 21, 621-626. https://doi.org/10.1051/agro:2001153

Soba, D., Aranjuelo, I., Gakière, B., Gilard, F., Pérez-López, U., Mena-Petite, A., Muñoz-Rueda, A., Lacuesta, M., Sanz-Saez, A., 2021. Soybean Inoculated With One Bradyrhizobium Strain Isolated at Elevated $\left[\mathrm{CO}_{2}\right]$ Show an Impaired $\mathrm{C}$ and $\mathrm{N}$ Metabolism When Grown at Ambient $\left[\mathrm{CO}_{2}\right]$. Front. Plant Sci. 12:656961. https://doi.org/10.3389/fpls.2021.656961.

Soba, D., Shu, T., Runion, G.B., Prior, S.A., Fritschi, F.B., Aranjuelo, I., SanzSaez, A., 2020. Effects of elevated $\left[\mathrm{CO}_{2}\right]$ on photosynthesis and seed yield parameters in two soybean genotypes with contrasting water use efficiency. Environ. Exp. Bot. 178, 104154. https://doi.org/10.1016/j.envexpbot.2020.104154

Soba, D., Zhou, B., Arrese-Igor, C., Munné-Bosch, S., Aranjuelo, I., 2019. Physiological, hormonal and metabolic responses of two alfalfa cultivars with contrasting responses to drought. Int. J. Mol. Sci. 20, 5099. https://doi.org/10.3390/ijms20205099

Sulieman, S., Schulze, J., 2010. Phloem-derived $\gamma$-aminobutyric acid (GABA) is involved in upregulating nodule $\mathrm{N}_{2}$ fixation efficiency in the model legume Medicago truncatula. Plant. Cell Environ. 33, 2162-2172. https://doi.org/10.1111/j.13653040.2010.02214.x

Vautard, R., Yiou, P., D’Andrea, F., de Noblet, N., Viovy, N., Cassou, C., Polcher, J., Ciais, P., Kageyama, M., Fan, Y., 2007. Summertime European heat and drought waves induced by wintertime Mediterranean rainfall deficit. Geophys. Res. Lett. 34. /https://doi.org/10.1029/2006GL028001

von Caemmerer, S., Farquhar, G.D., 1981. Some relationships between the biochemistry of photosynthesis and the gas exchange of leaves. Planta 153, 376-387. https://doi.org/10.1007/BF00384257

Vu, J.C. V, Allen JR, L.H., Boote, K.J., Bowes, G., 1997. Effects of elevated $\mathrm{CO} 2$ and temperature on photosynthesis and Rubisco in rice and soybean. Plant. Cell Environ. 20, 68-76. https://doi.org/10.1046/j.1365-3040.1997.d01-10.x

Xue, L., Cao, W., Luo, W., Dai, T., Zhu, Y., 2004. Monitoring Leaf Nitrogen Status in Rice with Canopy Spectral Reflectance. Agron. J. 96, 135-142. https://doi.org/10.2134/agronj2004.1350

Yin, X., Struik, P.C., 2017. Can increased leaf photosynthesis be converted into higher crop mass production? A simulation study for rice using the crop model GECROS. J. Exp. Bot. 68, 2345-2360. https://doi.org/10.1093/jxb/erx085

Yu, L., Jiang, J., Zhang, C., Jiang, L., Ye, N., Lu, Y., Yang, G., Liu, E., Peng, C., He, Z., Peng, X., 2010. Glyoxylate rather than ascorbate is an efficient precursor for

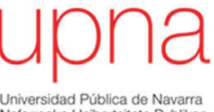


oxalate biosynthesis in rice. J. Exp. Bot. 61, 1625-1634. https://doi.org/10.1093/jxb/erq028

Zandalinas, S.I., Mittler, R., Balfagón, D., Arbona, V., Gómez-Cadenas, A., 2018. Plant adaptations to the combination of drought and high temperatures. Physiol. Plant. 162, 2-12. https://doi.org/https://doi.org/10.1111/ppl.12540

Zandalinas, S., Rivero, R., Martínez, V., Gómez-Cadenas, A., Arbona, V., 2016. Tolerance of citrus plants to the combination of high temperatures and drought is associated to the increase in transpiration modulated by a reduction in abscisic acid levels. BMC Plant Biol. 16, 105-120. https://doi.org/10.1186/s12870-016-0791-7

Zhou, R., Kong, L., Wu, Z., Rosenqvist, E., Wang, Y., Zhao, L., Zhao, T., Ottosen, C.-O., 2019. Physiological response of tomatoes at drought, heat and their combination followed by recovery. Physiol. Plant. 165, 144-154. https://doi.org/10.1111/ppl.12764 
ส

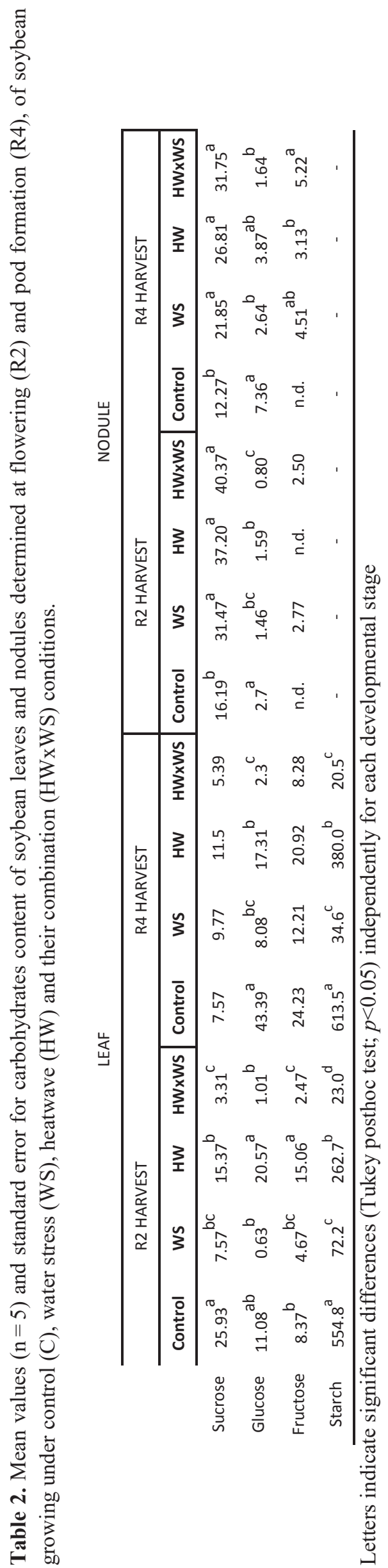




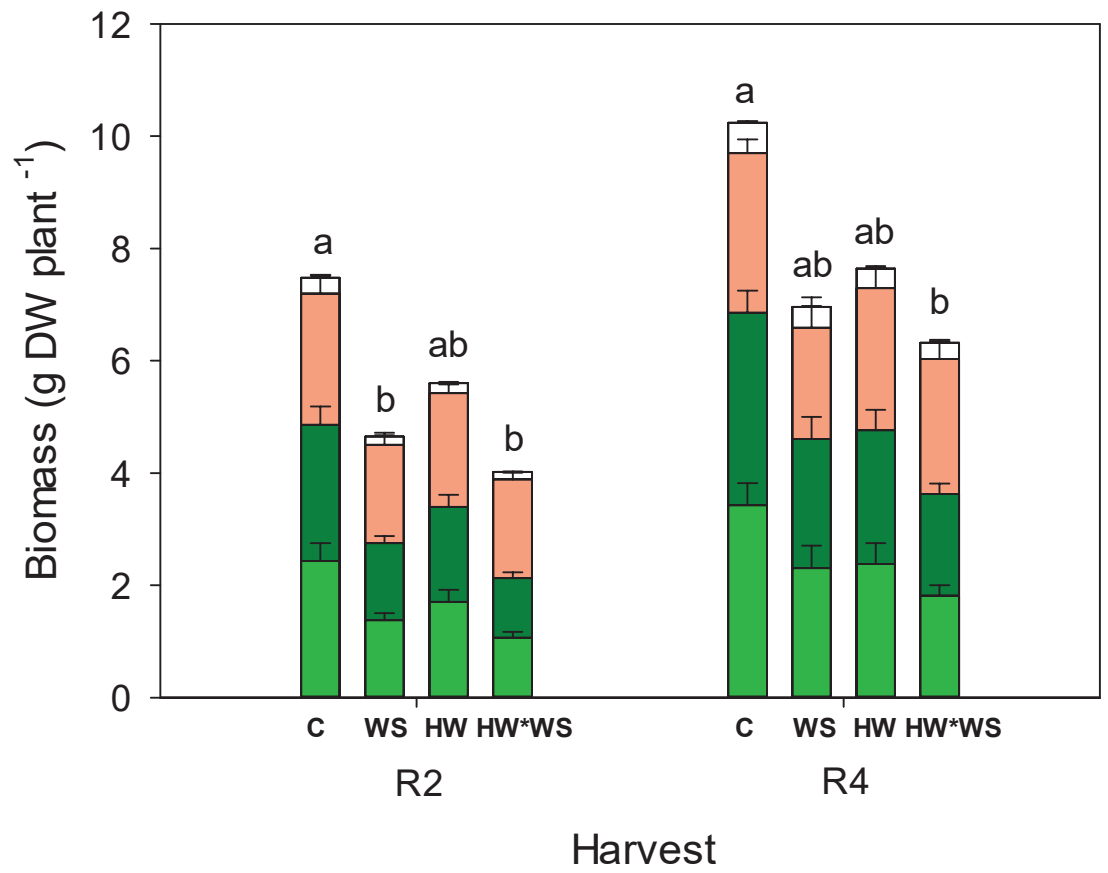

Figure 1. Leaf, stem, root and nodule biomass (g DW plant ${ }^{-1}$ ) of soybean plants growth at four conditions (control, HW, WS and HW x WS) and harvested at two different stages (R2 and R4). Bars correspond to the mean $\pm \mathrm{SE}$ of $\mathrm{n}=5$ of the biomass of each tissue. Results of statistics for total biomass (the sum of nodule, root, leaf and stem) are shown (two-way ANOVA, $p<0.05$ ). Letters indicate significant differences independently for each harvest (R2 and R4) (Tukey posthoc test $p<0.05$ ). 


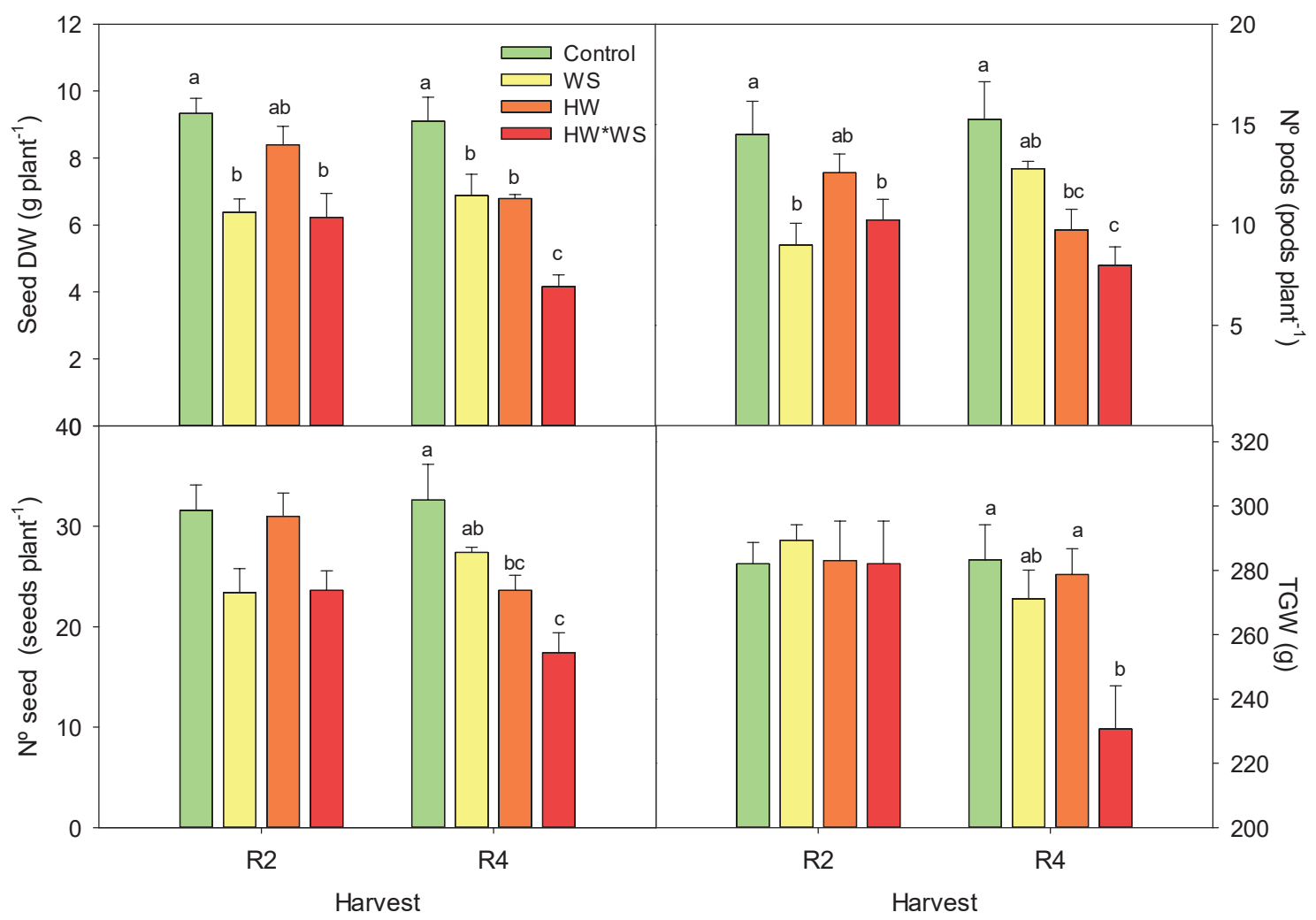

Figure 2. Seed DW, $\mathrm{N}^{\circ}$ pods, $\mathrm{N}^{\circ}$ seed and thousand seed weight (TSW) for soybean plants grown under four water and temperature treatments: control (non-heat-stressed and non-water-stressed), water-stressed $(\mathrm{WS})$, heatwave $(\mathrm{HW})$, and heatwave $\times$ water-stressed $(\mathrm{HW} \times \mathrm{WS})$ plants in two developmental stages ( 2 and $\mathrm{R} 4$ harvest). Bars expressed as mean and standard error $(\mathrm{n}=5)$. Letters indicate significant differences independently for each harvest (R2 and R4) (Tukey posthoc test $\mathrm{p}<0.05$ ). 


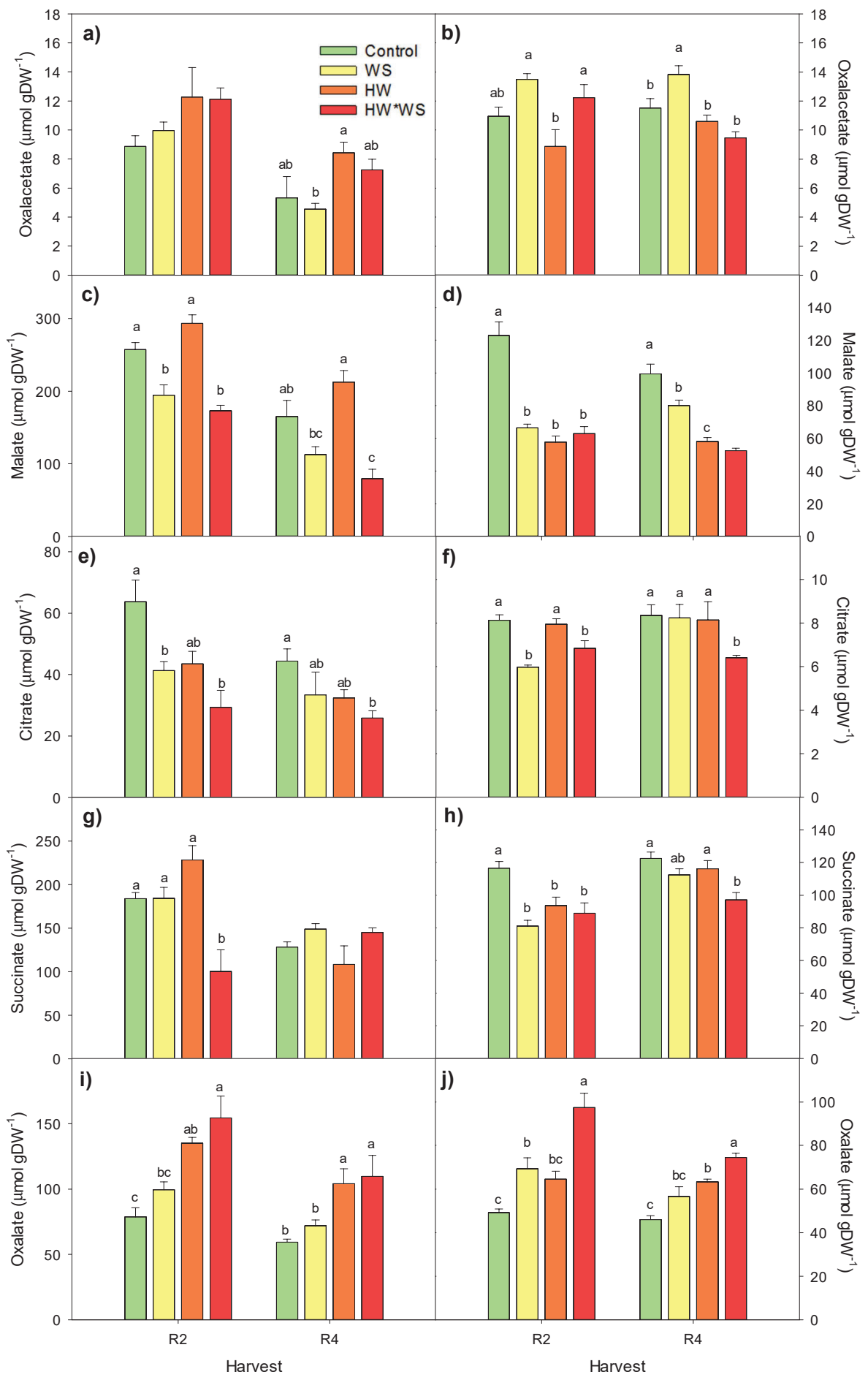

Figure 3. Organic acids contents in leaves (a, c, e, g, i) and nodules (b, d, f, h, j) of soybean plants grown under four water and temperature treatments: control (non-heat-stressed and non-water-stressed), waterstressed (WS), heatwave $(\mathrm{HW})$, and heatwave $\times$ water-stressed $(\mathrm{HW} \times \mathrm{WS})$ plants in two developmental stages (R2 and R4 harvest). Bars expressed as mean and standard error $(n=5)$. Letters indicate significant differences independently for each harvest (R2 and R4) (Tukey posthoc test $\mathrm{p}<0.05$ ). 




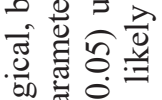

응

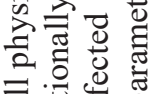

语密

运安

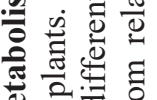

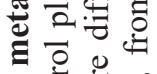

㤩泀芯

送要焉

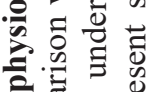

a

ङ

: $\Xi$ 蹗.

范

可 ฮ

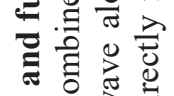

क 0

密

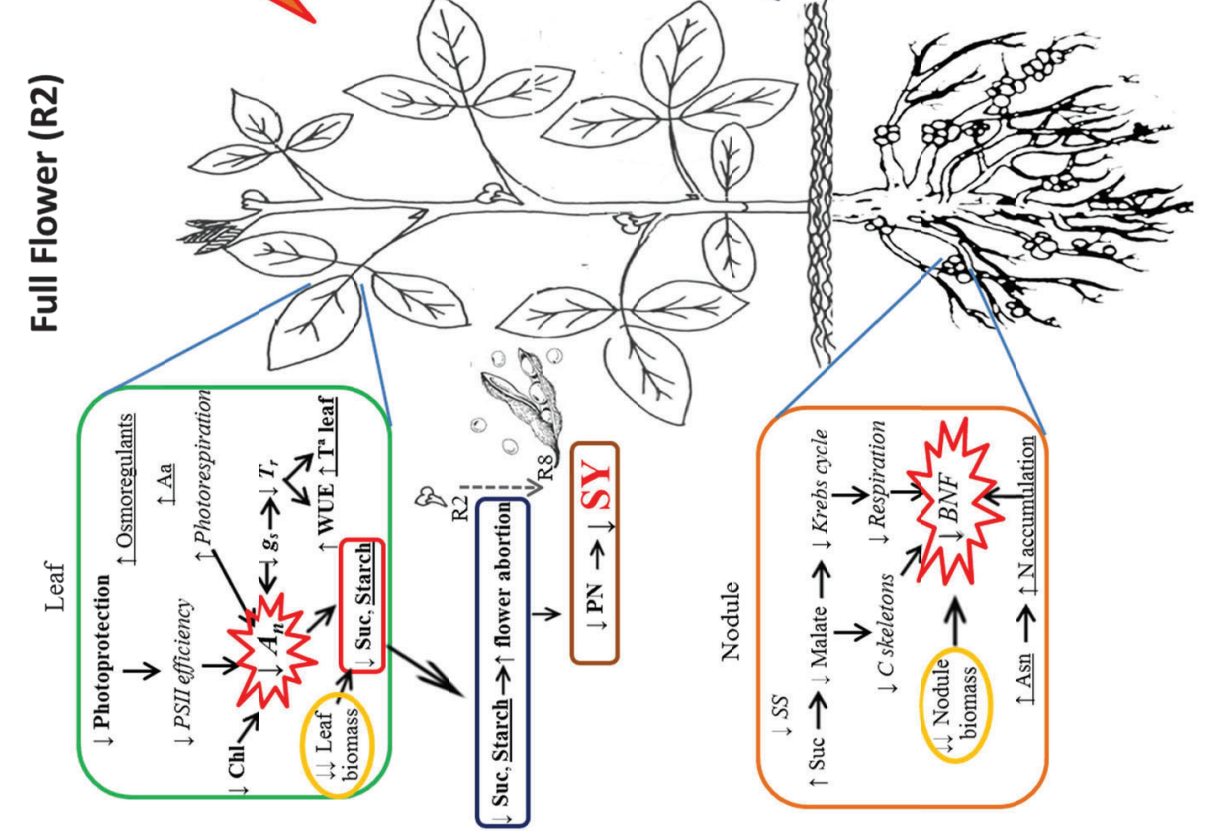

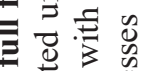

స

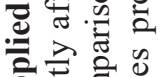

के हี छี

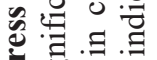

क क क

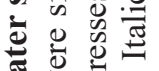

उ考

을

¿.引 है

氖它 离

造舒

है ज्ञ

क 30

-

芯芯芯芯

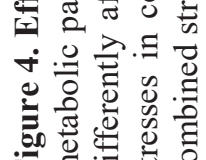


్ㅛ

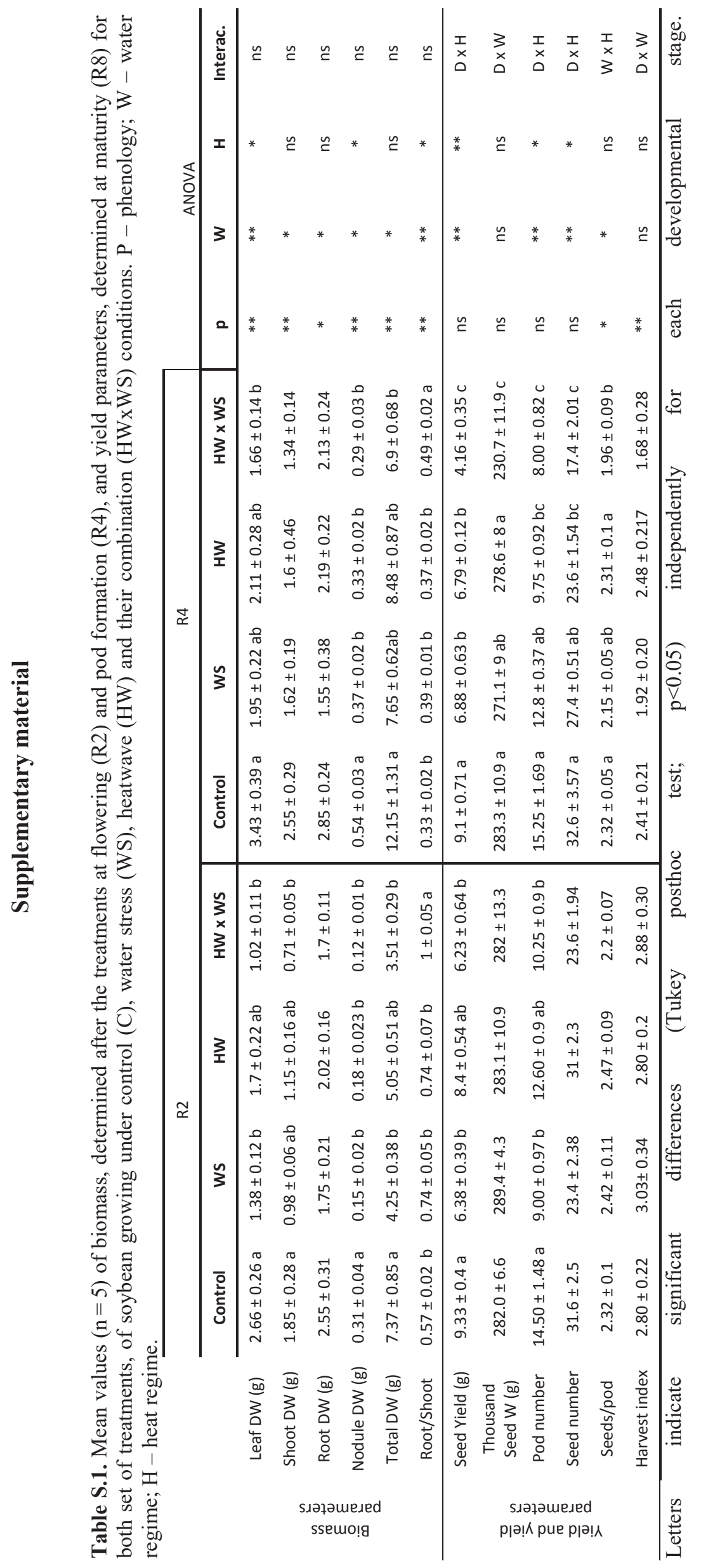


"VII. GENERAL DISCUSSION 
Global climate models predict a continuous increase in atmospheric $\mathrm{CO}_{2}$ concentration $\left[\mathrm{CO}_{2}\right]$ that may cause changes in temperature and water precipitation patterns and an increase in extreme events such as extreme heatwaves and droughts during the following decades (IPCC, 2014). Due to the impact of environmental parameters on crop yield and quality traits, it is expected that, during the coming decade's agriculture will be constrained (Zandalinas et al., 2021). This is a target issue because future global food demand continues to rise due to the population growth and increased food consumption per capita. After cereals, legumes are the second crop in agricultural importance. Legumes represent the main source of protein for humans and animal consumption (Graham and Vance, 2003). Further, their farming possess some characteristics (biological nitrogen fixation and low carbon footprint (Stagnari et al. 2017)) that made legume crops sustainable for future food and feed production. In this context, one of the greatest challenges facing agricultural research is to understand physiological, biochemical and metabolic responses of legumes to new climatic scenarios. Such information will be of great value to promote more environmental friendly agriculture able to face the increasing demands of safe and secure food.

In chapter 1, two soybean genotypes with contrasting water use efficiency (WUE) were grown in open top chambers $(\mathrm{OTC})$ under $\mathrm{a}\left[\mathrm{CO}_{2}\right](410 \mathrm{ppm})$ and $\mathrm{e}\left[\mathrm{CO}_{2}\right]$ (610 ppm) in order to study how future breeding for high WUE could interfere with the amount of carbon fixed by leaves and seed mineral composition under e $\left[\mathrm{CO}_{2}\right]$ due to lower $g_{s}$.

In chapter 2, two alfalfa cultivars with contrasting locations and drought strategies were selected and subjected to water stress conditions in order to identify the physiological, hormonal and metabolic traits conferring a better performance at whole plant level under these stressful conditions.

In chapter 3 of the present thesis, we performed a comparative study of the presence of vitamin $\mathrm{E}$ in different plant organs (leaves, roots and nodules) of three legumes (soybean, alfalfa and pea plants) with the aim to confirm their presence in belowground tissues, in special nodules. Additionally, we analyzsed their antioxidant role under water stress conditions, evaluating their relationship with the extent of membrane lipid peroxidation and nodule performance. 
Finally, in chapter 4, individual and combined effect of heatwave and drought were analyzsed during early reproductive stages in soybean plants. In order to do so, photosynthetic performance and nodule and leaf $\mathrm{C}$ and $\mathrm{N}$ metabolism were studied; in addition seed yield and yield related parameters were recorded at maturity.

\section{Production and quality}

Legume production and quality may be impaired by environmental factors associated with climate change. In pulses, like soybean, yield can be defined as the product of total dry matter accumulation and the partitioning of assimilated to seeds (Kumudini, 2002); in forage legumes, such as alfalfa, since the harvestable part are aboveground tissues, production is mainly determined by biomass accumulation (Soba et al., 2019). Therefore, environmental condition, such as $\mathrm{e}\left[\mathrm{CO}_{2}\right]$, water deficit or heatwaves, that affects $\mathrm{C}$ assimilation and the partitioning of this fixed $\mathrm{C}$ to the harvestable part, defined as HI, will influence production. Additionally, changes in biomass accumulation and transpiration due to environmental factors associated with climate change could have a significant impact on their nutritional quality and, hence, on human well-being and health (Ben Mariem et al., 2021). Therefore, in the context of global change, it is crucial to identify physiological and metabolic processes conferring a better production performance under stressful conditions.

$\mathrm{CO}_{2}$

Elevated atmospheric $\left[\mathrm{CO}_{2}\right]$ has been previously shown to increase biomass accumulation and to decrease transpiration in legumes (Ainsworth et al., 2002) and, therefore, as above mentioned, changes in production and quality should be expected. In chapter 1 , the seed yield response to $\mathrm{e}\left[\mathrm{CO}_{2}\right]$ was analyzsed on two genotypes of soybean with contrasting WUE, in order to maximize transpiration differences. The results showed that e $\left[\mathrm{CO}_{2}\right]$ increased seed yield between 65\% (Low_WUE) and 101\% (High_WUE) when compared to $\mathrm{a}\left[\mathrm{CO}_{2}\right]$, which was in accordance with previously works (reviewed by Ainsworth et al., 2002). The greater biomass accumulation and greater amount of photoassimilates partitioned from leaves to seeds could partially explain the greater increase in seed yield in High_WUE in response to e[CO $\left.\mathrm{CO}_{2}\right]$. Taking into account these two contrasting genotypes, our results suggest that selection for high WUE cultivars does not necessarily translate to lower yield benefit under e $\left[\mathrm{CO}_{2}\right]$ since 
this genotype is able to compensate the lower $g_{s}$ by increasing LA and greater nutrient remobilization to seed.

In terms of nutritional value, some studies have suggested that increased biomass and lower transpiration under $\mathrm{e}\left[\mathrm{CO}_{2}\right]$ may affect mineral composition of soybean seeds (Prior et al., 2008; Myers et al., 2014; Singh et al., 2016; Li et al., 2018). In our experiment, changes in mineral concentration were mainly due to differences between genotypes rather than between $\mathrm{CO}_{2}$ treatments. However, when both genotypes were taken together, $\mathrm{e}\left[\mathrm{CO}_{2}\right]$ consistently reduced seed $\mathrm{Zn}$ concentration, an essential mineral for the human immune system and to avoid stunted growth in children (Brown et al., 2001), (-4.5\%) in accordance with previous works (Myers et al., 2014). On the contrary, the observed higher $\mathrm{Fe}$ concentration under $\mathrm{e}\left[\mathrm{CO}_{2}\right]$ in the High_WUE genotype may be due to a continuous supply of Fe in nutrient solution and more root growth under $\mathrm{e}\left[\mathrm{CO}_{2}\right]$ that facilitated $\mathrm{Fe}$ acquisition for increased seed Fe concentration (Wiersma, 2005).

When compared between genotypes, a general trend of lower mineral concentration and greater total amount of nutrients under e $\left[\mathrm{CO}_{2}\right]$ in High_WUE compared to Low_WUE was found. This was caused by a higher seed yield $\mathrm{CO}_{2}$ response which resulted in greater total amounts of nutrients distributed throughout greater seed mass (dilution effect) as shown previously in wheat (Gifford et al., 2000; $\mathrm{Wu}$ et al., 2004) and soybean (Li et al., 2018). Since root system biomass under e $\left[\mathrm{CO}_{2}\right]$ was not different between genotypes, greater nutrient uptake in Low_WUE could be due to a greater LA that compensated for the lower transpiration per leaf area and allowed for bigger root-shoot flux of nutrients, under well watered conditions.

We conclude that $\mathrm{e}\left[\mathrm{CO}_{2}\right]$ promote seed yield in both studied soybeans genotypes. This increase was mainly due to increases in $\mathrm{C}$ fixation and, hence, more biomass accumulation that before harvest was effectively partitioned to seeds. Changes in seed mineral composition were related to dilution effect, since increases in seed yield under e $\left[\mathrm{CO}_{2}\right]$ were bigger than increases in root mineral uptake.

\section{Drought and heatwave}

One of the first effects of drought and extreme heat on plants is the inhibition of cell elongation and, therefore, of growth (Avramova et al., 2015). In opposition to 
legumes grown by their seed, in forage legumes the production is measured as aboveground biomass per unit of surface and, therefore, environmental factors affecting growth will affect production. Within species, different distribution can lead to variability in plant functional traits in response to environmental stresses (Hufford and Mazer, 2003). Therefore, research regarding differential adaptive strategies among populations within species enhances selection of appropriate traits suitable for drier future conditions (Alvarez-Maldini et al., 2020). As higher degrees of intraspecific variation have been observed in individuals from contrasting environmental conditions, in chapter 2, eight alfalfa cultivars from China and Spain were analysed under well watered and drought conditions. The results showed different cultivar drought responses, ranging from no significant changes to significant reductions in biomass and two contrasting cultivars, one from each location, were selected to analyse their intraspecific drought response. According to physiological and isotopic data, two different drought strategies were observed, indicating different drought strategies probably associated with local adaptation to water availability. While in Zhong Mu plants, a more conservative response was reflected by the diminishment of water loss through stomatal closure that also reduced $\mathrm{CO}_{2}$ fixation, thus limiting its growth, and, therefore, production under water limitation. On the other hand, San Isidro promoted root growth to enhance water uptake to replace water lost through transpiration due to its more open stomata, allowing a greater rate of carbon to be fixed and maintaining production under drought.

On the other hand, although normally studied in isolation, abiotic stresses often occur together. For example, the combination of water and temperature stresses is common in field crops and is expected to increase in the near future (IPCC, 2014), affecting their current and future production. Previously works show that pathways regulating plant responses to heat and water stress are largely distinct (Rizhsky et al., 2004) and that the addition of responses to the two single stresses is not a realistic response (Mittler, 2006; Ahmed et al., 2013; Zandalinas et al., 2018).

In chapter 4 , interesting information was observed on the impact of water and heatwave stress applied in isolation and combined at different phonologic stages in soybean plants. Drought reduced seed yield $(\sim 30 \%)$ during flowering and pod filling period. However, heatwave has only effect on seed yield only at pod formation, and at this phenological stage an additive effect of both stresses were observed on seed yield 
and a reduction of more than $50 \%$ was observed when compared to control plants. Our data suggest that when the stresses were applied at flowering, decreased seed yield under water regimen is due to flower abortion caused by insufficient sucrose supply from leaves (Farooq et al., 2017; Du et al., 2020). However, a correct photosynthetic performance in plants under heatwave allows maintaining yield similar to control plants. Therefore, as photosynthetic effects and reduction in sugar supply, were similar in water stressed plants and plants under combined effect, the final seed yield were similar reduced and no additive effect was observed.

In contrast, when applied at late pod formation, yield reductions in plants under combined stresses were significantly higher compared with the other treatments. Seed yield reduction was associated with the diminutions in pod and seed number and reductions in seed size, suggesting a poor photoassimilates supply that may indicate that the photosynthetic capacity of these plants may not be fully recovery when the stresses were ceased. The sum of reduced pod and seed number and seed size can help to explain the additive effect of heatwave and water stress on seed yield during late pod formation (Egli et al., 2005; Puteh et al., 2013). Overall, we suggest pod formation as the most critical stage for seed yield determination since pod number (later reduction in pod number would not expected (pods are already formed)) and seed size can be altered by abiotic stresses.

\section{Leaf metabolism}

Leaves have a primary role in the production and transport of photoassimilates to the harvestable parts. As a result, a correct leaf performance is close related with production. Exposure to environmental stresses induces numerous physiological responses in plants, between them alterations in photosynthetic efficiency, water flux in the plant and photoassimilates translocation are the most frequently impacted processes (Morales et al., 2020).

\section{Elevated $\mathrm{CO}_{2}$ concentration}

Elevated $\left[\mathrm{CO}_{2}\right]$ impact on plant performance could be indirectly, through its effect on air temperature and water stress, and directly, mainly through its positive role in photosynthesis and dry matter accumulation (Dusenge et al., 2018). Previous studies carried out in soybean plants exposed to $\mathrm{e}\left[\mathrm{CO}_{2}\right]$ have shown a reduction in stomatal 
conductance $\left(\mathrm{g}_{\mathrm{s}}\right)$ and enhanced photosynthesis rate $\left(A_{n}\right)$, WUE, growth and yield (Rogers et al., 1983; 1984; Sionit et al., 1984; Ainsworth et al., 2002; Ainsworth and Rogers, 2007; Prior et al., 2010). Within this context, some authors suggest that legume responses to $\mathrm{e}\left[\mathrm{CO}_{2}\right]$ could partialy offset other negative effects of climate change (Lobell and Gourdji, 2012). Future breeding for greater WUE has been proposed as a strategy for enhancing yield in certain environments (Condon et al., 2004; Gilbert et al. 2011; Sinclair, 2012), in order to reduce water loss through transpiration. However significant limitations may appear since lower $\mathrm{g}_{\mathrm{s}}$ will influence leaf internal $\left[\mathrm{CO}_{2}\right]\left(C_{i}\right)$ (Earl, 2002), thereby diminishing C fixed by photosynthesis. Taking this into account, in chapter 1, we hypothesise that in future $\mathrm{CO}_{2}$ scenarios, breeding for high WUE genotypes could interfere in the amount of carbon fixed by photosynthesis. We tested the hypothesis by growing two soybean genotypes previously selected by their contrasting WUE (Danaphal et al. 2015) in open top chamber (OTC) under a $\left[\mathrm{CO}_{2}\right]$ (410 ppm) and e[CO $\left.\left.\mathrm{CO}_{2}\right] 610 \mathrm{ppm}\right)$.

Differenced responsiveness of photosynthetic machinery under different $\left[\mathrm{CO}_{2}\right]$ or genotype could be due to: i) changes in photosynthetic efficiency of $\mathrm{C}$ fixation per unit of area; ii) changes in light interception through increases leaf area (LA). With the aim to distinguish between these two factors photosynthetic measures were taken at both: leaf and canopy level during grain filling period.

At leaf level, the genotype selected by their low WUE (Low_WUE) showed a significant increase in daily photosynthetic $\mathrm{C}$ gain $\left(A^{\prime}\right)$, estimated by integrating the area under the leaf photosynthesis curve through the day, in opposition to the genotype with high WUE (High_WUE). When taking together all the measures used for $A$ ', we observed the same trend for $A_{n}$ even with a general decrease in $g_{s}$ with increasing $\left[\mathrm{CO}_{2}\right]$ mainly due to the fact that stomatal closure did not affect $C_{i}$ (Figure 1). Therefore, under e $\left[\mathrm{CO}_{2}\right]$, an increase in $A_{n}$ was observed due to a greater $C_{i}$, in special in Low_WUE genotype, that allow the leave to close stomata with the subsequent decrease in water loss. Another reason for the higher $A^{\prime}$ and $\mathrm{e}\left[\mathrm{CO}_{2}\right]$ stimulation observed in Low_WUE may be the greater $\mathrm{Vc}_{\max }$ and $\mathrm{J}_{\max }$ observed in this genotype at the beginning of pod filling, indicating lower biochemical limitations of photosynthesis in this genotype (Morales et al., 2020). Therefore, our data showed that High_WUE had lower $A^{\prime}$, probably due to diffusive (lower $g_{s}$ ) and biochemical (lower $\mathrm{Vc}_{\max }$ and $\mathrm{J}_{\max }$ ) related limitations.

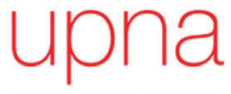




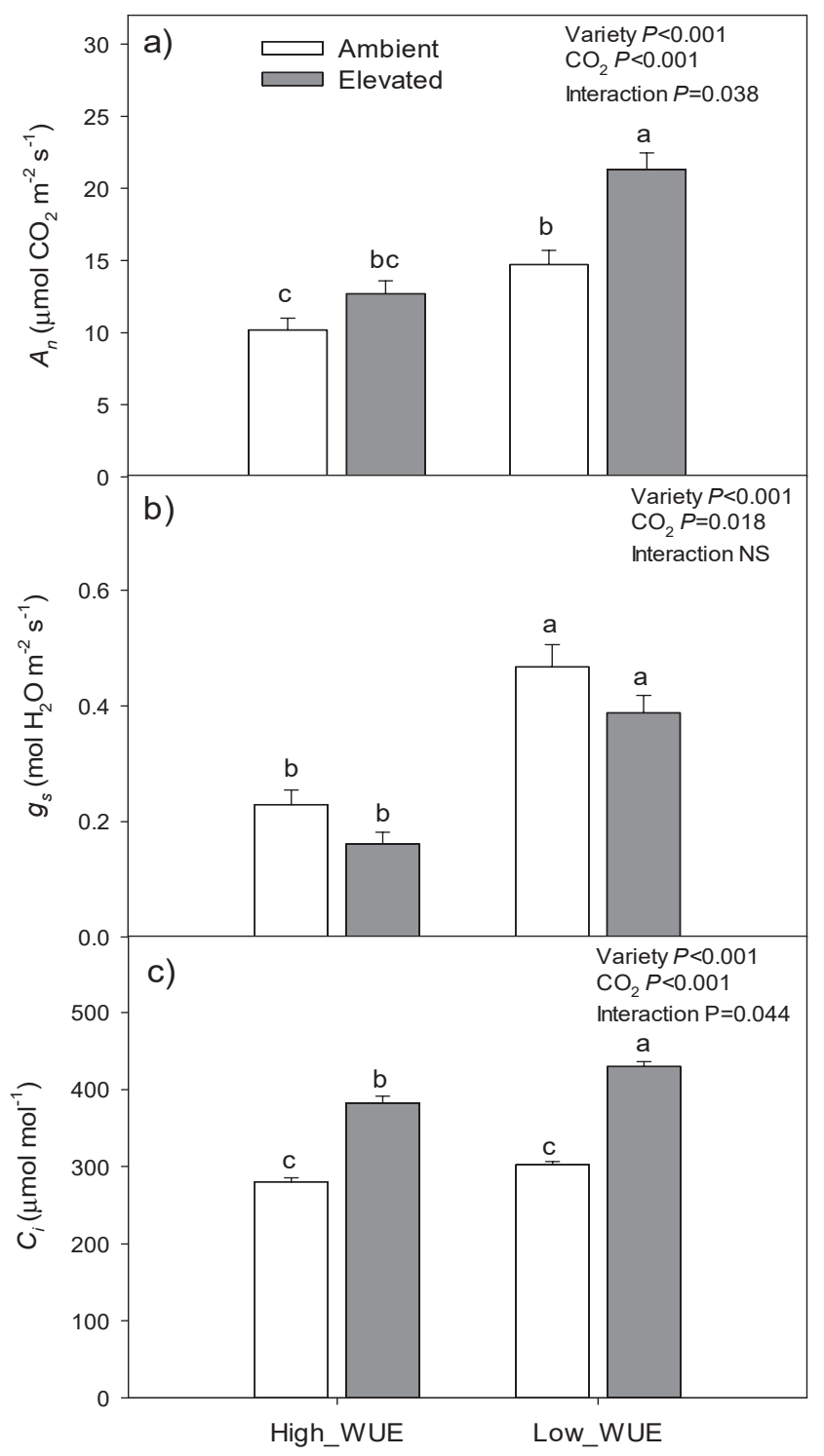

Figure 1. (a) Leaf photosynthetic rate $\left(A_{n}\right)$; (b) Stomatal conductance $\left(g_{s}\right)$; (c) Sub-stomatal $\left[\mathrm{CO}_{2}\right]\left(C_{i}\right)$ in leaves of two soybean genotypes grown under grown under ambient and elevated $\left[\mathrm{CO}_{2}\right]$. The bar chart shows the average of four replicate OTC's for each treatment $(\mathrm{n}=4)$. Results of statistics are shown (two-way ANOVA, $\mathrm{P}<0.05$ ). Letters indicate significant differences between treatments or genotypes (Tukey post hoc test $\mathrm{P}<0.05)$. NS, not significant.

However, High_WUE genotype compensated the lower $A$ ' by producing more leaf area (LA) to increase light interception. Increased LA in High_WUE in response to $\mathrm{e}\left[\mathrm{CO}_{2}\right]$, helps explain why canopy photosynthesis was similar in both genotypes. In conclusion, our findings demonstrate soybean intraspecific variations in photosynthetic responses to future atmospheric $\left[\mathrm{CO}_{2}\right]$. In opposition to our initial hypothesis, under 
proper irrigation, selection for higher WUE does not necessarily mean selecting against a greater $\mathrm{C}$ fixation response at $\mathrm{e}\left[\mathrm{CO}_{2}\right]$ and, as shown before, the observed grater leaf biomass in this genotype was translated to greater seed yield in both $\mathrm{CO}_{2}$ conditions when compared to Low_WUE genotype.

\section{Drought and heatwave}

Drought is considered the most limiting factor for plant growth (Bray, 1997). Plant response to water limitation is a trade-off between saving water by reducing transpiration, and capturing carbon through photosynthesis. Therefore, variation in photosynthesis is between the key physiological alterations in plants exposed to environmental stresses, like drought (Morales et al., 2020). The preliminary experiment carried out in chapter 2 with eight varieties of alfalfa showed that, exposure to drought reduced their $A_{n}$ (by -43.8 to $-78.3 \%$ ) associated with a general reduction of $C_{i}$ linked with the lower $g_{s}$ (from -58.2 to $-80.2 \%$ ). Within this trend, intraspecific variation was observed. The physiological analysis of the two alfalfa cultivars selected for their contrasting origin and drought response showed different strategies. For example, Zhong $\mathrm{Mu}$ response to water limitation was to maintaining the leaf relative water content through fast stomatal closure in order to limit water loss. As a consequence, $\mathrm{CO}_{2}$ diffusion from the atmosphere to the sub-stomatal cavity was reduced, decreasing their $A_{n}$ under water stress. This response to water limited condition has been reported in several crops, from wheat (Marček et al., 2019) to grapewine (Flexas et al., 2009). On the contrary, San Isidro cultivar, maintained its $\mathrm{C}$ fixation by replacing the water loss by transpiration with a more developed root system. These morpho-physiological observations were in accordance with isotopic information. Carbon isotope discrimination $\left(\Delta^{13} \mathrm{C}\right)$ has been used as a long-term plant water status indicator (Yousfi et al., 2012). The lower leaf and root $\Delta^{13} \mathrm{C}$ values in Zhong $\mathrm{Mu}$ were suggesting lower transpiration and greater WUE in comparison with San Isidro cultivar. This gas exchange intraspecific differences resulted in different biomass accumulation and, as shown before, differences in production between cultivars.In chapter 4 soybean under water stress (WS), heatwave (HW) and under their combined effects were analyzed. When compared to control all treatments showed a significant reduction in leaf biomass and this were the most affected tissue. Therefore, due to the close relation between plant photosynthetic capacity and the photosynthetic area of the plant, lower leaf biomass is expected to reduce photoassimilates production and export to harvestable parts. 
Additionally, as observed in Chapter 2, stomatal closure reduced the flow of $\mathrm{CO}_{2}$ entering in the leaf with the consequence of reduced photosynthetic rate. However, when these plants were subjected to HW the differences in gas exchange measures were not significant compared with control plants.

Those studies showed the fact that, in general, water stress caused a decrease in leaf biomass that, together with reductions in the photosynthetic efficiency (lower $g_{s}$ and sub-stomatal $\left[\mathrm{CO}_{2}\right]$ and $\mathrm{Chl}$ concentration), produced a fall in $\mathrm{C}$ assimilation and legume productivity (Medrano et al., 2002). As shown in chapter 2, this drought related stomatal closure is mediated by the phytohormone ABA. Regarding heat stress impact, opposition to what described in previous works (Vu et al., 1997; Mathur et al., 2014; Jumrani and Bathia, 2019) we did not observe photosynthetic affection when soybean plants were subjected to heatwave, probably due to enough water supply and, hence, stomatal opening to reduce leaf temperature (Katam et al., 2020). Finally, in cases where water and heat stresses were combined, we observed that, regardless of analyzed phonologic stages, stomatal response to WS prevailed over that to HW. Such results would reveal that, in the balance between preventing water loss and protecting from over-heating, seems that avoidance of water loss prevail.

In addition to diffusive related limitations, under WS (alone or combined with HW) plants showed an increase in photodamage of the photosystem II (PSII) (Chapter 4), probably due to an increase in the production of ROS (Chapter 3). On the contrary, photoinhibition of PSII activity was not found in soybeans under HW alone, which was in accordance with the lack of deleterious effects observed in gas exchange measures. This was in opposition with previously findings (Vu et al., 1997; Jumrani and Bathia, 2019), probably due to the short period of extreme high temperatures in our experiment in contrast with high temperature maintained during entire phases of plant growth in these experiments (Jumrani and Bathia, 2019; Killi et al., 2020).

The described decrease in photosynthetic performance under water regimen in alfalfa (chapter 2) and soybean (chapter 4) is translated into changes in the synthesis of carbohydrates. In alfalfa, decreased of leaf sucrose, the principal form of photoassimilates for long distance transport depends on cultivar. The water saving cultivar, through reducing photosynthesis and growth, were the one with significant decrease in leaf sucrose content. Contrary, the one that maintain their growth, through a 
bigger root system to replace water loss by transpiration, did not showed significantly changes in leaf sucrose content. In soybean, changes in leaf sucrose were significant between treatment during flowering but not at pod formation. However, decreases in other carbohydrates (glucose and starch) were significant at both developmental stages.

Therefore, although leaf carbohydrates seem to be reduced under water scarcity (chapters 2 and 4) and heatwave or their combination with drought (chapter 4) changes seem to be dependent on cultivar and phenological stage. Reduction in leaf carbohydrates may be due to a reduced photosynthetic performance, hydrolysis to other compounds or export to other tissues. In addition, leaf organic acids such as malate and citrate were reduced in soybean under drought (and their combination with heatwave) suggesting lower Krebs cycle activity under this treatments. On the other hand, high levels of oxalate, glycine and serine in soybean under heatwave (alone or combined with drought) seems to be related with an enhanced in photorespiration (Fahnenstich et al., 2008; Rollins et al., 2013; Soba et al., 2021) under high temperature (Sicher et al., 2015). Photorespiration could protect photosynthesis from photoinhibition as previously reported (Kozaki and Takeba, 1996; Vos et al., 2013), dissipating excess of energy and reducing ROS formation under heatwave condition (Rollins et al., 2013).

Under water limiting conditions, plants respond by changing their levels of endogenous hormones. Between them, ABA has been shown to be the main phytohormone involved in the rapid orchestration of the stress response (Schroeder et al., 2001). Our data showed that the alfalfa cultivar with lower stomatal conductance, according with isotopic data, showed higher contents of $\mathrm{ABA}$, suggesting their role in stomatal closure under drought (Wilkinson and Davies, 2010). Similarly, salicylic acid is also accumulated in leaves under drought as previously reported (Abreu and MunnéBosch, 2007), suggesting that these two are the main phytohormones involved in drought response.

In chapters 2 and 4 the solely source of $\mathrm{N}$ in the plants was the nitrogen fixed by nodule roots. Therefore, the reduction in $\mathrm{N}$ leaf content in alfalfa plants under drought and in soybean plants under drought when compared with heatwave could be due at the last to an impaired nitrogen fixation through legume nodules (Soba et al., 2019; 2021). In accordance, leaf Asn, Asp and Glu were decreased in alfalfa and Asp and Ala in soybean leaves under water limitation when compared with control and heatwave plants 
respectively. This amino acids depletion at leaf level may be indicating a nitrogenase activity inhibition. In addition to lower nodule performance, lower transpiration, related with stomatal closure (Serraj et al., 2001,) and remobilization of $\mathrm{N}$ from the leaf towards reserve organs (Aranjuelo et al., 2011), such as roots (chapter 2) or pods (chapter 4), could be under the observed drought related decrease in leaf $\mathrm{N}$ compounds.

\section{Nodule performance under changing environmental conditions}

\section{Nodule antioxidant response to lipid peroxidation (Chapter 3)}

Due to their intense biochemical activity nodules are sites of high risk of oxidative damage due to the production of reactive oxygen species (ROS) (Matamoros end Becana, 2020). Nitrogen-fixing nodules are well equipped with small molecules and enzymes to cope ROS, suggesting an important connection between $\mathrm{N}_{2}$-fixation and antioxidants activity (Becana et al., 2010; Wang et al., 2016). Lipid peroxidation is the oxidative damage of membrane lipid and has been widely described in photosynthetic tissues, however in non-photosynthetic subterranean tissues, such as root and nodules, the extent of lipid peroxidation or the presence of the main antioxidant inhibiting lipid peroxidation propagation, vitamin E, has been much less studied. For example, lipid peroxidation has been previously described in both, determinate (Gogorcena et al., 1997; Evans et al., 1999; Matamoros et al., 2018) and indeterminate nodules (Swaraj et al., 1995; Naya et al., 2007; Palma et al., 2014; Wang et al., 2016; Tysiganov et al., 2020; Irshad et al., 2021); however, the presence of vitamin $\mathrm{E}$ has been only showed in nodules of soybean (Evans et al., 1999).

In the present thesis, nine tocochromanols $(\alpha-, \beta-, \gamma-, \delta$-tocopherols and tocotrienols, also known as vitamin E, but also plastochromanol-8) were analyzsed in legume nodules of three different species (alfalfa, soybean and pea). Although $\alpha$ tocopherol is universally distributed in the plant kingdom and is the predominant vitamin E form in photosynthetic tissues (Muñoz and Munné-Bosch, 2019), $\alpha$ tocopherol has been only described in legume nodules by Evans et al. (1999). The presence of $\alpha$-tocopherol in nodules was determined by HPLC, as in Evans et al. (1999), but later also independently confirmed by using HPLC-MS/MS (Soba et al., 2020). Their presence was found in all three legume species studied, suggesting a widespread presence in this tissue, however more research is needed to confirm this point. Additionally, the presence of $\beta$-tocopherol was for the first time described in legume 
nodules, however this compound was only found (above detection limits) in alfalfa nodules (always in lower contents than $\alpha$-tocopherol) and, therefore, may not be present widely in other species. The other seven tocochromanol were under limit detection or were not confirmed by HPLC-MS/MS.

The current study revealed that in plant nodules, tocochromanol pathway is predominantly diverted to the formation of $\alpha$-tocopherol. The predominance of this tocopherol homologue has been extensively reported in photosynthetic organs (Szymanska and Kruk, 2008; Falk and Munné-Bosch, 2010), but is the first time to be described in underground nodules. The intraspecific levels of $\alpha$-tocopherol were found to be strongly differents, with higher levels on indeterminate (alfalfa and pea) when compared to determinate nodules (soybean). We hypothesize that on indeterminate nodules, new nodule meristem plays key role in vitamin E production or make stronger sink for remobilization of vitamin E from sources (leaves) (Muñoz and Munné-Bosch, 2019); however, this aspect requires further investigation.

Under drought, $\alpha$-tocopherol concentration and the extend of lipid peroxidation in legume nodules were used to evaluate the relationship between vitamin E and lipid peroxidation damage in nodules. The results from the three studied species showed a strongly significant and negative correlation between variables. In general terms, we observe that greater vitamin E content implied lower lipid peroxidation in nodules, supporting the hypothesis that vitamin $\mathrm{E}$ acts as an antioxidant in nodules, protecting against membrane damage caused by ROS.

In nodules under environmental limiting conditions, BNF efficiency is negatively affected, among other reasons, by the effect of oxidative damage (Naya et al., 2007; Aranjuelo et al., 2014). The formation of ROS under abiotic stresses has been related with the decreased in $\mathrm{O}_{2}$ permeability, leading to an $\mathrm{O}_{2}$ restriction to the bacteroid (Witty et al., 1986), and with nodule senescence (Zahran et al., 1999). Both consequences are close related with decreasing nodule performance (Aranjuelo et al., 2014). The hypothesis of vitamin $\mathrm{E}$ as an antioxidant protecting against ROS formation and, therefore, promoting nodule performance in legumes, was tested. To do this nodule $\alpha$-tocopherol content and nodule performance, estimated as ${ }^{15} \mathrm{~N}$ isotope labelling $\left(\delta^{15} \mathrm{~N}\right)$, were pooled together. As a result the correlation was significant and positive when all three species were taken into account and in particular in alfalfa when studied 
separately. This suggest that an increase in nodule performance, and therefore of nodule nitrogen fixation, occurred when $\alpha$-tocopherol contents were enhanced, particularly in alfalfa.

Nodule functioning under drought and heat conditions

Previous studies (Serraj et al., 1999; Streeter, 2003) show that soil water limitation inhibits nodule initiation, nodule growth and development, as well as nodule function. In fact, inhibition of BNF has been shown to precede photosynthesis inhibition in drought stressed legumes (Djekoun and Planchon, 1991). Under abiotic stresses, the mechanism associated with nitrogen fixation inhibition in legume nodules are: (i) reduction of photoassimilates to the bacteroid; (ii) accumulation of nitrogen compounds in the nodule (iii) decreased permeability of $\mathrm{O}_{2}$; and (iv) oxidative stress (Aranjuelo et al., 2014). However, most part of studies analyzing nodule stress-related effects had been carried out only under drought conditions.

In terms of nodule biomass, soybean nodule DW decreased under drought, heatwave or the combined stressed conditions (Chapter 4), in accordance with previous studies (Streeter, 2003). However, in alfalfa, drought treatment had positive, but not significant, effect on nodule DW (chapter 2).In this crop, increasing nodule biomass under water limitation has been recently described (Molero et al., 2019). This biomass specific drought response could be due to the fact that legumes exporting ureides (allantoin and allantoic acid, such as soybean) from the nodules are generally more sensitive to drought stress than those that export amides (principally glutamine (Gln) and asparagine (Asn), such as alfalfa) (Sinclair and Serraj, 1995; Valentine et al., 2018), making the last advantageous in water limited conditions/regions.

Nodule performance, of soybean, alfalfa and pea plants was strongly affected by water stress (chapter 3). Additionally, in chapter 2, nodule functioning in alfalfa was also calculated as the ratio between total $\mathrm{N}_{2}$ fixed and nodule biomass, also decreasing under water limited conditions. As previously described, drought-related decreased in nodule functioning has been well documented. Under these conditions, nodule Nfixation inhibition has been reported to be caused by a decrease in nitrogenase $\left(N_{\text {ase }}\right)$ activity due to a reduction of carbohydrates and $\mathrm{O}_{2}$ availability to the bacteroid and by increasing accumulation of N-compound and oxidative stress (Aranjuelo et al., 2008; Larrainzar et al., 2009; Soba et al., 2019) (Figure 2). However, nodule functioning 
under heat, and in special under combined stresses, has not been characterized in detail, highlighting the necessity to conduct further studies considering these factors (Aranjuelo et al., 2014).

Nitrogen fixation is fuelled by the provision of reduced carbon from the plant that is essential to provide sufficient ATP and reducing power and to synthesize carbon skeletons which act as $\mathrm{NH}_{2}$ acceptors (Aranjuelo et al., 2014). Although under water stress, photosynthetic capacity is generally reduced, nodule photoassimilates availability was not affected since an accumulation of sucrose was observed in water stressed alfalfa (chapter 2) and soybean plants (chapter 4). The same was observed in soybean nodules of plants subjected to heatwave or water stress and heatwave combination (chapter 4). Under both stresses, a decrease in sucrose synthase activity seems to be under this sucrose accumulation (Gonzalez et al., 1995; Galvez et al., 2005) and the consequent observed decrease in dicarboxylic acids, mainly malate, the main substrate for nodule respiration. Malate, and other organic acids, depletion was observed in nodules of soybean under drought, heatwave and their combination (chapter 4). This decrease in $\mathrm{C}$ bacteroid availability could, partially, explain the reported decrease in nodule functioning in chapter 1 and 3.

Additionally, under drought conditions there is an increase in nodule $\mathrm{N}$ compounds, such as Asn in alfalfa (chapter 2) and aspartic acid (Asp) and Asn in soybean (chapter 4) nodules that could have induced $\mathrm{N}$ feedback inhibition that affected $N_{\text {ase }}$ activity negatively (King and Purcel, 2005; Ladrera et al., 2007; Larrainzar et al., 2009) (Figure 2). As it is shown in chapters 2 and 4, the lower leaf $\mathrm{N}$ demand and leaf transpiration may be under specific nodule amino acid accumulation (Serraj et al., 2001; Soba et al., 2019) when subjected to water stresses or combined water stress and heatwave conditions. However, when heatwave was applied in isolation, lower leaf $\mathrm{N}$ demand and lower transpiration were not observed in soybean plants and as a consequence $\mathrm{N}$ related compound were not accumulated in nodules (chapter 4).

Under environmental stresses like drought, plants respond by changing the levels of endogenous phytohormones, playing a central role in the rapid orchestration of the stress response. Phytohormones have been previously studied in aboveground organs (Verma et al., 2016; Alhaithloul et al., 2020) or during nodule formation (Ferguson and Mathesius, 2014; Liu et al., 2018); however, in adult nodules remain largely unstudied. 
In alfalfa nodules under drought, an increase in abscisic acid (ABA) and gibberellins and a reduction in jasmonic acid (JA) were observed (chapter 2). Abscisic acid is considered the most important plant hormone regarding the plant response to drought. Despite this, the role of ABA in nodule function has not been extensively explored (Valentine et al., 2018). Cho and Harper (1993) showed that application of ABA to soybean decreased the nodule number and weight and Gonzalez et al. (2001) reported, in pea, that ABA drastically reduced SNF and in particularly decreased Lb content. Jasmonic acid has been reported to be a negative regulator in the initials moments of nodulation (Nakagawa and Kawaguchi, 2006; Sun et al., 2006); on the contrary, gibberellins has been suggested to control nodule formation; however, has not been previously described in mature nodules. Nevertheless, reduced JA and enhanced gibberellins on alfalfa nodules under drought conditions might involve an enhancement of nodule formation, compensating their reduced efficiency as observed by the enhancement of nodule biomass under these stressful conditions..

Another target mechanism involved on the adequate functioning of nitrogen fixation machinery is oxidative stress (Naya et al., 2007; Becana et al., 2010). As shown previously, under drought a negative correlation between legume nodule vitamin $\mathrm{E}$ content and the extent of lipid peroxidation and a positive correlation between vitamin $\mathrm{E}$ and nodule performance was observed (chapter 3), suggesting an oxidative stress due to drought and an active antioxidant response. Another sign of oxidative stress under water stress could be the accumulation of specific compound such as the amino acids proline (Pro) and $\gamma$-aminobutyric acid (GABA) observed in alfalfa (chapter 2) and soybean (chapter 4) nodules, that have been observed to have a protective role against ROS (Michaeli and Fromm, 2015; Defez et al., 2017).

In conclusion, the observed nodule $\mathrm{N}$-fixation inhibition under drought conditions (chapter 2 and 3) may be due to carbohydrate shortage to the bacteroid (chapter 2 and 4), nodule accumulation of nitrogenous compounds (chapter 2 and 4) and oxidative stress (chapter 3) (Figure 2). The same BNF limiting conditions were observed in soybean nodules under combined water stress and heatwave conditions (chapter 4) (Figure 3b). In contrast, nodules of soybean plants subjected to heatwave were capable to properly maintain $\mathrm{N}$ aboveground demand and only a significant increase of sucrose content and a decrease in nodule malate level were observed (Figure 3a). This was suggesting that heatwave alone were not able to disrupt nodule 
performance, as aboveground plant $\mathrm{N}$ content were similar to control plants. However, more research is needed with different legumes and different temperature conditions to confirm these observations.

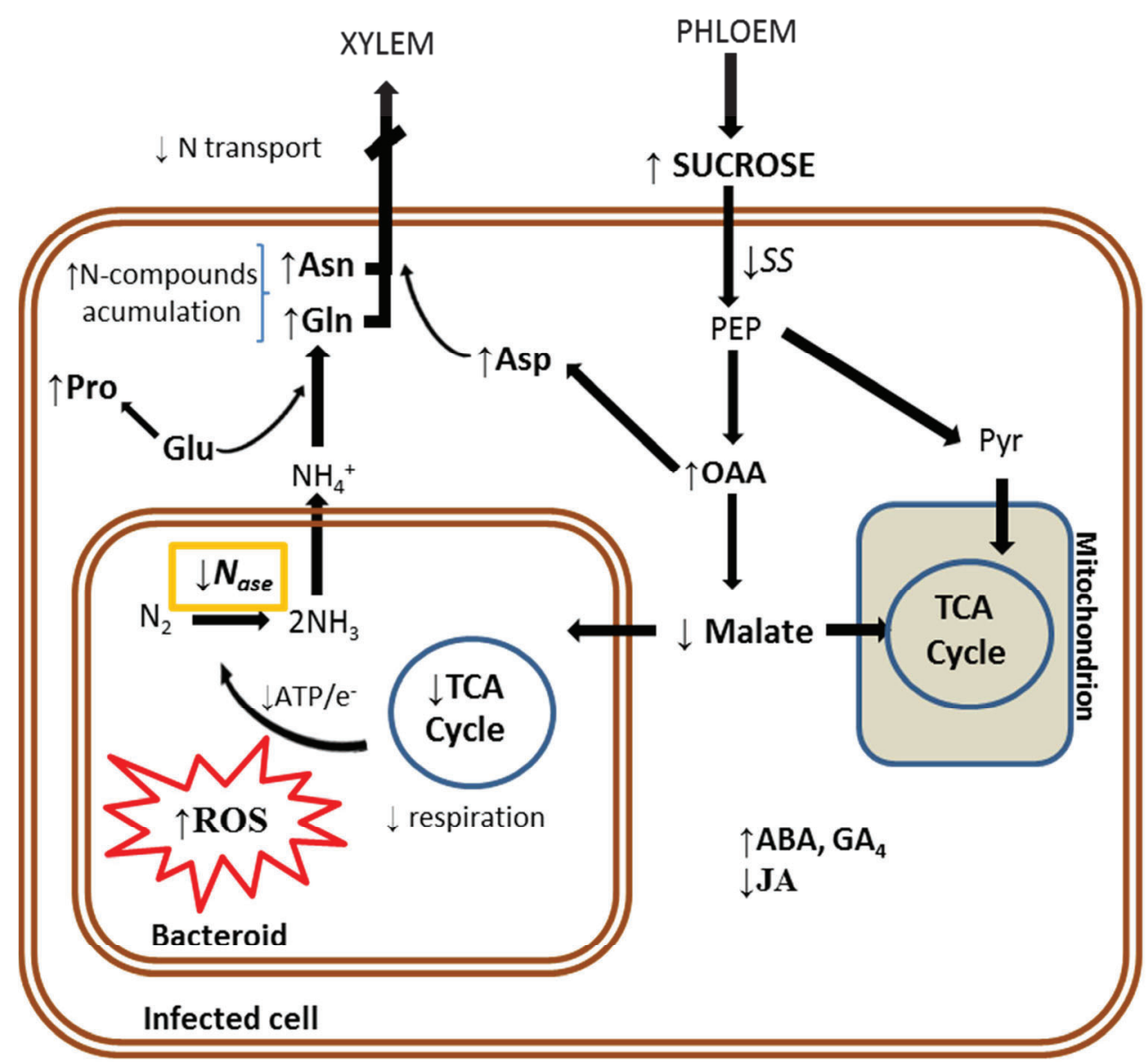

Figure 2. Model representing changes in nodule metabolism exposed to water stress. This figure is a summary representing the main finding of the present thesis. Arrows up ( $\uparrow$ ) and down $(\downarrow)$ represents compounds/reactions whose content/activity was up- or downregulated 

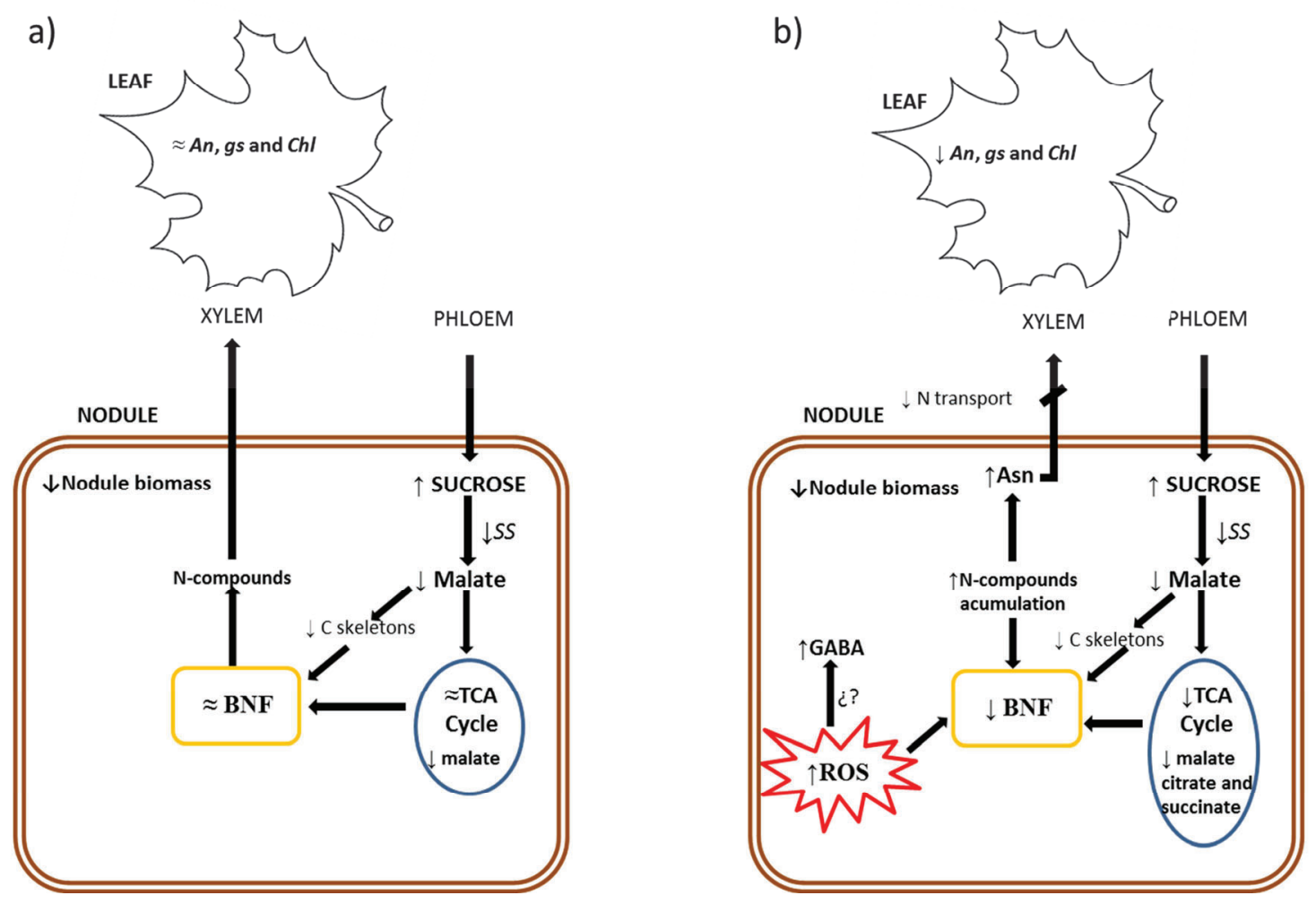

Figure 3. Model representing changes in soybean nodule metabolism exposed to a) heatwave and b) combined water and heatwave stresses. This figure is a summary representing the main finding in the chapter 4 of the present thesis. Arrows up ( $\uparrow)$ and down $(\downarrow)$ represents compounds/reactions whose content/activity was up- or down-regulated 


\section{Perspectives and constraints}

The present thesis provides new target points for further investigations of factors conditioning crop performance under changing environmental conditions. Among the main points that could be interesting to further analyse we could remark the following ones:

In Chapter 1, the importance of genetic variation (on parameters such as water use efficiency, WUE) in response to future $\mathrm{CO}_{2}$ conditions was analysed. This genetic variation should be considered when breading for future predicted environmental conditions. Further, the relevance of having contrasting WUE should be tested within interacting growth conditions (such as drought or heatwaves) in combination with $\mathrm{e}\left[\mathrm{CO}_{2}\right]$.

In Chapter 2, an important effort has been made in order to better understand the exchange metabolites between above/under-ground organs under water deficit conditions in nitrogen fixing legumes. However, transport of photoassimilates and Nfixation products between organs through xylem/phloem would deserve specific analyses in order to more clearly remark the role of the different compounds in crop development.

Chapter 3 shows, for the first time, the presence of $\alpha$-tocopherol in different types of legume nodules (determinate/indeterminate), which opens new target points in the study of this antioxidant in below-ground tissues. Further, a more specific characterization on the role of tocopherols should be carried out so to better understand of their regulatory mechanism under abiotic stresses or their relation with reactive oxygen species (ROS) in nodules in order to assess if redox stress module $\alpha$-tocopherol concentration. On the other hand, we described for the first time the presence of $\beta$ tocopherol in nodules of alfalfa; however, unlike in the case $\alpha$-tocopherol, this was not confirmed by MS/MS. Confirmation of the presence of this compound in legume nodules and their hypothetical function are the base for future works.

In Chapter 4, the combination of stresses at early reproductive stages on soybean was analysed. Our study remarked that physiological and yield sensibility of soybean to heat and water stress was highly conditioned by the phenological stage in which is applied. Grain yield losses were mainly due to by impaired carbon assimilation when 
both stresses were combined, information that could have implication for future breading strategies. However, due to the importance of soybean as human food and animal feed product, further research at grain yield level is needed, to assess not only grain yield but also grain quality and composition under combined stresses. Additionally, as commented in Chapter 2, xylem and phloem measures to assess our hypothesis based carbon transport between above-ground and under-ground tissues would be desirable. 
upna 
" VIII. GENERAL CONCLUSIONS 
upna 


\section{GENERAL CONCLUSIONS}

To summarize, the general conclusions drawn from this thesis are,

- Soybean genotype selected for Low_WUE had greater response to e $\left[\mathrm{CO}_{2}\right]$ in terms of leaf daily photosynthetic $\mathrm{C}$ gain, mainly due to greater $g_{s}$ but also to biochemical (lower $V_{c \max }$ and $J_{\max }$ ) related limitations. This were compensated, in the genotype selected for High_WUE, with a greater leaf area, equating photosynthesis at canopy level, which at the end resulted in a greater seed yield response to $\left[\mathrm{CO}_{2}\right]$.

- Elevated $\left[\mathrm{CO}_{2}\right]$ promote seed yield through photosynthetic $\mathrm{C}$ fixation, enhancing biomass accumulation that, before harvest, was effectively partitioned to seeds. Additionally, changes in seed mineral composition were related with dilution effect, since seed yield increases under $\mathrm{e}\left[\mathrm{CO}_{2}\right]$ were bigger that mineral root uptake.

- Tocochromanols, mainly in the $\alpha$-tocopherol form, are present in nodules of contrasting legume genera. Under drought, nodule $\alpha$-tocopherol content depends on the legume species and type of nodule. This antioxidant seems to be involved in legume nodule protection against lipid peroxidation and, eventually, improving their performance.

- The study of the drought response at physiological, hormonal and metabolic level revealed contrasting response in alfalfa cultivars adapted to different locations. While one cultivar from China was shown to have a water-saver strategy by closing stomata and fixing less carbon by photosynthesis, thus limiting its growth under water limitation, the other from Spain, promoted root growth enhancing water uptake to replace water lost through transpiration, allowing a greater rate of carbon to be fixed and maintaining biomass under drought.

- Water stress had higher impact than heatwave on soybean physiology and biochemical parameters and, when combined, effects were more similar to those of water stress than those of heatwave, in special when applied at flowering. 
- Water stress, alone or combined with heatwave, negatively affected photosynthetic performance (caused by closed stomata and photodamage), resulting in impaired sucrose and starch metabolism in leaves and reproductive organs during flowering and pod formation. As a result, fewer flower setting reduced seed yield equally in water stress and combined stresses, but not in heatwave treatment. At pod formation, seed yield effect of heatwave and water stress was exacerbate when both stresses were applied concomitantly, and were due to both, less pod setting and smaller seeds. We suggest pod formation as critical moment for soybean production under combined abiotic stresses.

- Nodule functioning were affected by water stress and combined stresses due to poor sugar supply to the bacteroid and N-compounds accumulation that negatively affect nodule $\mathrm{N}$-fixation activity. In contrast, heatwave alone were not able to disrupt nodule performance, being capable to properly maintain $\mathrm{N}$ aboveground demand. 
upna 
" BIBLIOGRAPHY 
Abdelhakim, L.O.A., Palma, C.F.F., Zhou, R., Wollenweber, B., Ottosen, C.O., Rosenqvist, E., 2021. The effect of individual and combined drought and heat stress under elevated $\mathrm{CO}_{2}$ on physiological responses in spring wheat genotypes. Plant Physiol. Biochem. 301-314. https://doi.org/10.1016/j.plaphy.2021.02.015

Acharya, B.R., Assmann, S.M., 2009. Hormone interactions in stomatal function. Plant Mol. Biol. 69, 451-462. https://doi.org/10.1007/s11103-008-9427-0

Adams, M.A., Buchmann, N., Sprent, J., Buckley, T.N., Turnbull, T.L., 2018. Crops, Nitrogen, Water: Are Legumes Friend, Foe, or Misunderstood Ally? Trends Plant Sci. 23, 539-550. https://doi.org/https://doi.org/10.1016/j.tplants.2018.02.009

Ainsworth, E.A., Davey, P.A., Bernacchi, C.J., Dermody, O.C., Heaton, E.A., Moore, D.J., Morgan, P.B., Naidu, S.L., Yoo Ra, H., Zhu, X., Curtis, P.S., Long, S.P., 2002. A meta-analysis of elevated $\left[\mathrm{CO}_{2}\right]$ effects on soybean (Glycine max) physiology, growth and yield. Glob. Chang. Biol. 8, 695-709. https://doi.org/10.1046/j.1365-2486.2002.00498.x

Ainsworth, E.A., Rogers, A., 2007. The response of photosynthesis and stomatal conductance to rising $\left[\mathrm{CO}_{2}\right]$ : mechanisms and environmental interactions. Plant. Cell Environ. 30, 258-270. https://doi.org/10.1111/j.1365-3040.2007.01641.x

Ainsworth, E.A., Rogers, A., Nelson, R., Long, S.P., 2004. Testing the "source-sink" hypothesis of down-regulation of photosynthesis in elevated $\left[\mathrm{CO}_{2}\right]$ in the field with single gene substitutions in Glycine max. Agric. For. Meteorol. 122, 85-94. https://doi.org/10.1016/J.AGRFORMET.2003.09.002

Alhaithloul, H., Abu-Elsaoud, A., Soliman, M., 2020. Abiotic Stress Tolerance in Crop Plants: Role of Phytohormones. https://doi.org/10.5772/intechopen.93710

Annicchiarico, P., Barrett, B., Brummer, E.C., Julier, B., Marshall, A.H., 2015. Achievements and Challenges in Improving Temperate Perennial Forage Legumes. CRC. Crit. Rev. Plant Sci. 34, 327-380. https://doi.org/10.1080/07352689.2014.898462

Apel, K., Hirt, H., 2004. REACTIVE OXYGEN SPECIES: Metabolism, Oxidative Stress, and Signal Transduction. Annu. Rev. Plant Biol. 55, 373-399. https://doi.org/10.1146/annurev.arplant.55.031903.141701

Aranjuelo, I., Arrese-Igor, C., Molero, G., 2014. Nodule performance within a changing environmental context. J. Plant Physiol. 171, 1076-1090. https://doi.org/10.1016/J.JPLPH.2014.04.002

Aranjuelo, I., Cabrera-Bosquet, L., Morcuende, R., Avice, J.C., Nogués, S., Araus, J.L., Martínez-Carrasco, R., Pérez, P., 2011. Does ear C sink strength contribute to overcoming photosynthetic acclimation of wheat plants exposed to elevated $\mathrm{CO}_{2}$ ? J. Exp. Bot. 62, 3957-3969. https://doi.org/10.1093/jxb/err095 
Aranjuelo, I., Irigoyen, J.J., Sánchez-Díaz, M., Nogués, S., 2008. Carbon partitioning in $\mathrm{N}_{2}$ fixing Medicago sativa plants exposed to different $\mathrm{CO}_{2}$ and temperature conditions. Funct. Plant Biol. 35, 306-317.

Aranjuelo, I., Molero, G., Erice, G., Aldasoro, J., Arrese-Igor, C., Nogués, S., 2015. Effect of shoot removal on remobilization of carbon and nitrogen during regrowth of nitrogen-fixing alfalfa. Physiol. Plant. 153, 91-104. https://doi.org/https://doi.org/10.1111/ppl.12222

Aranjuelo, I., Molero, G., Erice, G., Avice, J.C., Nogués, S., 2011. Plant physiology and proteomics reveals the leaf response to drought in alfalfa (Medicago sativa L.). J. Exp. Bot. 62, 111-123. https://doi.org/10.1093/jxb/erq249

Aranjuelo, I., Pérez, P., Hernández, L., Irigoyen, J.J., Zita, G., Martínez-Carrasco, R., Sánchez-Díaz, M., 2005. The response of nodulated alfalfa to water supply, temperature and elevated $\mathrm{CO}_{2}$ : photosynthetic downregulation. Physiol. Plant. 123, 348-358. https://doi.org/10.1111/j.1399-3054.2005.00459.x

Araújo, S.S., Beebe, S., Crespi, M., Delbreil, B., González, E.M., Gruber, V., LejeuneHenaut, I., Link, W., Monteros, M.J., Prats, E., Rao, I., Vadez, V., Patto, M.C.V., 2015. Abiotic Stress Responses in Legumes: Strategies Used to Cope with Environmental Challenges. CRC. Crit. Rev. Plant Sci. 34, 237-280. https://doi.org/10.1080/07352689.2014.898450

Awasthi, R., Kaushal, N., Vadez, V., Turner, N.C., Berger, J., Siddique, K.H.M., Nayyar, H., 2014. Individual and combined effects of transient drought and heat stress on carbon assimilation and seed filling in chickpea. Funct. Plant Biol. 41, $1148-1167$.

Balfagón, D., Zandalinas, S.I., Mittler, R., Gómez-Cadenas, A., 2020. High temperatures modify plant responses to abiotic stress conditions. Physiol. Plant. 170, 335-344. https://doi.org/10.1111/ppl.13151

Becana, M., Matamoros, M.A., Udvardi, M., Dalton, D.A., 2010. Recent insights into antioxidant defenses of legume root nodules. New Phytol. 188, 960-976. https://doi.org/10.1111/j.1469-8137.2010.03512.x

Bhattacharyya, P., Pathak, H., Pal, S., 2020. Introduction BT - Climate Smart Agriculture: Concepts, Challenges, and Opportunities, in: Bhattacharyya, P., Pathak, H., Pal, S. (Eds.), . Springer Singapore, Singapore, pp. 1-15. https://doi.org/10.1007/978-981-15-9132-7_1

Bishop, K.A., Betzelberger, A.M.Y.M., Long, S.P., Ainsworth, E.A., 2015. Is there potential to adapt soybean (Glycine max Merr.) to future $\left[\mathrm{CO}_{2}\right]$ ? An analysis of the yield response of 18 genotypes in free-air $\mathrm{CO}_{2}$ enrichment. Plant. Cell Environ. 38, 1765-1774. https://doi.org/10.1111/pce.12443

Bray, E.A., 1997. Plant responses to water deficit. Trends Plant Sci. 2, 48-54. https://doi.org/https://doi.org/10.1016/S1360-1385(97)82562-9 
Brown, K.H., Wuehler, S.E., Peerson, J.M., 2001. The Importance of Zinc in Human Nutrition and Estimation of the Global Prevalence of Zinc Deficiency. Food Nutr. Bull. 22, 113-125. https://doi.org/10.1177/156482650102200201

Bunce, J.A., 2015. Elevated Carbon Dioxide Effects on Reproductive Phenology and Seed Yield among Soybean Cultivars. Crop Sci. 55, 339-343. https://doi.org/10.2135/cropsci2014.04.0273

Carlsson, G., Huss-Danell, K., 2003. Nitrogen fixation in perennial forage legumes in the field. Plant Soil 253, 353-372. https://doi.org/10.1023/A:1024847017371

Cattivelli, L., Rizza, F., Badeck, F.-W., Mazzucotelli, E., Mastrangelo, A.M., Francia, E., Marè, C., Tondelli, A., Stanca, A.M., 2008. Drought tolerance improvement in crop plants: An integrated view from breeding to genomics. F. Crop. Res. 105, 114. https://doi.org/10.1016/j.fcr.2007.07.004

Chavan, S.G., Duursma, R.A., Tausz, M., Ghannoum, O., 2019. Elevated $\mathrm{CO}_{2}$ alleviates the negative impact of heat stress on wheat physiology but not on grain yield. J. Exp. Bot. 70, 6447-6459. https://doi.org/10.1093/jxb/erz386

Choukri, H., Hejjaoui, K., El-Baouchi, A., El haddad, N., Smouni, A., Maalouf, F., Thavarajah, D., Kumar, S., 2020. Heat and Drought Stress Impact on Phenology, Grain Yield, and Nutritional Quality of Lentil (Lens culinaris Medikus) . Front. Nutr. 596307. https://doi.org/10.3389/fnut.2020.596307

Cogato, A., Meggio, F., De Antoni Migliorati, M., Marinello, F., 2019. Extreme Weather Events in Agriculture: A Systematic Review. Sustain. 11(9), 2547. https://doi.org/10.3390/su11092547

Cohen, I., Zandalinas, S.I., Huck, C., Fritschi, F.B., Mittler, R., 2021. Meta-analysis of drought and heat stress combination impact on crop yield and yield components. Physiol. Plant. 171, 66-76. https://doi.org/10.1111/ppl.13203

Condon, A.G., Richards, R.A., Rebetzke, G.J., Farquhar, G.D., 2004. Breeding for high water-use efficiency. J. Exp. Bot. 55, 2447-2460. https://doi.org/10.1093/jxb/erh277

Daryanto, S., Wang, L., Jacinthe, P.-A., 2015. Global Synthesis of Drought Effects on Food Legume Production. PLoS One 10, e0127401.

Daryanto, S., Wang, L., Jacinthe, P.-A., 2017. Global synthesis of drought effects on cereal, legume, tuber and root crops production: A review. Agric. Water Manag. 179, 18-33. https://doi.org/10.1016/j.agwat.2016.04.022

Defez, R., Andreozzi, A., Dickinson, M., Charlton, A., Tadini, L., Pesaresi, P., Bianco, C., 2017. Improved Drought Stress Response in Alfalfa Plants Nodulated by an IAA Over-producing Rhizobium Strain. Front. Microbiol. 02466. https://doi.org/10.3389/fmicb.2017.02466 
Deser, C., Phillips, A., Bourdette, V., Teng, H., 2012. Uncertainty in climate change projections: the role of internal variability. Clim. Dyn. 38, 527-546. https://doi.org/10.1007/s00382-010-0977-x

Dhanapal, A.P., Ray, J.D., Singh, S.K., Hoyos-Villegas, V., Smith, J.R., Purcell, L.C., Andy King, C., Cregan, P.B., Song, Q., Fritschi, F.B., 2015. Genome-wide association study (GWAS) of carbon isotope ratio $\left(\delta^{13} \mathrm{C}\right)$ in diverse soybean [Glycine $\max$ (L.) Merr.] genotypes. Theor. Appl. Genet. 128, 73-91. https://doi.org/10.1007/s00122-014-2413-9

Dhanapal, A.P., Ray, J.D., Singh, S.K., Hoyos-Villegas, V., Smith, J.R., Purcell, L.C., King, C.A., Fritschi, F.B., 2015. Genome-Wide Association Analysis of Diverse Soybean Genotypes Reveals Novel Markers for Nitrogen Traits. Plant Genome 8, 0086. https://doi.org/10.3835/plantgenome2014.11.0086

Djanaguiraman, Prasad, P.V.V., 2010. Ethylene production under high temperature stress causes premature leaf senescence in soybean. Funct. Plant Biol. 37, 10711084. https://doi.org/10.1071/FP10089

Djanaguiraman, Prasad, P.V.V., Schapaugh, W., 2013. High Day- or Nighttime Temperature Alters Leaf Assimilation, Reproductive Success, and Phosphatidic Acid of Pollen Grain in Soybean. Crop Sci. 53, 1594-1604. https://doi.org/10.2135/cropsci2012.07.0441

Dodd, I.C., 2013. Abscisic acid and stomatal closure: a hydraulic conductance conundrum? New Phytol. 197, 6-8. https://doi.org/10.1111/nph.12052

Dong, J., Gruda, N., Lam, S.K., Li, X., Duan, Z., 2018. Effects of Elevated $\mathrm{CO}_{2}$ on Nutritional Quality of Vegetables: A Review. Front. Plant Sci. 9, 924. https://doi.org/10.3389/fpls.2018.00924

Du, H., Liu, H., Xiong, L., 2013. Endogenous auxin and jasmonic acid levels are differentially modulated by abiotic stresses in rice. Front. Plant Sci. 4, 397. https://doi.org/10.3389/fpls.2013.00397

Du, Y., Zhao, Q., Chen, L., Yao, X., Zhang, H., Wu, J., Xie, F., 2020. Effect of Drought Stress during Soybean R2-R6 Growth Stages on Sucrose Metabolism in Leaf and Seed. Int. J. Mol. Sci. 21, 618. https://doi.org/10.3390/ijms21020618

Durand, J.L., Sheehy, J.E., Minchin, F.R., 1987. Nitrogenase Activity, Photosynthesis and Nodule Water Potential in Soyabean Plants Experiencing Water Deprivation. J. Exp. Bot. 38, 311-321. https://doi.org/10.1093/jxb/38.2.311

Earl, H.J., 2002. Stomatal and non-stomatal restrictions to carbon assimilation in soybean (Glycine max) lines differing in water use efficiency. Environ. Exp. Bot. 48, 237-246. https://doi.org/10.1016/S0098-8472(02)00041-2

EAT-Lancet Commission, 2019. EAT-Lancet Commission Summary Report. 
Egli, D.B., TeKrony, D.M., Heitholt, J.J., Rupe, J., 2005. Air Temperature During Seed Filling and Soybean Seed Germination and Vigor. Crop Sci. 45, 1329-1335. https://doi.org/https://doi.org/10.2135/cropsci2004.0029

Ergo, V. V, Lascano, R., Vega, C.R.C., Parola, R., Carrera, C.S., 2018. Heat and water stressed field-grown soybean: A multivariate study on the relationship between physiological-biochemical traits and yield. Environ. Exp. Bot. 148, 1-11. https://doi.org/10.1016/j.envexpbot.2017.12.023

Erice, G., Sanz-Sáez, A., Aroca, R., Ruíz-Lozano, J.M., Avice, J.-C., Irigoyen, J.J., Sanchez-Diaz, M., Aranjuelo, I., 2014. Photosynthetic down-regulation in $\mathrm{N}_{2-}$ fixing alfalfa under elevated $\mathrm{CO}_{2}$ alters rubisco content and decreases nodule metabolism via nitrogenase and tricarboxylic acid cycle. Acta Physiol. Plant. 36, 2607-2617. https://doi.org/10.1007/s11738-014-1631-8

European Commission, 2020. Climate change consequences [WWW Document]. URL https://ec.europa.eu/clima/change/consequences_en (accessed 3.10.21).

Evans, P.J., Gallesi, D., Mathieu, C., Hernandez, M.J., de Felipe, M., Halliwell, B., Puppo, A., 1999. Oxidative stress occurs during soybean nodule senescence. Planta 208, 73-79. https://doi.org/10.1007/s004250050536

Fahnenstich, H., Scarpeci, T.E., Valle, E.M., Flügge, U.-I., Maurino, V.G., 2008. Generation of Hydrogen Peroxide in Chloroplasts of Arabidopsis Overexpressing Glycolate Oxidase as an Inducible System to Study Oxidative Stress. Plant Physiol. 148, 719 LP - 729. https://doi.org/10.1104/pp.108.126789

Falk, J., Munné-Bosch, S., 2010. Tocochromanol functions in plants: antioxidation and beyond. J. Exp. Bot. 61, 1549-1566. https://doi.org/10.1093/jxb/erq030

FAO, 2013. Climate smart agriculture sourcebook. Rome.

FAOSTAT, n.d. ProdStat. Core Production Data Base, Electronic resource. (2020). [WWW Document]. URL http://faostat.fao.org/ (accessed 4.23.20).

Farooq, M., Gogoi, N., Barthakur, S., Baroowa, B., Bharadwaj, N., Alghamdi, S.S., Siddique, K.H.M., 2017. Drought Stress in Grain Legumes during Reproduction and Grain Filling. J. Agron. Crop Sci. 203, 81-102. https://doi.org/https://doi.org/10.1111/jac.12169

Farooq, M., Wahid, A., Kobayashi, N., Fujita, D., Basra, S.M.A., 2009. Plant drought stress: effects, mechanisms and management. Agron. Sustain. Dev. 29, 185-212. https://doi.org/10.1051/agro:2008021

Foley, J.A., Ramankutty, N., Brauman, K.A., Cassidy, E.S., Gerber, J.S., Johnston, M., Mueller, N.D., O’Connell, C., Ray, D.K., West, P.C., Balzer, C., Bennett, E.M., Carpenter, S.R., Hill, J., Monfreda, C., Polasky, S., Rockström, J., Sheehan, J., Siebert, S., Tilman, D., Zaks, D.P.M., 2011. Solutions for a cultivated planet. Nature 478, 337-342. https://doi.org/10.1038/nature10452 
Foyer, C.H., Lam, H.-M., Nguyen, H.T., Siddique, K.H.M., Varshney, R.K., Colmer, T.D., Cowling, W., Bramley, H., Mori, T.A., Hodgson, J.M., Cooper, J.W., Miller, A.J., Kunert, K., Vorster, J., Cullis, C., Ozga, J.A., Wahlqvist, M.L., Liang, Y., Shou, H., Shi, K., Yu, J., Fodor, N., Kaiser, B.N., Wong, F.-L., Valliyodan, B., Considine, M.J., 2016. Neglecting legumes has compromised human health and sustainable food production. Nat. Plants 2, 16112. https://doi.org/10.1038/nplants.2016.112

Fuhrer, J., 2003. Agroecosystem responses to combinations of elevated $\mathrm{CO}_{2}$, ozone, and global climate change. Agric. Ecosyst. Environ. 97, 1-20. https://doi.org/https://doi.org/10.1016/S0167-8809(03)00125-7

Galloway, J.N., Townsend, A.R., Erisman, J.W., Bekunda, M., Cai, Z., Freney, J.R., Martinelli, L.A., Seitzinger, S.P., Sutton, M.A., 2008. Transformation of the Nitrogen Cycle: Recent Trends, Questions, and Potential Solutions. Science (80). 320, 889 - 892. https://doi.org/10.1126/science.1136674

Gálvez, L., González, E.M., Arrese-Igor, C., 2005. Evidence for carbon flux shortage and strong carbon/nitrogen interactions in pea nodules at early stages of water stress. J. Exp. Bot. 56, 2551-2561. https://doi.org/10.1093/jxb/eri249

Gifford, R.M., Barrett, D.J., Lutze, J.L., 2000. The effects of elevated $\left[\mathrm{CO}_{2}\right]$ on the C:N and C:P mass ratios of plant tissues. Plant Soil 224, 1-14. https://doi.org/10.1023/A:1004790612630

Gilbert, M.E., Zwieniecki, M.A., Holbrook, N.M., 2011. Independent variation in photosynthetic capacity and stomatal conductance leads to differences in intrinsic water use efficiency in 11 soybean genotypes before and during mild drought. J. Exp. Bot. 62, 2875-2887. https://doi.org/10.1093/jxb/erq461

Giorgi, F., Bi, X., Pal, J., 2004. Mean, interannual variability and trends in a regional climate change experiment over Europe. II: climate change scenarios (2071-2100). Clim. Dyn. 23, 839-858. https://doi.org/10.1007/s00382-004-0467-0

Gogorcena, Y., Gordon, A.J., Escuredo, P.R., Minchin, F.R., Witty, J.F., Moran, J.F., Becana, M., 1997. $\mathrm{N}_{2}$ Fixation, Carbon Metabolism, and Oxidative Damage in Nodules of Dark-Stressed Common Bean Plants. Plant Physiol. 113, 1193-1201. https://doi.org/10.1104/pp.113.4.1193

Gogorcena, Y., Iturbe-Ormaetxe, I., Escuredo, P.R., Becana, M., 1995. Antioxidant Defenses against Activated Oxygen in Pea Nodules Subjected to Water Stress. Plant Physiol. 108, 753-759. https://doi.org/10.1104/pp.108.2.753

González, E.M., Gordon, A.J., James, C.L., Arrese-lgor, C., 1995. The role of sucrose synthase in the response of soybean nodules to drought. J. Exp. Bot. 46, 15151523. https://doi.org/10.1093/jxb/46.10.1515

González, E.M., Gálvez, L., Arrese-Igor, C., 2001. Abscisic acid induces a decline in nitrogen fixation that involves leghaemoglobin, but is independent of sucrose synthase activity. J. Exp. Bot. 52, 285-293. https://doi.org/10.1093/jxb/52.355.285 
Graham, P.H., Vance, C.P., 2003. Legumes: Importance and Constraints to Greater Use. Plant Physiol. 131, 872-877. https://doi.org/10.1104/pp.017004

Gutiérrez, D., Gutiérrez, E., Pérez, P., Morcuende, R., Verdejo, A.L., MartinezCarrasco, R., 2009. Acclimation to future atmospheric $\mathrm{CO}_{2}$ levels increases photochemical efficiency and mitigates photochemistry inhibition by warm temperatures in wheat under field chambers. Physiol. Plant. 137, 86-100. https://doi.org/10.1111/j.1399-3054.2009.01256.x

Herridge, D.F., Peoples, M.B., Boddey, R.M., 2008. Global inputs of biological nitrogen fixation in agricultural systems. Plant Soil 311, 1-18. https://doi.org/10.1007/s11104-008-9668-3

Herritt, M.T., Fritschi, F.B., 2020. Characterization of Photosynthetic Phenotypes and Chloroplast Ultrastructural Changes of Soybean (Glycine max) in Response to Elevated Air Temperatures. Front. Plant Sci. 00153. https://doi.org/10.3389/fpls.2020.00153.

Högy, P., Fangmeier, A., 2008. Effects of elevated atmospheric $\mathrm{CO}_{2}$ on grain quality of wheat. J. Cereal Sci. 48, 580-591. https://doi.org/10.1016/j.jcs.2008.01.006

Hopkins, A., Del Prado, A., 2007. Implications of climate change for grassland in Europe: impacts, adaptations and mitigation options: a review. Grass Forage Sci. 62, 118-126. https://doi.org/10.1111/j.1365-2494.2007.00575.x

IPCC, 2014. Climate Change 2014: Synthesis Report. Contribution of Working Groups I, II and III to the Fifth Assessment Report of the Intergovernmental Panel on Climate Change.

Irshad, A., Rehman, R.N.U., Abrar, M.M., Saeed, Q., Sharif, R., Hu, T., 2021. Contribution of Rhizobium-Legume Symbiosis in Salt Stress Tolerance in Medicago truncatula Evaluated through Photosynthesis, Antioxidant Enzymes, and $\begin{array}{llll}\text { Compatible Solutes Accumulation. } & \text { Sustainability }\end{array}$ https://doi.org/10.3390/su13063369

Jensen, E.S., Peoples, M.B., Boddey, R.M., Gresshoff, P.M., Hauggaard-Nielsen, H., J.R. Alves, B., Morrison, M.J., 2012. Legumes for mitigation of climate change and the provision of feedstock for biofuels and biorefineries. A review. Agron. Sustain. Dev. 32, 329-364. https://doi.org/10.1007/s13593-011-0056-7

Jin, C.W., Du, S.T., Chen, W.W., Li, G.X., Zhang, Y.S., Zheng, S.J., 2009. Elevated Carbon Dioxide Improves Plant Iron Nutrition through Enhancing the IronDeficiency-Induced Responses under Iron-Limited Conditions in Tomato. Plant Physiol. 150, 272-280. https://doi.org/10.1104/pp.109.136721

Jumrani, K., Bhatia, V.S., 2019. Interactive effect of temperature and water stress on physiological and biochemical processes in soybean. Physiol. Mol. Biol. Plants 25, 667-681. https://doi.org/10.1007/s12298-019-00657-5 
Kaschuk, G., Kuyper, T.W., Leffelaar, P.A., Hungria, M., Giller, K.E., 2009. Are the rates of photosynthesis stimulated by the carbon sink strength of rhizobial and arbuscular mycorrhizal symbioses? Soil Biol. Biochem. 41, 1233-1244. https://doi.org/10.1016/j.soilbio.2009.03.005

Katam, R., Shokri, S., Murthy, N., Singh, S.K., Suravajhala, P., Khan, M.N., Bahmani, M., Sakata, K., Reddy, K.R., 2020. Proteomics, physiological, and biochemical analysis of cross tolerance mechanisms in response to heat and water stresses in soybean. PLoS One 15, e0233905-e0233905. https://doi.org/10.1371/journal.pone.0233905

Killi, D., Raschi, A., Bussotti, F., 2020. Lipid Peroxidation and Chlorophyll Fluorescence of Photosystem II Performance during Drought and Heat Stress is Associated with the Antioxidant Capacities of C3 Sunflower and C4 Maize Varieties. Int. J. Mol. Sci. . https://doi.org/10.3390/ijms21144846

King, C.A., Purcell, L.C., 2005. Inhibition of $\mathrm{N}_{2}$ Fixation in Soybean Is Associated with Elevated Ureides and Amino Acids. Plant Physiol. 137, 1389-1396. https://doi.org/10.1104/pp.104.056317

Kulkarni, K.P., Tayade, R., Asekova, S., Song, J.T., Shannon, J.G., Lee, J.-D., 2018. Harnessing the Potential of Forage Legumes, Alfalfa, Soybean, and Cowpea for Sustainable Agriculture and Global Food Security. Front. Plant Sci. 01314. https://doi.org/10.3389/fpls.2018.01314.

Kumagai, E., Aoki, N., Masuya, Y., Shimono, H., 2015. Phenotypic Plasticity Conditions the Response of Soybean Seed Yield to Elevated Atmospheric $\mathrm{CO}_{2}$ Concentration. Plant Physiol. 169, 2021-2029. https://doi.org/10.1104/pp.15.00980

Ladrera, R., Marino, D., Larrainzar, E., González, E.M., Arrese-Igor, C., 2007. Reduced carbon availability to bacteroids and elevated ureides in nodules, but not in shoots, are involved in the nitrogen fixation response to early drought in soybean. Plant Physiol. 145, 539-546. https://doi.org/10.1104/pp.107.102491

Larrainzar, E., Wienkoop, S., Scherling, C., Kempa, S., Ladrera, R., Arrese-Igor, C., Weckwerth, W., González, E.M., 2009. Carbon Metabolism and Bacteroid Functioning Are Involved in the Regulation of Nitrogen Fixation in Medicago truncatula Under Drought and Recovery. Mol. Plant-Microbe Interact. 22, 15651576. https://doi.org/10.1094/MPMI-22-12-1565

Law, D.R., Crafts-Brandner, S.J., Salvucci, M.E., 2001. Heat stress induces the synthesis of a new form of ribulose-1,5-bisphosphate carboxylase/oxygenase activase in cotton leaves. Planta 214, 117-125. https://doi.org/10.1007/s004250100592

Ledgard, S.F., Steele, K.W., 1992. Biological nitrogen fixation in mixed legume/grass pastures. Plant Soil 141, 137-153. https://doi.org/10.1007/BF00011314 
Leff, B., Ramankutty, N., Foley, J.A., 2004. Geographic distribution of major crops $\begin{array}{lllll}\text { across the } & \text { Gorld. Biogeochem. Cycles } 18 .\end{array}$ https://doi.org/https://doi.org/10.1029/2003GB002108

Li, M.-W., Xin, D., Gao, Y., Li, K.-P., Fan, K., Muñoz, N.B., Yung, W.-S., Lam, H.M., 2017. Using genomic information to improve soybean adaptability to climate change. J. Exp. Bot. 68, 1823-1834. https://doi.org/10.1093/jxb/erw348

Li, X., Shi, W., Broughton, K., Smith, R., Sharwood, R., Payton, P., Bange, M., Tissue, D.T., 2020. Impacts of growth temperature, water deficit and heatwaves on carbon assimilation and growth of cotton plants (Gossypium hirsutum L.). Environ. Exp. Bot. 179, 104204. https://doi.org/10.1016/j.envexpbot.2020.104204

Li, Y., Yu, Z., Jin, J., Zhang, Q., Wang, G., Liu, C., Wu, J., Wang, C., Liu, X., 2018. Impact of Elevated $\mathrm{CO}_{2}$ on Seed Quality of Soybean at the Fresh Edible and Mature Stages. Front. Plant Sci. 9, 1413. https://doi.org/10.3389/fpls.2018.01413

Li, Y., Yu, Z., Liu, X., Mathesius, U., Wang, G., Tang, C., Wu, J., Liu, J., Zhang, S., Jin, J., 2017. Elevated $\mathrm{CO}_{2}$ Increases Nitrogen Fixation at the Reproductive Phase Contributing to Various Yield Responses of Soybean Cultivars. Front. Plant Sci. 8, 1546. https://doi.org/10.3389/fpls.2017.01546

Li, Z., Li, X., Wang, Y., Quiring, S.M., 2019. Impact of climate change on precipitation patterns in Houston, Texas, USA. Anthropocene 25, 100193. https://doi.org/10.1016/j.ancene.2019.100193

Liu, H., Zhang, C., Yang, J., Yu, N., Wang, E., 2018. Hormone modulation of legumerhizobial symbiosis. J. Integr. Plant Biol. 60, 632-648. https://doi.org/10.1111/jipb.12653

Lobell, D.B., Gourdji, S.M., 2012. The Influence of Climate Change on Global Crop $\begin{array}{llllll}\text { Productivity. Plant Physiol. } & 160,1686 & \text { LP } & - & 1697 .\end{array}$ https://doi.org/10.1104/pp.112.208298

Loladze, I., 2014. Hidden shift of the ionome of plants exposed to elevated $\mathrm{CO}_{2}$ depletes minerals at the base of human nutrition. Elife 3, e02245-e02245. https://doi.org/10.7554/eLife.02245

Maestri, E., Klueva, N., Perrotta, C., Gulli, M., Nguyen, H.T., Marmiroli, N., 2002. Molecular genetics of heat tolerance and heat shock proteins in cereals. Plant Mol. Biol. 48, 667-681. https://doi.org/10.1023/A:1014826730024

Matamoros, M.A., Becana, M., 2020. Chapter Three - Redox control of the legumeRhizobium symbiosis, in: Frendo, P., Frugier, F., Masson-Boivin, C.B.T.-A. in B.R. (Eds.), Regulation of Nitrogen-Fixing Symbioses in Legumes. Academic Press, pp. 67-96. https://doi.org/https://doi.org/10.1016/bs.abr.2019.09.011

Matamoros, M.A., Kim, A., Peñuelas, M., Ihling, C., Griesser, E., Hoffmann, R., Fedorova, M., Frolov, A., Becana, M., 2018. Protein Carbonylation and Glycation 
in Legume Nodules. Plant Physiol. 177, 1510-1528. https://doi.org/10.1104/pp.18.00533

Mathur, S., Agrawal, D., Jajoo, A., 2014. Photosynthesis: Response to high temperature stress. J. Photochem. Photobiol. B Biol. 137, 116-126. https://doi.org/10.1016/j.jphotobiol.2014.01.010

Mazdiyasni, O., AghaKouchak, A., 2015. Substantial increase in concurrent droughts and heatwaves in the United States. Proc. Natl. Acad. Sci. 112, 11484 LP - 11489. https://doi.org/10.1073/pnas.1422945112

McGrath, J.M., Lobell, D.B., 2013. Reduction of transpiration and altered nutrient allocation contribute to nutrient decline of crops grown in elevated $\mathrm{CO}_{2}$ concentrations. Plant. Cell Environ. 36, 697-705. https://doi.org/10.1111/pce.12007

Medrano, H., Escalona, J.M., Bota, J., Gulías, J., Flexas, J., 2002. Regulation of Photosynthesis of C3 Plants in Response to Progressive Drought: Stomatal Conductance as a Reference Parameter. Ann. Bot. 89, 895-905. https://doi.org/10.1093/aob/mcf079

Meehl, G.A., Hu, A., Arblaster, J.M., Fasullo, J., Trenberth, K.E., n.d. Externally Forced and Internally Generated Decadal Climate Variability Associated with the Interdecadal Pacific Oscillation. J. Clim. 26, 7298-7310. https://doi.org/10.1175/JCLI-D-12-00548.1

Méndez-Espinoza, A.M., Romero-Bravo, S., Estrada, F., Garriga, M., Lobos, G.A., Castillo, D., Matus, I., Aranjuelo, I., del Pozo, A., 2019. Exploring Agronomic and Physiological Traits Associated With the Differences in Productivity Between Triticale and Bread Wheat in Mediterranean Environments. Front. Plant Sci. 00404. https://doi.org/10.3389/fpls.2019.00404.

Michaeli, S., Fromm, H., 2015. Closing the Loop on the GABA Shunt in Plants: Are GABA metabolism and signaling entwined?. Front. Plant Sci. 00419. https://doi.org/10.3389/fpls.2015.00419.

Mittler, R., 2006. Abiotic stress, the field environment and stress combination. Trends Plant Sci. 11, 15-19. https://doi.org/10.1016/j.tplants.2005.11.002

Molero, G., Iker, A., 2017. Legumes and climate change, in: Legumes for Global Food Security. pp. 27-40.

Molero, G., Tcherkez, G., Roca, R., Mauve, C., Cabrera-Bosquet, L., Araus, J.L., Nogués, S., Aranjuelo, I., 2019. Do metabolic changes underpin physiological responses to water limitation in alfalfa (Medicago sativa) plants during a regrowth period? Agric. Water Manag. 212, 1-11. https://doi.org/10.1016/j.agwat.2018.08.021

Morales, F., Ancín, M., Fakhet, D., González-Torralba, J., Gámez, A.L., Seminario, A., Soba, D., Ben Mariem, S., Garriga, M., Aranjuelo, I., 2020. Photosynthetic 
metabolism under stressful growth conditions as a bases for crop breeding and yield improvement. Plants. https://doi.org/10.3390/plants9010088

Mousavi-Derazmahalleh, M., Bayer, P.E., Hane, J.K., Valliyodan, B., Nguyen, H.T., Nelson, M.N., Erskine, W., Varshney, R.K., Papa, R., Edwards, D., 2019. Adapting legume crops to climate change using genomic approaches. Plant. Cell Environ. 42, 6-19. https://doi.org/10.1111/pce.13203

Muñoz, P., Munné-Bosch, S., 2019. Vitamin E in Plants: Biosynthesis, Transport, and Function. Trends Plant Sci. 24, 1040-1051. https://doi.org/10.1016/j.tplants.2019.08.006

Myers, S.S., Zanobetti, A., Kloog, I., Huybers, P., Leakey, A.D.B., Bloom, A.J., Carlisle, E., Dietterich, L.H., Fitzgerald, G., Hasegawa, T., Holbrook, N.M., Nelson, R.L., Ottman, M.J., Raboy, V., Sakai, H., Sartor, K.A., Schwartz, J., Seneweera, S., Tausz, M., Usui, Y., 2014. Increasing $\mathrm{CO}_{2}$ threatens human nutrition. Nature 510, 139-142. https://doi.org/10.1038/nature13179

Naeem, M., Shabbir, A., Ansari, A.A., Aftab, T., Khan, M.M.A., Uddin, M., 2020. Hyacinth bean (Lablab purpureus L.) - An underutilised crop with future potential. Sci. Hortic. (Amsterdam). 109551. https://doi.org/10.1016/j.scienta.2020.109551

Nakagawa, T., Kawaguchi, M., 2006. Shoot-applied MeJA Suppresses Root Nodulation in Lotus japonicus. Plant Cell Physiol. 47, 176-180. https://doi.org/10.1093/pcp/pci222

Naya, L., Ladrera, R., Ramos, J., González, E.M., Arrese-Igor, C., Minchin, F.R., Becana, M., 2007. The Response of Carbon Metabolism and Antioxidant Defenses of Alfalfa Nodules to Drought Stress and to the Subsequent Recovery of Plants. Plant Physiol. 144, 1104-1114. https://doi.org/10.1104/pp.107.099648

Olesen, J.E., Trnka, M., Kersebaum, K.C., Skjelvåg, A.O., Seguin, B., Peltonen-Sainio, P., Rossi, F., Kozyra, J., Micale, F., 2011. Impacts and adaptation of European crop production systems to climate change. Eur. J. Agron. 34, 96-112. https://doi.org/10.1016/j.eja.2010.11.003

Osakabe, Y., Osakabe, K., Shinozaki, K., Tran, L.-S., 2014. Response of plants to water stress. Front. Plant Sci. 00086. https://doi.org/10.3389/fpls.2014.00086.

Palma, F., López-Gómez, M., Tejera, N.A., Lluch, C., 2014. Involvement of abscisic acid in the response of Medicago sativa plants in symbiosis with Sinorhizobium meliloti to salinity. Plant Sci. 223, 16-24. https://doi.org/10.1016/j.plantsci.2014.02.005

Palombi, L., Sessa, R., 2013. Climate-smart agriculture: sourcebook. Clim. Agric. sourcebook. 
Poore, J., Nemecek, T., 2018. Reducing food's environmental impacts through producers and consumers. Science (80). 360, 987 - 992. https://doi.org/10.1126/science.aaq0216

Prasad, P.V. V, Staggenborg, S.A., Ristic, Z., 2008. Impacts of Drought and/or Heat Stress on Physiological, Developmental, Growth, and Yield Processes of Crop Plants, in: Response of Crops to Limited Water. John Wiley \& Sons, Ltd, pp. 301355. https://doi.org/10.2134/advagricsystmodel1.c11

Prior, S.A., Runion, G.B., Rogers, H.H., Arriaga, F.J., 2010. Elevated Atmospheric Carbon Dioxide Effects on Soybean and Sorghum Gas Exchange in Conventional and No-Tillage Systems. J. Environ. Qual. 39, 596-608. https://doi.org/10.2134/jeq2009.0181

Prior, S.A., Runion, G.B., Rogers, H.H., Torbert, H.A., 2008. Effects of Atmospheric $\mathrm{CO}_{2}$ Enrichment on Crop Nutrient Dynamics under No-Till Conditions. J. Plant Nutr. 31, 758-773. https://doi.org/10.1080/01904160801928364

Pushpavalli, R., Zaman-Allah, M., Turner, N.C., Baddam, R., Rao, M. V, Vadez, V., 2015. Higher flower and seed number leads to higher yield under water stress conditions imposed during reproduction in chickpea. Funct. Plant Biol. 42, 162174.

Puteh, A., Thuzar, M., Mondal, M., Abdullah, N.P.B., Halim, M., 2013. Soybean [Glycine max (L.) Merrill] seed yield response to high temperature stress during reproductive growth stages. Aust. J. Crop Sci. 7, 1472-1479.

Raza, A., Zahra, N., Hafeez, M.B., Ahmad, M., Iqbal, S., Shaukat, K., Ahmad, G., 2020. Nitrogen Fixation of Legumes: Biology and Physiology, in: Hasanuzzaman, M., Araújo, S., Gill, S.S. (Eds.), The Plant Family Fabaceae: Biology and Physiological Responses to Environmental Stresses. Springer Singapore, Singapore, pp. 43-74. https://doi.org/10.1007/978-981-15-4752-2_3

Reay, D.S., Davidson, E.A., Smith, K.A., Smith, P., Melillo, J.M., Dentener, F., Crutzen, P.J., 2012. Global agriculture and nitrous oxide emissions. Nat. Clim. Chang. 2, 410-416. https://doi.org/10.1038/nclimate1458

Reichstein, M., Bahn, M., Ciais, P., Frank, D., Mahecha, M.D., Seneviratne, S.I., Zscheischler, J., Beer, C., Buchmann, N., Frank, D.C., Papale, D., Rammig, A., Smith, P., Thonicke, K., van der Velde, M., Vicca, S., Walz, A., Wattenbach, M., 2013. Climate extremes and the carbon cycle. Nature 500, 287-295. https://doi.org/10.1038/nature12350

Robinson, G.H.J., Balk, J., Domoney, C., 2019. Improving pulse crops as a source of protein, starch and micronutrients. Nutr. Bull. 44, 202-215. https://doi.org/10.1111/nbu.12399

Rogers, A., Ainsworth, E.A., Leakey, A.D.B., 2009. Will elevated carbon dioxide concentration amplify the benefits of nitrogen fixation in legumes? Plant Physiol. 151, 1009-1016. https://doi.org/10.1104/pp.109.144113 
Rogers, H.H., Bingham, G.E., Cure, J.D., Smith, J.M., Surano, K.A., 1983. Responses of Selected Plant Species to Elevated Carbon Dioxide in the Field. J. Environ. Qual. 12, 569-574. https://doi.org/10.2134/jeq1983.00472425001200040028x

Rogers, H.H., Cure, J.D., Thomas, J.F., Smith, J.M., 1984. Influence of Elevated CO2 on Growth of Soybean Plants1. Crop Sci. 24, 20036. https://doi.org/10.2135/cropsci1984.0011183X002400020036x

Rollins, J.A., Habte, E., Templer, S.E., Colby, T., Schmidt, J., von Korff, M., 2013. Leaf proteome alterations in the context of physiological and morphological responses to drought and heat stress in barley (Hordeum vulgare L.). J. Exp. Bot. 64, 3201-3212. https://doi.org/10.1093/jxb/ert158

Rosenzweig, C., Karoly, D., Vicarelli, M., Neofotis, P., Wu, Q., Casassa, G., Menzel, A., Root, T.L., Estrella, N., Seguin, B., Tryjanowski, P., Liu, C., Rawlins, S., Imeson, A., 2008. Attributing physical and biological impacts to anthropogenic climate change. Nature 453, 353-357. https://doi.org/10.1038/nature06937

Roy, J., Picon-Cochard, C., Augusti, A., Benot, M.-L., Thiery, L., Darsonville, O., Landais, D., Piel, C., Defossez, M., Devidal, S., Escape, C., Ravel, O., Fromin, N., Volaire, F., Milcu, A., Bahn, M., Soussana, J.-F., 2016. Elevated $\mathrm{CO}_{2}$ maintains grassland net carbon uptake under a future heat and drought extreme. Proc. Natl. Acad. Sci. 113, 6224 LP - 6229. https://doi.org/10.1073/pnas.1524527113

Salvagiotti, F., Cassman, K.G., Specht, J.E., Walters, D.T., Weiss, A., Dobermann, A., 2008. Nitrogen uptake, fixation and response to fertilizer $\mathrm{N}$ in soybeans: A review.

F. Crop. Res. 108, 1-13. https://doi.org/10.1016/j.fcr.2008.03.001

Sanchez, D.H., Schwabe, F., Erban, A., Udvardi, M.K., Kopka, J., 2012. Comparative metabolomics of drought acclimation in model and forage legumes. Plant. Cell Environ. 35, 136-149. https://doi.org/10.1111/j.1365-3040.2011.02423.x

Sanz-Sáez, Á., Erice, G., Aguirreolea, J., Muñoz, F., Sánchez-Díaz, M., Irigoyen, J.J., 2012. Alfalfa forage digestibility, quality and yield under future climate change scenarios vary with Sinorhizobium meliloti strain. J. Plant Physiol. 169, 782-788. https://doi.org/10.1016/j.jplph.2012.01.010

Sanz-Sáez, A., Pérez-López, U., del-Canto, A., Ortiz-Barredo, A., Mena-Petite, A., Aranjuelo, I., Muñoz-Rueda, A., Lacuesta, M., 2019. Changes in environmental $\mathrm{CO}_{2}$ concentration can modify Rhizobium-soybean specificity and condition plant fitness and productivity. Environ. Exp. Bot. 162, 133-143. https://doi.org/10.1016/J.ENVEXPBOT.2019.01.013

Schlenker, W., Roberts, M.J., 2009. Nonlinear temperature effects indicate severe damages to U.S. crop yields under climate change. Proc. Natl. Acad. Sci. 106, 15594 LP - 15598. https://doi.org/10.1073/pnas.0906865106

Schmidhuber, J., Tubiello, F.N., 2007. Global food security under climate change. Proc. Natl. Acad. Sci. U. S. A. 104, 19703-19708. https://doi.org/10.1073/pnas.0701976104 
Sehgal, A., Sita, K., Bhandari, K., Kumar, S., Kumar, J., Vara Prasad, P. V, Siddique, K.H.M., Nayyar, H., 2019. Influence of drought and heat stress, applied independently or in combination during seed development, on qualitative and quantitative aspects of seeds of lentil (Lens culinaris Medikus) genotypes, differing in drought sensitivity. Plant. Cell Environ. 42, 198-211. https://doi.org/https://doi.org/10.1111/pce.13328

Sehgal, A., Sita, K., Siddique, K.H.M., Kumar, R., Bhogireddy, S., Varshney, R.K., HanumanthaRao, B., Nair, R.M., Prasad, P.V.V., Nayyar, H., 2018. Drought or/and Heat-Stress Effects on Seed Filling in Food Crops: Impacts on Functional Biochemistry, Seed Yields, and Nutritional Quality. Front. Plant Sci. 01705. https://doi.org/10.3389/fpls.2018.01705.

Serraj, R., Vadez, V., Denison, R.F., Sinclair, T.R., 1999. Involvement of Ureides in Nitrogen Fixation Inhibition in Soybean. Plant Physiol. 119, 289-296. https://doi.org/10.1104/pp.119.1.289

Serraj, R., Vadez, V., Sinclair, T., 2001. Feedback regulation of symbiotic $\mathrm{N}_{2}$ fixation under drought stress. Agronomie 21, 621-626. https://doi.org/10.1051/agro:2001153

Sicher, R.C., 2015. Temperature Shift Experiments Suggest That Metabolic Impairment and Enhanced Rates of Photorespiration Decrease Organic Acid Levels in Soybean Leaflets Exposed to Supra-Optimal Growth Temperatures. Metab. https://doi.org/10.3390/metabo5030443

Sinclair, T.R., Serraj, R., 1995. Legume nitrogen fixation and drought. Nature 378, 344. https://doi.org/10.1038/378344a0

Sinclair, T.R., 2012. Is transpiration efficiency a viable plant trait in breeding for crop improvement? Funct. Plant Biol. 39, 359-365.

Singh, S.K., Barnaby, J.Y., Reddy, V.R., Sicher, R.C., 2016. Varying Response of the Concentration and Yield of Soybean Seed Mineral Elements, Carbohydrates, Organic Acids, Amino Acids, Protein, and Oil to Phosphorus Starvation and $\mathrm{CO}_{2}$ Enrichment. Front. Plant Sci. 7, 1967. https://doi.org/10.3389/fpls.2016.01967

Sionit, N., Rogers, H.H., Bingham, G.E., Strain, B.R., 1984. Photosynthesis and Stomatal Conductance with $\mathrm{CO}_{2}$-Enrichment of Containerand Field-Grown Soybeans. Agron. J. 76, 447-451. https://doi.org/10.2134/agronj1984.00021962007600030018x

Smil, V., 1999. Nitrogen in crop production: An account of global flows. Global Biogeochem. Cycles 13, 647-662. https://doi.org/10.1029/1999GB900015

Soares, J.C., Santos, C.S., Carvalho, S.M.P., Pintado, M.M., Vasconcelos, M.W., 2019. Preserving the nutritional quality of crop plants under a changing climate: importance and strategies. Plant Soil 443, 1-26. https://doi.org/10.1007/s11104019-04229-0 
Soba, D., Müller, M., Aranjuelo, I., Munné-Bosch, S., 2020. Vitamin E in legume nodules: Occurrence and antioxidant function. Phytochemistry 172, 112261. https://doi.org/10.1016/j.phytochem.2020.112261

Soba, D., Shu, T., Runion, G.B., Prior, S.A., Fritschi, F.B., Aranjuelo, I., Sanz-Saez, A., 2020. Effects of elevated $\left[\mathrm{CO}_{2}\right]$ on photosynthesis and seed yield parameters in two soybean genotypes with contrasting water use efficiency. Environ. Exp. Bot. 178, 104154. https://doi.org/10.1016/j.envexpbot.2020.104154

Soba, D., Zhou, B., Arrese-Igor, C., Munné-Bosch, S., Aranjuelo, I., 2019. Physiological, hormonal and metabolic responses of two alfalfa cultivars with contrasting responses to drought. Int. J. Mol. Sci. 20, 5099. https://doi.org/10.3390/ijms20205099

Soba, D., Aranjuelo, I., Gakière, B., Gilard, F., Pérez-López, U., Mena-Petite, A., Muñoz-Rueda, A., Lacuesta, M., Sanz-Saez, A., 2021. Soybean Inoculated With One Bradyrhizobium Strain Isolated at Elevated $\left[\mathrm{CO}_{2}\right]$ Show an Impaired $\mathrm{C}$ and $\mathrm{N}$ Metabolism When Grown at Ambient $\left[\mathrm{CO}_{2}\right]$. Front. Plant Sci. 656961. https://doi.org/10.3389/fpls.2021.656961.

Stagnari, F., Maggio, A., Galieni, A., Pisante, M., 2017. Multiple benefits of legumes for agriculture sustainability: an overview. Chem. Biol. Technol. Agric. 4, 2. https://doi.org/10.1186/s40538-016-0085-1

Streeter, J.G., 2003. Effects of drought on nitrogen fixation in soybean root nodules. Plant. Cell Environ. 26, 1199-1204. https://doi.org/10.1046/j.13653040.2003.01041.x

Sun, J., Cardoza, V., Mitchell, D.M., Bright, L., Oldroyd, G., Harris, J.M., 2006. Crosstalk between jasmonic acid, ethylene and Nod factor signaling allows integration of diverse inputs for regulation of nodulation. Plant J. 46, 961-970. https://doi.org/10.1111/j.1365-313X.2006.02751.x

Swaraj, K., Dhandi, S., Sheokand, S., 1995. Relationship between defense mechanism against activated oxygen species and nodule functioning with progress in plant and nodule development in Cajanus cajan L. Millsp. Plant Sci. 112, 65-74. https://doi.org/10.1016/0168-9452(95)04231-I

Szymańska, R., Kruk, J., 2008. Tocopherol content and isomers' composition in selected plant species. Plant Physiol. Biochem. 46, 29-33. https://doi.org/10.1016/j.plaphy.2007.10.009

Tsyganov, V.E., Tsyganova, A. V, Gorshkov, A.P., Seliverstova, E. V, Kim, V.E., Chizhevskaya, E.P., Belimov, A.A., Serova, T.A., Ivanova, K.A., Kulaeva, O.A., Kusakin, P.G., Kitaeva, A.B., Tikhonovich, I.A., 2020. Efficacy of a PlantMicrobe System: Pisum sativum (L.) Cadmium-Tolerant Mutant and Rhizobium leguminosarum Strains, Expressing Pea Metallothionein Genes PsMT1 and PsMT2, for Cadmium Phytoremediation. Front. Microbiol. 29;11:15. doi: $10.3389 /$ fmicb. 2020.00015 
Tubiello, F.N., Soussana, J.-F., Howden, S.M., 2007. Crop and pasture response to climate change. Proc. Natl. Acad. Sci. 104, 19686-19690. https://doi.org/10.1073/pnas.0701728104

Valentine, A.J., Benedito, V.A., Kang, Y., 2018. Legume Nitrogen Fixation and Soil Abiotic Stress: From Physiology to Genomics and Beyond. Annu. Plant Rev. online, Major Reference Works. https://doi.org/10.1002/9781119312994.apr0456

Valliyodan, B., Nguyen, H.T., 2006. Understanding regulatory networks and engineering for enhanced drought tolerance in plants. Curr. Opin. Plant Biol. 9, 189-195. https://doi.org/10.1016/j.pbi.2006.01.019

Vautard, R., Yiou, P., D’Andrea, F., de Noblet, N., Viovy, N., Cassou, C., Polcher, J., Ciais, P., Kageyama, M., Fan, Y., 2007. Summertime European heat and drought waves induced by wintertime Mediterranean rainfall deficit. Geophys. Res. Lett. 34. https://doi.org/https://doi.org/10.1029/2006GL028001

Verma, V., Ravindran, P., Kumar, P.P., 2016. Plant hormone-mediated regulation of stress responses. BMC Plant Biol. 16, 86. https://doi.org/10.1186/s12870-0160771-y

Vicente, R., Pérez, P., Martínez-Carrasco, R., Morcuende, R., 2017. Improved responses to elevated $\mathrm{CO}_{2}$ in durum wheat at a low nitrate supply associated with the upregulation of photosynthetic genes and the activation of nitrate assimilation. Plant Sci. 260, 119-128. https://doi.org/10.1016/j.plantsci.2017.04.009

Vu, J.C. V, Allen JR, L.H., Boote, K.J., Bowes, G., 1997. Effects of elevated $\mathrm{CO}_{2}$ and temperature on photosynthesis and Rubisco in rice and soybean. Plant. Cell Environ. 20, 68-76. https://doi.org/10.1046/j.1365-3040.1997.d01-10.x

Wahid, A., Gelani, S., Ashraf, M., Foolad, M.R., 2007. Heat tolerance in plants: An overview. Environ. Exp. Bot. 61, 199-223. https://doi.org/10.1016/j.envexpbot.2007.05.011

Wang, T.L., Domoney, C., Hedley, C.L., Casey, R., Grusak, M.A., 2003. Can We Improve the Nutritional Quality of Legume Seeds? Plant Physiol. 131, 886 LP 891. https://doi.org/10.1104/pp.102.017665

Wang, Y., Zhang, Z., Zhang, P., Cao, Y., Hu, T., Yang, P., 2016. Rhizobium symbiosis contribution to short-term salt stress tolerance in alfalfa (Medicago sativa L.). Plant Soil 402, 247-261. https://doi.org/10.1007/s11104-016-2792-6

Wasko, C., Sharma, A., 2017. Global assessment of flood and storm extremes with increased temperatures. Sci. Rep. 7, 7945. https://doi.org/10.1038/s41598-01708481-1

Weigel, H.-J., 2014. Crops and Climate Change: Plant quality declines as $\mathrm{CO}_{2}$ levels rise. Elife 3, e03233. https://doi.org/10.7554/eLife.03233 
WILKINSON, S., DAVIES, W.J., 2010. Drought, ozone, ABA and ethylene: new insights from cell to plant to community. Plant. Cell Environ. 33, 510-525. https://doi.org/10.1111/j.1365-3040.2009.02052.x

Wu, D.-X., Wang, G.-X., Bai, Y.-F., Liao, J.-X., 2004. Effects of elevated $\mathrm{CO}_{2}$ concentration on growth, water use, yield and grain quality of wheat under two soil water levels. Agric. Ecosyst. Environ. 104, 493-507. https://doi.org/https://doi.org/10.1016/j.agee.2004.01.018

Yamaji, K., Matsuhashi, R., Nagata, Y., Kaya, Y., 1993. A study on economic measures for $\mathrm{CO}_{2}$ reduction in Japan. Energy Policy 21, 123-132. https://doi.org/10.1016/0301-4215(93)90134-2

Yamori, W., von Caemmerer, S., 2009. Effect of Rubisco Activase Deficiency on the Temperature Response of $\mathrm{CO}_{2}$; Assimilation Rate and Rubisco Activation State: Insights from Transgenic Tobacco with Reduced Amounts of Rubisco Activase. Plant Physiol. 151, 2073 - 2082. https://doi.org/10.1104/pp.109.146514

Young, N.D., Mudge, J., Ellis, T.H.N., 2003. Legume genomes: more than peas in a pod. Curr. Opin. Plant Biol. 6, 199-204. https://doi.org/10.1016/S13695266(03)00006-2

Zahran, H.H., 1999. Rhizobium-legume symbiosis and nitrogen fixation under severe conditions and in an arid climate. Microbiol. Mol. Biol. Rev. 63, 968-989.

Zandalinas, S.I., Fritschi, F.B., Mittler, R., 2021. Global Warming, Climate Change, and Environmental Pollution: Recipe for a Multifactorial Stress Combination Disaster. Trends Plant Sci. https://doi.org/10.1016/j.tplants.2021.02.011

Zandalinas, S.I., Mittler, R., Balfagón, D., Arbona, V., Gómez-Cadenas, A., 2018. Plant adaptations to the combination of drought and high temperatures. Physiol. Plant. 162, 2-12. https://doi.org/10.1111/ppl.12540

Ziska, L.H., Bunce, J.A., Caulfield, F., 1998. Intraspecific variation in seed yield of soybean (Glycine max) response to increased atmospheric carbon dioxide. Funct. Plant Biol. 25, 801-807. 
upna 
ANNEX 


\section{Lista de publicaciones originales}

Esta tesis se presenta en forma de compendio de publicaciones, en arreglo al "Acuerdo A3/2015 del Comité de Dirección de la Escuela de Doctorado de Navarra adoptado en sesión celebrada el 11 de febrero de 2015 por el que se modifica la normativa para la elaboración de tesis como compendio de publicaciones". Dichas publicaciones recogen los resultados que han sido obtenidos en los diferentes trabajos de investigación desarrollados con el fin de alcanzar el objetivo fijado para la realización de la tesis. A continuación, se listan las referidas publicaciones:

\section{Artículo 1.}

AUTORES (P.O.DE FIRMA): David Soba, Tianchu Shu, G. Brett Runion, Stephen A. Prior, Felix B.Fritschi, Iker Aranjuelo, Alvaro Sanz-Saez

TITULO: Effects of elevated $\left[\mathrm{CO}_{2}\right]$ on photosynthesis and seed yield parameters in two soybean genotypes with contrasting water use efficiency.

REFERENCÍA: DOI: 10.1016/j.envexpbot.2020.104154; Volume 178, October 2020, 104154

REVISTA: Environmental and Experimental Botany

EDITORIAL: Elsevier

FECHA DE PUBLICACIÓN: 2020

FACTORDE IMPACTO: 4.027 (JCR-2019)

POSICIÓN:

Plant Sciences $\rightarrow$ 26/234 (JCR-2019) First Quartile (Q1)

Environmental Sciences $\rightarrow$ 71/265 (JCR-2019) Second Quartile (Q2)

CONTRIBUCION DEL DOCTORANDO: Experimentación, procesado y análisis de muestras, análisis de datos, escritura del manuscrito original

\section{Artículo 2.}

AUTORES (P.O.DE FIRMA): David Soba, Bangwei Zhou, Cesar Arrese-Igor, Sergi Munné-Bosch, Iker Aranjuelo 
TITULO: Physiological, Hormonal and Metabolic Responses of two Alfalfa Cultivars with Contrasting Responses to Drought

REFERENCÍA: DOI: 10.3390/ijms20205099; Volume 20, Issue: 20, October 2019, 5099

REVISTA: International Journal of Molecular Science

EDITORIAL: MDPI

FECHA DE PUBLICACIÓN: 2019

FACTORDE IMPACTO: 4.556 (JCR-2019)

POSICIÓN:

Biochemistry and Molecular Biology $\rightarrow$ 74/297 (JCR-2019) First Quartile (Q1)

Chemistry, Multidisciplinary $\rightarrow$ 48/177 (JCR-2019) Second Quartile (Q2)

CONTRIBUCION DEL DOCTORANDO: Diseño del experimento, experimentación, procesado y análisis de muestras, análisis de datos, escritura del manuscrito original

\section{Artículo 3.}

AUTORES (P.O.DE FIRMA): David Soba, Maren Müller, Iker Aranjuelo, Sergi Munné-Bosch

TITULO: Vitamin E in legume nodules: Occurrence and antioxidant function

REFERENCÍA: DOI: 10.1016/j.phytochem.2020.112261; Volume 172, April 2020, 112261

REVISTA: Phytochemistry

EDITORIAL: Elsevier

FECHA DE PUBLICACIÓN: 2020

FACTORDE IMPACTO: 3.044 (JCR-2019)

POSICIÓN:

Plant Sciences $\rightarrow$ 47/234 (JCR-2019) First Quartile (Q1)

Biochemistry and Molecular Biology $\rightarrow$ 155/297 (JCR-2019) Third Quartile (Q3)

CONTRIBUCION DEL DOCTORANDO: Diseño del experimento, experimentación, procesado y análisis de muestras, análisis de datos, escritura del manuscrito original 